\title{
School choice, competition and achievement : Dutch compulsory education
}

Citation for published version (APA):

Cornelisz, I. (2014). School choice, competition and achievement : Dutch compulsory education. [Doctoral Thesis, Maastricht University]. Maastricht University. https://doi.org/10.26481/dis.20140115ic

Document status and date:

Published: 01/01/2014

DOI:

10.26481/dis.20140115ic

Document Version:

Publisher's PDF, also known as Version of record

\section{Please check the document version of this publication:}

- A submitted manuscript is the version of the article upon submission and before peer-review. There can be important differences between the submitted version and the official published version of record.

People interested in the research are advised to contact the author for the final version of the publication, or visit the DOI to the publisher's website.

- The final author version and the galley proof are versions of the publication after peer review.

- The final published version features the final layout of the paper including the volume, issue and page numbers.

Link to publication

\footnotetext{
General rights rights.

- You may freely distribute the URL identifying the publication in the public portal. please follow below link for the End User Agreement:

www.umlib.nl/taverne-license

Take down policy

If you believe that this document breaches copyright please contact us at:

repository@maastrichtuniversity.nl

providing details and we will investigate your claim.
}

Copyright and moral rights for the publications made accessible in the public portal are retained by the authors and/or other copyright owners and it is a condition of accessing publications that users recognise and abide by the legal requirements associated with these

- Users may download and print one copy of any publication from the public portal for the purpose of private study or research.

- You may not further distribute the material or use it for any profit-making activity or commercial gain

If the publication is distributed under the terms of Article $25 \mathrm{fa}$ of the Dutch Copyright Act, indicated by the "Taverne" license above, 
SCHOOL CHOICE, COMPETITION AND ACHIEVEMENT

Dutch compulsory education

Ilja Cornelisz 
(C) Ilja Cornelisz, Maastricht 2013.

All rights reserved. No part of this publication may be reproduced, stored in a retrieval system or transmitted in any form, or by any means, electronic, mechanical, photocopying, recording, or otherwise, without the prior permission in writing, from the author.

ISBN 978-94-003-0060-6

Cover design: Raadhuis voor creatieve communicatie, Alkmaar

This book is no. IV of the TIER Research Series, a PhD thesis series published by TIER. 
SCHOOL CHOICE, COMPETITION AND ACHIEVEMENT

Dutch compulsory education

Proefschrift

ter verkrijging van de graad van doctor

aan de Universiteit Maastricht,

op gezag van de Rector Magnificus,

Prof. dr. L.L.G. Soete

volgens het besluit van het College van Decanen,

in het openbaar te verdedigen

op woensdag 15 januari 2014 om 16.00 uur

door

Ilja Cornelisz 


\section{Promotores:}

Prof. dr. W.N.J. Groot

Prof. dr. H. Maassen van den Brink

Prof. dr. H.M. Levin

\section{Beoordelingscommissie:}

Prof. dr. L. Borghans

Prof. dr. J. Dronkers

Prof. dr. J. Hartog

Prof. dr. H. Oosterbeek

Prof. dr. J.M.M. Ritzen 


\section{Acknowledgements}

Writing a thesis is perhaps best thought of as a journey, rather than as a destination. Over these past few years, I have received support from several great people along the way.

First of all, I would like to thank my supervisors. Wim Groot, your many meticulous comments and adept interpretations of the results were of vital importance. Henriëtte Maassen van den Brink, the same holds for your ability to always keep in mind the bigger picture of my work and for your suggestions to strengthen its core and structure. Thank you both for your flexibility in accommodating a situation that enabled me to enter the Economics of Education program a Columbia University in New York, and to work with Henry M. Levin. Over the course of that program, he has had such a profound impact on my thinking of how to approach education and research. Hank, thank you for your tremendous support an insights, for offering to be your teaching assistant, and for trusting me with your classes during your sabbatical.

Next, I would like to thank the members of the assessment committee: Lex Borghans Jaap Dronkers, Joop Hartog, Hessel Oosterbeek and Jo Ritzen. I would like to express my gratitude not only for your time and effort in this respect, but also for all of your important contributions. With different approaches, perspectives and research designs, but with a shared passion for improving education, your work has had a profound impact on education, the literature, and on this thesis.

Sofie Cabus, thank you for the fruitful cooperation and I look forward to our next endeavor. Similarly, Barbara Hanisch-Cerda, thank you for playing such a vital role as the 
outside observer, and for sharing observations of the Dutch system I would otherwise overlook. Also, I would like to thank the students in the economics of education program for their useful questions during several in-class and workshop seminar presentations.

Throughout the journey, I was happy to meet Tommaso Agasisti and benefit from his work and useful feedback. Tommaso, thank you for this and for sharing your thoughts on our mutual research interests. I appreciate the opportunity to work with Liesbeth van Welie, to have so many conversations with her about education in the Netherlands, and to come up with at least one new research idea to pursue every lunch. Liesbeth, your passion and deep understanding of the Dutch education context inspire me.

During my time in New York City, I have also learned a great deal from Francisco Rivera Batiz in thinking about this project. Francisco, you have always emphasized the importance of having a theory before moving to empirical analyses. Judith Scott-Clayton, thank you for allowing me to develop one of the first chapters in one of your courses, and for your sharp observations and feedback. While there, I got to know so many nice people at the office, almost all from different countries, and to benefit from the countless conversations on education systems across the world. The same level of geographic diversity holds for my peers in the program. I would like to express my thanks to Alper Dinçer for his support during the first set of analyses. Throughout the entire process I have also had a lot of support from my friends in the dissertation work group, which would meet almost weekly and often in three different time zones. Thank you, Brooks, Emma and Jiyun for your invaluable support.

During the periods I was in Holland, I was fortunate to benefit from the generosity provided by TIER colleagues in both Amsterdam and Maastricht. Thank you all for useful comments and suggestions after presentations. I would like to express my gratitude to the people at Dienst Uitvoering Onderwijs, and in particular to Kees and Erik, for continuously working on improving the quality and availability of data so crucial for enabling meaningful analyses. Thank you also to Carla and Sebastiene for your help in dealing with numerous administrative issues, and also for your vital support in the last phases of this project.

Writing this dissertation has further deepened my passion for education. The root of this love affair can be traced back more than a decade ago, when I started working at a high school in the Netherlands. It was there that colleagues and students sparked this interest 
and from whom I have learned so much about education. Thank you all for those incredible years and I am already looking forward to my next surprise visit.

I would like to express my utmost gratitude to my parents, who have always supported me. These past few years, it has not always been easy to be on different sides of the Atlantic. It makes the time we are able to spend together all the more special and valuable to me. Lastly, thank you Bette for being by my side. Your love makes it easier to deal with difficult episodes and together with you I enjoy the nice things in life more fully. I would like to end with a quote that Hank often starts the semester with, as to prepare students for what lies ahead. It probably frightens and reassures them at the same time and symbolizes the process of writing this thesis: "Just remember, learning should be a struggle, but in the end it should be a pleasant one".

Ilja Cornelisz

December 2013 


\section{Contents}

1. Introduction 1

1.1 Motivation 1

1.2 Research objective 3

1.3 Outline of the dissertation 6

2. Review of international school choice literature 9

2.1 Introduction 9

$\begin{array}{lll}2.2 & \text { Design instruments of a choice plan } & 10\end{array}$

2.3 Framework for the effects of school choice on educational outcomes 11

$\begin{array}{lll}2.4 & \text { Theoretical considerations in dealing with school choice } & 13\end{array}$

2.5 Empirical results for the effects of school choice plans 23

2.5.1 Freedom of choice 23

$\begin{array}{lll}2.5 .2 & \text { Productive efficiency } & 25\end{array}$

$\begin{array}{lll}2.5 .3 & \text { Equity } & 33\end{array}$

$\begin{array}{lll}2.5 .4 & \text { Social cohesion } & 36\end{array}$

$\begin{array}{lll}2.6 & \text { Concluding remarks } & 39\end{array}$

3. Educational choice in the Dutch context 43

$\begin{array}{lll}3.1 & \text { Introduction } & 43\end{array}$

3.2 Design instruments of the Dutch compulsory education system 43

3.2.1 Finance 45 
$\begin{array}{lll}3.2 .2 & \text { Regulation } & 47\end{array}$

$\begin{array}{lll}3.2 .3 & \text { Support services } & 50\end{array}$

3.3 Educational outcomes in the Dutch choice context 51

$\begin{array}{ll}\text { 3.3.1 Freedom of choice } & 51\end{array}$

$\begin{array}{lll}\text { 3.3.2 Productive efficiency } & 55\end{array}$

$\begin{array}{lll}\text { 3.3.3 Equity } & 59\end{array}$

3.3.4 Social cohesion $\quad 62$

$\begin{array}{lll}3.4 & 60 n c l u d i n g ~ r e m a r k s & 64\end{array}$

4. Choice and student achievement in the Netherlands 67

$\begin{array}{lll}4.1 & \text { Introduction } & 67\end{array}$

$\begin{array}{lll}\text { 4.2. } & \text { Background and scope } & 68\end{array}$

$\begin{array}{lll}4.3 & \text { Data and methodology } & 70\end{array}$

$\begin{array}{lll}\text { 4.3.1 Data } & 70\end{array}$

4.3.2 Methodology 74

$\begin{array}{lll}4.4 & \text { Results } & 76\end{array}$

$\begin{array}{lll}4.5 & \text { Concluding remarks } & 84\end{array}$

$\begin{array}{lll}\text { 4.A } & \text { Appendix: full estimation results } & 87\end{array}$

5. School type effectiveness in the Netherlands $\quad 91$

$\begin{array}{lll}5.1 & \text { Introduction } & 91\end{array}$

5.2. Background and scope 92

5.3 Empirical research on identifying private school effectiveness 94

$\begin{array}{lll}5.4 & \text { Data and methodology }\end{array}$

5.4.1 Data 96

$\begin{array}{lll}\text { 5.4.2 Methodology } & 97\end{array}$

$\begin{array}{llr}5.5 & \text { Results } & 100\end{array}$

$\begin{array}{lll}5.6 & \text { Concluding remarks } & 123\end{array}$

5.A Appendix: full estimation results 125

6. Competition and student achievement in the Netherlands 141

$\begin{array}{lll}6.1 & \text { Introduction } & 141\end{array}$

6.2. Background and scope 142

6.3 Methodology and data 145 
$\begin{array}{lll}\text { 6.3.1 Methodology } & 145\end{array}$

$\begin{array}{lll}\text { 6.3.2 Data } & 148\end{array}$

$\begin{array}{lll}6.4 & \text { Results } & 152\end{array}$

$\begin{array}{lll}6.5 & \text { Concluding remarks } & 157\end{array}$

$\begin{array}{lll}\text { 6.A Appendix: full estimation results } & 160\end{array}$

7. Competition, sorting by ability and productive efficiency 161

$\begin{array}{lll}7.1 & \text { Introduction } & 161\end{array}$

$\begin{array}{lll}7.2 & \text { Background and scope } & 162\end{array}$

$\begin{array}{lll}7.3 & \text { Methodology and data } & 164\end{array}$

$\begin{array}{lll}\text { 7.3.1 Methodology } & 164\end{array}$

$\begin{array}{lll}\text { 7.3.2 Data } & 169\end{array}$

$\begin{array}{lll}7.4 & \text { Results } & 170\end{array}$

7.4.1 Competition and sorting by ability 176

$\begin{array}{lll}\text { 7.4.2 Competition and student performance } & 179\end{array}$

$\begin{array}{lll}7.5 & \text { Concluding remarks } & 181\end{array}$

8. Social justice in Dutch compulsory education 183

$\begin{array}{lll}8.1 & \text { Introduction } & 183\end{array}$

$\begin{array}{lll}\text { 8.2 Social justice and educational outcomes } & 184\end{array}$

$\begin{array}{lll}\text { 8.3 Social justice in Dutch compulsory education } & 185\end{array}$

$\begin{array}{lll}\text { 8.3.1 Freedom of choice } & 185\end{array}$

$\begin{array}{ll}\text { 8.3.2 Productive Efficiency } & 186\end{array}$

$\begin{array}{lll}\text { 8.3.3 Equity } & 187\end{array}$

$\begin{array}{lll}\text { 8.3.4 Social cohesion } & 189\end{array}$

$\begin{array}{lll}8.4 & \text { Concluding remarks } & 191\end{array}$

9. Conclusions and discussion 193

$\begin{array}{lll}9.1 & \text { Introduction } & 193\end{array}$

9.2 Key conclusions with policy implications 194

9.3 Limitations and suggestions for further research 199

$\begin{array}{ll}\text { References } & 203\end{array}$

Appendix A: Overview of data sets and variables used 219 
Summary

225

Samenvatting

229

Biography

235 


\section{List of Tables}

1.1 Overview structure of dissertation 5

2.1 Summary of theoretical considerations - freedom of choice 15

2.2 Summary of theoretical considerations - productive efficiency 18

2.3 Summary of theoretical considerations - equity 19

2.4 Summary of theoretical considerations - social cohesion 22

2.5 Summary of empirical results - freedom of choice 25

2.6 Summary of empirical results - productive efficiency 33

2.7 Summary of empirical results - equity 36

2.8 Summary of empirical results - social cohesion 39

3.1 Summary of results for the Netherlands - freedom of choice 55

3.2 Summary of results for the Netherlands - productive efficiency 59

3.3 Summary of results for the Netherlands - equity 62

3.4 Summary of results for the Netherlands - social cohesion 64

4.1 Summary statistics school choice, G31 and G4 73

4.2 OLS, School choice intensity effect on CITO test score, G31 76

4.3 OLS, School choice intensity effect on CITO test score, G4 78

4.4 Associations choice intensity and instrument with neighborhood features 80

4.5 Checks for relevance and validity of instrument 81

4.6 2SLS, School choice intensity effect on CITO test score, G31 82

4.7 School choice effects, augmented with school size and quality, G31 83 
4.8 Choice and missing CITO test score data comparisons, BRON PO '08-'09 84

5.1a Summary statistics PISA 2006

5.1b Summary statistics PISA 2009

5.2a OLS results private school attendance, PISA $2006 \quad 103$

5.2b OLS results private school attendance, PISA 2009

5.3 First-stage results IV approach, PISA 2006 and 2009

5.4a 2SLS IV results private school attendance, PISA 2006

5.4b 2SLS IV results private school attendance, PISA 2009

5.5a Weighted regression-adjusted PSM results, PISA $2006 \quad 108$

5.5b Weighted regression-adjusted PSM results, PISA 2009

5.6 Balance before and after matching algorithm, PISA 2006 and 2009

5.7 Private school attendance effect mathematics, PISA 2006 and 2009

5.8a Unobserved bias for PSM to match with OLS and IV, PISA 2006112

5.8b Unobserved bias for PSM to match with OLS and IV, PISA 2009

5.9a Private vocational school attendance effect, PISA 2006 and 2009

5.9b Private academic school attendance effect, PISA 2006 and 2009

5.10 Summary statistics, BRON PO '08-'09 115

5.11 OLS, Private school attendance effect, BRON PO '08-'09 116

5.12 OLS, Private school type attendance effects, BRON PO '08-'09 117

5.13 PSM, Private school attendance effects, BRON PO '08-'09 118

5.14 Private Catholic/non-religious school effects, BRON PO '08-'09 118

5.15 Missing CITO test score data comparisons, BRON PO '08-'09 120

5.16 Logit, Private school attendance effect "upward mobility" 121

5.17 PSM, Private school attendance effect "upward mobility" 122

5.18 Overview (switched to) private school effect, PO BRON '08-'09 123

6.1 Summary statistics competition intensity, G31 and G4 150

6.2 Associations competition measures and background characteristics 151

6.3 OLS, School competition intensity effect on CITO test score 152

6.4 SQR, School competition intensity effect on CITO test score 153

6.5 SQR, School choice and competition effects on CITO test score 155

6.6 OLS, School competition effects across private public schools 156

6.7 Missing CITO test score data comparisons, BRON PO '08-'09 157 
7.1 T-test mean differences outcomes between control and treatment group

7.2 T-test mean differences in student background characteristics

7.3 T-test mean differences in school supply characteristics

7.4 T-test mean differences in school choice determinants

7.5 T-test mean differences in student characteristics after Kernel matching

7.6 Competition and sorting across schools by math grade 7 performance

7.7 Competition and sorting across schools by language grade 7 performance 


\section{List of Figures}

3.1 Structure of the Dutch Education System 45

4.1 School choice intensity in Amsterdam 73

4.2 Association number of schools and distance to main road entry/exit 79

5.1 Overlap of propensity scores PISA 2006 and 2009

6.1 Competition intensity across schools in Amsterdam 149

6.2 Distribution competition intensity, G31 and G4 149

7.1 Distribution of competition intensity measure 170

7.2 Distribution propensity scores HCM and NCM in matched sample 176

7.3 Competition and performance gains in math performance 179

7.4 Competition and performance gains in language performance 180 


\section{Introduction}

\subsection{Motivation}

Nations around the world search for ways to improve their schools, with the objective to enhance the skills and employability of their youth and to reduce inequalities in lifetime outcomes (Hansson and Charbonnier, 2010). As such, countries invest substantial proportions of financial resources in education. For taxpayers and policy makers, it is important to see this money being spent efficiently, as to realize the potentially large returns on these investments, (cf. Groot and Maassen van den Brink, 2003).

There is no widespread consensus on how education should be funded or provided in reaching the above objectives. For example, the literature provides largely mixed results on the effects of input-based policy measures. ${ }^{1}$ Aiming for more efficiency in education, governments around the world have increasingly been seeking to improve their schools through a variety of market-based approaches in providing and funding education. Underlying these developments is the notion that introducing market principles in education is considered to be an important prerequisite for enabling what the economist Samuelson referred to as the "tremendous vitality" of the free enterprise system. ${ }^{2}$

\footnotetext{
${ }^{1}$ For more details on this, see, for example, Hanushek $(1997,2003)$ who provides surveys of input-based policies and finds no consistent pattern in optimal resource allocations. Also, Loeb and McEwan (2010) show some positive small-scale results, but point to potentially unanticipated general equilibrium effects of scaling up an intervention.

2 Paul A. Samuelson, Economics (New York: McGraw Hill, 1948); as quoted in Shleifer (1998).
} 


\subsubsection{Educational choice}

Market-based approaches in education most typically include policies enhancing parental choice and promoting school competition. This can, for example, be realized through the abolishment of catchment areas and by implementing voucher programs, through deregulation and the devolution of formal decision-making authority to lower levels of hierarchy, or by allowing more autonomous school types to enter the educational arena.

In this respect, educational choice can refer to a variety of situations, such as residential mobility (i.e. "Tiebout choice"), inter- and intra-district choice, charter schools, homeschooling, educational vouchers, tuition tax credits and private schools (Levin, 2009). Educational systems differ importantly in the extent in which various elements of the above choice features apply, and also in terms of how they are designed. This highlights the complex nature of educational choice and, as outcomes will arguably depend on the specific design and context, this warrants caution in speaking about its effects in all too general terms.

While the conditions of educational choice, in many contexts, continue to remain unresolved at the political level, choice has in practice become an established and integral part of the educational landscape in many countries (Hirsch, 2002; Plank and Sykes, 2003). In countries that are member of the "Organisation for Economic Co-operation and Development" (OECD), opportunities for school choice have generally expanded over the last 25 years, and particularly so through ongoing processes of public school decentralization and newly enacted funding mechanisms (Hansson and Charbonnier, 2010). In Europe, the Parliamentary Assembly of the Council of Europe (PACE) issued resolution no. 1904 "The right to freedom of choice in education in Europe" in 2012, in which it recommends all member States to allow for, and promote, educational choice and private schooling opportunities in compulsory education. ${ }^{3}$

With its increasing prominence around the globe, school choice has also been at the heart of the educational debate, but appears to take place mostly at the ideological level (see: Belfield and Levin, 2005a; Ladd, 2003). Historically, much of the choice literature focused on the United States context, but important lessons can be learned from the

\footnotetext{
${ }^{3}$ Source: http://assembly.coe.int/ASP/Doc/XrefATDetails_E.asp?FilelD=19162
} 
growing body of international empirical evidence on this topic. For example, the work by Plank and Sykes (2003) provides eight of such international case studies. ${ }^{4}$

\subsubsection{Educational outcomes and schooling provision}

The objectives of educational policy go beyond teaching literacy and numeracy (e.g. see: Godwin and Kemerer, 2002). Levin (2002) employs a useful evaluative framework for describing and analyzing an education system in terms of different policy objectives. The framework draws upon a large range of educational goals and defines four main criteria: (a) freedom of choice, (b) productive efficiency, (c) equity, and (d) social cohesion. Private objectives of education relate primarily to the first two goals, whereas the latter three are particularly relevant for societal objectives of education.

Accepting that education has indeed both public- and private goals, few people would disagree that government ought to play some role in education (Cohn and Geske, 1990). For example, Friedman (1955) argued that, based on the benefits to society at large, it is appropriate for governments to finance compulsory education. However, this is different from stating that education should also be provided by the government as well (Friedman, 1962; Shleifer, 1998). Instead, some countries do indeed make a sharp distinction between the roles of the public and private sector in terms of education financiers and education providers.

A recent World Bank report defines the concept of public-private partnerships (PPPs) in education as a system that, besides public finance and public delivery, recognizes the existence of alternative options for providing education services (Patrinos, Barrera-Osorio and Guequeta, 2009). The report examines PPPs in which government guides policy and provides funding, but with the private sector involved in delivering the actual education services. In this respect, the Netherlands is highlighted as a prime example.

\subsection{Research objective and outline of dissertation}

The expanding research on educational choice (see Chapter 2) points to i) a demand for empirical results on student performance in large-scale choice contexts, ii) questions whether private educational provision yields better academic results, and iii) the need to

\footnotetext{
${ }^{4}$ Included are Chile, New Zealand, Great Britain, Sweden, Australia, South Africa, China, and Central Europe.
} 
interpret the implications of school choice along a range of both private and public educational goals.

The objective of this dissertation is to address the above three issues. I do so by focusing on educational choice for compulsory education in Dutch education. In the Netherlands, virtually all education is financed publicly, but with privately organized schools accommodating over two-thirds of all students in compulsory education. Furthermore, the educational system in the Netherlands has been providing universal choice to households since 1848 , with private and public schools under equal government treatment and funding ever since 1917. I exploit these features of the Dutch education system to examine relative private school effectiveness and how household choice and school-level competition relate to students' academic performance. The results are discussed and interpreted in Levin's framework of educational outcomes.

There are three main components to this dissertation (Table 1.1). Chapter 2 provides a review of the international school choice literature, using Levin's framework for evaluation, thereby distinguishing between theoretical considerations and the existing, and growing, body of empirical findings. Chapter 3 introduces the Dutch choice contexts and summarizes the body of literature; again using the aforementioned framework of four different goals of education. As such, the first three chapters form the first part of this thesis with the aim to introduce i) the objective of this dissertation, ii) what is known from previous work and iii) the Dutch context used for answering the research questions on how academic performance relates to school type, choice and competition.

The second part of this dissertation consists of four empirical chapters, each exploring a different aspect of the Dutch education sector. Chapter 4 exploits the long history of universal school choice for households in the Netherlands by investigating whether, in general, it is possible to find a causal link between school choice intensity and academic performance. Chapter 5 follows up on this through examining the notion of relative private school effectiveness by applying a variety of empirical methodologies that all have been proposed to address this issue (i.e. ordinary least squares, instrumental variables and propensity score matching). The objective of these analyses is to find a consistent answer to the question whether one school type is most effective in generating student performance, by using different sources of data, and by looking at both sectors in compulsory education (i.e. primary- and secondary education). Chapter 6 focuses on what, 
beyond school type and school choice intensity, the effects are of competition intensity between primary schools on students' academic performance. Chapter 7 follows up on this by looking at how competition relates to the sorting of students into secondary education, based on their performance at the end of primary education. The data set and approach used in this chapter also allow for examining the effects of competition on achievement gains throughout the first few years of secondary education, as to corroborate the findings for competition and achievement presented in Chapter 6.

The objective of the third part of this thesis is to interpret the above findings along different objectives of education. Chapter 8 presents a discussion on how the aforementioned elements of Dutch education (i.e. private government-funded schools, choice and competition) relate to social justice in Dutch education. In this respect, social justice is reflected in the responsiveness of the educational system to both families' and society's educational objectives. Chapter 9 concludes with a discussion of the key findings presented throughout this dissertation, together with the main policy implications, limitations of the results presented, and suggestions for further research.

\section{Table 1.1: Overview structure of dissertation}

\begin{tabular}{|l|ll|}
\hline \multicolumn{1}{|c|}{ Part I: } & Chapter 1: & Introduction \\
$\begin{array}{l}\text { An introduction to, and overview of, } \\
\text { school choice and the Dutch context }\end{array}$ & Chapter 2: & Review of international school choice literature \\
& Chapter 3: & Educational choice and outcomes in the Dutch context \\
\hline
\end{tabular}

\begin{tabular}{|l|ll|}
\hline \multicolumn{1}{|c|}{ Part II: } & Chapter 4: & Choice and achievement in the Netherlands \\
Empirical analyses of school choice & Chapter 5: & School type effectiveness in the Netherlands \\
and competition in the Netherlands & Chapter 6: & Competition and achievement in the Netherlands \\
& Chapter 7: & Competition, sorting by ability and productive efficiency \\
\hline
\end{tabular}

\begin{tabular}{|l|ll|}
\hline \multicolumn{1}{|c|}{ Part III: } & Chapter 8: & Social justice in Dutch compulsory education \\
$\begin{array}{l}\text { Interpreting the findings for different } \\
\text { outcomes and general conclusions }\end{array}$ & Chapter 9: & Conclusions and discussion \\
\hline
\end{tabular}




\subsection{Contributions of this dissertation}

One of the main arguments of proponents of educational choice is that it will generate competition for students among schools. This competitive pressure will then force schools to deliver high quality education, or parents will go elsewhere (see, for example, Hastings et al., 2005). However, some of the (market) assumptions on which such productivity gains are premised have been challenged (e.g. Belfield and Levin, 2005b; Levin, 2012). For instance, education is often viewed as a largely homogeneous good, with academic achievement as the most important choice determinant. But, heterogeneity in households' preferences towards student performance and other school attributes is likely to limit the potential for school choice and competition to deliver gains in academic performance. The current body of empirical research on this is largely inconclusive, with the exception of positive differential effects for certain groups, grades and indicators (see, for example, Waslander et al., 2010). Research on educational choice has been shown to be methodologically difficult, because of sorting processes and (unobserved) differences between households and schools, suggesting that more research on large-scale choice contexts and long-term outcomes is necessary (Ladd, 2003). This dissertation contributes to this research by distinguishing between the effects of choice and competition, across different achievement levels and school types, in the universal school choice context of Dutch compulsory education.

Another distinct question in the debate on how to organize educational choice effectively is whether private schools provide better education than public schools. In empirical research, such relative school type effectiveness is often assessed by comparing the performance on a standardized test of achievement of students in a certain sector (e.g. private, Catholic) to that of their counterparts accommodated by other school types. Research faces several methodological challenges in identifying such an effect when comparing students across different school types, resulting primarily from funding disparities and processes of sorting and selection. There is no consensus on whether private educational provision consistently outperforms public provision, and whether a positive effect can be found across different subgroups of students, subjects and measures of performance (e.g. see: Murnane et al., 1985; Grogger et al., 2000; McEwan 2000; Vandenberghe and Robin, 2004; Belfield and Levin, 2005a; Reardon, 2009; Rouse and Barrow, 2009; Dronkers and Avram, 2010). This dissertation contributes to this research by 
analyzing the performance, in terms of both standardized achievement as well as upward mobility, for different school types and educational sectors in the Netherlands.

Finally, realizing multiple objectives of education (i.e. private and public) through educational choice seems to induce important tensions and tradeoffs (Godwin and Kemerer, 2002; Levin, 2009; Waslander et al., 2010). This highlights the importance of understanding the effects of educational choice across a range of educational outcomes. This dissertation contributes to this by presenting and interpreting the results for the Netherlands using Levin's framework for evaluation, using social justice in education as a specific angle for evaluating the effects of school choice and privatization. 
School Choice, Competition and Achievement 


\section{Review of International School Choice Literature*}

\subsection{Introduction}

Educational choice is arguably one of the major principles of both a market economy and a democratic society (Levin, 1991). School choice policies refer to a variety of programs aimed at expanding educational choice. These differ widely from country to country, as well as across time, but can commonly be described along two important dimensions. At the demand side of schooling, choice programs are designed which give parents more choices about the schools their children attend. On the supply side of education, school choice policies foster competition among schools for students and revenues (Plank and Sykes, 2003).

A recent comprehensive overview of the range of school choice systems across OECD countries is found in the organization's "Education at a Glance 2010" report. The key results in that report are i) that already four in five OECD countries allow government-dependent private schools and independent private schools to provide compulsory education, and ii) that opportunities for school choice have generally expanded over the last 25 years. In addition, reforms that promote school choice most often apply to public schools and less to independent private schools. Also, homeschooling opportunities have expanded in six of the OECD countries (Hansson and Charbonnier, 2010).

Whereas much of the choice debate historically focused on the United States

\footnotetext{
* This chapter is based on the paper: "School Choice Policies and Educational Outcomes: A Review of International School Choice Literature", TIER working paper
} 
context, the objective of this literature review is, similar to the work by Plank and Sykes (2003), to include school choice results from a variety of countries and educational contexts. ${ }^{5}$ First, the main theoretical considerations regarding school choice are presented to facilitate the process of interpreting school choice outcomes in different educational contexts. With the vast and expanding literature on school choice, this review aims to be comprehensive, but will not be exhaustive.

Much of the school choice literature focuses on a limited range of educational outcomes only (e.g. achievement or equity). Instead, this review adopts the aforementioned evaluative framework in Levin (2002) to allow for a more coherent discussion of this complex topic. Focusing on a wide range of educational outcomes has the advantage of highlighting apparent trade-offs that education policy makers face in dealing with educational choice (Levin, 2009). Thus, the objective here is to provide a summary of the school choice literature across multiple outcomes. In achieving this goal, this review first starts with describing the main design tools of choice plans (2.2), followed by Levin's framework of educational outcomes (2.3). This framework is then applied to review the theoretical literature on school choice (2.4). This is followed by an overview of the empirical body of knowledge (2.5), and some concluding remarks that result from this review of school choice (2.6). ${ }^{6}$

\subsection{Design instruments of educational choice}

The definition of schooling can be anything ranging from public schooling, private-religious schooling, private-independent schooling, to even homeschooling (Belfield, 2004). There are several policies and mechanisms that contribute to (or limit) educational choice. Within a system of public schooling only, choice can be exercised through residential sorting, intra- or inter-district choice plans (e.g. open enrollment), decentralization (e.g. charter schools), or through choosing homeschooling. Market choice approaches include private schooling

\footnotetext{
${ }^{5}$ For reasons of comparability and scope, the focus will be on countries that are member of the "Organisation for Economic Co-operation and Development" (OECD).

${ }^{6}$ It is worth emphasizing this is not an exhaustive literature review or meta-analysis. Instead, multiple searches were conducted through scholar.google.com with the term "school choice" together with one of the four different outcomes of education (i.e. "freedom of choice", "productive efficiency", "equity", "social cohesion") and closely related terms (e.g. "constraints", "achievement", "school quality", "inequity", "stratification", "segregation"). Next, studies were chosen on the basis of their appropriateness (e.g. OECD countries) and assigned to either the theoretical or empirical section, or both.
} 
options, such as educational vouchers, tuition tax credits or private schools (Levin, 2009). In describing such vastly different educational systems, three general design instruments available to educational policy makers are (a) finance, (b) regulation, and (c) support services (Levin, 2002).

Finance relates not only to the sources and amount of funds devoted to education, but also to the allocation of those resources, the eligibility criteria for receiving public funds, and what costs are covered by such funds (Levin, 1991). Important issues to address are, for example, whether schools are allowed to charge fees and if funds are differentiated by educational needs and/or socioeconomic background of the student.

The body of regulations determines which schools are eligible to provide education and/or receive public funds, as well as the discretionary power schools have regarding important issues, such as student admission selection, curriculum content and personnel (Levin, 1991). As such, regulations importantly determine the choice set of educational products on offer for households. Important elements to consider in this respect, for example, are the effects of regulations on the diversity of educational offerings, pedagogical innovation and the socioeconomic mix of the student body across schools.

Following Levin (2002), support services refer to those types of publicly provided services designed to increase the effectiveness of the educational sector. Examples of these are instruments to collect and disseminate information on educational choices to households, as well as the provision of transportation.

\subsection{Framework for the effects of school choice on educational outcomes}

Using the above design tools, Levin (2002) provides an evaluative framework for analyzing educational choice in terms of private- and public objectives. It seems important to make this distinction. For example, the struggle over these public- and private objectives in education is arguably at the root of many educational conflicts in the United States (Labaree, 1997). The problem here is that education takes place at the intersection of two sets of rights: i) that of the households and ii) that of society at large (Levin, 1999).

The criteria in Levin's framework draw upon a wide array of proposed potential goals for education and include: (a) freedom of choice, (b) productive efficiency, (c) equity, and (d) social cohesion. For each criterion, indicators are proposed that would make this 
framework for evaluation an appropriate one in reviewing the international school choice literature.

\section{Freedom of Choice}

Freedom of choice primarily emphasizes private benefits of education. For many choice advocates, the freedom for households to choose a school that matches their values, educational philosophies, religion and political outlooks is among the most important reasons to expand school choice (Levin, 1999). Empirical analysis of this outcome should address the impact of school choice (expansion) on the variety of options available to parents in different education systems. This choice set will partially be determined by financial arrangements and regulations regarding school philosophies, religious practices, curriculum, admissions and testing requirements (Levin, 2002). For the households, issues regarding financial constraints, school proximity, information constraints and parental preferences towards school attributes will also affect (revealed) school choice decisions (Schneider, Teske and Marschall, 2002).

\section{Productive Efficiency}

Productive efficiency refers to the maximization of educational results for any given resource constraint (Levin, 2002). It incorporates both private- and public objectives of education once it is assumed that if, for example, schooling makes the individual more productive, the economy at large also benefits from this. Thus, analysis of school choice should give insight into its effects on both micro-level and aggregate achievement. Ideally, empirical results are available that shed light on the effects of school choice expansions on both academic- and non-academic achievement outcomes. Potential heterogeneity in the effects of school choice on productive efficiency (e.g. for subgroups of students) is relevant to consider, as this leads to the next educational outcome: equity.

\section{Equity}

Equity constitutes an important public benefit of education and refers to the notion of fairness in access to education, resources, and outcomes by gender, social class, race, 
language origins and geographical location of students (Levin, 2002). ${ }^{7}$ Analysis of school choice should thus explore what the effects are on educational access, resources and outcomes. Sorting processes and the role of peer effects need to be understood in order to examine the effect of school choice on achievement gaps between groups of students (e.g. Ladd, 2002). The effect of school choice expansion on the sorting of students is also relevant for analyzing another objective of education: social cohesion.

\section{Social Cohesion}

Social cohesion also focuses primarily on the public benefits of education and includes those common elements that prepare students for civic participation. Common schooling elements that can foster cohesion include curriculum, social values, goals and language of instruction. Productive interactions between students of different backgrounds and cultures are also considered to be important for promoting social cohesion (Levin, 2002). Analysis of the effects of school choice should thus include several elements in order to address its impact on social cohesion. Important empirical relationships to consider here are those linking school choice, parental involvement, and common schooling experiences. In addition, the effects of school choice on sorting (e.g. by ability), stratification (e.g. along class-based lines), and/or segregation (e.g. along ethnical lines) should be addressed.

\subsection{Theoretical considerations in dealing with school choice}

For each of the educational outcomes outlined above, an overview of the main theoretical considerations regarding school choice is presented in this section.

\section{Freedom of Choice}

As an educational goal by itself, Friedman (1955) refers to the freedom of the individual (or family) as the ultimate objective of a society. Allowing households to decide on a school adheres to this notion of freedom. The market outcome of different choices on offer will depend largely on households' preferences over school characteristics, and on how those preferences vary in the population (Hastings et al., 2005). If such demand is indeed

\footnotetext{
${ }^{7}$ Following Yinger (2004), equity is a complex concept and includes, but is not limited to, horizontal equity, vertical equity, fiscal neutrality, and adequacy.
} 
heterogeneous, and with a variety of educational offers to choose from, informed households will then choose the option that maximizes private benefits (Levin, 2009). A common assumption is that households, like all rational consumers of goods and services, first decide on what they want from a school and then determine which school is best for their child. This decision can be subject to several constraints, including financial constraints, regulations, incomplete information and limited transportation (Teske and Schneider, 2001). Highlighting that a child might not be able to attend the preferred school due to ineligibilityand/or capacity constraints, Hirsch (2002) adds some additional constraints that households could face in exercising school choice.

Freedom of choice is arguably improved by alleviating regulatory constraints. Allowing households and schools to add on financial resources (e.g. tuition) further increases the diversity in the choice set on offer to households (Friedman, 1962). Expanding school choice options responds to the heterogeneous demand across households and ensures a more efficient matching of students and schools. This will then increase household satisfaction with the school (Teske and Schneider, 2001). However, the range of choices might only marginally increase for households that face more severe financial-, residential-, transportation- and/or information constraints (Levin, 2009). In addition, school choice critics argue that the resulting competition between schools will induce attempts to exclude certain students. For example, students with disabilities are more costly to educate and, when schools are not financially accommodated for this, these students may encounter explicit, or implicit, barriers to attending choice schools. Also, high concentrations of special needs students in a school could act as a deterrent to other households. These considerations could lead some schools to adopt policies that discourage households with special needs children from enrolling, thereby limiting the choices available to them (Cullen and Rivkin, 2003). The above theoretical outcomes for freedom of choice are synthesized in Table 2.1. 
Table 2.1: Summary of theoretical considerations - freedom of choice

\begin{tabular}{|c|c|c|}
\hline \multicolumn{3}{|l|}{ Freedom Of Choice } \\
\hline Theoretical outcomes of school choice & Description & Reference(s) \\
\hline acknowledge fundamental right & $\begin{array}{l}\text { The freedom of the individual (or family) to make their own decisions with } \\
\text { respect to education is one of the main objectives of a free society. }\end{array}$ & Friedman (1955) \\
\hline heterogeneity of supply & $\begin{array}{l}\text { If preferences towards school characteristics vary in the population, choice } \\
\text { will promote a variety of educational offers to choose from, and households } \\
\text { will choose the option that maximizesprivate satisfaction. }\end{array}$ & $\begin{array}{l}\text { Friedman (1962), Hastings et al. (2005), } \\
\text { Levin(2009), Teske and Schneider (2001) }\end{array}$ \\
\hline differential ability to exercise choice & $\begin{array}{l}\text { Constraints (e.g. financial, regulatory, information, transportation, capacity, } \\
\text { ineligibily) will limit the ability for households to exercise educational choice }\end{array}$ & $\begin{array}{l}\text { Teske and Schneider (2001), Hirsch (2002), } \\
\text { Levin (2009) }\end{array}$ \\
\hline incentives to exclude students & $\begin{array}{l}\text { Competition between schools will lead schools to adopt policies that } \\
\text { discourage more costly to educate, or less favourable, students }\end{array}$ & Cullen and Rivkin (2003) \\
\hline
\end{tabular}

\section{Productive Efficiency}

A major argument for fostering choice among schools is that it will lead to improved school efficiency in generating student achievement (Levin, 1991). Several theoretical mechanisms for such an effect have been proposed. One of the main claims is that school choice will generate competition for students among schools. If all households place high value on academic achievement, the market pressure of competition will then force schools to deliver high quality education, or parents will go elsewhere (Hastings et al., 2005).

A choice plan that allows households to choose private schools could also improve productive efficiency if private schools are found to be more efficient in delivering education (Hsieh and Urquiola, 2003). Shleifer (1998) argues that compulsory education is indeed a clear example of a service for which the case for government provision, in a well-developed democracy with high quality contracting and regulation in place, has become indefensible. Instead, the innovative potential of private entities, together with their strong incentives for cost reduction and major emphasis on consumer satisfaction, should be exploited by allowing private provision of education (Shleifer, 1998). Relative private school effectiveness is then explained either by their overall resource efficiency, or by their superior ability to serve particular subsets of families, or niche markets.

Even if school type does not matter in this respect, improved matching between schools and students is yet another mechanism through which school choice can improve productive efficiency. Some students do better in small schools than in larger ones, or in schools with a particular pedagogical approach, organization or curriculum; depending on their specific educational needs (Levin, 1991). With a wide variety of schools from which to 
choose, each of which provides a different mix of educational services, households will choose one that best meets their preferences and educational needs; thus producing better educational outcomes.

Lastly, another popular mechanism proposed for school choice and productive efficiency gains is parental involvement (e.g. Henderson, 1981; Godwin and Kemerer, 2002). Hirschman (1970) describes two mechanisms through which households express dissatisfaction with the school: "exit" and "voice". Choice advocates point out that expanding school choice not only improves households' exit option (i.e. by choosing another school), but also makes them more likely to be involved in school decision-making. Put differently, "exit" and "voice" act as complements in this scenario. This notion of promoting households' interests through school choice is underscored by Chubb and Moe (1990). If parents put more value on their child's academic achievement than the school staff, such increased parental involvement is likely to increase academic standards (Hoxby, 1999). However, opponents of school choice emphasize the notion of "exit" and "voice" as substitutes in that, if parents are able to choose another school, they face fewer incentives to devote time and effort in their child's current school (Hoxby, 1999). For example, McMillan (2000) describes a model for public school performance, in which both competition and parental involvement, independently, improve public schools' productive efficiency. However, if vocal active parents are the ones most likely to opt for private schools, a negative interaction exists between private school competition and public school parental involvement. This casts doubt on the common presumption that greater competition will uniformly raise public school productivity (McMillan, 2000).

The competition effect of school choice is also premised on the assumption of education as a largely homogeneous good, with academic achievement as the (major) choice determinant. However, it has been argued that households do not only value academic achievement gains, but other school attributes as well (e.g. Levin, 1998). If households have very heterogeneous preferences regarding school quality and attributes, schools could face only little competitive pressure to improve quality, as measured by productive efficiency (Hastings et al, 2005, 2008). In this case, school choice may not result in better academic outcomes (Goldhaber, 1999).

Potential "peer effects", the extent to which a student's learning outcomes depend on the characteristics of their classmates, are important in this respect as well. Rothstein's 
(2006) model highlights that households, in the presence of peer effects and with the ability to choose a school, may actually prefer less effective schools, but with desirable peer groups, to more effective schools. Schools, then face incentives enrolling high-quality peers, rather than offering effective instruction. In equilibrium, high-choice educational markets will then be more stratified by ability than low-choice markets (Rothstein, 2006). If this is the case, and peer effects do matter for academic achievement, the resulting distribution of educational benefits is likely to be quite unequal across groups of students (Epple and Romano, 1998).

Even without peer effects or differential preferences towards school attributes, MacLeod and Urquiola (2009) point to school reputation as another limitation for school choice to foster academic achievement through competition. In one specification of their model, not allowing schools to select students, competition between schools will lead to greater productive efficiency (through processes similar to the ones described in the paragraphs above). However, with choice and selectivity, schools can also increase school reputation by excluding weak students. If it is assumed that the signal of a student's skill level to the labor market is partially determined by the reputation of the school, selectivity then also gives rational reasons for students to lower (costly) effort. This could lower the overall productive efficiency of the education system (MacLeod and Urquiola, 2009).

If academic achievement is indeed the main choice determinant for households in deciding on a school, competitive pressure induced by school choice could still have adverse productive efficiency effects on other learning outcomes. One such example is the effect of narrowing the curriculum (e.g. test preparation) at the expense of non-academic skills or subjects (Levin, 1998). Choice advocates and opponents largely disagree on the actual effect school choice expansion will have on schools' curricula, academic standards and resources spent on non-cognitive activities (Hoxby, 1999).

Lastly, the implementation of a school choice plan (e.g. voucher system) could not only affect output (i.e. academic achievement), but also (macro-level) educational inputs. This suggests both of these dimensions should be addressed when analyzing the productive efficiency effects of school choice and competition (e.g. see: Levin and Driver, 1997). The above theoretical outcomes for productive efficiency are synthesized in Table 2.2. 
Table 2.2: Summary of theoretical considerations - productive efficiency

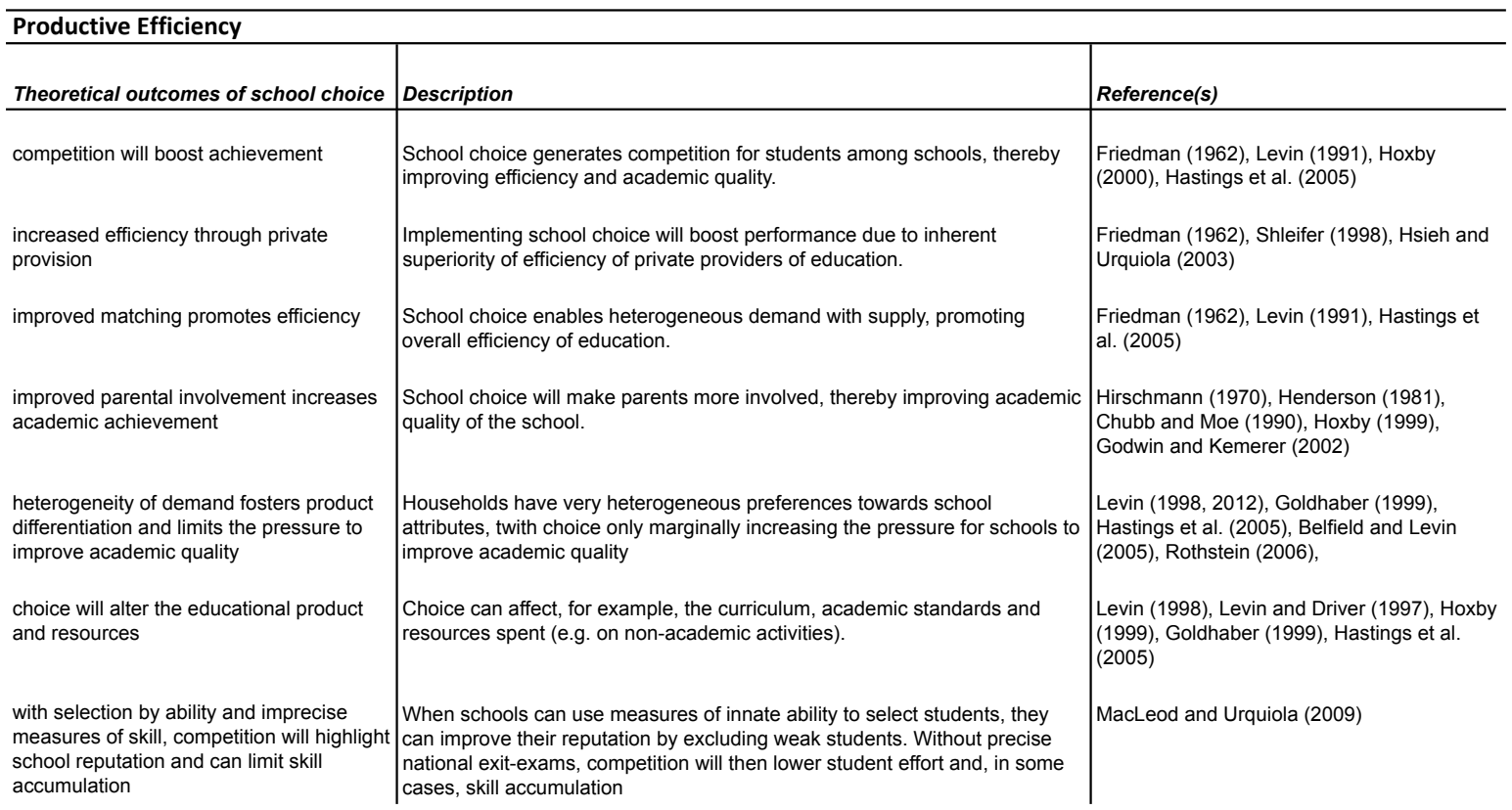

Equity

The theoretical framework by Nechyba $(1999,2000)$ highlights how the household choice of attending a particular public school, in a public schooling system with so-called catchment areas, is essentially bundled with the choice of residence. This decision is thus linked to housing markets that price not only the quality of housing, but also the associated amenities (including access to schools). As a result, even in a public schooling system with no tuition fees, the best public schools are in practice not free to households, as they will need to pay more for accessing these schools through the housing prices (or rental rates) required to gain such access.

Choice advocates argue that expansion of school choice liberates families from such residential constraints; a theory referred to by Archbald (2004) as the liberation model. This would thus suggest that, once school choice options are expanded, households in a poor school quality neighborhood will have the option to send their children to better quality schools elsewhere. The models in Nechyba $(1999,2000)$ describe how negative peer externalities within schools coincide with poor residential neighborhoods, highlighting these potential equity benefits of school choice expansion. On the other hand, Hastings et al. (2008) point out that heterogeneous preferences towards schooling could also result in school choice expansion widening, rather than narrowing, the achievement gap. 
The model in Epple and Romano (1998) emphasizes such peer effects as a key determinant of school quality. The model has important equity implications if student ability and household income are positively correlated, or if the demand for school quality rises with student ability. The authors show that a public system with neighborhood schooling can lead to a stratified equilibrium outcome, even in the absence of per-student expenditure differences. The effects of expanding school choice options in this respect depend strongly on the design (i.e. finance, regulation and support services) of the choice plan (Levin, 2009). For example, with no choice constraints (e.g. transportation costs are paid by the government and no admission constraints), a public school choice system has the potential to equalize schooling qualities in equilibrium (Epple and Romano, 2003). If private schools are allowed to enter the market (e.g. through vouchers), assuming peer effects and allowing schools to charge tuition and provide tuition subsidies, the equilibrium outcome is stratified by both income and ability across schools (but not neighborhoods). Ability sorting and achievement gaps, through the financial aid provided to attract higherability students, could be even greater than under a no-choice public system of neighborhood schooling (Epple and Romano, 2003).

Whereas the previous effects of school choice and sorting depend strongly on the existence of peer effects, the framework in MacLeod and Urquiola (2009) predicts socioeconomic stratification across schools will occur through the student admission selection process, regardless of any peer effects. If school reputation depends partially on the student-body intake, school choice will lead to a so-called "anti-lemons effect" in which selective schools enter, crowd out non-selective (public) schools, and increase inequality in the educational system (MacLeod and Urquiola, 2009). The theoretical outcomes for equity are synthesized in Table 2.3.

Table 2.3: Summary of theoretical considerations - equity

\begin{tabular}{|c|c|c|}
\hline \multicolumn{3}{|l|}{ Equity } \\
\hline Theoretical outcomes of school choice & Description & Reference(s) \\
\hline $\begin{array}{l}\text { liberates families in poor neighborhoods } \\
\text { from bad schools and peers }\end{array}$ & $\begin{array}{l}\text { Households that live in poor neighborhoods, often facing poor schooling } \\
\text { options, can exploit choice to move to a school of higher quality and benefit } \\
\text { from better peers. }\end{array}$ & Nechyba (1999, 2000), Archibald (2004) \\
\hline $\begin{array}{l}\text { stratification by ability and income that } \\
\text { depends largely on design of choice plan }\end{array}$ & $\begin{array}{l}\text { Whether a (public) school choice system equalizes schooling qualities } \\
\text { depends strongly on design (finance, regulation, support services), with } \\
\text { equity results potentially even worse relative to the no-choice alternative. }\end{array}$ & $\begin{array}{l}\text { Epple and Romano (1998, 2003), Levin } \\
\text { (2009), }\end{array}$ \\
\hline $\begin{array}{l}\text { schools are induced to improve reputation, } \\
\text { and constrain opportunities for some }\end{array}$ & $\begin{array}{l}\text { Schools have an incentive to enroll good peers, exclude certain students } \\
\text { and improve reputation, which could exacerbate stratification by } \\
\text { socioeconomic status and/or ability. }\end{array}$ & $\begin{array}{l}\text { Hirsch (2002), Levin (2009), Rothstein } \\
\text { (2006), Cullen and Rivkin (2003), MacLeod } \\
\text { and Urquiola (2009) }\end{array}$ \\
\hline
\end{tabular}




\section{Social Cohesion}

The work by Hirschman (1970) provides a way of thinking about potential school choice effects on parental involvement. As mentioned, choice advocates point out that school choice expands households' exit option, but will also makes them more involved in the school decision-making process (Hoxby, 1999). Schneider et al. (1997) hypothesize that expanding public school choice options to households will provide them with incentives to engage in activities that build social capital. ${ }^{8}$

It is relevant to distinguish between different levels of social cohesion in this case. For example, the above situation can be described as one in which the sense of social cohesion within the community of a specific school is strengthened. The importance of such within-school social cohesion is highlighted by Coleman (1988), who states that independent schools face the important challenge of forming a school community out of a set of relatively independent individuals. Different from religious schools (i.e. church community) and public schools (i.e. neighborhoods), these independent schools accommodate a group of children from households that do not already form a strong community together. However, strengthening the school community does not imply that cohesion at a societal level is improved as well.

Also, the view expressed in OECD's "Education at a Glance 2010" is that school choice and parent voice are inextricably linked and that, when school choice (i.e. exit) is limited parents will be more likely to try and influence schools (i.e. voice). Similarly, when there are ample opportunities for "voice", parents will be less likely to "exit" and choose another school for their children (Hansson and Charbonnier, 2010). The above implies that the effect of school choice expansion on parental involvement, social capital and cohesion within schools depends on whether "voice" is substituted for "exit", and on whether the resulting sorting of students across schools resembles that of existing communities.

This notion of student sorting is particularly important for discussing social cohesion at a societal level, when analyzing productive interactions between students of different backgrounds and cultures. School choice affects such interactions through its effects on the segregation of students from different backgrounds. The liberation model in Archbald (2004) argues that school choice will reduce such segregation by creating access for low-

\footnotetext{
${ }^{8}$ Social capital can be described as those elements that contribute to the construction of institutions that build social cohesion (White and Maxim, 2003).
} 
income minority families to higher quality schools outside their poor- and segregated neighborhoods. However, racial- and class-based preferences, transportation constraints, limited information, and admission constraints can all violate the assumptions of the liberation model. As such, expanding school choice might actually increase school-level segregation (Archbald, 2004).

Therefore, the role played by household preference theories is important in the context of segregation (Bifulco et al., 2009). The outgroup avoidance theory posits that expanding school choice will increase segregation by making it easier for majority, advantaged households to avoid schools accommodating high proportions of minority, disadvantaged students in maintaining their social status. The neutral ethnocentrism theory provides a more general argument, stating that parents of all races will seek out schools in which their children can be with students of similar backgrounds. Given the general preference for socioeconomically advantageous schools (e.g. as a proxy for school quality), Bifulco et al. (2009) argue that these segregating forces are likely to be stronger for majority households, whereas minority households face a trade-off in optimizing school quality preferences, together with class- and/or racial preferences.

Household preferences also feed into a theoretical discussion on how school choice relates to a child's actual schooling experience. Expansion of choice is generally considered to shift control over the school away from policy makers, in favor of private stakeholders, such as households, teachers and school principals (e.g. Chubb and Moe, 1990; Hoxby, 1999; Bifulco et al., 2009). Social cohesion is primarily a societal benefit. As with other outcomes, the design of a school choice program (i.e. finance, regulation and support services) will ultimately determine the effect of such a policy on social cohesion. For example, social cohesion in a system of choice could be promoted through regulations on a common curriculum, teacher credential- and performance standards, testing requirements, and admission selection criteria (Levin, 2009). The theoretical outcomes for social cohesion are synthesized in Table 2.4 . 
Table 2.4: Summary of theoretical considerations - social cohesion

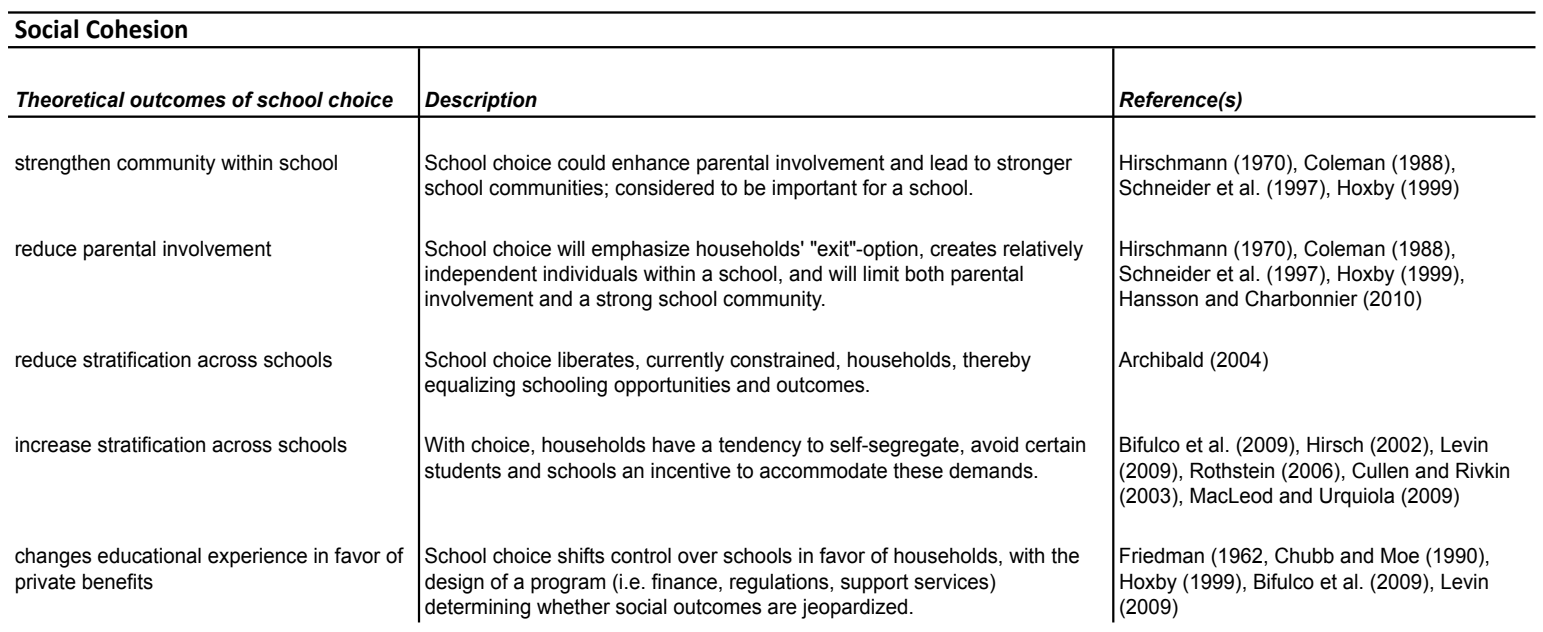

\section{Discussion of Theoretical Considerations}

The previous paragraphs point out that school choice expansion is likely to affect a range of educational objectives, and different effects have been hypothesized within each of them. This dispersion can be partially explained through different assumptions and also depend on the actual design of a specific choice program. Nevertheless, some general inferences can be drawn from the above theoretical discussion.

School choice expansion is likely to emphasize private objectives of education, which might not always align with societal goals. Households value the freedom to choose a school, not only as a goal in itself, but also as it allows them to find a school that closely matches their values, preferences and other educational aspirations (Levin, 2009). In addition, the proposed mechanisms for productive efficiency gains through school choice further contribute to the potential benefits to households (and society). But, these gains in freedom of choice and productive efficiency could turn out to be only marginal. First of all, there are theoretical reasons to believe that choice constraints will not be alleviated, particularly for certain (socioeconomically) disadvantaged households. In addition, some of the (market) assumptions on which productivity gains are premised have been challenged. The heterogeneity of households' preferences towards academic achievement and other school attributes is likely to limit the ability of school choice expansion to generate academic achievement gains through competition. Furthermore, the potential relevance of peer effects and school reputation provide further reasons for caution, particularly for the effects on certain (socioeconomically) disadvantaged groups of households. 
The observation that gains in freedom of choice and productive efficiency could be limited, or negative, for (disadvantaged) households fuels the discussion of what the effects are on primarily societal outcomes (i.e. equity and social cohesion). The above considerations highlight that rigid choice constraints, potential peer effects, school reputation, and issues of segregation, all provide arguments for equity concerns. By separating the household's choice of school from the choice of residence, class- and racial based preferences could be revealed more evidently, which further contributes to concerns of social cohesion. Lastly, the fact that school choice will shift control over the educational experience from policy makers to households provides another challenge in securing the social benefits of education.

The wide array of potential effects of school choice is partially due to differential assumptions regarding household preferences, peer effects and the role of school reputation. In addition, results will also strongly depend on how a school choice program is designed in terms of finance, regulation and support services (Levin, 2009). What follows, therefore, is an empirical review of school choice effects that will emphasize the above issues, as to gain insight in how school choice effects actually play out in practice.

\subsection{Empirical results for the effects of school choice plans}

For each of the four educational outcomes, a summary of the empirical findings is presented in this section.

\subsubsection{Freedom of Choice}

Teske and Schneider (2001) provide a valuable review on school choice effects on several educational outcomes in the United States context, based on over 100 studies. Their results indicate that households that actively choose schools differ in important ways from other households, a notion confirmed by others (e.g. Godwin and Kemerer, 2002). If households have the option to choose (i.e. option-demand), those who take up this opportunity score higher on socioeconomic status, are more likely to belong to the majority ethnic group, and prefer a school of high average academic performance. Choice expansion programs targeted at low-income households also reveal that educational quality is the most important choice determinant referred to in surveys. Observed residential sorting patterns are in line with 
such behavior (Hoxby, 1999). However, revealed school choice behavior is often different from choosing only on the basis of academic achievement (e.g. Schneider and Buckley, 2002). The resulting differences seem to be explained by a combination of choice constraints for socioeconomically disadvantaged households, and outgroup avoidance behavior by majority households. Importantly, the existing body of evidence points to a positive effect of school choice on households' satisfaction with their school (Witte, 1998; Teske and Schneider, 2001; Mayer et al., 2002; Rouse and Barrow, 2009, Waslander et al., 2010).

In a comprehensive international review on the behavioral responses of school choice in compulsory education, based on 255 studies, Waslander et al. (2010) conclude that many households exercise choice, when given the option, but that households that are relatively more educated, well-off, and involved do so more frequently. They also cite empirical support for outgroup avoidance behavior on behalf of advantageous majority households. Relative to academic quality, student-body composition seems to be an even more important choice determinant in explaining observed choice patterns (Waslander et al., 2010).

Evidence from case studies outside the United States seems to reiterate this notion that households do not "simply" choose schools on the basis of educational quality. Hsieh and Urquiola (2003) analyze the effects of a nationwide school voucher program for primary- and secondary education in Chile. Their results also show that households from higher socioeconomic backgrounds are more likely to exercise the choice option. In addition, households that choose a school put much emphasis on choosing a school that accommodates a socioeconomically advantageous student-body (Hsieh and Urquiola, 2003). In New Zealand, a system was implemented which resembles more of a public school choice program (or "quasi-voucher"). Observed enrollment effects reveal that households prefer to send their child to a socioeconomically advantageous school (Fiske and Ladd, 2003). The design of that program was such that, in terms of finance, it allowed schools to ask "voluntary" fees from parents, regulations permitted schools to use "enrollment schemes" in selecting students, and, as for support services, it did not publicly fund transportation costs. In the People's Republic of China, increased school choice is a rather recent development with the development of non-governmental schools. An analysis of this system also highlights that school choice is available only to economically advantageous households 
(Tsang, 2003).

Based on the above, the notion that the range of choices might only marginally increase for socioeconomically disadvantaged households thus seems to be one that is empirically supported (Levin, 2009). It is questionable whether support services are capable of completely overcoming such issues. For example, experimental findings in Hastings and Weinstein (2008) show that the timely provision of relevant information on choice options only slightly improves the school choice decision of disadvantageous households. The empirical results for freedom of choice are synthesized in Table 2.5.

Table 2.5: Summary of empirical results - freedom of choice

\begin{tabular}{|c|c|c|}
\hline \multicolumn{3}{|l|}{ Freedom Of Choice } \\
\hline Empirical results of school choice & Description & Reference(s) \\
\hline choosers differ from non-choosers & $\begin{array}{l}\text { When presented with the option to choose a school, those who do so } \\
\text { (actively) are relatively affluent, more likely to belong the the majority ethnic } \\
\text { group, and better informed. }\end{array}$ & $\begin{array}{l}\text { Teske and Schneider (2001), Godwin and } \\
\text { Kemerer (2002), Schneider and Buckley } \\
\text { (2002,) Tsang (2003), Hsieh and Urquiola } \\
\text { (2003), Hastings and Weinstein (2008), } \\
\text { Waslander et al. (2010) }\end{array}$ \\
\hline $\begin{array}{l}\text { households prefer a school with high } \\
\text { academic achievement }\end{array}$ & $\begin{array}{l}\text { Households express that an important choice determinant is a high average } \\
\text { academic performance. }\end{array}$ & $\begin{array}{l}\text { Teske and Schneider (2001), Godwin and } \\
\text { Kemerer (2002), Hoxby (1999), Schneider } \\
\text { and Buckley (2002), Waslander et al. (2010) }\end{array}$ \\
\hline $\begin{array}{l}\text { desire to attend a socioeconomically } \\
\text { advantageous school }\end{array}$ & $\begin{array}{l}\text { The (revealed) behavior of households is such that they put much emphasis } \\
\text { on choosing a school that accommodates a socioeconomically } \\
\text { advantageous student-body. }\end{array}$ & $\begin{array}{l}\text { Schneider and Buckley (2002), Waslander et } \\
\text { al. (2010), Hsieh and Urquiola (2003), Fiske } \\
\text { and Ladd (2003) }\end{array}$ \\
\hline choice improves customoer satisfaction & Enabling households to choose improves satisfaction with the school. & $\begin{array}{l}\text { Witte (1998), Teske and Schneider (2001), } \\
\text { Mayer et al. (2002), Rouse and Barrow } \\
\text { (2009), Waslander et al. (2010) }\end{array}$ \\
\hline
\end{tabular}

\subsubsection{Productive Efficiency}

It has been widely documented that, in the absence of explicit school choice options, some sense of household choice still exists through residential sorting (e.g. Tiebout, 1956; Lankford and Wyckoff, 1999; Urquiola, 2005; Waslander et al., 2010). Variation in the amount of such choice available to households, often referred to as "Tiebout choice", allows researchers to empirically address the long-term effect of school choice on student achievement for large-scale contexts. Using the number of streams within a metropolitan area in the United States as an instrument for "Tiebout" school choice, Hoxby (2000) finds a large and positive effect of school choice on student test scores and attributes these results to inter-district competition. However, Rothstein (2005) criticizes the sensitivity of the instrument chosen and highlights how several alternative specifications (both ordinary least squares- and instrumental variable approaches) show in fact no significant effect of school choice on achievement. 
Researchers thus face methodological challenges in isolating the effect of competition on achievement. Hoxby (2003) analyzes the implementation of vouchers in Milwaukee and charter schools in Michigan and Arizona to look at the competition effect on public school performance and, using a difference-in-differences analysis, finds statistically significant improvements in achievement for public schools. Belfield and Levin's (2002) review on the United States contains 25 empirical estimates for the effect of competition on (public) school academic performance. The majority of results report positive and statistically significant correlations. Importantly, however, the results appear to be substantively modest and suggest that an increase of one standard deviation in competition would probably increase test scores by around $0.1 \sigma$ (Belfield and Levin, 2002). In their review of the effects of voucher programs, Rouse and Barrow (2009) also conclude there is inconclusive support for the potential of vouchers to spur public school performance.

Chile provides an international case study for the effect of a large-scale school choice program on aggregate achievement. Hsieh and Urquiola (2003) analyze the effects of 20 years of school choice in the universal voucher choice setting of Chile and find no evidence of relative improvements in aggregate achievement, as measured by international tests (i.e. TIMSS). ${ }^{9}$ In Denmark, competition among schools, through the introduction of vouchers for private schools, does not seem to yield positive competition effects for public school students' achievement either (Andersen and Serritzlew, 2007). In a similar reform in Sweden, an increase in the private share did seem to initially yield some beneficial competition effects on average student achievement, but with smaller and more ambiguous long-term effects (Boehlmark and Lindahl, 2007, 2008, 2012). Based on the results of several international case studies, Ladd (2003) concludes that there are many methodological challenges and that the international evidence of choice and competition on student achievement is unclear or, at best, mixed. Waslander et al. (2010) also summarize their review of competition effects on public school performance by stating that, in cases where positive effects are found, the benefits are very modest in size.

In a recent effort to overcome some of the methodological challenges, West and Woessmann (2010), based on PISA 2003 data, exploit "the share of Catholics in 1900" as an instrument to generate exogenous variation in the amount of competition observed today

\footnotetext{
${ }^{9}$ The Trends in International Mathematics and Science Study (TIMSS) provides internationally comparable data on the mathematics- and science achievement of students from many countries around the world.
} 
(as measured by the size of the private sector). Using this methodology, a 10 percent increase in the size of the private sector, leads to gains in mathematics achievement (approximately $0.1 \sigma)$, and has slightly smaller effects for science and reading $(0.05 \sigma)$. In addition, the same increase in the private sector size also tends to reduce educational expenditure per student by about 5 percent, further indicating productive efficiency gains of competition (West and Woessmann, 2010).

As mentioned, another mechanism for school choice to improve productive efficiency is through relative private school effectiveness. Coleman et al. (1982) provide one of the earliest estimates of private Catholic school attendance in the US and find positive effects on academic outcomes. ${ }^{10}$ The results have been criticized on the grounds that the regression models (i.e. covariate controls) do not adequately control for initial achievement and unobserved selection mechanisms, yielding biased estimates for Catholic schooling effects (Goldberger and Cain, 1982). More recently, McEwan (2000) reviewed the evidence for Catholic schooling and finds modest effects on achievement for minority students, though only for lower elementary grades, and only for mathematics. In addition, the modeling of the school-choice selection process appears to be crucial and can lead to results that vary substantially across subgroups (e.g. Murnane et al., 1985; Grogger et al., 2000). The main criticism on results derived from covariate adjustments stems from the fact that the comparability of the Catholic and public school students upon entry into high school cannot be ensured (Reardon et al., 2009). The results on attainment appear to be stronger, but are methodologically difficult to determine (McEwan, 2000). Neal (1998) also summarizes the Catholic school attendance effects as being mixed for achievement, but consistent and positive for attainment. The latter seems particularly true for urban minority households, facing poor public schooling alternatives (Neal, 1998).

Similarly, private voucher schools could also outperform traditional public schools. One of the oldest publicly funded voucher programs in the US for grades K-8 is the Milwaukee voucher experiment. The design was such that it was targeted at low-income households, small-scale with only $1-1.5 \%$ of total enrollments, and (initially) only independent, secular schools were eligible to receive the voucher. Witte (1998) compares students in choice schools with a comparable sample of low-income public school students

\footnotetext{
${ }^{10}$ Catholic schools are the vast majority of the private schools in the US.
} 
and finds no statistically significant achievement differences. Using different methodologies, Greene et al. (1998), do find statistically significant effects for both subjects tested. Rouse (1998) points out some additional validity issues and finds small (i.e. $0.06 \sigma-0.11 \sigma$ ) achievement gains, though only for mathematics. Peterson et al. (2003) analyze the impact of attending a private school through voucher lotteries in New York City, Washington DC and Ohio. The authors, comparing lottery winners to losers, find statistically significant positive achievement effects on standardized tests over a three-year period, though only for African American students. No overall differences were found.

Results for voucher schools are not stable across programs, years and cities. Mayer et al. (2002) find similarly large positive effects for the New York context for African American students. But, Krueger and Zhu (2004) adapted the analysis by including students that were lacking base-line results, as well as allowing for a broader definition of African American students. The effects of these changes were for the results to become statistically insignificant. In comparing the results of private-, charter-, and public schools students' $4^{\text {th }}$ and $8^{\text {th }}$ grade mathematics achievement on the 2003 NAEP exam, Lubienski and Lubienski (2006) find that, after accounting for the student-body intake, public schools perform remarkably well, and often even outperform private- and charter schools. ${ }^{11}$ Analyzing the US debate on voucher schemes, Belfield and Levin (2005) highlight the very small differences between achievement of voucher students and comparable ones in public schools. Rouse and Barrow (2009) also conclude that the best research to date finds relatively small achievement gains for students offered education vouchers, most of which are not statistically different from zero.

In Chile, the differences in educational effectiveness and productive efficiency between private- and government schools also appear to be difficult to determine and have been found to be small (McEwan and Carnoy, 2000). Vandenberghe and Robin (2004), based on PISA 2000 data, also highlight the methodological difficulties in comparing students across different school types and find that private education does not generate systematic

\footnotetext{
${ }^{11}$ The National Assessment of Educational Progress (NAEP) is the largest nationally representative and continuing assessment of what America's students know and can do in various subject areas. Assessments are conducted periodically in mathematics, reading, science, writing, the arts, civics, economics, geography, and U.S. history.. Source: http://nces.ed.gov
} 
academic achievement gains. ${ }^{12}$ Based on TIMSS 2003 data for $8^{\text {th }}$ grade mathematics- and science achievement, Rutkowski and Rutkowski (2009) portray a slightly different picture. Using multilevel modeling, and propensity score matching methods to account for selection bias, their findings indicate that private schools have significantly higher achievement levels (i.e. widely varying between $0.1 \sigma$ and $0.7 \sigma$ ) in five of eight education systems analyzed. ${ }^{13}$ However, these effects were neither uniform across educational systems, nor were they uniform within an educational system across content domains. Also, these results do not take into account differences in educational expenditures. Using PISA 2000 data and a multilevel model approach, Dronkers and Robert (2008) find that students in governmentdependent private schools do consistently outperform their public counterparts, with related analyses suggesting this is particularly true for pupils with little cultural capital (Corten and Dronkers, 2006). But, Dronkers and Avram (2010) apply a propensity-score matching approach to account for selection issues, and base their analysis on three waves of PISA data. They find that the substantial advantage in reading achievement for students in publicly funded private schools remains to exist in just 10 out of the 26 countries included.

In addition to competition and school type effectiveness, a third mechanism for school choice to promote productive efficiency is through improvements in the matching of students with schools. Cullen et al. (2005) exploit the implementation of a large public choice program in Chicago. Whereas children from households that choose have better graduation rates, the results seem to be largely driven by unobserved differences between households that choose and those that do not. Their estimates for a causal effect of school choice, using an instrument based on the distance to schools, suggest virtually no academic achievement gains for choosers. The same authors also analyze academic results for lottery winners and losers and find no effect of attending the school of choice on traditional academic outcomes (e.g. test scores and attainment). However there is evidence that attendance at such schools may improve a subset of non-traditional outcome measures, such as self-reported disciplinary incidences and arrest rates (Cullen et al., 2003).

\footnotetext{
${ }^{12}$ The OECD project PISA, Programme for International Student Assessment, takes place every three years and the survey has been designed to collect information about 15-year-old students in participating countries. Every three years, it assesses how far students near the end of compulsory education have acquired some of the knowledge and skills essential for full participation in society (OECD, 2006).

${ }^{13}$ Given the fact it was not possible to make proper school-type distinctions for all countries in the TIMSS data set, their results are based on only a subset of (widely differing) countries, being: Bahrain, (the Flemish region of) Belgium, Chile, Iran, Japan, Lebanon, the Philippines, and the United States.
} 
In an effort to understand the relationship between peer effects, school choice and the effects on achievement, Rothstein (2006) utilizes variation in "Tiebout choice" in US metropolitan areas and analyzes students' SAT scores. ${ }^{14}$ He finds little evidence that parents use Tiebout choice to select more effective schools over those with desirable peers. The validity of generalizing these results to school choice plans that decouple the school choice decision from the residential choice is unclear. ${ }^{15}$ Cullen et al. (2003) provide such an example, by analyzing the public school choice plan in Chicago. The authors find that, on average, students winning lotteries to high-achieving schools attend schools with peers who score substantially higher on standardized tests, have lower rates of poverty (as measured by free lunch eligibility), and have higher graduation rates. However, as mentioned, their results provide little evidence for the notion that attending such a sought after program also benefits the student in terms of academic measures. Epple et al. (2004) use data from the National Education Longitudinal Survey (NELS) and find support for the theoretical prediction in Epple and Romano (1998) that an educational system with choice of (expensive) private schools, in equilibrium, will lead to stratification across schools by ability and income. ${ }^{16}$ This suggests that the effects of peers on student achievement, whatever their magnitude, will be distributed unevenly with respect to socioeconomic status in the presence of (expensive) school choice. Similar sorting processes are observed in the Chilean voucher context, making it very difficult to empirically distinguish between the effects of choice, competition, school type, and peers on achievement (Hsieh and Urquiola, 2006).

Methodological difficulties are also present when estimating the effects of school choice on achievement through changes in parental involvement. Although there is consensus on the notion that school choice increases household satisfaction (Witte, 1998; Teske and Schneider, 2001; Mayer et al., 2002; Rouse and Barrow, 2009), this increase in satisfaction is not always supported by corresponding empirical gains in learning outcomes (Teske and Schneider, 2001). In addition, households that choose do tend to be more

\footnotetext{
${ }^{14}$ The SAT is a standardized test for college admissions in the United States.. Source: http://nces.ed.gov

${ }^{15}$ For, example, under Tiebout choice, parents may have to give up desired neighborhood amenities and may be unwilling to do this; even though they would choose the better school, were that choice separable from the residential location decision.

${ }^{16}$ National Education Longitudinal Survey (NELS), is a nationally representative sample of public and private school students representing over one thousand schools, which first interviewed and tested eighth graders in 1988, then followed these students through high school and beyond. The results in Epple et al. (2004) will be discussed more fully in the section on equity.
} 
involved, but these differences between households appear to exist already prior to the choice decision (Ladd, 2002; Cullen et al., 2005; Hanushek et al., 2007). Empirical results for a public school choice plan in North Carolina suggest that when parents are given choice, the revealed preferences are heterogeneous, with the preference for academic achievement increasing with household income and child ability (Hastings et al., 2005, 2008). In contrast, Jacob and Lefgren (2007) find evidence for low-income and minority families strongly valuing standardized measures of student achievement, whereas higher-income and non-minority families put more emphasis on a principal's reports of a teacher's ability to promote overall student satisfaction instead. In their international review, Waslander et al. (2010) point out that, in the face of school choice and competition, a system of local hierarchical schools is likely to emerge in order to adhere to such heterogeneity in households' demands. Thus, the potential for competition to induce academic achievement gains is limited by this notion that different schools appeal to different households.

With respect to school reputation and school choice, Waslander et al. (2010) argue that households (i.e. demand side) highly value a school's reputation and that schools (i.e. supply side) correspondingly respond, either explicitly or implicitly, by improving their reputation through both student admission policies (e.g. selection by ability) and educational offerings (e.g. tracking and non-academic services). However, the empirical effects of choice on school reputation and academic achievement are still largely unknown.

Another issue in dealing with school choice and productive efficiency is to understand the effects of school choice on both micro and macro level costs of education. In the Milwaukee voucher plan, for example, private schools were performing as well as the public schools in terms of academic achievement, though the voucher was only $60 \%$ of the public school per-pupil spending. However, Levin (1998) points out that private schools often rely heavily on supplements to tuition in the form of fund-raising events, special activities fees, and in-kind contributions. Furthermore, private school tuition does not account for transportation- or food service costs, and private schools often serve relatively few students who are in more costly programs (e.g. special needs). Levin's adjusted comparison suggests that voucher schools are comparable in terms of efficiency. More recently, Miron et al. (2011) also argue that, although KIPP charter schools show higher levels of student achievement on standardized tests, these schools also receive far more 
resources from both public- and private sources. ${ }^{17}$ In Chile, school types also differ in the amount of resources available to them. McEwan and Carnoy (2000) add cost-estimates to the school types measures of achievement. Based on achievement only, non-religious schools and public schools are more or less comparable. Catholic schools score better, but also utilize more resources. In terms of productive efficiency, non-religious schools turn out to be the most efficient, with public- and Catholic voucher schools approximately equally efficient (McEwan and Carnoy, 2000).

At the macro-level, there may also be costs associated with how a choice system deals with the transportation of children to and from school, the record keeping of student enrollment, and the process of adjudicating disputes. Levin and Driver (1997) roughly estimate that, because of these reasons, the public costs of a voucher system in the US context could actually exceed that of a neighborhood schooling policy by $25 \%$ or more. Waslander et al. (2010) add to this that, for educational markets to really function efficiently, buyers need to actively respond to changes in the price/quality relation (i.e. elasticity of demand), and sellers need to respond to customer demand by either diminishing or extending production (i.e. elasticity of supply). In education, both of these dynamics seem to be limited in practice (Waslander et al., 2010). The above empirical results for productive efficiency are synthesized in Table 2.6.

\footnotetext{
${ }^{17}$ The Knowledge is Power Program (KIPP) began as a fifth-grade public school program in Houston, Texas, in 1994. The vast majority of schools serve middle school grades, are often placed in "high need" urban and rural neighborhoods. These charter schools are tuition-free, open-enrollment, public schools.
} 
Table 2.6: Summary of empirical results - productive efficiency

\begin{tabular}{|c|c|c|}
\hline \multicolumn{3}{|l|}{ Productive Efficiency } \\
\hline Empirical results of school choice & Description & Reference(s) \\
\hline $\begin{array}{l}\text { competition moderately boosts } \\
\text { achievement, with estimates subject to } \\
\text { methodological difficulties }\end{array}$ & $\begin{array}{l}\text { Competition between schools for students sometimes } \\
\text { seems to moderately improve achievement, but results } \\
\text { are often statistically insignificant and face several } \\
\text { methodological challenges. }\end{array}$ & $\begin{array}{l}\text { Hoxby }(2000,2003), \text { Rothstein (2005), Belfield and Levin (2002), } \\
\text { Rouse and Barrow (2009), Hsieh and Urquiola (2003), Andersen } \\
\text { and Serritzlew (2007), Gibbons et al. (2008), Boehlmark and } \\
\text { Lindahl (2007, 2008, 2012), West and Woessmann (2010), Ladd } \\
\text { (2003), Waslander et al. (2010) }\end{array}$ \\
\hline $\begin{array}{l}\text { inconclusive evidence for private } \\
\text { provision to outperform public schools }\end{array}$ & $\begin{array}{l}\text { Observed achievement in private schools is often higher, } \\
\text { but challenged by selection biases, with more robust } \\
\text { results for improvements in terms of attainment. }\end{array}$ & $\begin{array}{l}\text { Coleman (1982), Goldberger and Cain (1982), McEwan (2000), } \\
\text { Neal (1998), Witte (1998), Greene et al. (1998), Rouse (1998), } \\
\text { Peterson et al. (2003), Mayer et al. (2002), Krueger and Zhu } \\
\text { (2004), Lubienski and Lubienski (2006), McEwan and Carnoy } \\
\text { (2000), Vandenberghe and Robin (2004), Rutkowski and Rutkowski } \\
\text { (2009), Dronkers and Robert (2008), Dronkers and Avram (2010), } \\
\text { Belfield and Levin (2005), Rouse and Barrow (2009) }\end{array}$ \\
\hline $\begin{array}{l}\text { the effect of choice on achievement } \\
\text { through its effects on peers is difficult to } \\
\text { isolate }\end{array}$ & $\begin{array}{l}\text { School choice often simultaneously impacts many things } \\
\text { (e.g. peers, competition, residential sorting, school type } \\
\text { and accountability), making it methodologically } \\
\text { challenging to isolate the effect of choice on achievement } \\
\text { through the mechanism of peer effects. }\end{array}$ & $\begin{array}{l}\text { Rothstein (2006), Cullen et al. (2003), Epple et al. (2004), Hsieh } \\
\text { and Urquiola (2006), Waslander et al. (2010) }\end{array}$ \\
\hline $\begin{array}{l}\text { the effect of choice on achievement } \\
\text { through parental involvement is } \\
\text { ambiguous }\end{array}$ & $\begin{array}{l}\text { Households that choose are often more satisfied and } \\
\text { involved, although difficult to attribute this to choice, but } \\
\text { effects on achievement are limited due to heterogeneity } \\
\text { of preferences across households (despite improvements } \\
\text { in other non-academic outcomes). }\end{array}$ & $\begin{array}{l}\text { Witte (1998), Teske and Schneider (2001), Mayer et al. (2002), } \\
\text { Cullen et al. (2003, 2005), Ladd (2002), Hanushek et al. (2007), } \\
\text { Rouse and Barrow (2009), Waslander et al. (2010) }\end{array}$ \\
\hline $\begin{array}{l}\text { local hierarchical education markets } \\
\text { limit the potential for choice to generate } \\
\text { achievement gains }\end{array}$ & $\begin{array}{l}\text { Household preferences vary, but include school } \\
\text { reputation, and schools respond to this through adjusting } \\
\text { student-body intake and educational- and non-academic } \\
\text { offerings. }\end{array}$ & Waslander et al. (2010) \\
\hline efficiency effects of choice are limited & $\begin{array}{l}\text { When resources are taken into account, choice systems, } \\
\text { and private provision of education, do not systematically } \\
\text { improve efficiency. }\end{array}$ & $\begin{array}{l}\text { Levin and Driver (1997), Levin (1998), Miron et al. (2011), McEwan } \\
\text { and Carnoy (2000), Waslander et al. (2010) }\end{array}$ \\
\hline
\end{tabular}

\subsubsection{Equity}

In a system of neighborhood schooling, equity concerns arise in acknowledging the fact that (some) households already exercise some sense of school choice through residential sorting. House price differentials are used in empirical research to show that households value academic achievement and other neighborhood attributes (e.g. Black, 1999; Fack and Grenet, 2010; Bayer et al., 2007; Kane et al., 2006). By focusing on the school attendance district boundaries in Massachusetts, Black (1999) finds that households are willing to pay $2.5 \%$ extra for a $5 \%$ increase in test scores. Fack and Grenet (2010), using a similar strategy in Paris, also find that a standard deviation increase in public school performance raises housing prices by 1.5 to $2.5 \%$. Importantly, their analyses also show that this price effect can be mitigated through providing alternative (private) schooling options (cf. Nechyba, 2003). Bayer et al. (2007) stress the methodological difficulties in dealing with endogenous household sorting, unobserved neighborhood differences, and the heterogeneity of household preferences and, based on detailed Census data, find smaller estimates for the direct effect of school quality on house prices. But, their results also highlight that residential sorting with respect to school quality is largely determined by household income. 
Results in Kane et al. (2006) also show that the impact of school quality on housing prices in no-choice systems can be largely indirect, through residential sorting induced by school boundaries and reassignment policies.

Epple et al. (2004) examine the relationships between peer effects and competition across the public- and private sector in equilibrium. The authors use data from the National Education Longitudinal Survey (NELS) and find support for the theoretical prediction that an educational system with choice of (expensive) private schools, in equilibrium, will lead to stratification across schools by ability and income. Lankford and Wyckoff (1999), based on household-level data for upstate New York, find similar sorting effects through the choice of residence and private school choice decisions. If peer effects are indeed relevant for academic achievement, a context of public neighborhood schooling with private schooling options thus seems to benefit advantageous households, at the expense of low-income, low-ability households.

The theoretical models in Nechyba $(1999,2000)$ predict that decoupling the school choice from the residential choice decision (e.g. through private-school vouchers) will decrease residential stratification. Based on a inter-district choice plan in Minnesota, Reback (2005) does indeed find evidence for this in that residential properties appreciate in school districts where households are able to transfer their child to other districts (and decline in districts that accept transferring students). Urquiola (2005) also looks at inter-district choice and exploits within-metropolitan area variation in school choice (as measured by the number of districts) between the primary- and secondary level of education. The findings suggest that increased district availability indeed affects a child's district- and school level peer groups (i.e. more homogeneous), and that school choice reduces private enrollment.

In order to understand how school choice expansion affects educational equity, Archbald (2004) looks at the effect of magnet-school choice plans in the US. He finds no evidence for a relationship between income-based stratification and whether or not a district implemented magnet-based school choice. Saporito (2003) looks at the effect of magnet schools in Philidelphia and finds that particularly non-poor students in high poverty areas opt for applying to magnet schools. However, he finds only a small effect on the level of income stratification across schools. Cullen et al. (2005) examine enrollment patterns in Chicago, where more than half the students opt out of their assigned neighborhood school. They find that high-performing children, and those from relatively highly educated- and 
involved households, are more likely to opt out for another school. Hastings et al. (2005, 2008), for a public open choice program in North Carolina, also find that households with high achieving students are much more likely to choose schools with high average achievement levels, and further away from home, with heterogeneous preferences towards school choice contributing to the socioeconomic achievement gap.

For Chile, Hsieh and Urquiola (2006) find that its large-scale voucher program led to significant sorting by ability and income. The voucher system seemed to induce relatively advantageous households to transfer to private schools. Moreover, voucher-induced expansion of choice led to an increase in the variation of academic achievement across schools and students. Carnoy and McEwan (2003) add to this that the Chilean results arguably show that the voucher plan is less likely to benefit the poor in terms of academic achievement, as children from these households are more often to be found in lowperforming public- or non-religious voucher schools. The universal public school choice plan in New Zealand is likely to have yielded similar results. Fiske and Ladd (2000) argue that for schools at the bottom of the achievement distribution, with the expansion of choice, it became increasingly difficult to provide an adequate education for their students. Ladd (2003) adds to this that the existing international evidence points to important political and market barriers to terminate poorly performing schools, and to difficulties in finding alternative (better) schools for low-performing disadvantaged students.

Based on the available international evidence, Ladd (2002) therefore concludes that much of the ultimate effects on equity depend on the design and scale of a choice plan. Small means-tested and targeted voucher programs could open up educational possibilities for, and provide benefits to, currently disadvantaged households (Belfield and Levin, 2002). In line with this, Hoxby (2003), based on results from US charter- and voucher schools, concludes that these programs do not lead to "cream-skimming". Instead, these schools tend to disproportionally attract, and benefit, students who would otherwise attend poorly performing public schools. She also concludes that sorting consequences of a school choice plan depend strongly on its design.

In general, though, there is a strong tendency of households to opt for schools that have a reputation of a socioeconomically advantageous student body (e.g. Hsieh and Urquiola, 2003). As mentioned, there is also empirical evidence that certain households will still face choice constraints, even in a universal choice plan (e.g. Fiske and Ladd, 2003). 
Therefore, policy makers should be concerned with the distribution of students across schools, and corresponding equity issues, in large-scale choice plans (Ladd, 2002). The above empirical results for equity are synthesized in Table 2.7 .

Table 2.7: Summary of empirical results - equity

\begin{tabular}{|c|c|c|}
\hline \multicolumn{3}{|l|}{ Equity } \\
\hline Theoretical outcomes of school choice & Description & Reference(s) \\
\hline $\begin{array}{l}\text { choice generally fosters student sorting by } \\
\text { income and ability }\end{array}$ & $\begin{array}{l}\text { School choice, whether through Tiebout sorting or more explicit forms of } \\
\text { public or private choice, seems to foster stratification by income and ability } \\
\text { across schools and is partially due to constraints faced by disadvantageous } \\
\text { households. }\end{array}$ & $\begin{array}{l}\text { Black (1999), Bayer et al. (2007), Epple et al. } \\
\text { (2004), Lankford and Wyckoff (1999), } \\
\text { Urquiola (2005), Cullen et al. (2005), } \\
\text { Hastings et al. (2005), Hsieh and Urquiola } \\
\text { (2006), Carnoy and McEwan (2003), Fiske } \\
\text { and Ladd (2000), Ladd (2003) }\end{array}$ \\
\hline $\begin{array}{l}\text { stratification by ability and income depends } \\
\text { largely on design of choice plan and can } \\
\text { sometimes benefit disadvantaged } \\
\text { households }\end{array}$ & $\begin{array}{l}\text { Several empirical findings suggest that choice not necessarily increases } \\
\text { stratification by income and ability and can even open up opportunities for } \\
\text { disadvantaged households, whereby the ultimate effects depend largely on } \\
\text { the design of the choice plan (i.e. finance, regulation and support services). }\end{array}$ & $\begin{array}{l}\text { Archbald (2004), Saporito (2003), Ladd } \\
\text { (2002), Belfield and Levin (2002), Hoxby } \\
(2003)\end{array}$ \\
\hline
\end{tabular}

\subsubsection{Social Cohesion}

School choice expansion, through improvements in parental involvement, has the potential to strengthen school communities, and possibly affect cohesion at a societal level. Households that choose do indeed tend to be more involved, although these differences between households appear to exist already prior to the choice decision (Ladd, 2002; Cullen et al., 2005; Hanushek et al., 2007; Schneider et al., 1997).

At the school level, based on NELS 1988 data, McMillan (2000) shows that parental involvement indeed raises school average reading scores. However, he also finds some evidence that choice and competition, induced by private school availability, tends to have a negative or insignificant effect on student achievement. The results thus appear to imply that parental involvement and choice act as substitutes and are in line with theoretical predictions that the more vocal, active parents are the first to switch to private schools (McMillan, 2000). This notion is also supported by results in the OECD's "Education at a Glance 2010" report. Based on several formal types of parental involvement, the empirical review suggests that if school choice is limited, there is likely to be more parental voice 
(Hansson and Charbonnier, 2010). ${ }^{18}$

At a societal level of social cohesion, it is important to understand how choice expansion relates to sorting patterns across schools and areas. This determines the extent to which productive interactions with peers from different perspectives or cultures are promoted. As mentioned, Epple et al. (2004) find support for the notion that a system of public neighborhood schooling and (expensive) private schools, in equilibrium, will lead to stratification by income and ability. Archbald (2004) reviews the empirical evidence on socioeconomic segregation and public (magnet) school choice in the US and highlights the methodological difficulties in attributing such effects to school choice. ${ }^{19}$ Instead, Saporito (2003) does find that the magnet school program in Philadelphia had an effect, albeit small, on the level of racial and income segregation across schools. For charter schools in Arizona, Cobb and Glass (1999) also find evidence for increased socioeconomic and racial segregation.

In Texas, where charter schools were highly targeted towards at-risk students, no such results were found, whereas the California case led to some increase in racial segregation (Booker et al., 2005). These mixed results tend to suggest that the design (e.g. targeting) of the charter school program matters for the effect on socioeconomic segregation. For North Carolina, Bifulco et al. (2009) analyze the actual composition of schools in the existing system of public school choice and compare it to what the distribution of students would have been under a system of geographically assigned schools. The authors find evidence for increased segregation, with the effects of choice on classbased segregation being larger than the effects on racial segregation. Based on the voting behavior of households on a survey question regarding a universal voucher plan in California, Brunner et al. (2010) also find evidence for segregation effects that are largely class-driven.

In New Zealand, choice seemed to foster class and racial segregation, with more opportunities available to advantageous households (Fiske and Ladd, 2000). Results for the United Kingdom are somewhat mixed with some researchers pointing to increased segregation (e.g. Willms, 1996; Reay, 2004), but others to a lack of choice-induced

\footnotetext{
${ }^{18}$ The formal types of parent voice considered are: i) participation in governance, ii) involvement in advising and iii) complaints or grievances. Informal ways to exercise choice, especially by directly communicating with teachers and school administrators are not covered in that review.

${ }^{19}$ Archbald (2004) argues that the only valid inference to date is that magnet school systems have greater social-class segregation compared to either random distributing students or when students are compulsory assigned to schools, with the aim of socioeconomic balancing.
} 
segregation instead (e.g. Gorard, 2001). In Sweden, a system of attendance areas was replaced in 1992 by one based on open enrollment, which allowed for private schools to receive public funding. This has also been found to increase class and racial segregation (Boehlmark and Lindahl, 2007) and these effects cannot be fully explained by stratification by ability only (Söderström and Uusitalo, 2010). For Denmark, the distribution of students in the actual system of open enrollment with independent schools was compared to a hypothetical one, based on residential sorting. Similar to the results found for North Carolina, the system in Copenhagen seems to foster segregation, with independent schools accommodating both high and low proportions of immigrant students (Rangvid, 2007). Already mentioned is Chile, which displayed an increase in socioeconomic segregation after the introduction of a large-scale voucher plan (Hsieh and Urquiola, 2006).

From the theoretical section, two theories that help explain the apparent relationship between school choice and segregation are "outgroup avoidance" and "neutral ethnocentrism". Empirical support for the former comes from evidence of majority households avoiding schools with substantial proportions of minority students (e.g. Lankford and Wyckoff, 1999; Saporito, 2003; Brunner et al., 2010). Empirical support for selfsegregation due to neutral ethnocentrism is found for US charter school programs (e.g. Weiher and Tedin, 2002; Hanushek et al., 2002; Booker et al., 2005; Bifulco and Ladd, 2007), as well as for Denmark (Rangvid, 2007) and the Netherlands (Denessen et al., 2005).

In addition to school composition effects, school choice can also alter the actual schooling experience, by shifting control over the school away from policy makers, and in favor of households. There is still limited evidence on how school choice affects the actual education being offered. In part this is because choice expansion is often accompanied by changes in accountability measures, making it difficult to attribute observed patterns to school choice (Waslander et al., 2010). Results from public choice expansion in North Carolina suggest that, when parents are given choice, the preferences are heterogeneous with the preference for academic achievement increasing in household income and child ability (Hastings et al., 2005). Based on a review of international choice plans, Waslander et al. (2010) conclude that the effect of increased competition on the education supplied depends on the position of a school in the local hierarchy of the educational market. Evidence suggests that schools try to appeal to socioeconomically advantageous households by adopting a selection admission policy, by introducing ability tracking, and by offering 
advanced, or specific, courses and programs. The authors conclude that the combination of school responses to competition and the entrance of new providers in the education market, despite the fact these new schools do not seem to be inherently different from traditional providers, does seem to add diversity to the educational landscape (Waslander et al., 2010). The above empirical results for social cohesion are synthesized in Table 2.8.

Table 2.8: Summary of empirical results - social cohesion

\begin{tabular}{|c|c|c|}
\hline \multicolumn{3}{|l|}{ Social Cohesion } \\
\hline Theoretical outcomes of school choice & Description & Reference(s) \\
\hline $\begin{array}{l}\text { choice is likely to ethnic and socioeconomic } \\
\text { segregation }\end{array}$ & $\begin{array}{l}\text { In general, school choice (expansion) seems to induce } \\
\text { stratification along socioeconomic and ethnic lines, with the } \\
\text { magnitude of the effect depending on the design of the choice } \\
\text { plan (finance, regulation and support services). }\end{array}$ & $\begin{array}{l}\text { Epple et al. (2004), Archbald (2004), Saporito (2003), } \\
\text { Cobb and Glass (1999), Booker et al. (2005), Bifulco et } \\
\text { al. (2009), Brunner et al. (2010), Fiske and Ladd (2000), } \\
\text { Willms (1996), Reay (2004), Boehlmark and Lindahl } \\
\text { (2007), Soederstroem and Uusitalo (2010), Rangvid } \\
\text { (2007), Hsieh and Urquiola (2006) }\end{array}$ \\
\hline $\begin{array}{l}\text { choice can enable households to express } \\
\text { outgroup avoidance behavior and neutral } \\
\text { ethnocentrism. }\end{array}$ & $\begin{array}{l}\text { Empirical results support the notion that majority households } \\
\text { use choice as to avoid schools with substantial proportions of } \\
\text { minority students, and households of all backgrounds choose } \\
\text { schools with a majority of students from similar backgrounds. }\end{array}$ & $\begin{array}{l}\text { Lankford and Wyckoff (1999), Saporito (2003), Brunner } \\
\text { et al. (2010), Weiher and Tedin (2002), Hanushek et al. } \\
\text { (2002), Booker et al. (2005), Bifulco and Ladd (2007), } \\
\text { Rangvid (2007), Denessen et al. (2005) }\end{array}$ \\
\hline
\end{tabular}

\subsection{Concluding remarks}

In general, school choice expansion improves freedom of choice. Households display a wide variety in preferences towards school attributes, though rather common is the notion that, all else equal, households prefer schools of high academic quality and with a socioeconomically advantageous student body composition. Important is the observation that the range of choices might only marginally increase for households that still face financial, residential, transportation, eligibility or information constraints.

Regarding productive efficiency gains, the results are modestly positive for the potential of competition to increase overall average achievement, with average effect sizes around $0.1 \sigma$. The magnitude of such an effect seems to be constrained by the fact that, with the heterogeneity in preferences across households, local hierarchical educational systems emerge in which competition between schools is limited. The notion of relative (private) school type effectiveness finds only mixed, and marginal, support for achievement, whereas attainment gains appear to be more consistent. Cost comparisons across different school types are methodologically difficult, with schools accommodating different students and providing different educational services. Furthermore, proper productive efficiency studies should also take into account the potential macro-level costs associated with implementing 
a choice system.

An important observation is that a system of neighborhood schooling, through residential sorting and (expensive) private schooling options, can already be inequitable. The effects of school choice expansion on equity depend largely on its design (i.e. finance, regulation, support services) and scale. It is argued that a well-designed choice plan, targeted at disadvantageous households can improve their educational opportunities. But, large-scale choice systems, particularly those that allow for funding disparities and that constrain possibilities for disadvantageous households, are likely to exacerbate inequity.

Empirical research on social cohesion, a goal that is difficult to define in measurable outcomes, is limited. School choice, through its impact on social capital and parental involvement, has the potential to contribute to social cohesion. However, by shifting the power over the school from policy makers to households, there are reasons to believe that the resulting stratified student-body compositions across schools, as well as the actual schooling experience, are more likely to adhere to private benefits of education. This can come at the expense of enhancing common social objectives of education.

The notion of trade-offs between private- and public benefits to education is an important one in analyzing the effects of a choice plan. By shifting power over schools to households, school choice plans are more likely to promote private outcomes, as measured in the dimensions of freedom of choice and productive efficiency. Empirical results show these beneficial effects are limited though. In addition, benefits could apply primarily to relative advantageous majority households, with smaller, or even adverse effects, for disadvantageous minority groups. Thus, the societal benefits of education, measured through gains in (overall) productive efficiency, equity and social cohesion need to be considered, and safeguarded, through the design of a school choice plan.

Contrasting the theoretical literature with empirical research in the freedom of choice dimension, research often applies to situations in which constraints apply, distinguishing choosers from non-choosers. Research on choice intensity in universal (mandatory) choice contexts, in which this distinction does not strictly apply, is relatively underexposed in empirical work. For productive efficiency, whereas theoretical predictions range from positive to negative, most empirical work looks at standardized test scores and attainment. For equity, the theoretical prediction that the potential negative effects will depend largely on the design and scale of the choice plan seems to be confirmed by 
empirical work. For social cohesion, empirical research is difficult as quantifiable measures are not always readily available, except for indices of stratification and segregation. Social cohesion, as with equity, is considered to be important to acknowledge when evaluating potential tradeoffs in the effects of school choice.

A recurrent theme in the empirical research on school choice is the methodological challenge of dealing with sorting processes across schools in the presence of unobserved differences between households. In general, most research adopts this household point of view, whereas it seems important to also understand how schools respond to choiceinduced competition. Also, much of the existing research is on relatively recent and smallscale choice programs, whereas results are arguably scale-dependent.

Thus, this dissertation sets out to complement the body of empirical literature i) by analyzing relative private school effectiveness in both academic achievement and "upward mobility" (Chapter 5), ii) by estimating the effects of "choice intensity", as opposed to "choice versus no-choice" (Chapter 4), iii) by exploring the effects of competition between schools at different levels of achievement (Chapter 6), and iv) by exploring whether schools seem compete for "favorable" students (Chapter 7). In line with demands expressed in the literature, it does so by analyzing the design of a long-term, large-scale universal choice context (Chapter 3), and by evaluating the results along different educational objectives (Chapter 8). 
School Choice, Competition and Achievement 


\section{Educational Choice and Outcomes in the Dutch Context ${ }^{*}$}

\subsection{Introduction}

Whereas Chapter 2 included many different educational contexts, this chapter applies Levin's framework for an in-depth description of the context of interest for this dissertation: compulsory education in the Netherlands. The next section (3.2) provides a short general introduction of the system and then describes the main design instruments (i.e. finance, regulation and support services). Section 3.3 summarizes the existing body of (empirical) literature for the Netherlands for each of the four educational outcomes (i.e. freedom of choice, productive efficiency, equity and social cohesion). The chapter ends with a summary of the main findings and a brief discussion on how the following chapters will complement the existing body of literature on Dutch education (3.4).

\subsection{Design instruments of the Dutch compulsory education system}

The current educational system of universal school choice and public funding in the Netherlands emerged from a "pillarized" system, and is the result of decades of religious and political disputes in the 19th century. ${ }^{20}$ This situation was not unique to the Netherlands and led to a system with public and private (religious/subsidized) school sectors in several continental European countries (Dronkers, 1995). The educational system in the

\footnotetext{
* This chapter is partially based on: Levin, H. M., I. Cornelisz and B. Hanisch-Cerda (2013). "Does educational privatisation promote social justice?" Oxford Review of Education 39(4): 514-532.

${ }^{20}$ The phenomenon of "pillarization" is a denominational segregation of society. In the Dutch society it implied a division of society by religion in several societal institutions such as education, sports and cultural clubs, housing associations, insurance companies, etc. (cf. Sturm, Groenendijk, Kruithof and Rens, 1998).
} 
Netherlands has been providing universal choice to households since 1848 , with private and public schools under equal government treatment and funding ever since $1917 .^{21}$

Educational privatization in the Netherlands encompasses freedom of choice from both the demand- and supply side. Parents are free to choose schools for their children. In primary education such freedom is universal, whereas in secondary education the system is organized in tracks according to students' abilities. ${ }^{22}$ At the supply side, there is freedom to provide education as parents can establish new private schools with government funding if they do not see the educational, religious or philosophical needs of their pupils satisfied. For almost a century now, there exists freedom to provide education, with full public funding and quality assurance guarantees, regardless of a school's (religious) denomination.

In the current system, most Dutch children enter primary school in the year they turn 4 years old. ${ }^{23}$ Primary education lasts for 8 years and, on average, children are 12 years of age when they enter secondary education (OCW, 2010). This sector offers several options: pre-vocational secondary education (VMBO), general secondary education (HAVO) and preuniversity education (VWO). Pupils can also transfer into practical training (PRO), secondary special education (VSO) or get additional support to finish lower vocational education within mainstream education (LWOO). ${ }^{24}$ Figure 3.1 gives a description of the Dutch educational system.

Figure 3.1: Structure of the Dutch Education System

\footnotetext{
${ }^{21}$ Ritzen, J. M., Van Dommelen, J., and De Vijlder, F. J. (1997) provide an insightful overview of the developments in school finance and educational choice in the Netherlands, thereby focusing on the role of the government in providing reliable information to parents and compensating schools with higher proportions of disadvantaged students.

${ }^{22}$ An important educational reform to note here is the "Mammoth Law" of 1968, which main objectives was to create a more meritocratic school system through comprehensive classroom settings in the first year(s) of secondary education, compulsory testing and a teacher's recommendation at the end of primary schooling, and the clustering of various tracks within schools (see: Dronkers, 1993).

${ }^{23}$ As of 2000 , the Dutch government has started to stimulate several forms of pre- and early childhood education. On average, only $8 \%$ of households do not participate in such programs, with the highest percentages found among relatively disadvantageous households from non-Western immigrant backgrounds (Veen, Roeleveld and Heurter, 2010).

${ }^{24}$ Students of primary or secondary education in need of special care and support are accommodated in either regular or specialized schools. In primary education, around $93 \%$ of all students are considered within mainstream education. The proportion of special needs pupils in secondary education (PRO, VSO and LWOO) almost doubled in recent years: from 9.3 per cent in 1990 to 17.5 percent in 2010 (OCW, 2011a).
} 


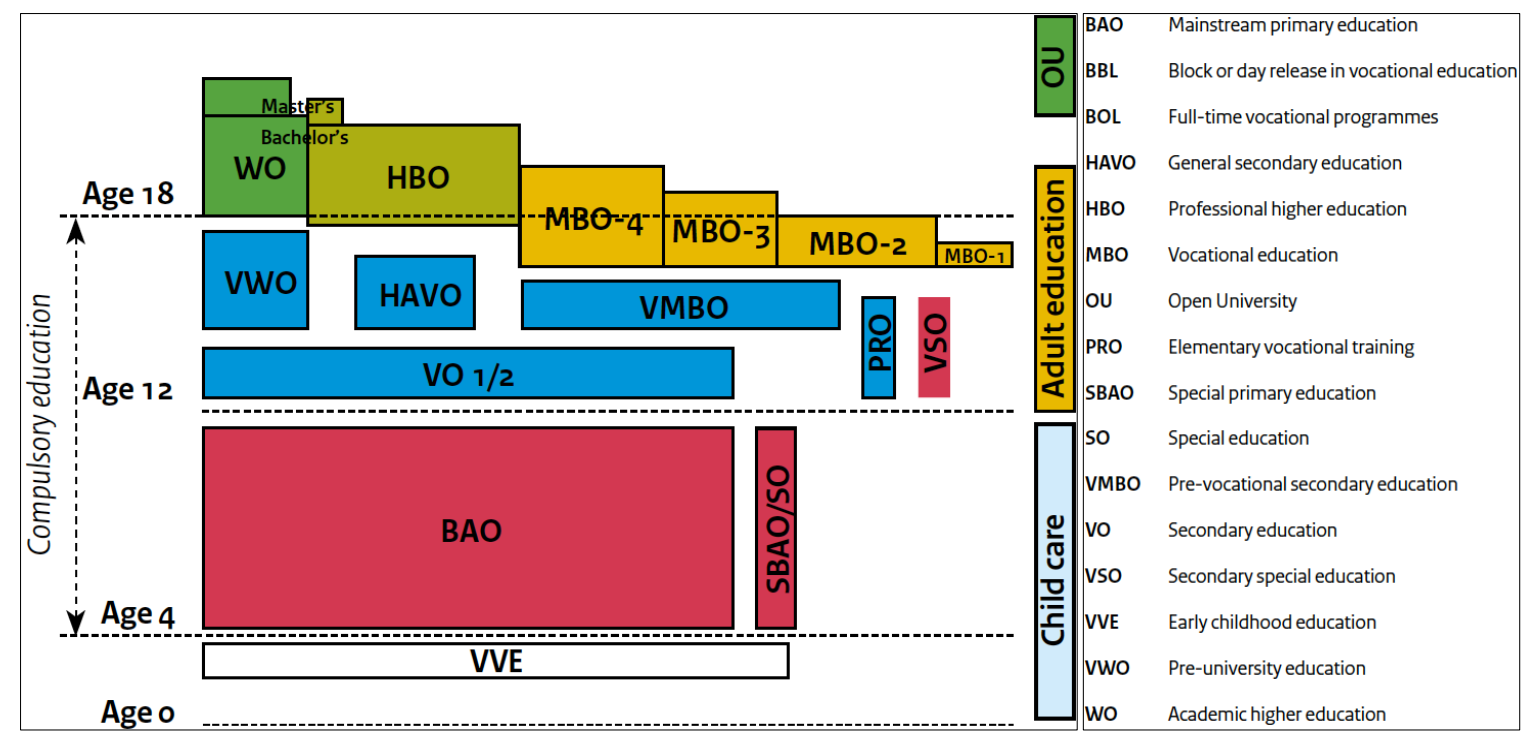

Source: Ministry of Education, Culture and Science

In 2010, primary education accommodated almost 1.7 million students in 7,480 primary schools, with $70 \%$ of primary education students enrolled in private governmentfunded schools (OCW, 2011a). The secondary sector consisted of 940,200 students in 646 institutions, with $72 \%$ of the enrollment concentrated in private government-funded schools (CBS, 2012). ${ }^{25}$ Homeschooling is not recognized by Dutch law, and practically absent. ${ }^{26}$ Teaching in private government-funded schools is based on religious or ideological beliefs and this category includes Catholic, Protestant, Jewish, Muslim, Hindu and anthroposophist schools. Schools that base teaching on specific educational ideas, such as the Montessori, Dalton, Freinet or the Jena Plan method, can be either publicly or privately run (Education Inspectorate, 2012).

\subsubsection{Finance}

The 1917 Constitution guarantees equal funding of all schools; regardless of whether they are publicly- or privately operated. Money follows students and each school receives, for each student enrolled, a sum equivalent to the per-capita cost of public schooling (Patrinos,

\footnotetext{
${ }^{25}$ Private independent for-profit schools are allowed, though virtually non-existent (see Hirsch, 2002; de Regt and Weenink, 2005)). Parents often turn to these private independent institutions after a period of educational problems. Such schools account around $1 \%$ of the enrollment, and do not receive public funds (Education Inspectorate, 2012).

${ }^{26}$ The Compulsory Education Act, Article 2, paragraph 1, states that school attendance is mandatory. One recent estimate is that around 170 children, through exemptions based on deeply held (religious) beliefs, are being homeschooled (Schmidt and Sperling, 2010).
} 
2002). ${ }^{27}$ Schools are allowed to ask a voluntary contribution from parents, but options are limited and need to be destined for specific extra-curricular activities (Eurydice, 2009).

In the mid-1980s, student-based weights were added to the school-funding program. The criteria to offer weighted funding differ between primary and secondary education. Prior to 2006-2007, these weights were based on both the socio-economic background and minority status of students. In the current system, weights are on the basis of socioeconomic background only. In primary education, it depends on the level of parental education of the individual student. Primary schools receive an additional $30 \%$ of funding for children of parents with no more than lower vocational training (LBO) or pre-vocational education (VBO), and an additional $120 \%$ for pupils who have one parent with only primary education and one parent with no more than LBO or VBO. In secondary education, schools accommodating a threshold proportion of students from poorer areas receive additional funding. In addition, a secondary school receives extra funds for each individual that has recently (i.e. less than two years ago) immigrated to the Netherlands (Smeets, Driessen, Elfering and Hovius, 2009). ${ }^{28}$

For students that require additional funds to succeed in the mainstream education system, or that require special care and support, several sources of additional funds are available to both schools and parents. The pupil-specific funding system (the "rucksack" system) allows pupils requiring additional care and support to enroll in mainstream education or special primary education (SBAO). Other options for pupils with special needs are special schools and secondary special schools (SO and VSO). These schools receive additional funding for personnel, materials and other services (OCW, 2011a). Parents of special needs students are also eligible for additional child-specific funding (PGB), for which they can decide on the actual allocation; conditional on that it is spent on materials and services that contribute to the child's care and/or (educational) development (Smeets, Ramakers, Schellingerhout, van den Wijngaart and Hovius, 2008). There are also financial

\footnotetext{
27 Per pupil expenditure varies in primary and secondary mainstream education. In 2010, the expenditure per pupil in primary education was of 5,680 Euros, whereas for pupils in secondary education was of 7,550 Euros (OCW, 2011a). Students in special education, for which average expenditures are considerably higher, currently account for around 5\% of the student population (OCW, 2011a).

${ }^{28}$ The portion of students in mainstream education covered by this weighting system in 2010 was around $13 \%$, with 111,200 and 84,800 students in the first- and second category, respectively (OCW, 2011a). Until August 2006, the following weighting system of added funding applied in primary education: $25 \%$ extra for Dutch pupils whose parents have a low level of education; $40 \%$ for bargees' children; $70 \%$ for caravan dwellers' and gypsies' children; and $90 \%$ for ethnic minority pupils whose parents have a low level of education.
} 
resources available to secondary schools for students in the lower vocational tracks (i.e. LWOO and PRO), requiring additional care and/or assistance in order to succeed in mainstream education schools and the labor market (Smeets, et al., 2009). For students that require additional care for only a limited period of time (up to two academic years), schools have (access to) resources in order to provide the necessary support (i.e. "Zorgbudget").

In an effort to promote greater efficiency and improved performance, important changes have taken place in the way schools are funded (Karsten and Meijer, 1999). In recent decades, there has been a shift towards more decentralized funding. A system of lump-sum funding was first introduced in vocational secondary education in 1992, shortly followed by all of secondary education in 1995. A similar system was also implemented in primary education in 2006. A common feature among the new systems is that, based on actual enrollment levels, schools receive a fixed budget in advance delivered as block grant funding, instead of the former earmarked grants. ${ }^{29}$

\subsubsection{Regulation}

The Dutch education system is characterized by centralized education policy at the national level, but with administration and management of the schools largely decentralized (Eurydice, 2009). As such, it has been referred to as a quasi-market (cf. Onderwijsraad, 2001). Historically, private schools enjoyed more autonomy, relative to public schools, with the former governed by private school boards and the latter by municipal councils. Over the past decades, schools faced major reforms and organizational changes. Government regulations now relate primarily to the inputs and outcomes of education, whereas managerial- and educational processes were part of the deregulation and devolution of formal decision-making authority to lower levels of hierarchy (Karsten and Meijer, 1999). As of 1996, it has been possible for municipalities to transfer the control over their public schools to (independent) school boards (Zoontjens, 2003). All school boards are now fully responsible for the organization of teaching and learning, personnel and materials and responsible for the quality of education provided.

\footnotetext{
${ }^{29}$ Other features of the lump-sum financing system are that i) decentralized decision making and delegated budgeting is done at the school board level, ii) the budget is allocated by formula and not by administrative discretion, and iii) a school board's discretion is limited by employment laws, teacher qualifications, pay and conditions, building standards, and rules for inspection of educational standards and quality (Karsten and Meijer, 1999).
} 
The Dutch educational system considers several regulations for all governmentfunded schools. The main regulations refer to (i) admission policies, (ii) curriculum, attainment targets and national examinations, (iii) teacher qualifications, training and salaries, and (iv) quality of the education provided. The Education Inspectorate identifies schools that are "at risk" on a yearly basis. The aim is to assess potential problems affecting the quality of education offered and to monitor schools in realizing improvements. Schools that perform adequately do not require such intense risk-based inspection, allowing the Inspectorate to focus most of its attention on the academic improvement of poorly performing schools (Education Inspectorate, 2012).

In terms of students' admission policies, public schools admit pupils irrespective of religion or beliefs. Also, schools are not allowed to reject students if their parents are not able to fulfill the "voluntary" financial contributions. ${ }^{30}$ If a public school has no more space to receive an applicant student, the municipality has to ensure that student is admitted to another public school. Private schools can set admission criteria according to the denomination or ideology of the school (Eurydice, 2009). But, private (religious) schools are not allowed to refuse a child on the basis of religion or ideology if there is no public school in reasonable proximity with capacity to accommodate the child. If a student is not admitted into a private school due to capacity constraints, the school board has to refer that student to another private school within the same school board.

Primary schools can decide to give preference to households, for example, if they live in the 4-digit zip code of the school, if there are siblings already attending the school, or if the parents work at the school. Secondary schools are allowed to apply similar decision rules, but are not allowed to use geographical location to assign preference, as the educational market they serve is considered to surpass their own 4-digit zip code-area. However, secondary schools can use the pedagogical approach used in primary education as a preference rule to decide on admission. Also, secondary schools have a system of early tracking, which allows them to have additional admission regulations based on whether students meet the threshold end-of-primary (test) results, required for a particular academic track. Secondary schools can thus refuse a student based on his/her results on an exit exam in primary education and/or primary school advice. When oversubscription is present, an "ability-neutral" lottery will need to be conducted.

\footnotetext{
${ }^{30}$ source: http://www.rijksoverheid.nl/ministeries/ocw
} 
The Ministry of Education, Culture and Science determines the core elements of the curriculum, sets attainment targets for schools and defines regulations for the number of teaching periods per year (Eurydice, 2009). The Dutch Constitution prescribes that public schools must be secular, but they can address philosophical, religious and/or social values (Merry and Karsten, 2011). All private religious schools can offer the opportunity for students to study world religions, as well as practice the religion of their denomination, but this is not compulsory. For all other subjects, schools are free to organize the actual teaching process towards reaching the attainment targets (Eurydice, 2009).

Along with defining the subjects and their end-terms, the Ministry also determines the content of national examinations. There is a compulsory end-of-secondary national examination for each subject. Standardized end-of-primary school tests are not (yet) mandatory, though there are plans to prescribe one within the foreseeable future.

Towards the end of primary education, all students must receive a secondary school advice from their primary school. This advice is an important determinant for enrolling into the tracked secondary system. At the end of secondary education, a weighted average of the performance on the national examinations, together with the performance on schoolbased examinations, determines whether a student is granted a leaving certificate. For many programs in higher education, leaving certificates from HAVO and VWO are the only requirement to enter into the higher education system (Canton, Venniker et al., 2001). ${ }^{31}$ Programs that are oversubscribed generally perform a lottery, in which high-ability students can receive a higher probability of gaining entrance, although some programs resort to more direct selection practices.

The quality of teaching is regulated through teacher certifications and training requirements. All teachers in primary- and secondary education need to be certified. To teach in primary and lower secondary grades, teachers need to have a Bachelor's degree. In higher grades, a Master's degree in the field of teaching and extra training of teaching are required (OCW, 2011b). Teacher salaries and work conditions are regulated through national collective agreements. A recent system of various salary scales allows for more

\footnotetext{
${ }^{31}$ The Dutch higher education has two different levels: a professional level (HBO) for which HAVO leaving certification is required, and a level of academic training (WO) for which a VWO leaving certification is required. Vocational training is also available (MBO), and after successful completion students can apply to universities (HBO).
} 
differentiation in pay across teachers, in which higher scales are associated with more responsibility for certain processes and/or departments within a school (OCW, 2011b).

A national Education Inspectorate oversees the quality of every school. It performs inspections based on a risk-oriented approach, and checks annually for indicators (outcomes, annual accounts and failure signals) that show if a school is performing below minimum required standards (Education Inspectorate, 2009). ${ }^{32}$ These indicators, together with a programmed visit to every school at least once every four years, determine the tailored inspection a school receives. The Inspectorate focuses on the rapid improvement of schools that supply low-quality education (i.e. risks detected) and achieve unsatisfactory results. If a school does not improve as planned towards meeting these threshold quality requirements, the Inspectorate reports to the Ministry. Besides the quality of education, schools are also required to comply with statutory rules and regulations, and be able to show healthy financial reports. If a school does not comply with the statutory rules and regulations, a sanction by the Minister of Education, Culture and Science is in order. On the basis of a complete report, the Minister may proceed to impose administrative and/or funding sanctions (Education Inspectorate, 2009).

An important regulatory aspect to consider in the light of school choice in the Netherlands is the wave of regulations related to school consolidation over the past few decades. In primary education, school consolidation started when kindergarten- and primary schools were merged (Onderwijsraad, 1982). From 1991 onwards, important increases were determined regarding the minimum school size required for funding eligibility in compulsory education. Mergers between schools have been further stimulated through fiscal incentives promoting large school boards; such as the aforementioned perstudent grants and lump-sum financing (Waterreus, 2009).

\subsubsection{Support Services}

Support services refer to public services provided to safeguard freedom of choice and equity, such as transportation to schools and distribution of information for parental school choice. The key players in this respect are the Education Inspectorate, municipalities and the

\footnotetext{
${ }^{32}$ Regarding quality indicators of education, the Inspectorate assesses the outcomes of a school on the basis of achievement levels and progress in pupils' development. With regard to the organization of the teaching, they look at the curriculum, learning time, teaching climate, school climate, teachers' teaching strategies, special needs provision and tests, assignments or exams (Education Inspectorate, 2009).
} 
national government. The information and reports generated by the Inspectorate are made available to all stakeholders (i.e. parents, schools and policy makers). Schools are obliged to publish a prospectus setting a school's objective and the results achieved (Eurydice, 2009). Beyond that, schools offer information sessions, or allow parents to sit in classes.

It is the responsibility of the municipalities to ensure every student is able to reach a school. Transportation arrangements can differ on an individual basis, and will also be different across municipalities. For students under 10 years old, or any student with special requirements of transportation, the municipality of the pupil is responsible for arranging it. If a child under 10 lives at a distance of over 6 kilometers from the nearest school, or a child with special needs at a distance of over 2 kilometers, transportation should be arranged for them (De Boer, 2005). In secondary education, if necessary, the municipality will subsidize public transportation for both the special needs student as well as a supervisor. ${ }^{33}$

\subsection{Educational Outcomes in the Dutch Choice Context}

\subsubsection{Freedom of Choice}

Educational choice in the Netherlands can be understood as universal, constitutionally guaranteed, mandatory, financially supported and strictly regulated. This does not necessarily mean it is also unconstrained and restrictions in this dimension can be identified from both a school- and household perspective.

As mentioned, schools are generally not allowed to select students by ability. The freedom of schools is further restricted through the set of regulations a school needs to adhere to, in order to be (or remain) eligible for funding. However, in recent decades, schools have been increasingly given more freedom through decentralization and lump-sum financing. All schools now have high levels of financial discretionary power to spend funds. This holds for the lump-sum funds covering current expenditures (Karsten and Meijer, 1999), the additional funds schools receive for children from disadvantaged backgrounds (Smeets et al., 2009), but also for many of the special needs education funds available to schools (Smeets, 2007).

\footnotetext{
${ }^{33}$ If public transportation is unfeasible, however, municipalities will have to provide special transportation or provide sufficient funds to parents that enable them to make individual arrangements.
} 
For households, the regulations applying to school choice are slightly different in primaryand secondary education. In primary education, parental choice is universal. However, private primary schools can reject students, albeit restricted to criteria related to requiring households to adhere to the denomination or ideological character of the school (Eurydice, 2009). In practice, however, this does not seem to occur often (Karsten, Ledoux, Roeleveld, Felix and Elshof, 2003).

Primary schools often use results of a (standardized) test, in addition to students' overall educational performance, interests and motivation, to advise parents about the secondary education track(s) considered to be best suited for their child (Eurydice, 2009). ${ }^{34}$ In secondary education, this system of early tracking makes students ineligible to attend any school they like. Ability tracking restricts the choice set for households, particularly since $83 \%$ of all schools do not offer all of the program types (Herweijer, 2008). Schools can, and do, reject students if there is a discrepancy between the primary school's advice (and/or standardized exit exam test results) and the level of the academic tracks offered at the secondary school (OCW, 2011b).

In both sectors, household choice could be restricted through i) financial, ii) distance, iii) capacity, iv) diversity, and v) information constraints. In both primary and secondary education, financial constraints seem to be non-existent (Dronkers, 1995). As mentioned, schools are not allowed to reject students if their parents are not able to fulfill the "voluntary" financial contributions. Of all primary schools, $94 \%$ ask less than 50 euros (or \$60) a year in the year 2008-2009 (Education Inspectorate, 2010). In secondary schools, approximately $73 \%$ of the parents report paying such a yearly voluntary amount; the median value of which is approximately $\$ 100$ dollars (Broersen and Klein, 2004). Likewise, secondary schools can ask for voluntary participation in specific extra-curricular activities. One estimate is that the median value of such contributions is around $\$ 85$ (Baarsma and van Leeuwen, 2002). School admission policies should be unrelated to the ability to pay for

\footnotetext{
${ }^{34}$ Over $85 \%$ of all Dutch primary schools take the test designed by the National Institute for Educational Measurement (CITO). The other $15 \%$ of students is assessed by tests devised by other institutions.
} 
these activities and schools have a legal obligation to support families that are willing, but unable, to pay these contributions. ${ }^{35}$

Bunschoten (2008) reports that about $89 \%$ of the students live less than one kilometer from the nearest primary school. Over $80 \%$ of primary school parents bring their child to school, either by bike or foot, at least the first couple of years (Karsten, et al., 2003). On average, there are more than two primary schools available within 1 kilometer, although important urban/rural differences exist (CBS, 2012). As such, the distance to schools is not considered to be an important constraint to parental school choice in the Dutch context. Nevertheless, it could be argued that this irrelevance applies less to the non-western migrant population. Results in Karsten et al. (2003) show that distance is an important determinant in primary education and that i) particularly native/Western households are more willing to send their children to a school that is relatively far away and that ii) they are especially likely to consider a school outside their own 4-digit zip-code area. For secondary education, households live on average 2.4 kilometers from the nearest school. Nine out of ten households have at least one secondary school within a radius of 5 kilometer. Over $75 \%$ of secondary school students go to school by bike. Again, important urban/rural differences exist, with much larger average distances to the nearest school found in low-density areas (CBS, 2012).

A reduction of the diversity in educational supply, due to several consolidation processes in school locations and -boards, could further restrict households' freedom of choice. This process led to a significant decrease in primary schools in the late 1990s, reducing their amount by on average $15 \%$, with significant geographic differences (De Haan, Leuven and Oosterbeek, 2011). Waterreus (2009) adds, that during the last decade, consolidation has further reduced the number of school boards significantly (i.e. by around $30 \%$ in secondary education). This also led to a slightly further decrease in the actual number of primary school locations. In secondary education, consolidation has reduced the number of schools offering only one track by almost $50 \%$, with a corresponding increase in the number of schools offering multiple tracks (Bronneman-Helmers, 2007). Also, the consolidation wave has reduced the diversity of school boards from which households can

\footnotetext{
${ }^{35}$ A recent representative survey among (primary) schools gives reasons to believe that schools do not always adequately inform parents about both the voluntary contribution, and the amount of money asked for specific extra-curricular activities (Education Inspectorate, 2010).
} 
choose. This is particularly true in rural areas and for secondary education (Waterreus, 2009).

Secondary schools offering only the highest academic track form the exception to the above-mentioned general pattern consolidation and are increasingly popular. They have also become more likely to face capacity constraints, particularly in urban areas (Waterreus, 2009; Koning and Van der Wiel, 2013). When capacity constraints are so severe that students will need to be rejected, primary schools make use of giving preference to households that live in the same 4-digit zip-code neighborhood, that endorse the school's religion or philosophy, and/or that already have children attending the school. More recently, municipalities have also enacted policies to reduce segregation, which has led schools to give preference to students that, on the basis of their ethnic background, would positively influence their student-body composition. ${ }^{36}$ In secondary education, an abilityneutral lottery is performed relatively more often, in the absence of such clear preference rules. One recent estimate is that around $1 \%$ of secondary schools had to accommodate over-subscription over the period 1995-2008 (Koning and Van der Wiel, 2013). In an attempt to understand how many households are restricted in their choice through lotteries, Amsterdam, the largest city and familiar with lotteries, has reported these trends for the years 2008-2012. Results are such that the group of "popular" schools is seemingly increasing. In the academic year 2011-2012, 6\% of all students were not able to get into their first school of choice. ${ }^{37}$

A fifth possible constraint to household choice refers to their ability to make wellinformed decisions. Since the latter half of the 20th century, parental choice in the Netherlands has shifted from being religious-based to choice based on perceived school quality (Dronkers, 1995). Whereas, school quality information is publicly available, information constraints do exist to a certain extent. In particular, parents from migrant groups are generally more difficult to reach (Herweijer, 2009) and household information about school quality is also correlated with parental education (Dronkers, 1995). As of February 2011, a new website has been launched (i.e. www.schoolvo.nl), which has more extensive school-level information on results, policies and levels of customer satisfaction. The Dutch government has also enacted a special 'Ethnic Minority Parents Platform' to

\footnotetext{
${ }^{36}$ These policies are dealt with in more detail in the section dealing with social cohesion.

${ }^{37}$ source: www.amsterdam.nl
} 
increase parental awareness and involvement among parents from migrant groups. Local platforms have been set up in 30 large municipalities to promote activities designed to reach migrant parents. The activities include home visits by teachers and special parent information points in the school (Herweijer, 2009). The above outcomes for freedom of choice are synthesized in Table 3.1.

Table 3.1: Summary of results for the Netherlands - freedom of choice

\begin{tabular}{|c|c|c|}
\hline \multicolumn{3}{|l|}{ Freedom Of Choice - Netherlands } \\
\hline Empirical results of school choice & Description & Reference(s) \\
\hline $\begin{array}{l}\text { schools have considerable discretionary } \\
\text { power to spend funds and to organize } \\
\text { the educational process }\end{array}$ & $\begin{array}{l}\text { With ongoing processes of decentralization and lumpsum financing, schools } \\
\text { have high levels of discretionary power to spend funds and organzie the } \\
\text { educational process. }\end{array}$ & $\begin{array}{l}\text { Karsten and Meijer (1999), Smeets et al. } \\
\text { (2009), Smeets, 2007) }\end{array}$ \\
\hline $\begin{array}{l}\text { households have universal choice, but } \\
\text { some constraints are relevant to consider } \\
\text { in practice }\end{array}$ & $\begin{array}{l}\text { Private schools can reject students for (religious) reasons, but this rarely } \\
\text { happens in practice. Some eligibility constraints exist in secondary } \\
\text { education, which, together with ongoing consolidation processes and } \\
\text { capacity constraints in popular (urban) schools, seem to limit the choice set } \\
\text { available to households. Financial- and distance constraints are on average } \\
\text { not of prime importance, although these vary quite a bit. Information } \\
\text { constraints seem to be relevant for households from non-Western } \\
\text { background. }\end{array}$ & $\begin{array}{l}\text { Karsten et al. (2003), Eurydice (2009), } \\
\text { Herweijer (2008, 2009), Dronkers (1995), } \\
\text { OCW (2003), Broersen and Klein (2004), } \\
\text { Baarsma and van Leeuwen (2002), Education } \\
\text { Inspectorate (2010), Dijkstra et al. (2001), } \\
\text { Bunschoten (2008), CBS (2012), De Haan et } \\
\text { al. (2011), Waterreus (2009), Bronneman- } \\
\text { Helmers (2007) }\end{array}$ \\
\hline $\begin{array}{l}\text { households, in general, prefer a school } \\
\text { with high academic achievement. }\end{array}$ & $\begin{array}{l}\text { Choice has shifted from religious-based to perceived quality. A notable } \\
\text { difference is that distance and differentiation are particularly important for } \\
\text { non-Western households, whereas a match between home and school is } \\
\text { relatively emphasized by Dutch households. }\end{array}$ & $\begin{array}{l}\text { James (1984), Dronkers (1995), Karsten et al. } \\
\text { (2003), Denessen et al. (2005) }\end{array}$ \\
\hline
\end{tabular}

\subsubsection{Productive Efficiency}

In the Netherlands, macro-level efficiency seems high, with educational expenditures around the OECD average and achievement well above the OECD average in international comparisons. ${ }^{38}$ A study of the Netherlands Bureau for Economic Policy Analysis (CPB) highlights that the Dutch system seems efficient in saving inputs, but not so much in boosting outputs. The authors analyze data of PISA 2003, TIMSS 1999 and 2003, and IALS 1994 and conclude that the Dutch skill level is high on average, but is mainly due to the relative high performance at the left-hand side of the skill distribution (Minne, Rensman, Vroomen and Webbink, 2007). A more recent report by the CPB restates this notion and adds two important elements. First, the performance of Dutch students on international tests is dropping, both in actual scores as well as in rankings. Second, there seem to be an important difference between primary- and secondary education in that both sectors perform relatively well at the lower end of the skill distribution, but that particularly high-

\footnotetext{
${ }^{38}$ For more information on this, see Sutherland, Price and Gonand (2009) who suggest that, among OECD countries, the most favorable institutional frameworks for enhancing efficiency in the education sector are to be found in the Netherlands, Sweden and the United Kingdom.
} 
performing Dutch students in primary education do no longer belong to the international top students. In secondary education, these students seem to somewhat catch up with their international peers, which could be due to early ability tracking (Vermeer and Van der Steeg, 2011).

Grade retention is another source of concern in terms of the relative macroefficiency of the Dutch education system. Repetition rates in the Netherlands are already above $25 \%$ at the age of 15 (OECD, 2011). ${ }^{39}$ One explanation for the skill distribution being positively skewed, and for the high rates of grade retention, is that there are many regulations for schools to achieve minimum standards, but not many incentives to perform well beyond them. There is a strict curriculum that defines the contents and the level of performance students have to achieve in nationals assessments. However, there seem no strong incentives (i) for schools to emphasize the learning of those students who (will) already achieve the attainment standards, or (ii) for students to reach higher levels of performance after meeting the benchmark. The current government acknowledges this lack of incentives and has proposed a law in the "Strategic Agenda 2025", which will abandon lotteries in higher education to allow programs to select high-ability and/or motivated students. ${ }^{40}$

To understand the extent to which choice and competition between schools fosters the academic achievement of schools, it is necessary that i) households value academic achievement and ii) schools do indeed compete in this dimension with neighboring schools. Back in the first half of twentieth century, as James (1984) points out, "religion seem(ed) to be the major source of differentiated demand for education and private nonprofit supply" (p.608). With the secularization of society after World War II, religious schools seem to be mainly a nominal heritage from the "pillarized" system from that era. The equal system of funding for private and public schools allows for an assessment of micro-efficiency. If similar effectiveness is found in both types of schools, and private (religious) schools are popular, one could conclude that households find in such schools, for the same cost and same outcomes, something else that appeals to them. According to James (1984) this could be due to more responsiveness to consumer interests, more careful usage of funds in private government-funded schools, more flexibility, and less bureaucracy. Other explanations are

\footnotetext{
${ }^{39}$ This is, for example, high in comparison to American standards (Dijskstra, Dronkers and Karsten, 2001).

${ }^{40}$ source: http://www.rijksoverheid.nl/documenten-en-publicaties/rapporten/2011/07/01/kwaliteit-in-verscheidenheid.html
} 
that private (religious) schools have adapted and retained their attractiveness in a secularized society, enable stratification, enjoy political protection, offer conservative valueoriented education and are perceived to perform well on (non-) cognitive outcomes (Dijkstra, Dronkers and Karsten, 2004).

In terms of differences in academic quality between school types in Dutch compulsory education, one of the earliest empirical studies by van Van Laarhoven et al. (1990) indicates a positive effect of private religious schools on student attainment in secondary schools. ${ }^{41}$ Levin (2004) finds that Catholic primary schools outperform both Protestant and public schools and argues the results cannot be solely explained by teachingand school characteristics. Similarly, Patrinos (2011) also finds a statistically significant positive effect for private school attendance on achievement. Dronkers (2004) summarizes the Dutch empirical literature as that there seem to be positive effects of Catholic and Protestant schools on academic achievement, as reported in terms of dropout rates, test scores, degrees and attainment. However, a number of apparent exceptions to the general religious school advantage complicate the picture. There are important geographic differences in which, for example, public schools perform relatively well in areas in which they are not the majority school type. Furthermore, the positive outcomes seem to be more pronounced in primary education, hold only for academic outcomes, and appear to be confined to a period between the late 1960's and early 1990's. The latter result might be due to a combination of school consolidation affecting the size of religious schools (Dronkers, 2004) and the ongoing process of decentralization of public school management.

When choosing a school, the perceived quality is generally expressed to be an important determinant (Dronkers, 1995; Karsten et al. 2002; Herweijer and Vogels, 2004; Denessen, Driessena and Sleegers, 2005; Koning and Van der Wiel, 2013). For secondary education, Koning and Van der Wiel (2013) use yearly reported quality indicators in a Dutch newspaper (i.e. "Trouw) and find that, although the overall impact is relatively small (cf. Dronkers, 1999), the largest positive effects on enrollments are found for the highest academic track. Also, households seem respond to the most recent and most prominently displayed information. Using the same quality indicators, Ruijs and Oosterbeek (2012) focus on "schools of first choice" in the largest city Amsterdam and find less conclusive results for

\footnotetext{
${ }^{41}$ One example of a study that looks at the performance of students beyond compulsory education is provided by CuyckRemijssen and Dronkers (1990) who find that differences in success in tertiary education and in the labor market are not systematically in favor of private Catholic or Protestant schools.
} 
this source of information and, instead, find more consistent patterns for households preferring schools that are relatively close to their home and that accommodate a larger percentage of their primary school peers. Analyzing determinants across groups, there are differences among religious and ethnic groups, but less among different social classes. Among religious groups, Muslims and Protestants also choose schools for religious reasons. Also, among ethnic groups, immigrant households tend to more often choose schools aligned with their own religion. Dutch parents report that the "match between home and school" (i.e. with respect to culture, religious convictions and/or social milieu) is among the most important factors to choose a primary school (Karsten, et al. 2003). Instead, non-Dutch parents prioritize primary schools based on their "degree of differentiation" (i.e. attention to slow and fast learners and attention to non-native speakers), and the academic standard of the school (e.g. assessment of the Education Inspectorate).

In a recent study, heterogeneous preferences and product differentiation by schools is suggested as to explain the small effects for competition on achievement in Dutch primary education, as parents also value other factors, such as school activities, maintenance of buildings, cultural specificity, and religious denomination when choosing a school (Noailly, Vujic and Aouragh, 2009). Similarly, observing a negative association between competition and achievement in secondary education, Dijkgraaf, van der Geest, Gradus and de Jong (2008) also posit that Dutch schools seem to compete more on secondary elements such as sport, music facilities or the attractiveness of the building, leaving fewer resources for the primary process of teaching. Weenink (2009) shows that school managers associate quality and excellence in education more with the abilities of students than with the quality of educational programs, staff or facilities and that international curricular offerings are arising to serve a niche market that stems from schools' competitive engagement with local education markets.

A recent report by the OECD on markets in education claims that often, in the presence of heterogeneous household preferences and educational supply, local hierarchies of schools are indeed established. Actions that schools can take in order to maintain, or improve, their position within the market include the selection of pupils, specific marketing and promotion, cooperation with neighboring schools, course offerings and tracking (Waslander et al., 2010). One recent, and growing, phenomenon that is arguably in line with this notion of local hierarchies is the rise of internationalized (and bilingual) education in 
Dutch secondary education. These programs, in the absence of explicit options to select students, enable schools to target to high-ability, affluent households (Weenink, 2009). Patterns of local hierarchies, together with heterogeneous household preferences, are considered to make it more difficult for choice and competition to boost academic achievement (Waslander et al., 2010).

There are other policies, designed to increase efficiency in the Netherlands, such as changes in the rule of minimum school size, consolidations of school boards, or new policies that promote excellence. In 1994, the Netherlands changed the rules determining school size, raising the minimum enrollment required to receive public funding. As a consequence, the number of primary schools declined 15\%, from 8,362 schools in 1992 to 7,100 in 1997 (De Haan, Leuven and Oosterbeek, 2011). The authors show that a reduction in choice due to a reduction in supply of schools has had a small positive impact on students' performance on a standardized exit-exam (i.e. CITO). The authors interpret this as that the benefits of economies of scale more than outweigh the potential loss of reduced school choice and competition. The above outcomes for productive efficiency are synthesized in Table 3.2.

Table 3.2: Summary of results for the Netherlands - productive efficiency

\begin{tabular}{l|l|l}
\hline Productive Efficiency - Netherlands & Reference(s) \\
\hline $\begin{array}{l}\text { Empirical results of school choice } \\
\begin{array}{l}\text { the Netherlands scores high in terms of } \\
\text { average achievement and efficiency, which } \\
\text { could partially be due to choice. }\end{array}\end{array}$ & $\begin{array}{l}\text { Description } \\
\text { Dutch students score relatively high on average, with } \\
\text { This seems to be particularly true for the lower half of the } \\
\text { skill distribution, with relatively few high-performing Dutch } \\
\text { students belonging to the international top students. }\end{array}$ & $\begin{array}{l}\text { Sutherland et al. (2009), Minne et al. (2007), Vermeer and van der } \\
\text { Steeg (2011) }\end{array}$ \\
$\begin{array}{l}\text { some, albeit inconclusive, evidence for } \\
\text { private provision to outperform public } \\
\text { schools }\end{array}$ & $\begin{array}{l}\text { There seems to be a positive effect of Catholic and } \\
\text { Protestant schools on achievement, though more } \\
\text { pronounced in primary education and largely confined to } \\
\text { 1960-1990. }\end{array}$ & $\begin{array}{l}\text { Van Laarhoven et al. (1990), Levin (2004), Patrinos (2011), } \\
\text { Dronkers (2004) }\end{array}$ \\
$\begin{array}{l}\text { competition has an inconclusive effect on } \\
\text { academic achievement. }\end{array}$ & $\begin{array}{l}\text { Empirical estimates suggest only a small positive } \\
\text { association of competition and achievement in primary } \\
\text { education and even a negative relationship in secondary } \\
\text { education, suggesting schools compete on other } \\
\text { dimensions. }\end{array}$ & Dijkgraaf et al. (2008), Noailly et al. (2009), \\
$\begin{array}{ll}\text { choice and competition leads to local } \\
\text { hierarchical education markets }\end{array}$ & $\begin{array}{l}\text { Household preferences vary and schools respond to this } \\
\text { through adjusting student-body intake and educational- } \\
\text { and non-academic offerings. }\end{array}$ & $\begin{array}{l}\text { Noailly et al. (2009), Dijkgraaf et al. (2008), Weenink (2009), } \\
\text { Waslander et al. (2010) }\end{array}$
\end{tabular}

\subsubsection{Equity}

One of the most important equity features of the Dutch context is the system of central funding in which schools are restricted in attracting additional resources (e.g. through tuition or endowments). For horizontal equity this means that, for a given student, it does 
not matter which school he/she attends in terms of financial resources available. Financial constraints are considered to be largely irrelevant and a financially induced stratified system is absent (Dronkers, 1995). The equal funding of private and public schools, with strict regulations regarding the selection of students, has promoted the diminution of prestigious elite schools outside the state-subsidized sector (Dijkstra et al., 2004). Religious and public schools' right to equal financing thus seems to have prevented the skimming off of the most able students by either public or religious schools.

In terms of adequacy, one of the main objectives of Dutch policies is raising each student's level of achievement/attainment to a desired minimum standard. Several measures guarantee those attainment targets, such as uniform curriculum content, clear attainment targets and national examinations.

With respect to vertical equity, several arrangements have been described that allow for more resources to be available to students with differential needs and outcomes. As mentioned, the Dutch system has made available a wide range of resources to carry out education plans designed for accommodating students with special needs. Also, the system of weighted student funding allocates more resources to schools accommodating students from disadvantaged backgrounds (or neighborhoods). The groups of special concern for Dutch policymakers are the native Dutch students whose parents have low levels of education, those whose parents are in low-skilled occupations, and children of non-Western immigrants (Ladd and Fiske, 2009).

The largest groups of immigrants in the Netherlands are from non-Western countries such as Morocco, Turkey and from former Dutch colonies such as Surinam and the DutchAntilles. ${ }^{42}$ Around $40 \%$ of primary schools in Amsterdam and Rotterdam have a student body with over $80 \%$ of the students from non-Western origin. These segregation patterns are high in comparison to those found in the most segregated US cities, with trends suggesting this phenomenon is somewhat increasing over the past few years as well (Ladd, Fiske and Ruijs, 2010).

In a recent international comparison, Dutch primary students of immigrant background perform relatively well (Shewbridge, Kim, Wurzburg and Hostens, 2010). However, on average, they only perform at the level of the least-advantaged native Dutch

\footnotetext{
${ }^{42}$ Indonesia is not identified as non-Western country because of their long exposure to Dutch culture and language.
} 
students. There is evidence indicating that the lag of students with non-Western background is already significant in the second year of primary education (Gijsberts and Herweijer, 2007 cited in Shewbridge, et al., 2010). For this reason, the Dutch government started to promote pre-schooling among these students as of 2001 , though empirical results on the effectiveness of this approach are not yet available (Education Inspectorate, 2011).

With tracked secondary schools, the between-school variances in achievement account for $60 \%$ of all variance; which is well above the OECD average (Hansson and Charbonnier, 2010). Woessmann (2009) shows that a system of early tracking is likely to increase the achievement gap between advantageous- and disadvantageous families (e.g. possibly through peer effects). Herweijer (2009) adds to this that migrant pupils are underrepresented in the highest tracks of secondary education, and concludes that the system of early tracking is disproportionally challenging to non-Western immigrant students. The high rates of grade repetition seem to further promote this, as it is found that in countries where more students repeat grades, socio-economic differences in performance tend to be wider; suggesting that people from lower socio-economic groups are more likely to be negatively affected by grade repetition (Shewbridge et al., 2010).

Driessen and Dekkers (2008) analyze the evolution of Dutch policies and programs designed to tackle educational disadvantages since 1960 up to 2004. The authors find no direct evidence to suggest that a specific policy has successfully reduced the gap, as well as there is no evidence that any intervention has worsened the gap. Leuven et al. (2007) focus on two specific subsidies (i.e. extra personnel funding and additional resources for computers and software) targeted at schools accommodating at least a certain threshold proportion (70\%) of disadvantaged pupils and also find no, or even somewhat negative, effects. Nevertheless, the relatively good international ranking of Dutch students in the lower half of the skill-distribution discussed earlier does seem to suggest that the Dutch education system, through mechanisms other than the ones addressed above, has been somewhat successful in lifting the achievement of students from disadvantageous backgrounds towards the mean.

Recent adjustments made to the system of weighted student funding are also relevant to mention. Since 2006 (primary education) and 2007 (secondary education), this system is based only on the socio-economic characteristics of the student (body), irrespective of ethnic background. However, Christensen and Segeritz (2008) find that first- 
and second generation immigrant students in the Netherlands greatly underachieve in PISA 2006 (almost 60 points on science or one and a half year); and do so by an amount that is relatively larger than found in other OECD countries. The authors claim there is a substantial performance gap, even after accounting for the lower levels of SES of many immigrant students. This relatively low performance of immigrant students in secondary education is deemed worrisome (De Knecht-van Eekelen, Gille and Van Rijn, 2007). The above outcomes for equity are synthesized in Table 3.3.

Table 3.3: Summary of results for the Netherlands - equity

\begin{tabular}{|c|c|c|}
\hline \multicolumn{3}{|l|}{ Equity - Netherlands } \\
\hline Theoretical outcomes of school choice & Description & Reference(s) \\
\hline $\begin{array}{l}\text { equity is promoted through funding } \\
\text { mechanisms and regulations }\end{array}$ & $\begin{array}{l}\text { Horizontal equity is promoted through equal funding of all schools, uniform } \\
\text { curriculum, attainment targets, the absence of tuition and lack of cream- } \\
\text { skimmming, just as vertical equity is promoted through weighted-student } \\
\text { funding and additional funds for special needs students, although no single } \\
\text { policy can be attributed to have narrowed achievement gaps. }\end{array}$ & $\begin{array}{l}\text { Dronkers (1995), Dijkstra et al. (2001), Ladd } \\
\text { and Fiske (2009), Shewbridge et al. (2010), } \\
\text { Driessen and Dekkers (2008) }\end{array}$ \\
\hline $\begin{array}{l}\text { stratification by ability and socioeconomic } \\
\text { status, with particular concerns for students } \\
\text { from non-Western background }\end{array}$ & $\begin{array}{l}\text { Stratification by ability and socioeconomic status is present, and further } \\
\text { promoted in secondary education through a system of early ability tracking, } \\
\text { which contributes to achievement gaps and unequal outcomes in } \\
\text { education; particular for student of non-Western background. }\end{array}$ & $\begin{array}{l}\text { Ladd and Fiske (2009), Shewbridge et al. } \\
\text { (2010), Gijsberts et al. (2007), Education } \\
\text { Inspectorate (2011), Woessmann (2009), } \\
\text { Herweijer (2009), Christensen and Segeritz } \\
\text { (2008), De Knecht-van Eekelen et al. (2007). }\end{array}$ \\
\hline
\end{tabular}

\subsubsection{Social Cohesion}

A major public purpose of education is to provide a common educational experience to students that will allow students to participate in society. In the Netherlands, schools that receive government funds accommodate virtually all students and must indeed adhere to many attainment targets, enrollment regulations and curriculum requirements; thus promoting a common experience (Education Inspectorate, 2009). The common experience refers particularly to "what" is being taught, with more freedom for schools in terms of "how" the curriculum is offered (i.e. pedagogy). There is also a strong monitoring policy that oversees whether schools actually comply with these regulations (Education Inspectorate, 2009). In the Netherlands, there could be three main threats to social cohesion: segregation i) by socioeconomic background, ii) by immigration status or iii) by religion.

Regarding socioeconomic stratification, it is important to note that home schooling and private elite schools are virtually absent. The system of equal financing to all schools, and weighted student funding, according to Dronkers (1995), avoided the development of an institutionalized hierarchy of schools within types of schools. Nevertheless, Jenkins, 
Mickelwright and Schnepf (2006) show that the segregation of highly educated households across schools in the Netherlands is the highest of all OECD countries. Herweijer (2008) adds to this that the system of universal parental choice and early tracking promote secondary school stratification. Merry and Karsten (2011) highlight that the Dutch education system has always been segregated, especially along religious and ideological lines. However, the arrival of non-Western immigrants has made these divisions clearly visible and, moreover, the extent to which this segregation reflects real social inequities is now very apparent.

Regarding segregation by immigration status, for the years 1997 to 2005, empirical findings indicate that $80 \%$ of the disadvantaged immigrant students from the four main cities are in schools with more than a majority of students like themselves (70\%) and that percentage has slightly increased (Ladd, Fiske and Ruijs, 2010). This percentage is slightly lower in other cities in the country. Aiming to reduce segregation in primary schools, particularly ethnic segregation, the Ministry allocated financial resources for pilot programs, to be conducted by 12 segregated municipalities, in the years 2008-2011. Some of the policy measures addressing segregation consider providing more information to parents of disadvantaged students. Others consider the promotion of contact between segregated schools; and more severe measures consider 'controlling choice' through a balanced distribution of students with weighted funding, such as a pilot underway in Nijmegen (Merry and Karsten, 2011). As another example, in Amsterdam, a "covenant" between schools and policymakers was put in place in 2007 with the objective to allocate (primary) students in such a way to promote ethnic integration whenever there is oversubscription. ${ }^{43}$ However, student-body compositions have not changed, as private schools find it difficult to compromise parental freedom to choose, often find the increased role of the municipality to be intrusive, and are afraid to lose their (beneficial) position in the education market (Brink and Van Bergen, 2012).

With a highly secularized Dutch society, most private religious schools from traditional denominations only offer selective religious courses, which are often courses in world religions or religious orientation (OCW, 2011b). The establishment of new religious schools, however, like the Islamic schools is sometimes regarded as a threat to the social integration of these students into Dutch society (Dijkstra, Dronkers and Karsten, 2004). The above outcomes for social cohesion are synthesized in Table 3.4.

\footnotetext{
${ }^{43}$ source: www.vosabb.nl
} 
Table 3.4: Summary of results for the Netherlands - social cohesion

\begin{tabular}{|c|c|c|}
\hline \multicolumn{3}{|l|}{ Social Cohesion - Netherlands } \\
\hline Theoretical outcomes of school choice & Description & Reference(s) \\
\hline
\end{tabular}

\subsection{Concluding remarks}

The system of compulsory schooling in the Netherlands fits the definition of a quasi-market (cf. Onderwijsraad, 2001; Belfield and Levin, 2005), in that i) suppliers of education are in competition with each other, ii) entry into, and exit from, the schooling market is regulated, iii) household demands are expressed through a voucher-type system of funding, and iv) the government maintains an important role in accountability and standards.

Within the dimension of freedom of choice, the freedom for schools to choose is highly regulated in terms of their inputs and outcomes, although increasingly there is more freedom in terms of the educational process and school management. Households' freedom to choose schools is slightly different in primary and secondary education due to a universalvs. tracking system of education. Financial- and transportation constraints do not seem to be a matter of concern for households. Existing constraints are due to limited capacity of schools, reduced diversity of supply through consolidation processes and because of limited access to information for a subgroup of parents. Chapter 4 addresses whether choice intensity in primary education is related to academic performance.

Regarding productive efficiency, achievement within the compulsory education system, when contrasting this with other countries, is well on average but seems to be dropping. Measures like increasing the school size have seemed to boost the efficiency of schools. The academic achievement of private and public schools seems largely similar, although some results point to relatively higher levels of performance for (Catholic) private schools. Chapter 5 of this dissertation contributes to this discussion of relative school type effectiveness. The system has scope to increase efficiency when considering how highly skilled students are left behind, and how relatively high repetition rates are. Recent 
empirical research suggests that schools might not compete (exclusively) on the basis of achievement. Chapter 6 analyzes how competition intensity between schools affects the academic performance for students along different segments of the skill distribution. Chapter 7 adds to this by exploring how competition between schools during the transition from primary to secondary education relates to the targeting of students.

In terms of equity, horizontal equity and adequacy seem to be guaranteed through equal funding and academic standards for all schools. Vertical equity is blatant in special funding for students with special needs. Nevertheless, there are inequities between populations of students from different migration status, which in secondary education seems to be worsened by the system of early ability tracking. Several policies and programs have been implemented to address this issue, but the evidence available provides mixed conclusions of whether the interventions have reduced the gap.

Finally, social cohesion seems safeguarded by strict curriculum and outcome regulations, although schools are relatively autonomous in organizing the actual educational process. Importantly, there is also a considerable degree of stratification in the system and particularly so in the ability-tracked secondary sector. This phenomenon is not new, since the system was based on religious segregation already in the beginning of the 20th century, but the phenomenon has shifted to stratification based on socioeconomic status and ethnicity. Recent policies to reduce ethnic segregation do not appear to have been successful. Chapter 8 readdresses the above four outcomes, thereby integrating the findings from Chapters 4-7 and emphasizing social justice in education. 
School Choice, Competition and Achievement 


\section{Choice and Student Achievement in the Netherlands*}

\subsection{Introduction}

As described in Chapter 3, the Dutch compulsory education sector has a long history of universal school choice, in which households have to choose in which school they would like their child to enroll. All schools, whether publicly- or privately operated, are funded equally by the central government on a so-called "money follows the student"-system.

With distance to school being an important determinant for choosing a primary school, this chapter exploits the variation in the number of schools in close proximity to the household to estimate the effect of choice on student achievement at the end of primary education. The proximity of schools could be correlated with several important background characteristics, which make it less straightforward to attribute results to school choice. To account for this, an instrument is proposed that is unrelated to background characteristics and designed to capture exogenous variation in school choice.

The estimates presented in this chapter are largely in line with existing school choice literature in that the effect of choice on student achievement appears to be modest. In particular, the results indicate that doubling the level of choice intensity leads to improvements in cognitive achievement in the range of 0.05-0.09 of a standard deviation. Instrumenting school choice is imperfectly successful in removing all of the associations with urbanicity, but yields qualitatively similar effects. These modest effects of school choice do

\footnotetext{
* This chapter is based on the paper: Cornelisz I. (2012) "School Choice Intensity and Achievement: the Netherlands", unpublished manuscript, Maastricht University, TIER
} 
not seem to be explained by general school quality and school size effects.

The next section (4.2) provides a brief description of both the background and scope of the analyses conducted in this chapter. Section 4.3 describes the data and methodology. The results of the analyses are discussed in 4.4, with some concluding remarks presented in the final section (4.5).

\subsection{Background and scope}

The literature review in Chapter 2 discusses several mechanisms through which choice could increase student achievement. First, competition across schools requires all schools to increase efficiency. Second, private entities are potentially more efficient in allocating resources in providing services (to particular groups) than the government. Third, a more efficient matching and sorting of students across different schools and school types in a system of educational choice. Fourth, parental involvement could be improved through choice and/or be different across school types.

As described in Chapter 3, the Dutch Education system is characterized by a long history of universal school choice. Nechyba $(1999,2000)$ describes how the household choice of attending a (public) school, in a neighborhood schooling system, is closely bundled with the choice of residence. Thus, even in a public schooling system with no tuition fees, public schools are in practice not free to households who pay for access to schools through housing prices. However, school choice is mandatory in the Netherlands, as no neighborhood schools or catchment areas exist. As such, the residential- and school choice decisions are relatively more distinct in Dutch compulsory education.

With respect to this school choice decision, survey results show that parents state school quality to be one of the most important factors (Karsten et al., 2002; Herweijer and Vogels, 2004). School quality is a composite term, however, and includes performance on the CITO-test, a school's reputation, whether students progress successfully to academic secondary education, and the Education Inspectorate assessments. Important other factors, and potentially (indirectly) related to quality, are "a match between school and home" and "identification with the school" (Karsten et al., 2002).

One important school choice determinant, and particularly relevant for the analyses in this chapter, is distance to school (Karsten et al., 2002; Ruijs and Oosterbeek, 2012; 
Koning and Van der Wiel, 2013). Consequently, most households choose a school that is in, or close to their immediate neighborhood. A recent survey on children in primary education finds that the average distance that children travel is $1.26 \mathrm{~km}$ (Van der Houwen, Goossen and Veling, 2004). These survey results can be checked with a large nationwide administrative database called "Basisregister Onderwijsnummer" (BRON), which has also been constructed for primary school students as of 2008. This dataset confirms the initial survey results and shows the average distance to the primary school of choice in the academic year $2008-2009$ is indeed around $1.3 \mathrm{~km}$ (i.e. 0.8 mile), with $75 \%$ and $90 \%$ of all primary school students attending a school that is within $1.6 \mathrm{~km}$ (1.0 mile) and $2.7 \mathrm{~km}(1.7$ miles) respectively.

Chapter 3 discussed which choice restrictions in Dutch compulsory education are likely to limit potential gains in efficiency and the dimensions considered were financial reasons, proximity, information, selection by schools and capacity constraints. Given the restrictions schools face in attracting additional money, Dronkers (1995) highlights that financial criteria are considered to be irrelevant with respect to school choice in the Netherlands. Although distance to school will influence the school choice decision, Dijkstra et al. (2001) argue that distance is not considered to be a constraint in the Dutch context due to a high population- and school density, together with well-established public transportation opportunities. Another potential constraint is a lack of information. In this respect, households from migrant backgrounds are considered more difficult to reach (Herweijer, 2009).

As discussed in Chapter 2, there are other reasons why the proposed gains in productive efficiency due to choice could prove to be only marginal. First, some of the (market) assumptions on which productivity gains are premised have been challenged. The heterogeneity of households' preferences towards academic achievement and other school attributes is likely to limit the ability of school choice expansion for generating academic achievement gains through competition. Furthermore, the potential relevance of peer effects and school reputation provide further reasons for caution, particularly for the effects on certain (socioeconomically) disadvantaged groups of households.

In addition to the above, regardless of whether effects of choice on achievement exist, empirical research faces methodological challenges in isolating them. In particular, Belfield and Levin (2002) refer to biases due to ability-omission, resource-omission and 
socio-economic-omission. As such, it is important to have a credible treatment measure (i.e. choice intensity) and information on important background characteristics. Particularly relevant for the analysis in this chapter is the research conducted by Gibbons et al. (2008) on primary schools in the United Kingdom. The authors focus on the number of schools surrounding households, and use discontinuities generated by admissions district boundaries for exogenous variation in their measures of choice and competition. The authors find that pupils who have a wider choice of schools at their place of residence perform no better than those with more limited choice.

The analysis in this chapter adds and contributes to this debate on empirically estimating the effects of choice in two ways. First of all, the focus throughout this chapter is on the effects of household choice, which captures more than merely competition effects. In particular, by focusing on (increased) household choice, the design also accounts for potentially increased matching efficiencies and changes in parental involvement. The results in this chapter should therefore be interpreted as a composite (or net) result of all of these mechanisms related to school choice. In addition, a new instrument is proposed to account for the potential endogeneity of household choice (i.e. distance to entry/exit main road).

\subsection{Data and methodology}

\subsubsection{Data}

The analysis in this chapter uses several sources of data. The primary data source for this paper is the Dutch administrative data set "Basisregister Onderwijsnummer" or BRON, with data for students that were in the last year of primary school in the year 2008-2009 (i.e BRON PO '08-'09). Every student attending a school in the Dutch educational system receives their own personal identification number. Schools register students by using this personal identification number. All registrations are recorded in this large nationwide database. As such, this is a remarkably rich data set, covering all students enrolled in compulsory education. The database has student-specific information about his/her personal characteristics (e.g., gender, ethnicity and weighted funding eligibility), the school of choice (e.g., school identification number, student-body composition), some information 
about the household (e.g., single parent household), and on schooling outcomes (i.e. standardized secondary school exit-exam results and school quality report cards). ${ }^{44}$

The student-level outcome variable used here is the CITO-test, a standardized test score obtained at the end of primary education. The test consists of over 200 multiplechoice questions, dealing with language, arithmetic/mathematics, and information processing skills. ${ }^{45}$ A composite score is derived from the performance on each of these dimensions, referred to as the CITO-score. This score varies from 500 to 550 points, with a national average of 535 points and a standard deviation of 10 points. Students have an incentive to perform well since these test scores are one of the acceptance criteria into different (academic) tracks of secondary education. Likewise, schools have an incentive as well, since school-averages are commonly used by the Education Inspectorate to evaluate the quality of primary schools. Average CITO scores are publicly available (e.g. through folders, websites) and, since 2003, the Education Inspectorate publishes whether a school performs above or below the average of schools with a comparable student population.

The data show the average distance to school in the largest 31 cities, defined by the Euclidean distance from the centroid of a household's neighborhood to the exact school's address, is $1.16 \mathrm{~km}$. Among these students, 27,943 of the 46,084 (or $61 \%$ ) attend a school within $1 \mathrm{~km}$. On average, households are surrounded by 4 schools within $1 \mathrm{~km}$ to choose from, which goes up to as many as 20 schools. For students travelling less than $1 \mathrm{~km}$, even 16,651 (or 60\%) attend a school that is not the closest school. ${ }^{46}$ Thus, households appear indeed to make a deliberate choice, even when they choose a school that is in close proximity. This lends support to the notion that using the variation in the number of schools within $1 \mathrm{~km}$ can serve as a proxy to grasp differences in school choice to which households are exposed. It is important to note here that, for this measure, each school is weighted equally (i.e. as "one"). Obviously, some schools will be considered a more realistic option than others (e.g. due to denomination, student-body composition). However, the analyses here exploit variation in the total number of schools, irrespective of their characteristics,

\footnotetext{
${ }^{44}$ More information on the variables in this data set is presented in Appendix $\mathrm{A}$

${ }^{45}$ It's also optional to add a section dealing with environmental studies to the CITO-test. The test is administered at school during three days. The answer sheets are sent to the national testing institute (i.e. CITO), where they are marked. The results for each pupil are then returned to the primary schools.

${ }^{46}$ It is important to note here that this figure is based on distance to the school from the household's neighborhood centroid. This undoubtedly introduces measurement error and will label some households wrongfully as non-nearest choosers and vice-versa.
} 
under the assumption that being surrounded by more schools, in general, means having more options to choose from.

Some of the individual-level background characteristics are aggregated at the schoollevel (i.e. share of students from non-Western background, average socioeconomic status). Also, important neighborhood characteristics are added, made possible by using the information on students' 4-digit zip code residence. ${ }^{47}$ Throughout the analyses, to avoid estimating choice effects in (rural) areas in which there might hardly be any actual choice for households, results are presented for a subset of the BRON-data set, covering all students within the 31 major municipalities (G31). ${ }^{48}$ To grasp the importance of differences in urban density with respect to choice and educational outcomes, analyses are also performed on a subsample consisting of only the 4 largest municipalities. ${ }^{49}$

Table 4.1 reports the summary statistics for the variables and data subsets used in this chapter. Figure 4.1 is a map of Holland's largest city Amsterdam, used as an example to describe the context of this paper. It shows the spatial distributions of primary schools and the corresponding choice intensity in different areas of the city.

\footnotetext{
${ }^{47}$ A rich index for socioeconomic status is the "statusscore", provided by the Netherlands Institute for Social Research (SCP). Further neighborhood information is obtained from "Kerncijfers Postcodegebieden 2008" and "Buurtkaarten 2008, versie 3", both constructed by Statistics Netherlands (CBS).

${ }^{48}$ The Dutch government's so-called urban policy is one in which the major cities in the Netherlands collaborate on a variety of topics, among which education is one of them. It was introduced in 1994 for the 31 large and medium-sized cities, the G31 municipalities. These are the four largest cities (G4) and 27 medium-sized cities (G27). Source: www.government.nl/issues/municipalities-andcities/urban-policy

${ }^{49}$ The four largest cities, referred to as G4, are Amsterdam, Rotterdam, The Hague and Utrecht. Collectively, these four cities account for approximately $10 \%$ of all students. Together with the other 27 major cities, the G31 account for close to $30 \%$ of all students.
} 
Table 4.1: Summary statistics school choice, G31 and G4

\begin{tabular}{l|cc|cc|}
\hline & G31 & & G4 & \\
VARIABLE & mean & (sd) & mean & (sd) \\
\hline CITO-score & 534.43 & $(10.26)$ & 533.11 & $(11.06)$ \\
\# of schools within 1km & 4.06 & $(3.36)$ & 6.11 & $(4.28)$ \\
male (yes=1) & 0.5 & $(0.50)$ & 0.5 & $(0.50)$ \\
relative age (in years) & 0 & $(0.69)$ & 0.04 & $(0.70)$ \\
\% with nonwestern background & 0.31 & $(0.46)$ & 0.53 & $(0.50)$ \\
\% 2nd generation immigrant & 0.33 & $(0.47)$ & 0.52 & $(0.50)$ \\
student funding weight & 0.15 & $(0.32)$ & 0.27 & $(0.40)$ \\
\% one-parent household & 0.05 & $(0.22)$ & 0.09 & $(0.29)$ \\
\% non-western at primary school & 0.31 & $(0.30)$ & 0.53 & $(0.33)$ \\
mean school SES intake & 0 & $(1.10)$ & -0.43 & $(1.29)$ \\
neighborhood SES index & 0 & $(1.30)$ & -0.43 & $(1.49)$ \\
urbanicity index & 2.93 & $(1.07)$ & 3.63 & $(0.66)$ \\
G31 (yes=1) & 1 & $(0.00)$ & 1 & $(0.00)$ \\
G4 (yes=1) & 0.36 & $(0.48)$ & 1 & $(0.00)$ \\
N & 46084 & - & 16384 & - \\
\% & $100.00 \%$ & - & $35.55 \%$ & - \\
\hline
\end{tabular}

Figure 4.1: School choice intensity in Amsterdam

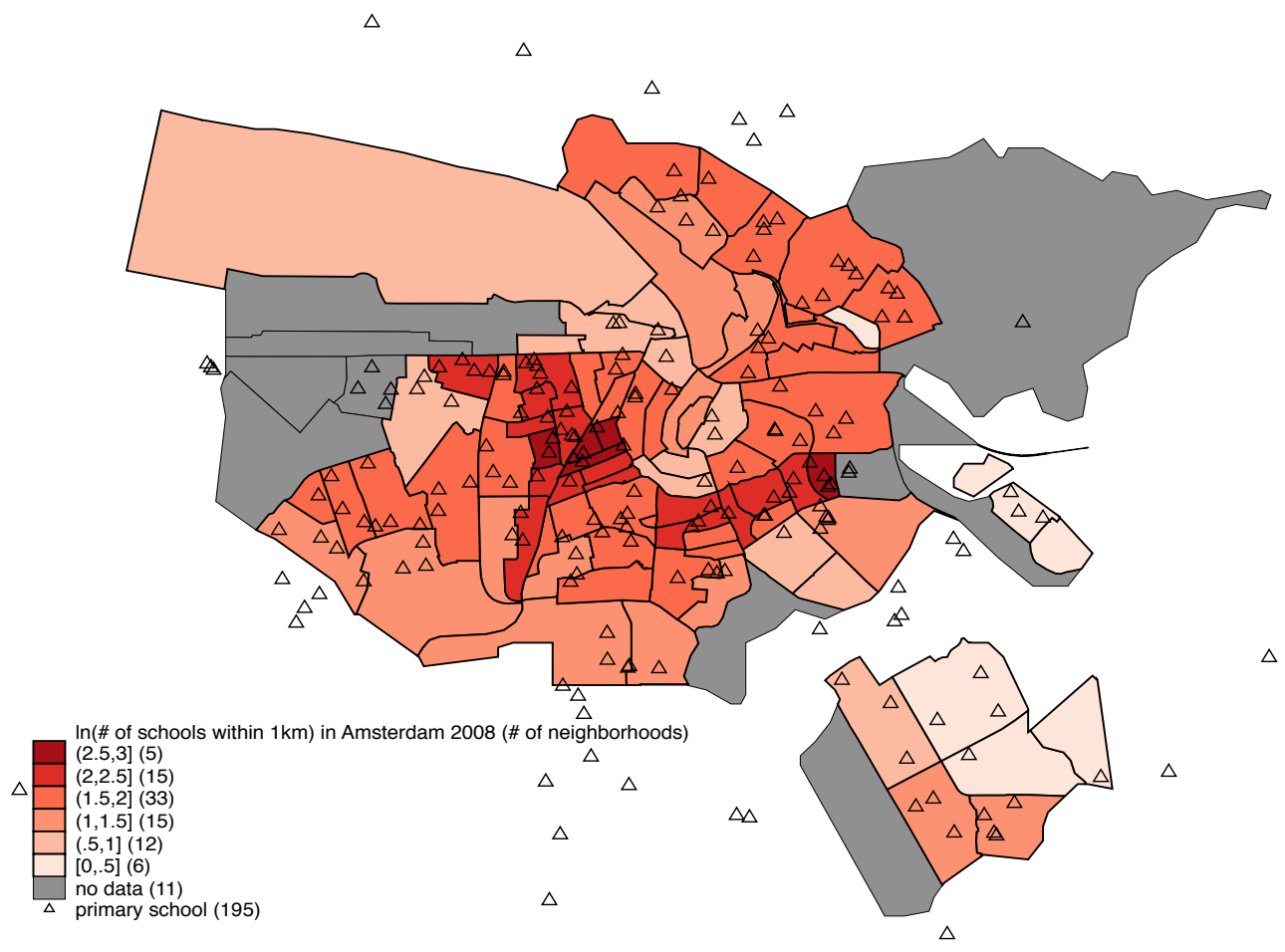

Note: The neighborhoods depicted here do not refer to 4-digit zip codes. Instead, displayed are "buurten", which can contain multiple 4-digit zip codes. As to match the 4-digit zip code data to the map, the most prevalent zip code in each "buurt" is used. For Amsterdam, $81 \%$ or more of all addresses share the same zip code in 65 out of the 97 "buurten" (source: "CBS Buurtkaart met cijfers 2008", available at www.cbs.nl). The concept of "buurten" is only used for this graphical representation. Throughout the empirical analyses, 4-digit zip codes are used. 


\subsubsection{Methodology}

The main approach is to estimate the effect of choice on students' achievement, by exploiting variation in the level of choice households are exposed to $(C)$. The following relationship is estimated:

$$
Y_{i j k m}=\alpha_{0}+x_{i j k}^{\prime} \beta+\gamma \cdot C_{i j k m}+\lambda_{m}+\varepsilon_{i j k m}
$$

where $Y_{i j k m}$ is the CITO-score for student $i$, attending school $j$, from neighborhood $k$, in municipality $m$. A set of background characteristics is provided by $x_{i j k}$ with municipality dummies $\lambda_{m}$ to account for idiosyncratic differences in achievement between cities, and an idiosyncratic error term $\varepsilon_{i j k m}{ }^{50}$ The level of choice available to a student in neighborhood $k$ is calculated as the (natural logarithm of the) number of schools within a meaningful radius around the centroid of a student's neighborhood of residence $\left(C_{i j k m}\right) .{ }^{51} \mathrm{~A}$ logarithm is used, because the effect of a given absolute difference of, for example, 2 schools is arguably different in a context with 2 and 4 schools, than in one with 8 and 10 schools. The effect $\lambda$ is therefore to be interpreted as the effect of a $100 \%$ change in the number of surrounding schools (within $1 \mathrm{~km}$ ) on students' test scores. ${ }^{52}$

The identifying assumption is thus that, conditional on background characteristics, the observed variation in choice intensity $(C)$ is exogenous, making it possible to extract the effect of choice on achievement. Differences in the number of schools surrounding a household's neighborhood could of course be due to unobserved differences also related to achievement. For example, it could be that the market structures observed can be partially influenced by the households' residential decision. For example, this would be problematic if households that are particularly motivated about their child's education and/or relatively affluent live in areas in which school density is high (or low). Also, there can be important mobility differences between neighborhoods, making it relatively more/less costly or difficult to travel longer distances. In this case, using a radius of $1 \mathrm{~km}$ might only be a reasonable approximation of choice intensity for certain neighborhoods. Finally, in the

\footnotetext{
${ }^{50}$ It is not directly clear what the appropriate level of clustering should be. Acknowledging the interdependence of students within a neighborhood, and since this level is the focus of this research design, standard errors are clustered at the neighborhood level, unless otherwise reported.

${ }^{51}$ Based on the arguments from the previous section, the main analyses use a radius of $1 \mathrm{~km}$ to generate variation in the number of schools "reasonably" available to households. However, different radii will be used in order to check the sensitivity of the results to the choice of radius (e.g. $0.5 \mathrm{~km}$ and $1.5 \mathrm{~km}$ ) .

${ }^{52}$ Put differently, a percentage increase in the number of schools is associated with a $\lambda / 100$ change in test score $Y$.
} 
presence of school openings and -closures, the current spatial distribution of schools observed could also be related to the socioeconomic characteristics of an area, with perhaps fewer schools in relatively disadvantageous areas (in which poorly performing schools have been closed down in recent history).

Because of the above, an instrumental variable approach is conducted to complement the main analyses, in which the first stage is:

$$
C_{i j k m}=\alpha_{0}+x_{i j k}^{\prime} \beta+\gamma \cdot D_{i j k m}+\lambda_{m}+\varepsilon_{i j k m}
$$

where $C$ is instrumented by the average distance to the main entrance/exit-road for households in neighborhood $k$, as represented by $D_{i j k m}$. Communities and municipalities pursue active policy with the objective to i) avoid schools from being built near major roads and ii) to resolve dangerous traffic situations near primary schools, both for safety- and health reasons. ${ }^{53}$ The intuition behind using this instrument is that households that live relatively far from (close to) one of the municipality's main roads face relatively more (less) schools surrounding their direct neighborhood, because of the abovementioned policies. The variation in observed school choice intensity $(C)$ is thus predicted by variation in the average distance to the main road $(D)$. These predicted values for school choice intensity are then used in the second stage to estimate the 2SLS effect of choice on outcomes:

$$
Y_{i j k m}=\alpha_{0}+x_{i j k}^{\prime} \beta+\gamma \cdot \hat{C}_{i j k m}+\lambda_{m}+\varepsilon_{i j k m}
$$

For this identification to work and to be valid, there should i) be a significant association in the first stage (i.e. relevance assumption) and ii) the distance to the main road should only affect educational achievement through its effect on choice (i.e. exclusion restriction). A major challenge for this instrument is that it is the first time this instrument will be used in this context. It will particularly be important to get some reassurance on whether the exclusion restriction does indeed seem to hold. ${ }^{54}$

\footnotetext{
${ }^{53}$ The society of cooperating municipalities (VNG) has designed a general covenant "Safe Schools", which municipalities use to address safety in and around schools. Part of it deals explicitly with traffic safety around school (see: www.vng.nl). Also, most provinces are involved in a collaborative framework, with the explicit objective to guarantee safe traffic environments around schools (see: www.verkeersveiligheidslabel.nl). Lastly, a national community with the objective to improve safety in traffic specifically advises stakeholders in how to improve traffic safety around schools (see: www.veiligverkeernederland.nl/dossier_schoolomgeving).

${ }^{54}$ Since the IV approach will only use a portion of the initial variation in choice intensity (i.e. the part explained by distance to main road), any remaining bias through violation of the exclusion restriction will only be inflated in the corresponding 2SLS estimates. In this case, the IV approach is potentially even more troublesome than the OLS strategy it is trying to improve upon.
} 


\subsection{Results}

Table 4.2 presents the results of the main specification. These results assume that the variation in the number of schools within $1 \mathrm{~km}$, after controlling for background characteristics at the student-, school- and residential level, is indeed exogenous and can be credibly used to estimate the effect of choice (intensity) on student achievement. The results in model 1 imply that a 100\% increase in the number of surrounding schools is associated with roughly a 1-point decrease in CITO-score, which amounts to $-0.1 \sigma$.

Table 4.2: OLS, school choice intensity effect on CITO test score, G31

\begin{tabular}{|c|c|c|c|c|}
\hline G31 & (1) & (2) & (3) & (4) \\
\hline VARIABLES & CITO & CITO & CITO & CITO \\
\hline \multirow[t]{2}{*}{ In(\# of schools within $1 \mathrm{~km})$} & $-1.12^{\star * \star}$ & 0.25 & $0.88^{* * *}$ & $0.45^{\star *}$ \\
\hline & $(0.279)$ & $(0.215)$ & $(0.224)$ & $(0.229)$ \\
\hline individual covariates & no & yes & yes & yes \\
\hline school-level covariates & no & no & yes & yes \\
\hline neighborhood covariates & no & no & no & yes \\
\hline \multirow[t]{2}{*}{ Constant } & $535.71^{* * *}$ & $535.50^{* * *}$ & $535.45^{\star * *}$ & $534.23^{* * *}$ \\
\hline & $(0.337)$ & $(0.277)$ & $(0.309)$ & $(0.733)$ \\
\hline Observations & 12,910 & 12,899 & 12,899 & 12,888 \\
\hline R-squared & 0.01 & 0.15 & 0.18 & 0.20 \\
\hline Adj. R-squared & 0.00612 & 0.154 & 0.176 & 0.199 \\
\hline
\end{tabular}

When important student-level background characteristics turn out to be correlated with choice intensity, this estimate will suffer from omitted variable bias (OVB). The results in model 2 highlight the importance of controlling for these individual differences in background, turning the choice effect to insignificance and significantly improving the explanatory power of the model (i.e. from 1\% to 15\%). For similar reasons of OVB, models 3 and 4 add control variables to take into account observed differences at the school- and 4digit zipcode level, respectively. Model 4 also includes municipality dummies, allowing for unobserved, or structural, differences in performance across cities. These more complete models imply a positive association between choice intensity and student achievement. In 
particular, a $100 \%$ increase in the number of surrounding schools is associated with an increase in performance in the range of 0.05-0.09б.

Whereas the inclusion of control variables arguable decreased potential endogeneity problems, the fact they are so relevant to include raises the question to what extent these results might still suffer from omitted variable bias. These next sections provide some extensions designed to deal with this. One of the main concerns with the measure of choice used is that it reflects general urban density effects, as the two phenomena are positively related in this context. ${ }^{55}$ The control variable urbanicity is directly derived from urban density, in an attempt to deal with this. ${ }^{56}$ If, however, this variable does not properly capture general urban density effects, this problem of unsuccessfully controlling for such effects should arguably play out differently in highly urban settings. Therefore, the same OLS analyses are performed for the subset of the four largest cities (G4), which are significantly more urban than the remaining 27 cities of the G31. ${ }^{57}$

The results of this, presented in Table 4.3, are highly similar with estimates for all models in the same range as those presented in Table 4.2. An advantage of the G4 subsample could be that the relative variation of the potentially confounding urban density is less, relative to that in the G31 sample, while variation in choice intensity is largely maintained..$^{58}$ In addition, the explanatory power of the models is also somewhat higher (i.e. $24 \%$ relative to $20 \%$ ). In any case, the G4 estimates imply that a $100 \%$ increase in choice intensity is associated with a $0.08 \sigma$ increase in student achievement.

\footnotetext{
${ }^{55}$ The correlation between the \# of schools per $\mathrm{km}$ and the measure of urban density used (i.e. urbanicity) is around 0.55 in the data set used.

${ }^{56}$ In particular, the range for urbanicity is [0;4], with 0 if there are less than 500 addresses per square $\mathrm{km}, 1$ if 500-1000 addresses per square km, 2 if 1000-15000 addresses per square km, 3 if 1500-2500 addresses per square $\mathrm{km}$ and 4 if there are more than 2500 addresses per square $\mathrm{km}$ (see Appendix $B$ for a description of the variables used).

${ }^{57}$ For example, the mean value for urbanicity for the G4 is 3.63 (sd: 0.7 ), whereas for the remaining 27 cities in the $\mathrm{G} 31$ this is on average 2.54 (sd: 1.0). Alternatively, as of November 1, 2012, the population of the largest G4-city (i.e. Amsterdam) was 798.164 and for the smallest G4 city (i.e. Utrecht) this was 321.583 , whereas the population of the largest non-G4 city (i.e. Eindhoven) is 218.559 . Source: www.cbs.nl

${ }^{58}$ The coefficient of variation in the number of schools for the G31 is 3.4/4.1=0.83, whereas the equivalent for the $\mathrm{G} 4$ subsample is $4.3 / 6.1=0.70$. The coefficient of variation in urban density for the $\mathrm{G} 31$ is $1.1 / 2.9=0.38$, while for the $\mathrm{G} 4$ this number is $0.7 / 3.6=0.19$.
} 
Table 4.3: OLS, School choice intensity effect on CITO test score, G4

\begin{tabular}{lcccc}
\hline G4 & $(\mathbf{1})$ & $(\mathbf{2})$ & $(\mathbf{3})$ & $(\mathbf{4})$ \\
VARIABLES & CITO & CITO & CITO & CITO \\
\hline In(\# of schools within 1km) & & & & \\
& $-0.95^{*}$ & 0.36 & $0.78^{* *}$ & $0.80^{* *}$ \\
& $(0.484)$ & $(0.323)$ & $(0.307)$ & $(0.377)$ \\
individual covariates & & & & \\
school-level covariates & $n o$ & yes & yes & yes \\
neighborhood covariates & $n o$ & $n o$ & yes & yes \\
& $n o$ & $n o$ & $n o$ & yes \\
Constant & & & & \\
& $534.56^{* * *}$ & $536.12^{* * *}$ & $537.62^{* * *}$ & $534.24^{* * *}$ \\
& $(0.885)$ & $(0.700)$ & $(0.741)$ & $(1.900)$ \\
Observations & & & & \\
R-squared & 4,858 & 4,847 & 4,847 & 4,842 \\
Adj. R-squared & 0.00 & 0.20 & 0.23 & 0.24 \\
\hline Notes: Robust clusterd standard errors (at neighborhood level) in parentheses, ${ }^{* * *} p<0.01,{ }^{* *} p<0.05,{ }^{*} p<0.1$
\end{tabular}

It could, of course, still be the case that there is endogeneity through unobserved urban density effects, or by acknowledging that the observed market configurations arise through endogenous processes. This would be the case if, for example, more motivated households with high-achieving children deliberately choose to reside in neighborhoods with ample schools around and/or if the spatial distribution of schools is related to unobserved socioeconomic characteristics through new school openings and closures in the past (Gibbons et al., 2008).

Because of these endogeneity concerns, a source of potentially exogenous variation in the number of surrounding schools is isolated, by using the distance to the entry/exit of a main road as an instrument. This measure is calculated by Statistics Netherlands at the household level. This is aggregated at the level of the "buurt" (a concept which can contain more than one 4 digit zip code), after which this average is matched to the most prevalent the 4-digit zip code (i.e. neighborhood level); the level at which the choice intensity measure has been determined.

Figure 4.2 compares the associations between the number of surrounding schools and the distance to the main road (i.e. the first stage). It confirms the intuition behind this instrument, with the number of surrounding schools increasing in with household's distance to the main road. 


\section{Figure 4.2: Association number of schools and distance to main road entry/exit}

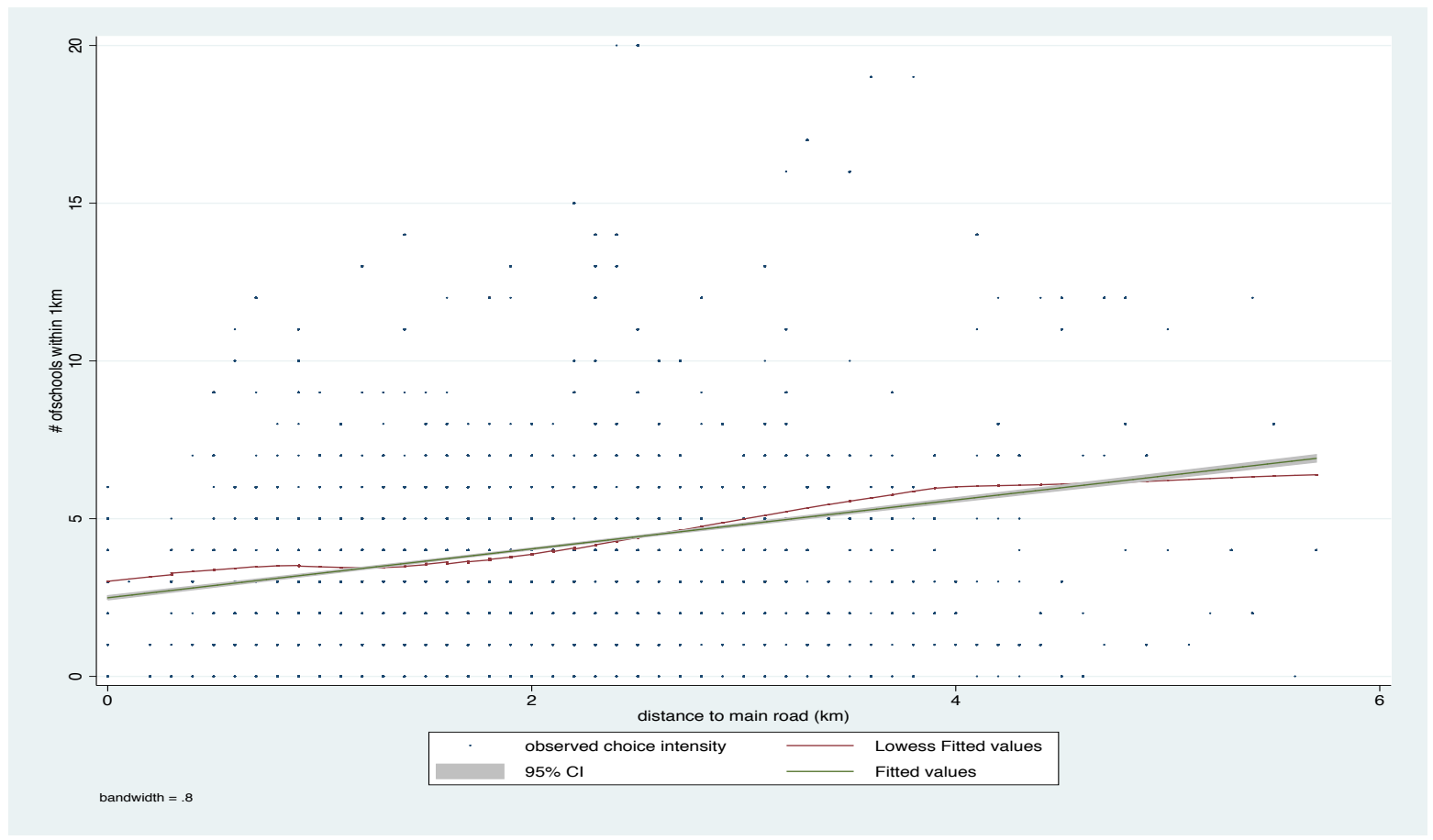

Note: Each dot represents one 4-digit zip code neighborhood centroid. The average distance to the main road entry/exit is known for "buurten", which can contain multiple 4-digit zip codes. As to match the 4-digit zip code data to this, the most prevalent zip code in each "buurt" is used. The scatter plot shows the association of this figure with the choice intensity measure. A linearly fitted line, with $95 \%$ confidence interval, is plotted, just as a locally weighted scatterplot smoothing regression line with bandwith 0.8 . (source: "CBS Buurtkaart met cijfers 2008", available at www.cbs.nl).

Table 4.4 gives some insight into whether this instrument is indeed less influenced by general neighborhood characteristics, relative to the initial choice intensity measure used up till now. It gives the OLS associations with dependent variables i) neighborhood SES, ii) average monthly fiscal neighborhood income ( $x € 100)$, iii) the \% of population between $0-15$ years old, iv) the \% of population from a non-Western background, and v) general urban density. These are indeed generally weaker for the instrument than for the choice intensity measure. However, statistically significant relationships with general urbanicity and the proportion of 0-15 year olds in the neighborhood still remain for the instrument as well. Also, these results do not assure that the instrument will be unrelated to other (unobserved) confounding factors. 
Table 4.4: Associations choice intensity and instrument with neighborhood features

\begin{tabular}{|c|c|c|c|c|c|}
\hline G31 & (1) & (2) & (3) & (4) & $(5)$ \\
\hline VARIABLES & SES index & income $(\mathbf{x} 100)$ & $\% 0-15$ year & $\%$ nonwestern & urbanicity \\
\hline \multirow[t]{2}{*}{ distance to main road entry/exit } & -0.00 & 0.07 & $0.63^{* *}$ & 0.47 & $0.08^{* * *}$ \\
\hline & $(0.024)$ & $(0.123)$ & $(0.248)$ & $(0.569)$ & $(0.032)$ \\
\hline \multirow[t]{2}{*}{ In(\# of schools within $1 \mathrm{~km}$ ) } & $-0.08^{* *}$ & -0.13 & $0.79^{*}$ & $2.71^{* *}$ & $0.55^{* * *}$ \\
\hline & $(0.037)$ & $(0.183)$ & $(0.470)$ & $(1.101)$ & $(0.047)$ \\
\hline individual background characteristics included & yes & yes & yes & yes & yes \\
\hline school-level characteristics included & yes & yes & yes & yes & yes \\
\hline neighborhood characteristics included & yes & yes & yes & yes & yes \\
\hline municipality dummies included & yes & yes & yes & yes & yes \\
\hline
\end{tabular}

Notes: Robust clustered standard errors (at neighborhood level) in parentheses ${ }^{* * *} p<0.01,{ }^{* *} p<0.05,{ }^{*} p<0.1$

The first-stage results are presented in Table 4.5, and is the result of estimating equation 4.2. The first-stage regresses the logarithm of the number of surrounding schools on the distance to the main road, controlling for the full set of covariates. The coefficient implies that a kilometer increase in the distance to the main road is associated with an additional $11 \%$ of schools. The corresponding F-statistic of the instrument is 334.34 and significant at the $1 \%$ level. The "2SLS Size of nominal $5 \%$ Wald test" similarly rejects the nullhypothesis of a weak instrument (i.e. $334.34>16.38$ ). However, the results also indicate that, although there is a strong first-stage relationship, much of the association between choice intensity and distance to the main road coincides with the control variables in the model (i.e. partial $\left.R^{2}=0.026\right) .{ }^{59}$ It could thus be the case that the instrument, capturing only a little bit of unique variation in choice intensity, will lead to relatively large bias- and/or standard error issues. Also, based on the instrument used, the hypothesis that the initial choice intensity measure is indeed exogenous, and does not require to be instrumented, cannot be rejected $(p=0.65)$.

\footnotetext{
${ }^{59}$ See Bound, Jaeger, and Baker (1995) for a discussion in favor of using the partial $\mathrm{R}^{2}$.
} 
Table 4.5: Checks for relevance and validity or instrument

\begin{tabular}{|c|c|c|c|c|c|c|}
\hline $\begin{array}{l}\text { Variable } \\
\ln (\# \text { schools within } 1 \mathrm{~km})\end{array}$ & & $\begin{array}{l}\text { R-sq. } \\
0.4404\end{array}$ & $\begin{array}{l}\text { adj. R-sq. } \\
0.4385\end{array}$ & $\begin{array}{l}\text { partial R-sq. } \\
\quad 0.026\end{array}$ & $\begin{array}{c}\mathrm{F}(1,12522) \\
334.34\end{array}$ & $\begin{array}{c}\text { Prob }>F \\
0.000\end{array}$ \\
\hline $\begin{array}{l}\text { First Stage Effect } \\
\text { distance to main road entry/exit }\end{array}$ & & $\begin{array}{c}\text { Coefficient } \\
0.11 \\
(0.01)\end{array}$ & & & & \\
\hline Minimum eigenvalue statistic & $=$ & 334.34 & & & & \\
\hline Critical Values & & \# of endogenc & egressors: 1 & & & \\
\hline \multirow[t]{2}{*}{ Ho: Instruments are weak } & & \# of excluded & uments: & & & \\
\hline & & $10 \%$ & $15 \%$ & $20 \%$ & $25 \%$ & \\
\hline 2 SLS Size of nominal $5 \%$ Wald test & & 16.38 & 8.96 & 6.66 & 5.53 & \\
\hline \multicolumn{7}{|l|}{ Tests of endogeneity } \\
\hline Durbin (score) chi2(1) & $=$ & 0.206095 & $(p=0.6498)$ & & & \\
\hline Wu-Hausman F(1,12521) & $=$ & 0.205393 & $(p=0.6504)$ & & & \\
\hline
\end{tabular}

Keeping in mind the abovementioned observations, the 2SLS estimate described in equations 2 and 3 is calculated, using the same covariates as in the initial OLS estimates. The results are presented in Table 4.6 and confirm the initial observation that the instrument is less correlated with the observed background characteristics, given that now the inclusion of those variables does not alter the sign of the estimated effect of choice (i.e. there is a positive association between choice and student achievement throughout models 1-4). Also, as only a portion of the variation in choice intensity is exploited, the estimates are much more imprecise, leading to a statistically insignificant, and imprecisely estimated effect of a $0.09 \sigma$ increase in achievement for each $100 \%$ increase in choice intensity. 
Table 4.6: 2SLS, School choice intensity effect on CITO test score, G31

\begin{tabular}{|c|c|c|c|c|}
\hline $\begin{array}{l}\text { G31 } \\
\text { VARIABLES }\end{array}$ & $\begin{array}{l}\text { (1) } \\
\text { CITO }\end{array}$ & $\begin{array}{l}\text { (2) } \\
\text { CITO }\end{array}$ & $\begin{array}{l}\text { (3) } \\
\text { CITO }\end{array}$ & $\begin{array}{l}\text { (4) } \\
\text { CITO }\end{array}$ \\
\hline $\ln (\#$ of schools within $1 \mathrm{~km})$ & $\begin{array}{c}1.50 \\
(1.425)\end{array}$ & $\begin{array}{c}2.24^{\star *} \\
(1.045)\end{array}$ & $\begin{array}{c}2.28^{\star *} \\
(1.095)\end{array}$ & $\begin{array}{c}0.88 \\
(1.488)\end{array}$ \\
\hline individual covariates & no & yes & yes & yes \\
\hline school-level covariates & no & no & yes & yes \\
\hline neighborhood covariates & no & no & no & yes \\
\hline Constant & $\begin{array}{c}532.83^{* * *} \\
(1.598)\end{array}$ & $\begin{array}{c}533.55^{\star * \star} \\
(1.075)\end{array}$ & $\begin{array}{c}534.27^{* \star \star} \\
(0.990)\end{array}$ & $\begin{array}{c}534.05^{\star \star \star} \\
(0.875)\end{array}$ \\
\hline Observations & 12,579 & 12,570 & 12,570 & 12,564 \\
\hline R-squared & & 0.14 & 0.17 & 0.20 \\
\hline Adj. R-squared & . & 0.136 & 0.168 & 0.198 \\
\hline
\end{tabular}

There are at least two other potential mechanisms that could explain the above results and would invalidate the findings presented in this chapter so far. First, De Haan et al. (2011) show that, by exploiting exogenous variation in (changes in) minimum school size rules, economies of scale matter in the sense that larger schools perform better than smaller schools. If it is the case that larger schools are found particularly in dense areas with many surrounding schools, this could explain assumed choice effects. Second, as Gibbons et al. (2008) argue, the observed spatial distribution of schools could be such that quality schools are clustered relatively close together in certain (favorable) neighborhoods, leaving poorly performing schools relatively dispersed from each other. In this case, the positive association of achievement with choice intensity is not so much due to choice, but merely reflects the fact that quality schools happen to be clustered together for reasons other than choice. ${ }^{60}$ To investigate the above issues, equation 3 is subsequently augmented with variables capturing school size and school quality. Both variables are derived from Education

\footnotetext{
${ }^{60}$ School size and quality variables have been left out of the preferred specifications as choice (and competition) can obviously contribute to both. Instead, with inclusion of these variables, the effects of choice intensity are to be interpreted as "over and above" the effects it has on achievement through school size and reported quality.
} 
Inspectorate assessments. ${ }^{61}$ The results, presented in Table 4.7, show that school size and quality contribute to achievement, but leave the choice intensity effect unaffected and significant at $0.05 \sigma$ for each $100 \%$ increase. $^{62}$

Table 4.7: School choice effects, augmented with school size and quality, G31

\begin{tabular}{lcccc}
\hline G31 & $(\mathbf{1})$ & $(\mathbf{2})$ & $(3)$ & $(4)$ \\
VARIABLES & CITO & CITO & CITO & CITO \\
\hline In(\# of schools within 1km) & & & & \\
& $0.45^{* *}$ & $0.43^{*}$ & $0.49^{* *}$ & $0.48^{* *}$ \\
school size & $(0.229)$ & $(0.233)$ & $(0.219)$ & $(0.216)$ \\
& & $0.52^{*}$ & & 0.18 \\
school quality score & & $(0.313)$ & & $(0.328)$ \\
& & & $3.39^{* * *}$ & $3.37^{* * *}$ \\
individual covariates & & & $(0.281)$ & $(0.278)$ \\
school-level covariates & & & & \\
neighborhood covariates & $y e s$ & yes & yes & yes \\
& $y e s$ & yes & yes & yes \\
Constant & yes & yes & yes & yes \\
& & & & \\
& $534.23^{* * *}$ & $531.22^{* * *}$ & $531.35^{* * *}$ & $530.31^{* * *}$ \\
Observations & $(0.733)$ & $(1.902)$ & $(0.611)$ & $(1.990)$ \\
R-squared & & & & \\
Adj. R-squared & 12,888 & 12,700 & 12,432 & 12,432 \\
\hline Notes: Robust clusterd standard errors (at neighborhood level) in parentheses, ${ }^{* * *} p<0.01,{ }^{* *} p<0.05,{ }^{*} p<0.1$
\end{tabular}

A likely caveat to the above estimates is the large proportion of students for which no test scores are recorded. To grasp the potential selection biases at hand, one approach is to compare these different subsets of students on the basis of background characteristics and educational outcomes (Table 4.8). Selection would be problematic for the internal validity of the results, if there were reasons to believe that choice intensity is related to nonresponse and achievement (e.g. when low-performing, socioeconomically disadvantageous,

\footnotetext{
${ }^{61}$ The actual school size of the primary school for the academic year of this data set is given. The school quality score is a categorical variable (i.e. $0,1,2)$ with higher values implying a better school. Given the risk-based approach in which some schools are only assessed once every four years, some of these quality indicators are from different years. In these cases, the quality level for that year is assumed to apply to 2008-2009 as well. ${ }^{62}$ When both size and quality are added, the effect of the former drops to insignificance. This is assumed to be due to the fact that school quality encompasses any quality increases due to size.
} 
"high-choice" children are more likely to be among the missing outcome observations). In general, pupils that receive a relatively low secondary school advice (i.e. PRO, VSO, LWOO) can be exempted from having to perform the standardized CITO-test, just as students who lack behind in Dutch language skills and have entered the Netherlands less than 4 years ago. Indeed, students with observed CITO scores, have somewhat higher advice scores (a $0.3 \sigma$ difference). Also, they are from slightly advantageous neighborhoods and schools (a $0.1 \sigma$ difference). However, Table 4.8 gives no clear signs of strong non-random response patterns in terms of choice intensity.

Table 4.8: Choice and missing CITO test score data comparisons, BRON PO '08-'09

\begin{tabular}{l|cc|cc|cc|}
\hline & \multicolumn{3}{|c|}{ no missing cito } & missing cito & & \multicolumn{2}{l|}{ all students } \\
\hline & mean & $(\mathbf{s d})$ & mean & (sd) & mean & (sd) \\
\hline CITO-score & 534.43 & $(10.26)$ &. &. & 534.43 & $(10.26)$ \\
secondary school advice score & 50.33 & $(15.93)$ & 45.41 & $(18.63)$ & 47.53 & $(17.68)$ \\
In(\# of schools within 1km) & 1.14 & $(0.72)$ & 1.16 & $(0.76)$ & 1.15 & $(0.75)$ \\
male & 0.49 & $(0.50)$ & 0.51 & $(0.50)$ & 0.50 & $(0.50)$ \\
relative age (in years) & -0.05 & $(0.68)$ & 0.02 & $(0.70)$ & 0.00 & $(0.69)$ \\
nonwestern background & 0.31 & $(0.46)$ & 0.30 & $(0.46)$ & 0.31 & $(0.46)$ \\
2nd generation immigrant & 0.33 & $(0.47)$ & 0.32 & $(0.47)$ & 0.33 & $(0.47)$ \\
weighted student funding & 0.16 & $(0.33)$ & 0.15 & $(0.32)$ & 0.15 & $(0.32)$ \\
one-parent household & 0.05 & $(0.21)$ & 0.05 & $(0.23)$ & 0.05 & $(0.22)$ \\
\% non-western at primary school & 0.31 & $(0.31)$ & 0.30 & $(0.30)$ & 0.31 & $(0.30)$ \\
mean school SES & 0.07 & $(1.13)$ & -0.03 & $(1.08)$ & 0.00 & $(1.10)$ \\
neighborhood SES 2006 & 0.07 & $(1.32)$ & -0.03 & $(1.29)$ & 0.00 & $(1.30)$ \\
urbanicity & 2.89 & $(1.10)$ & 2.94 & $(1.06)$ & 2.93 & $(1.07)$ \\
school size & 5.72 & $(0.49)$ & 5.73 & $(0.48)$ & 5.73 & $(0.48)$ \\
school quality score & 1.12 & $(0.43)$ & 1.10 & $(0.38)$ & 1.11 & $(0.40)$ \\
$\mathrm{N}$ & 12910 & - & 33174 & - & 46084 & - \\
\hline
\end{tabular}

\subsection{Concluding remarks}

This chapter set out to exploit the variance in the number of schools in the proximity of households in order to estimate the influence of choice intensity on student achievement at the end of primary education in the Netherlands. The Dutch primary education context is known for a long history of universal choice, in which households can freely choose between government-funded primary schools and arguably in the absence of financial constraints and (ability) selection. 
Since distance to school is an important determinant in choosing a primary school, the measure for school choice intensity used is derived from the number of schools within $1 \mathrm{~km}$ of households in the 31 largest cities. Using a rich set of controls at the student-, school- and neighborhood level reveals a positive association between choice and achievement in which a $100 \%$ increase in the number of surrounding schools is associated with around 0.05-0.09 of a standard deviation increase in achievement. This is similar to an increase of 0.03-0.06 $\sigma$ for each standard deviation increase in choice intensity. This result is interpreted as the compound result of a variety of mechanisms that have been associated with school choice (e.g. competition, matching and parental involvement).

Unfortunately, the choice intensity measure is significantly correlated with several of the background variables included in the analyses. Consequently, the results attributed to school choice can be (partially) due to general urban effects instead. Limiting the sample to the 4 largest cities reduces variation in urban density and gives estimates in the upper end of the range of estimates.

When school choice intensity is instrumented with the distance to the main road, results are imprecise but qualitatively similar. The instrument, although largely successful in removing the associations with school choice and general urban density, cannot completely disentangle these effects. School quality and school size effects do not seem to explain the findings.

The results are further challenged by the fact that only a proportion of schools complied with the request to submit standard achievement data. However, there are no clear signs that the results can be completely attributed to non-random response patterns. Also, each school within $1 \mathrm{~km}$ is considered equally in determining the choice intensity index. Obviously, some schools within this radius might not be considered by households as realistic options (e.g. due to denomination), just as others outside it might actually be part of the relevant choice set. The key assumption used for the analyses presented here is that, in general, more schools within $1 \mathrm{~km}$ around the centroid of a household's neighborhood corresponds to a higher level of choice intensity.

The results reported here are in line with existing school choice literature in that the effect of choice on student achievement appears to be modest. One interpretation could be that households value not only cognitive student achievement, but different school aspects as well. In other words, even when choice increases efficient matching between schools and 
students, this does not have to translate into strong effects on achievement. The education market in the Netherlands has been described as a heterogeneous one, with different schools serving different groups of households, which arguably limits the potential for competitive pressure between schools to spur academic performance. 


\section{A Appendix: Full estimation results}

Table 4.2: OLS, School choice intensity effect on CITO test score, G31

\begin{tabular}{|c|c|c|c|c|}
\hline G31 & (1) & $(2)$ & (3) & (4) \\
\hline VARIABLES & CITO & CITO & CITO & CITO \\
\hline \multirow[t]{2}{*}{$\ln (\#$ of schools within $1 \mathrm{~km})$} & $-1.12^{\star * *}$ & 0.25 & $0.88^{* * *}$ & $0.45^{\star *}$ \\
\hline & $(0.279)$ & $(0.215)$ & $(0.224)$ & $(0.229)$ \\
\hline \multirow[t]{2}{*}{ male (yes=1) } & & $1.12^{* * *}$ & $1.13^{* * *}$ & $1.13^{* * *}$ \\
\hline & & $(0.182)$ & $(0.177)$ & $(0.177)$ \\
\hline \multirow[t]{2}{*}{ relative age (in years) } & & $-3.43^{\star * *}$ & $-3.36^{\star \star *}$ & $-3.28^{* \star *}$ \\
\hline & & $(0.127)$ & $(0.126)$ & $(0.124)$ \\
\hline \multirow[t]{2}{*}{ non-western immigrant background (yes=1) } & & $-3.92^{* * *}$ & $-1.96^{* \star *}$ & $-1.77^{* * *}$ \\
\hline & & $(0.351)$ & $(0.361)$ & $(0.356)$ \\
\hline \multirow[t]{2}{*}{ 2nd generation non-western background (yes=1) } & & -0.23 & -0.03 & -0.16 \\
\hline & & $(0.311)$ & $(0.303)$ & $(0.301)$ \\
\hline \multirow[t]{2}{*}{ student's weighted funding } & & $-3.86^{* \star *}$ & $-2.32^{* \star *}$ & $-2.23^{* * *}$ \\
\hline & & $(0.448)$ & $(0.437)$ & $(0.424)$ \\
\hline \multirow[t]{2}{*}{ single-parent household } & & $-3.27^{\star * *}$ & $-2.34^{* * *}$ & $-2.41^{* * *}$ \\
\hline & & $(0.452)$ & $(0.415)$ & $(0.424)$ \\
\hline \multirow[t]{2}{*}{ proportion non-western immigrants at school } & & & $-5.35^{\star \star *}$ & $-7.34^{* * *}$ \\
\hline & & & $(0.755)$ & $(0.790)$ \\
\hline \multirow[t]{2}{*}{ SES-index of school intake } & & & $0.65^{\star * *}$ & -0.18 \\
\hline & & & $(0.205)$ & $(0.259)$ \\
\hline \multirow[t]{2}{*}{ neighborhood SES index } & & & & $0.85^{\star * *}$ \\
\hline & & & & $(0.154)$ \\
\hline \multirow[t]{2}{*}{ neighborhood urbanicity index } & & & & $0.54^{* *}$ \\
\hline & & & & $(0.209)$ \\
\hline individual covariates & no & yes & yes & yes \\
\hline school-level covariates & no & no & yes & yes \\
\hline neighborhood covariates & no & no & no & yes \\
\hline \multirow[t]{2}{*}{ Constant } & $535.71^{* * *}$ & $535.50^{* * *}$ & $535.45^{\star * *}$ & $534.23^{* * *}$ \\
\hline & $(0.337)$ & $(0.277)$ & $(0.309)$ & $(0.733)$ \\
\hline Observations & 12,910 & 12,899 & 12,899 & 12,888 \\
\hline R-squared & 0.01 & 0.15 & 0.18 & 0.20 \\
\hline Adj. R-squared & 0.00612 & 0.154 & 0.176 & 0.199 \\
\hline
\end{tabular}


Table 4.3: OLS, School choice intensity effect on CITO test score, G4

\begin{tabular}{|c|c|c|c|c|}
\hline G4 & $(1)$ & $(2)$ & $(3)$ & $(4)$ \\
\hline VARIABLES & CITO & CITO & CITO & CITO \\
\hline \multirow[t]{2}{*}{$\ln (\#$ of schools within $1 \mathrm{~km})$} & $-0.95^{*}$ & 0.36 & $0.78^{* *}$ & $0.80^{* *}$ \\
\hline & $(0.484)$ & $(0.323)$ & $(0.307)$ & $(0.377)$ \\
\hline \multirow[t]{2}{*}{ male (yes=1) } & & $1.33^{\star * *}$ & $1.29^{\star * *}$ & $1.32^{\star * *}$ \\
\hline & & $(0.310)$ & $(0.301)$ & $(0.301)$ \\
\hline \multirow[t]{2}{*}{ relative age (in years) } & & $-3.75^{\star * *}$ & $-3.63^{\star \star *}$ & $-3.52^{\star * \star}$ \\
\hline & & $(0.215)$ & $(0.211)$ & $(0.209)$ \\
\hline \multirow[t]{2}{*}{ non-western immigrant background (yes=1) } & & $-5.44^{* \star *}$ & $-2.99^{* * *}$ & $-2.83^{* * *}$ \\
\hline & & $(0.520)$ & $(0.531)$ & $(0.522)$ \\
\hline \multirow[t]{2}{*}{ 2nd generation non-western background (yes=1) } & & -0.14 & 0.05 & -0.04 \\
\hline & & $(0.491)$ & $(0.478)$ & $(0.467)$ \\
\hline \multirow[t]{2}{*}{ student's weighted funding } & & $-3.55^{\star \star \star}$ & $-2.38^{\star \star *}$ & $-2.15^{\star \star \star}$ \\
\hline & & $(0.581)$ & $(0.582)$ & $(0.550)$ \\
\hline \multirow[t]{2}{*}{ single-parent household } & & $-3.44^{* * *}$ & $-2.80^{* * *}$ & $-2.75^{\star \star \star}$ \\
\hline & & $(0.574)$ & $(0.517)$ & $(0.527)$ \\
\hline \multirow[t]{2}{*}{ proportion non-western immigrants at school } & & & $-7.44^{\star * \star}$ & $-7.86^{* \star *}$ \\
\hline & & & $(1.272)$ & $(1.230)$ \\
\hline \multirow[t]{2}{*}{ SES-index of school intake } & & & -0.01 & -0.63 \\
\hline & & & $(0.368)$ & $(0.450)$ \\
\hline \multirow[t]{2}{*}{ neighborhood SES index } & & & & $0.81^{\star * *}$ \\
\hline & & & & $(0.240)$ \\
\hline \multirow[t]{2}{*}{ neighborhood urbanicity index } & & & & 0.62 \\
\hline & & & & $(0.533)$ \\
\hline individual covariates & no & yes & yes & yes \\
\hline school-level covariates & no & no & yes & yes \\
\hline neighborhood covariates & no & no & no & yes \\
\hline \multirow[t]{2}{*}{ Constant } & $534.56^{* * *}$ & $536.12^{* * *}$ & $537.62^{* * *}$ & $534.24^{* * *}$ \\
\hline & $(0.885)$ & $(0.700)$ & $(0.741)$ & $(1.900)$ \\
\hline Observations & 4,858 & 4,847 & 4,847 & 4,842 \\
\hline R-squared & 0.00 & 0.20 & 0.23 & 0.24 \\
\hline Adj. R-squared & 0.00340 & 0.203 & 0.227 & 0.239 \\
\hline
\end{tabular}

Notes: Robust clusterd standard errors (at neighborhood level) in parentheses

${ }^{* * *} p<0.01,{ }^{* *} p<0.05,{ }^{*} p<0.1$ 
Table 4.6: 2SLS, School choice intensity effect on CITO test score, G31

\begin{tabular}{|c|c|c|c|c|}
\hline G31 & (1) & (2) & (3) & (4) \\
\hline VARIABLES & CITO & CITO & CITO & CITO \\
\hline \multirow[t]{2}{*}{ In(\# of schools within $1 \mathrm{~km})$} & 1.50 & $2.24^{* *}$ & $2.28^{* *}$ & 0.88 \\
\hline & $(1.425)$ & $(1.045)$ & $(1.095)$ & $(1.488)$ \\
\hline \multirow[t]{2}{*}{ male (yes=1) } & & $1.17^{* * *}$ & $1.16^{* * *}$ & $1.14^{* * *}$ \\
\hline & & $(0.185)$ & $(0.181)$ & $(0.183)$ \\
\hline \multirow[t]{2}{*}{ relative age (in years) } & & $-3.43^{* * *}$ & $-3.36^{* * *}$ & $-3.31^{* * *}$ \\
\hline & & $(0.130)$ & $(0.127)$ & $(0.127)$ \\
\hline \multirow[t]{2}{*}{ non-western immigrant background (yes=1) } & & $-4.35^{\star * *}$ & $-1.90^{* * *}$ & $-1.72^{* \star *}$ \\
\hline & & $(0.444)$ & $(0.372)$ & $(0.364)$ \\
\hline \multirow[t]{2}{*}{ 2nd generation non-western background (yes=1) } & & -0.36 & -0.06 & -0.15 \\
\hline & & $(0.327)$ & $(0.314)$ & $(0.311)$ \\
\hline \multirow[t]{2}{*}{ student's weighted funding } & & $-4.51^{* \star *}$ & $-2.41^{* * *}$ & $-2.32^{* * *}$ \\
\hline & & $(0.575)$ & $(0.463)$ & $(0.450)$ \\
\hline \multirow[t]{2}{*}{ single-parent household } & & $-3.39^{\star * *}$ & $-2.26^{* * *}$ & $-2.34^{* * *}$ \\
\hline & & $(0.480)$ & $(0.432)$ & $(0.454)$ \\
\hline \multirow[t]{2}{*}{ proportion non-western immigrants at school } & & & $-6.66^{* * *}$ & $-7.56^{\star * *}$ \\
\hline & & & $(1.217)$ & $(0.913)$ \\
\hline \multirow[t]{2}{*}{ ESCS-index of school intake } & & & $0.65^{\star \star *}$ & -0.21 \\
\hline & & & $(0.216)$ & $(0.319)$ \\
\hline \multirow[t]{2}{*}{ neighborhood ESCS index } & & & & $0.87^{* * *}$ \\
\hline & & & & $(0.168)$ \\
\hline \multirow[t]{2}{*}{ neighborhood urbanicity index } & & & & 0.42 \\
\hline & & & & $(0.578)$ \\
\hline individual covariates & no & yes & yes & yes \\
\hline school-level covariates & no & no & yes & yes \\
\hline neighborhood covariates & no & no & no & yes \\
\hline \multirow[t]{2}{*}{ Constant } & $532.83^{* * *}$ & $533.55^{\star * *}$ & $534.27^{\star * *}$ & $534.05^{* * *}$ \\
\hline & $(1.598)$ & $(1.075)$ & $(0.990)$ & $(0.875)$ \\
\hline Observations & 12,579 & 12,570 & 12,570 & 12,564 \\
\hline R-squared & & 0.14 & 0.17 & 0.20 \\
\hline Adj. R-squared & & 0.136 & 0.168 & 0.198 \\
\hline
\end{tabular}

Notes: Robust clusterd standard errors (at neighborhood level) in parentheses

${ }^{* * *} p<0.01,{ }^{* *} p<0.05,{ }^{*} p<0.1$ 
Table 4.7: School choice effects, augmented with school size and quality, G31

\begin{tabular}{|c|c|c|c|c|}
\hline G31 & (1) & $(2)$ & (3) & (4) \\
\hline VARIABLES & CITO & CITO & CITO & CITO \\
\hline \multirow[t]{2}{*}{ In(\# of schools within $1 \mathrm{~km}$ ) } & $0.45^{\star *}$ & $0.43^{*}$ & $0.49^{* *}$ & $0.48^{* *}$ \\
\hline & $(0.229)$ & $(0.233)$ & $(0.219)$ & $(0.216)$ \\
\hline \multirow[t]{2}{*}{ male (yes=1) } & $1.13^{* * *}$ & $1.14^{\star \star *}$ & $1.13^{* * *}$ & $1.13^{* * *}$ \\
\hline & $(0.177)$ & $(0.180)$ & $(0.182)$ & $(0.182)$ \\
\hline \multirow[t]{2}{*}{ relative age (in years) } & $-3.28^{* * *}$ & $-3.29^{* \star *}$ & $-3.24^{* * *}$ & $-3.24^{* * *}$ \\
\hline & $(0.124)$ & $(0.124)$ & $(0.122)$ & $(0.122)$ \\
\hline \multirow[t]{2}{*}{ non-western immigrant background (yes=1) } & $-1.77^{\star \star \star}$ & $-1.76^{* \star *}$ & $-1.73^{* * *}$ & $-1.73^{\star \star *}$ \\
\hline & $(0.356)$ & $(0.362)$ & $(0.367)$ & $(0.367)$ \\
\hline \multirow[t]{2}{*}{ 2nd generation non-western background (yes=1) } & -0.16 & -0.23 & -0.20 & -0.20 \\
\hline & $(0.301)$ & $(0.303)$ & $(0.303)$ & $(0.303)$ \\
\hline \multirow[t]{2}{*}{ student's weighted funding } & $-2.23^{\star * *}$ & $-2.20^{* * *}$ & $-2.29^{\star * *}$ & $-2.29^{\star \star *}$ \\
\hline & $(0.424)$ & $(0.425)$ & $(0.417)$ & $(0.418)$ \\
\hline \multirow[t]{2}{*}{ single-parent household } & $-2.41^{* * *}$ & $-2.47^{* * *}$ & $-2.59^{\star * *}$ & $-2.59^{\star \star *}$ \\
\hline & $(0.424)$ & $(0.425)$ & $(0.420)$ & $(0.420)$ \\
\hline \multirow[t]{2}{*}{ proportion non-western immigrants at school } & $-7.34^{* * *}$ & $-7.19^{* * *}$ & $-5.92^{\star * *}$ & $-5.88^{\star \star *}$ \\
\hline & $(0.790)$ & $(0.806)$ & $(0.820)$ & $(0.829)$ \\
\hline \multirow[t]{2}{*}{ ESCS-index of school intake } & -0.18 & -0.22 & -0.31 & -0.34 \\
\hline & $(0.259)$ & $(0.272)$ & $(0.267)$ & $(0.269)$ \\
\hline \multirow[t]{2}{*}{ neighborhood ESCS index } & $0.85^{* * *}$ & $0.83^{* * *}$ & $0.79^{* * *}$ & $0.79^{\star * *}$ \\
\hline & $(0.154)$ & $(0.156)$ & $(0.147)$ & $(0.147)$ \\
\hline \multirow[t]{2}{*}{ neighborhood urbanicity index } & $0.54^{* *}$ & $0.52^{* *}$ & 0.27 & 0.27 \\
\hline & $(0.209)$ & $(0.212)$ & $(0.211)$ & $(0.212)$ \\
\hline \multirow[t]{2}{*}{ school size } & & $0.52^{*}$ & & 0.18 \\
\hline & & $(0.313)$ & & $(0.328)$ \\
\hline \multirow[t]{2}{*}{ school quality score } & & & $3.39^{* * *}$ & $3.37^{* * *}$ \\
\hline & & & $(0.281)$ & $(0.278)$ \\
\hline individual covariates & yes & yes & yes & yes \\
\hline school-level covariates & yes & yes & yes & yes \\
\hline neighborhood covariates & yes & yes & yes & yes \\
\hline \multirow[t]{2}{*}{ Constant } & $534.23^{* * *}$ & $531.22^{* * *}$ & $531.35^{* \star *}$ & $530.31^{* * *}$ \\
\hline & $(0.733)$ & $(1.902)$ & $(0.611)$ & $(1.990)$ \\
\hline Observations & 12,888 & 12,700 & 12,432 & 12,432 \\
\hline R-squared & 0.20 & 0.20 & 0.21 & 0.21 \\
\hline Adj. R-squared & 0.199 & 0.199 & 0.212 & 0.212 \\
\hline
\end{tabular}

Notes: Robust clusterd standard errors (at neighborhood level) in parentheses ${ }^{* * *} p<0.01,{ }^{* *} p<0.05,{ }^{*} p<0.1$ 


\section{School type Effectiveness in the Netherlands ${ }^{*}$}

\subsection{Introduction}

As described in Chapter 2, one of the questions in the educational debate is whether private schools provide better education than public schools. Therefore, a solid body of empirical results on the causal effects of private- and public school attendance on student achievement is important for understanding how (compulsory) education should be funded and provided. Chapter 3 points to a rather complex picture for the Netherlands, in which the positive outcomes for private government-dependent schools seem to be more pronounced in primary education, hold only for academic outcomes, and appear to be confined to a period between the late 1960's and early 1990's.

This chapter re-addresses this issue of school type effectiveness, using both PISA 2006 and 2009 data and by adopting three different methodologies that have been used with this data. The results are complemented with results obtained from the BRON PO '08'09 data set, looking at both standardized achievement and "upward mobility". The overall objective of this chapter is to find consistent patterns in relative school type effectiveness in Dutch compulsory schooling.

Overall, the PISA results point to insignificant differences in achievement between school types, once background characteristics are taken into account. One exception is a positive association of private school attendance and mathematics achievement of around

\footnotetext{
"This chapter is partially based on the paper: Cornelisz, I. (2013), "Relative Private School Effectiveness in the Netherlands: A Reexamination of PISA 2006 and 2009 data." in Procedia Economics and Finance (5) (2013), pp. 192-201, DOI information: 10.1016/S2212-5671(13)00025-7
} 
0.10; found only for the PISA 2006 data. Whereas the results based on ordinary least squares and propensity score matching are relatively stable across subjects, subsets of data and for both waves of data, an instrumental variable approach yields vastly unstable and conflicting results.

Using the BRON PO '08-'09 data, the preferred weighted regression-adjusted propensity matching estimates, show no structural school type effects in terms of student achievement (as measured by cognitive skills). The only statistically significant effect from these models seems to imply that private schools are marginally more effective in educating students from non-Western background in the (largest) cities, relative to students from (Dutch) Western background. While generally significant in statistical terms, the effect seems too small to be relevant in terms of policy decision-making. Differential patterns in "upward mobility" after two years of secondary education, based on "structural switches", seem to imply, if anything, that public schools do slightly better in that dimension instead. Overall, the analyses in this chapter do not provide conclusive evidence for a consistent school type effect in Dutch compulsory education.

The next section (5.2) provides a brief description of both the background and scope of the analyses conducted in this chapter. This is followed by a general description of the main empirical approaches used (5.3). Section 5.4 describes the data and methodology. The results of the analyses are discussed in 5.5, with some concluding remarks presented in the final section (5.6).

\subsection{Background and scope}

The literature review in Chapter 2 discusses several mechanisms through which choice and private schooling could actually increase student achievement. First, competition across schools requires all schools to increase efficiency. Second, private entities are potentially more efficient in allocating resources in providing services (to particular groups) than the government. Third, a more efficient matching and sorting of students across different schools and school types in a system of educational choice. Fourth, parental involvement, considered to be important for achievement, could be improved through choice and/or be different across school types. This chapter will focus on one of them, which is that private schools could be found to be more efficient in delivering educational services. 
A number of studies (predominantly within the US) have contributed to this debate on the relative effectiveness of private- and public schooling. Despite the prevalence of publicly funded private schooling, European results are relatively scarce. The evolution of more elaborate (international) data sets is likely to contribute to this literature. The PISA data set is particularly important in this respect. ${ }^{63}$ Ever since the first cycle in 2000, the PISA data set has been used for cross-national comparisons to better understand the determinants underlying student achievement. PISA data are increasingly being utilized for providing estimates on school (type) effectiveness. ${ }^{64}$

Related to this is the literature on so-called public-private partnerships (PPPs) in education. A recent World Bank report defines the concept of public-private partnerships in education as a system that recognizes the existence of alternative options for providing education services besides public finance and public delivery (Patrinos et al., 2009). While different systems of PPPs are conceivable, the report examines PPPs in which government guides policy and provides funding with the private sector involved in delivering the actual education services. The Dutch education context is one that fits their definition of PPPs. In particular, the Netherlands are mentioned as exemplary of a country in which such a sharp distinction between the role of the public sector as education financier and that of the private sector as education provider is in place.

In terms of the available empirical evidence on PPPs, Woessmann (2006) finds that systems of PPPs that combine private operation with public funding do best among all possible operation-funding combinations, and that the advantage of private operation is particularly strong in countries with large shares of public funding. While it is acknowledged that more rigorous evidence is needed, the World Bank evaluation on PPPs concludes that, in general, private management of public schools tends to be more efficient and yields higher test scores than public institutions, when students reach the end of basic education (Patrinos et al., 2009). Distinguishing between public and private provision of education, a recent OECD evaluation of achievement argues that, after accounting for the socio-

\footnotetext{
${ }^{63}$ The Programme for International Student Assessment (PISA) takes place every three years and the survey has been designed to collect information about 15-year-old students in participating countries. Every three years, it assesses how far students near the end of compulsory education have acquired some of the knowledge and skills essential for full participation in society (OECD, 2006)

${ }^{64}$ For an example, see Vandenberghe and Robin (2004). Also, the OECD has produced an adapted version of the survey, to be used for the analysis of individual schools, known as "The PISA-Based Test for Schools". The first international pilot of this test was completed in March 2013 (see: http://www.oecd.org/pisa/pisabasedtestforschools/).
} 
economic and demographic profiles of students and schools, students in OECD countries who attend private schools show a level of performance that is similar to that of students enrolled in public schools (Hansson and Charbonnier, 2010).

\subsection{Empirical research on identifying private school type effectiveness}

In the language of Rubin's Causal Model (see: Holland, 1986), each student has two potential outcomes: (1) his or her achievement score under the treatment condition (i.e. private school attendance) and (2) his or her achievement score under the control condition (i.e. public school attendance). Unfortunately, for each student, only one outcome is observed. It is thus not straightforward to empirically assess the effect of private school attendance on schooling outcomes. The main problem is that of non-random selection of students into private- and public schools. This makes it crucial to extract selection effects from school type effects. Studies that compare the schooling outcomes of private and public schools use several approaches to overcome this issue. Given the absence of randomized controlled trials (e.g. lotteries or experiments), researchers generally look for a source of variation in private school attendance that is exogenous to potential schooling outcomes.

In dealing with this problem of school choice endogeneity, research has mostly relied on three types of models to address the issue of selection bias: (1) covariate adjustment (regression) models, (2) instrumental variables models and (3) (propensity score) matching estimators. The validity of the covariate adjustment approach depends on whether it is possible to eliminate selection bias by directly controlling for observable covariates (Murnane and Willett, 2010). Coleman et al. (1982) provide one of the earliest estimates of private Catholic school attendance. As described in more detail in Chapter 2, their, and other, results based on covariate adjustment have often been challenged on the grounds that comparability of students upon entry into the school cannot be ensured.

The validity of any instrumental variable approach is based on whether or not the instrument is successful in carving out exogenous variation in treatment (Murnane and Willett, 2010). Altonji et al. (2005) evaluate the credibility of religious affiliation and geographical proximity as instruments for identifying the effect of Catholic school attendance on schooling outcomes. They conclude that their results are sufficient to rule out religious affiliation as a useful instrument. 
The validity of Propensity Score Matching (PSM) hinges on the ability to match treatment and control groups in such a way that differences between the two are due to treatment only and free from selection bias (Murnane and Willett, 2010). The main idea behind the PSM technique is that it approximates a quasi-experimental design with observational data by comparing individuals in a treatment group (e.g. students in private schools) to those in a control group (e.g. students in public schools), in which both groups are similar in the probability of receiving treatment based on observable characteristics. In their PSM approach, Dronkers and Avram (2010) acknowledge the limitations of this design. Two important assumptions need to be met to effectively deal with selection bias. First, all observable variables influencing both the treatment (private school attendance) and the outcome (student achievement) must be included in the propensity score model. This is necessary to assure the necessary assumption of conditional independence. Second, all (unobserved) selection processes need to be captured by the observed variables used to predict the propensity to treatment.

The above assumptions arguably explain why mixed results are found in terms of the ability of PSM approaches to replicate results from random-assignment experiments (Murnane and Willett, 2010). Morgan (2001) also highlights these weaknesses of PSM estimates and suggests using them in addition to estimates based on other designs. Dronkers and Avram (2010) agree with this and also point to the issue of no considerable overlap in the propensities of those in the treatment- and control group. In this case, the differences in achievement will not reflect the average treatment effect of attending a private school for the full sample. Instead, it will only apply to those students who actually have the possibility to attend a private school. Therefore, PSM results should ideally be complemented with estimates based on alternative designs.

Summarizing the above, the evidence from different empirical methods is rather inconclusive about the effect of private school attendance on student learning (e.g. see: McEwan, 2000). The covariate adjustment approaches suffer from omitted variable bias; the instrumental variable approaches require a non-problematic instrument, which is hard to find. PSM models share challenges similar to those of covariate adjustment approaches. As such, comparing results across different approaches seems to be a sensible strategy.

Private school achievement is not uniform across educational systems (see e.g.: Rutkowski and Rutkowski, 2009). Evidence found in other countries, or through cross- 
national comparisons, may therefore not apply to the Netherlands. As described more elaborately in Chapter 3, results for private school achievement in the Netherlands can be summarized as that there seem to be positive effects of Catholic and Protestant private schools on academic achievement, as reported in terms of dropout rates, test scores, degrees and attainment. The positive outcomes seem to be more pronounced in primary education, to hold only for academic outcomes, and appear to be largely confined to a period between the late 1960's and early 1990's, although more recent analyses seem to reiterate the relative efficiency of private (Catholic) schools (see: Van Laarhoven et al., 1990; Dronkers, 2004; Levin, 2004; Patrinos, 2011).

\subsection{Data and methodology}

This chapter readdresses the achievement across school types in Dutch compulsory education using two different data sources and several non-experimental methodologies. First, the two data sets are described in more detail (5.4.1), followed by the empirical approaches that will be applied to each of them (5.4.2).

\subsubsection{Data}

PISA 2006-2009

The first part of the analyses is based on the PISA 2006 and 2009 surveys organized by the OECD under the OECD Program for International Student Assessment (PISA). In PISA 2006 and 2009, students' skills were assessed in language, mathematics and science. For PISA 2006 and 2009, while all subjects were assessed, the main emphasis was on science and reading respectively. ${ }^{65} \mathrm{~A}$ representative sample of 15 -year old students is selected through a two-stage sampling design. Schools are first selected and, within each selected school, classes or students are then randomly sampled. For the Netherlands, 186 schools participated in the 2009 survey, from different secondary education modes. ${ }^{66}$ The PISA data set is cross-sectional and provides no information about the length of the stay of the pupils at the current school or about the characteristics of former schools of the students. There is

\footnotetext{
${ }^{65}$ This focus changes with every cycle (i.e. PISA 2000 focused on reading and PISA 2003 on mathematical skills). A total of about seven hours of test items is covered, with different students taking different combinations of test items.

${ }^{66}$ In particular, the data set consists of 95 vmbo-schools (i.e. offering a mixture of vocational and theoretical education), 86 havo/vwo-schools (i.e. preparing students for higher professional/university education) and 5 "praktijkscholen" (i.e. offering mainly vocational education) (CITO, 2010).
} 
also no indicator for the entry-level performance at the current school. This might lead to a misspecification of the effect of the characteristics of the current school. This is particularly true, given that all 15-year-old pupils in the Netherlands have moved recently to another school (i.e. from primary- to secondary education).

\section{BRON PO '08-'09}

The above challenges are why the results are complemented with analyses based on the Dutch administrative data set "Basisregister Onderwijsnummer" or BRON, with data for students that were in the last year of primary school in the year 2008-2009. The studentlevel outcome variable used in this respect is the CITO-test, a standardized test score. The test consists of over 200 multiple-choice questions, dealing with language, arithmetic/mathematics, and information processing skills. Students have an incentive to perform well since these test scores are one of the acceptance criteria into different (academic) tracks of secondary education. ${ }^{67}$

\subsubsection{Methodology}

\section{PISA 2006-2009}

The first empirical approach conducted is based on ordinary least squares (OLS). An attempt is being made to isolate a potential private school effect; thereby controlling for observed student- and school-level background characteristics that are considered to be nonmanipulable by the school. The objective is that, by controlling for observed selection bias, any unobserved selection is adequately dealt with as well. The OLS model to predict student achievement is given by:

$$
Y_{i j}=\beta_{0}+\sum_{k=1}^{m} \beta_{k} X_{k i j}+\sum_{k=1}^{s} \delta_{k} S_{k j}+\gamma \text { Private }_{i j}+\varepsilon_{i j}
$$

where $Y_{i j}$ is the achievement score for student $i$ in school $j, X_{k i j}$ a set of $m$ student-level background characteristics and $S_{t j}$ a set of $s$ school-level background characteristics, $v$ the treatment effect of attending a private school and an error term $\varepsilon_{i j}$.

Additional results are obtained through an instrumental variable approach, which bases the effect of private schooling on exogenous variation in treatment generated by the

\footnotetext{
${ }^{67}$ More elaborate descriptions of the variables used from both data sources are presented in Appendix A.
} 
instrument. In particular, the identification strategy proposed Patrinos (2011) is replicated. The first stage in the 2SLS is given by:

$$
D_{i j}=\alpha_{0}+\sum_{k=1}^{m} \alpha_{k} X_{k i j}+\sum_{k=1}^{s} \phi_{k} S_{k j}+\delta I V_{i j}+v_{i j}
$$

where $D_{i j}$ is private school attendance, $I V_{i}$ is the student's school principal response to whether parents' endorsement of the instructional or religious philosophy of the school is taken into consideration at the time of admission ( $D_{i j}=1$ if "yes" and 0 otherwise). As before, $X_{k i j}$ is a set of $m$ student-level background characteristics and $S_{t j}$ a set of $s$ school-level background characteristics. The predicted values for private school attendance are then used in the second stage:

$$
Y_{i j}=\beta_{0}+\sum_{k=1}^{m} \beta_{k} X_{k i j}+\sum_{k=1}^{s} \delta_{k} S_{k j}+\gamma \hat{\mathrm{D}}_{i j}+\varepsilon_{i j}
$$

where $\gamma$ is the 2SLS estimate for the effect of private school attendance on student achievement. The same variables used in Patrinos (2011) are included in the model. ${ }^{68}$

Finally, in an attempt to strictly control for observed selection bias, a propensity score matching (PSM) identification strategy is conducted. The treatment effect for an individual student of attending a private school is given by:

$$
\tau_{i}=Y_{i}(1)-Y_{i}(0)
$$

which can be described by an average treatment on the treated (ATT) effect as:

$$
\tau_{A T T}=E(\tau \mid D=1)=E[Y(1) \mid D=1]-E[Y(0) \mid D=1]
$$

Obviously, the counterfactual $Y(0)$ is never observed. However, if matching students on the propensity score is successful, the unconfoundedness assumption holds:

$$
Y_{i}(1), Y_{i}(0) \perp D_{i} \mid X_{i}
$$

The unconfoundedness assumption implies that potential outcomes are independent of treatment status, conditional on certain background characteristics. If this holds, the propensity score can be expressed as an identity:

$$
P_{i}(D) \equiv \operatorname{Pr}\left\{D=1 \mid X_{i}\right\}=E_{i}\left\{D_{i} \mid X_{i}\right\}
$$

\footnotetext{
${ }^{68}$ The only difference is that standard errors will be presented in such that they are clustered at the school level, instead of at the individual level, as is the case in Patrinos (2011), as the instrument is also measured at the school level. Furthermore, clustering at the school level adheres to the two-stage sampling design of the PISA data, acknowledging potential interdependence between students within the same school, while leaving the point estimates unaffected.
} 
Equation (5.7) implies that in this case, public school student achievement results can be used as estimate for the unobserved counterfactual. The PSM treatment estimate is then:

$$
\tau_{A T T}^{P S M}=E_{P(X \mid D=1)}\{E[Y(1) \mid D=1, P(X)]-E[Y(0) \mid D=0, P(X)]\}
$$

In the first stage of this estimation strategy, the propensity score of attending a private school is predicted for all students along the lines of the matching algorithm suggested by Dehejia and Wahba (2002). This is done through estimating a logistic regression model. A nearest-neighbor strategy, with replacement, is then used to estimate the treatment effect of attending a private school. As a regression can potentially improve the precision of the estimates, a weighted regression using the treatment and matched comparison units is estimated, with the comparison units weighted by the number of times they are matched to a treated unit. This model can then be presented as:

$$
Y_{i j}=\beta_{0}+\sum_{k=1}^{m} \beta_{k} X_{k i j}+\sum_{k=1}^{s} \delta_{k} S_{k j}+\gamma \text { Treated }_{i j}+\varepsilon_{i j}
$$

where $Y_{i j}$ is the achievement score for student $i$ in school $j, X_{k i j}$ a set of $m$ student-level background characteristics and $S_{t j}$ a set of $s$ school-level background characteristics, $\gamma$ the treatment effect of attending a private school for the subset of treated students after the matching process has been performed, and an error term $\varepsilon_{i j}$.

\section{BRON PO '08-'09}

In an attempt to complement the results for secondary education above, school type analyses are also performed on the end-of-primary test scores available in the BRON data:

$$
Y_{i j k m}=\beta_{0}+\sum_{k=1}^{m} \beta_{k} X_{i j}+\sum_{k=1}^{s} \delta_{k} S_{k j}+\sum_{k=1}^{p} \varphi_{k} A_{k}+\gamma . \text { Private }_{i j k m}+\lambda_{m}+\varepsilon_{i j k m}
$$

where $Y_{i j k m}$ is the CITO-score for student $i$, attending school $j$, from neighborhood $k$, in municipality $m$. Sets of individual, school and neighborhood background characteristics are provided by $X_{i j k m}, S_{k j}$ and $A_{k}$ respectively. Municipality dummies $\lambda_{m}$ account for idiosyncratic differences in achievement between cities, and an idiosyncratic error term is given by $\varepsilon_{i j k m}$.

In addition, all schools in the Netherlands offer primary or secondary education only. This means that all students must switch schools at the end of the last academic year in primary education to attend secondary education. This exogenous change allows to compare the educational trajectory in secondary school of students who moved from a 
public to a private school to the secondary school performance of those who stayed in the public system; referred to as the analysis of "structural switches" (cf. Lara, Mizala and Repetto, 2011). In particular, the effects of private school attendance on the likelihood of progressing to a higher track in secondary education is estimated:

$Y_{i j k m}=\beta_{0}+\sum_{k=1}^{m} \beta_{k} X_{i j}+\sum_{k=1}^{s} \delta_{k} S_{k j}+\sum_{k=1}^{p} \varphi_{k} A_{k}+\phi \cdot C i t o_{i j k m}+\gamma \cdot$ Private $_{i j k m}+\lambda_{m}+\varepsilon_{i j k m}$

where $Y_{i j k m}$ is now an outcome indicator reflecting whether a student has successfully progressed to a higher track (i.e. upward mobility) at the beginning of the third year of secondary education, and Cito ${ }_{i j k m}$, the student's end-of-primary test score, is added as an additional control variable to account for endogenous selection processes between primary and secondary education. Both (5.10) and (5.11) are also estimated through a propensity score weighted regression model, similar to the approach in (5.9), in an attempt to further restrict the analysis to otherwise comparable students.

\subsection{Results}

\section{PISA 2006-2009}

The raw achievement differences between public- and private school students for PISA 2006 and 2009 are displayed in Tables 5.1a and 5.1b respectively. For PISA 2006, private school students perform relatively better for mathematics $(0.09 \sigma)$, and slightly above public school students for science and reading. However, in PISA 2009, private school students appear to perform worse on all three subjects; ranging from approximately 6 points lower (approximately $0.06 \sigma$ ) in science to almost 11 points (close to $0.13 \sigma$ ) in reading.

It would be naive to attribute such differences in achievement to private school attendance, since students across both school types are different in some observed characteristics. For example, from Tables 5.1a and 5.1b it becomes clear that private school students, on average, are relatively more often to be found in vocational tracks, in slightly lower level program types and in lower grades. Also, household characteristics, as measured by an index for economic, social and cultural status $(\mathrm{ESCS})^{69}$, are relatively disadvantageous

\footnotetext{
${ }^{69}$ The Programme for International Student Assessment (PISA) index of economic, social and cultural status (ESCS) was created on the basis of the following variables: the International Socio-Economic Index of Occupational Status (ISEI); the highest level of education of the student's parents, converted into years of schooling; the PISA index of family wealth; the PISA index of home educational resources; and the PISA index of possessions related to "classical" culture in the family home. Source: http://stats.oecd.org
} 
for private school students in PISA 2006 and 2009. On the other hand, home educational resources tend to be relatively better for these students. In line with existing literature for the Netherlands, private school students are somewhat less likely to come from an immigrant background.

Table 5.1a: Summary statistics PISA 2006

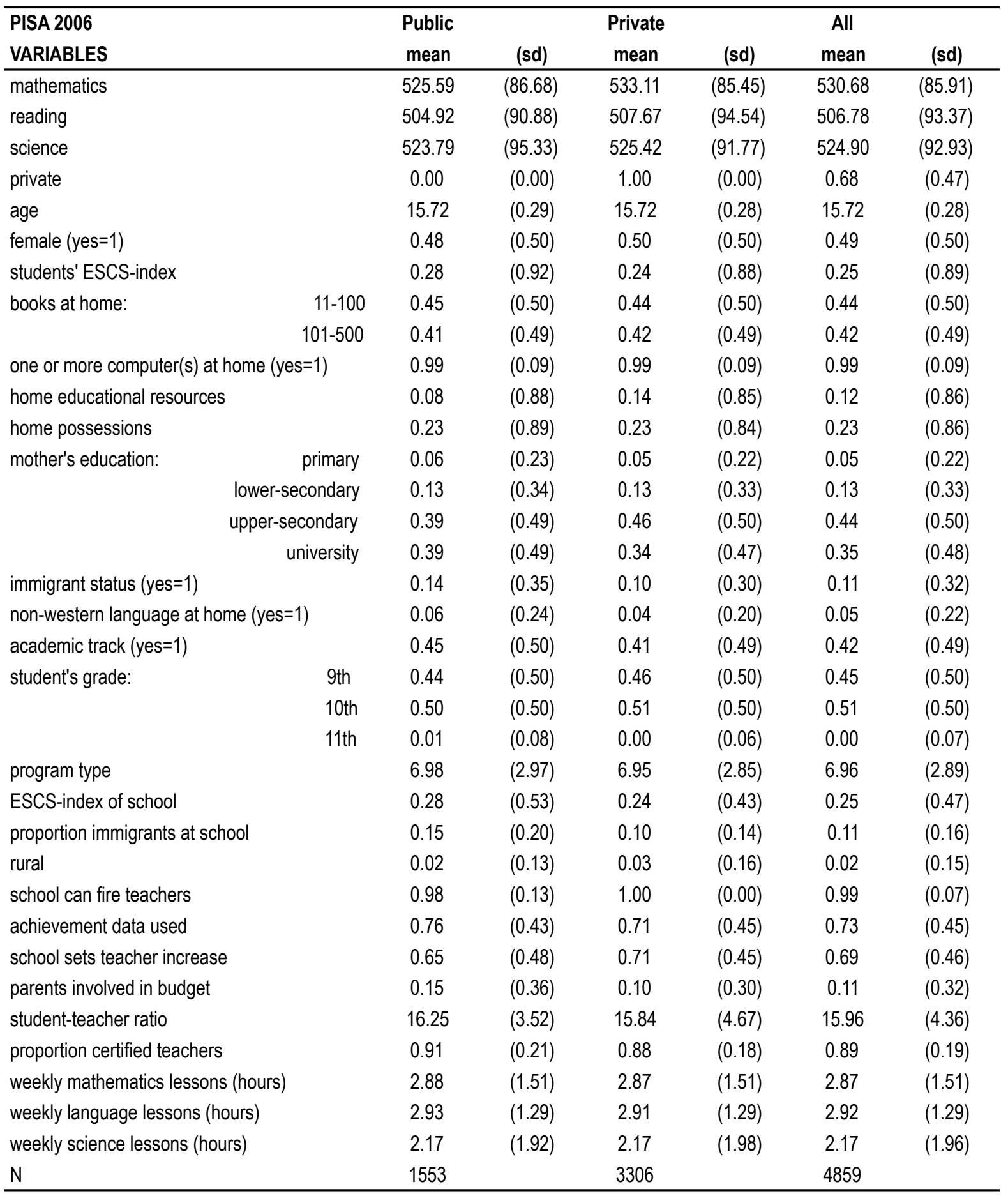


Table 5.1b: Summary statistics PISA 2009

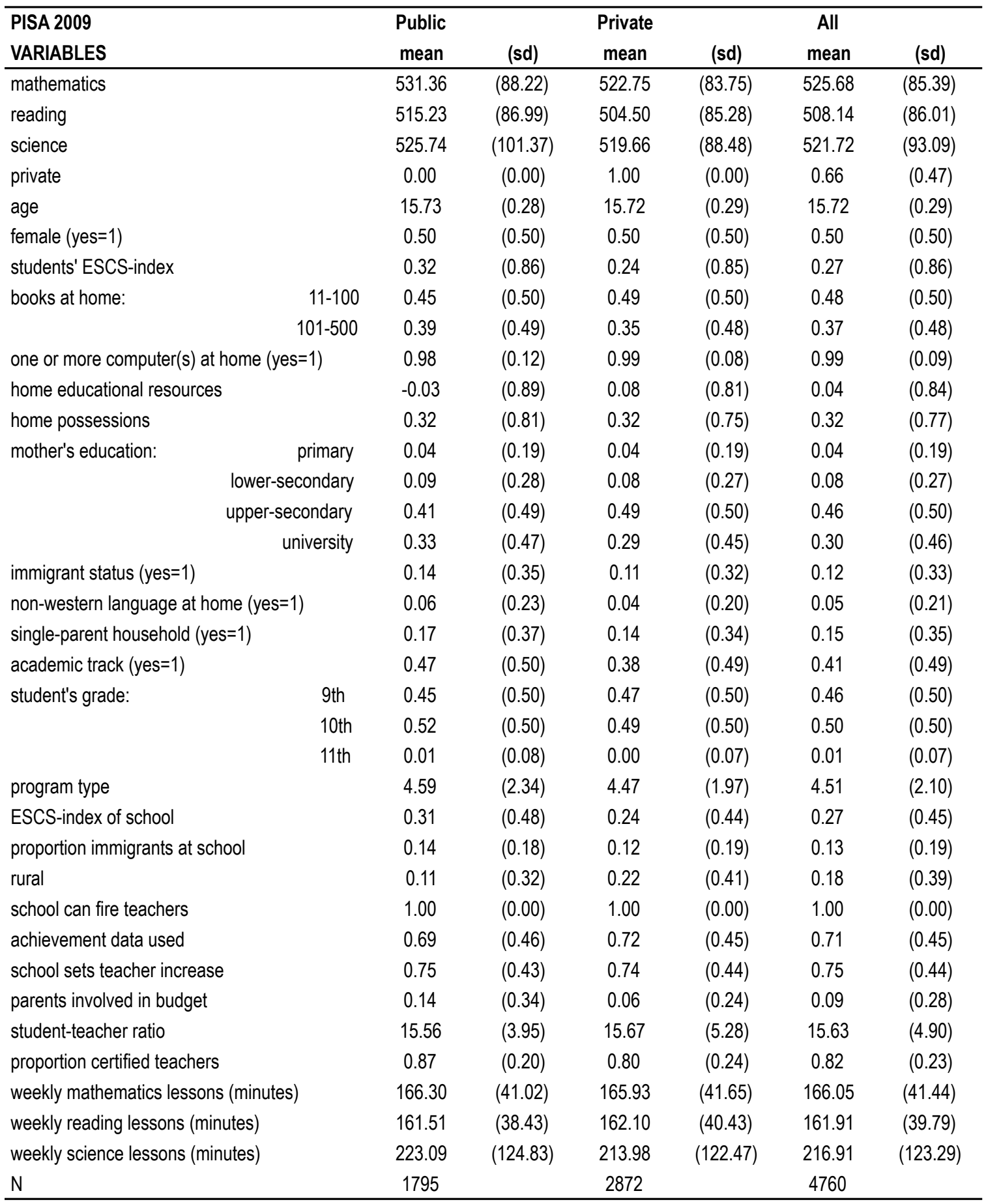

The results of the first attempt in estimating the effect of private school attendance, by controlling for observed student- and school level characteristics are displayed in Tables $5.2 \mathrm{a}$ and $5.2 \mathrm{~b}$. Given the two-stage sampling design of the data, selected students attending the same school should not be considered as independent observations, as would be the case in a simple random sample. Students within a school are usually more similar to each 
other than students attending distinct educational institutions. To account for this, standard errors are clustered at the appropriate (school) level of randomization. ${ }^{70}$ The results presented are all for different versions of the specification in equation (5.1).

Table 5.2a: OLS results private school attendance, PISA 2006

\begin{tabular}{|c|c|c|c|c|c|c|c|c|c|}
\hline $\begin{array}{l}\text { PISA } 2006 \\
\text { VARIABLES }\end{array}$ & $\begin{array}{c}\text { (1) } \\
\text { Mathematics }\end{array}$ & $\begin{array}{c}\text { (2) } \\
\text { Reading }\end{array}$ & $\begin{array}{c}(3) \\
\text { Science }\end{array}$ & $\begin{array}{c}\text { (4) } \\
\text { Mathematics }\end{array}$ & $\begin{array}{c}(5) \\
\text { Reading }\end{array}$ & $\begin{array}{c}(6) \\
\text { Science }\end{array}$ & $\begin{array}{c}\text { (7) } \\
\text { Mathematics }\end{array}$ & $\begin{array}{c}\text { (8) } \\
\text { Reading }\end{array}$ & $\begin{array}{c}(9) \\
\text { Science }\end{array}$ \\
\hline Constant & $\begin{array}{l}172.76^{\star * *} \\
(57.435)\end{array}$ & $\begin{array}{l}140.16^{* *} \\
(58.085)\end{array}$ & $\begin{array}{l}125.00 * * \\
(62.234)\end{array}$ & $\begin{array}{l}138.66^{* * *} \\
(46.687)\end{array}$ & $\begin{array}{l}103.16^{* *} \\
(48.131)\end{array}$ & $\begin{array}{c}88.28^{*} \\
(50.591)\end{array}$ & $\begin{array}{c}59.74 \\
(53.086)\end{array}$ & $\begin{array}{c}59.59 \\
(50.799)\end{array}$ & $\begin{array}{c}-42.94 \\
(50.374)\end{array}$ \\
\hline
\end{tabular}

Notes: Robust clustered standard errors (at school level) in parentheses ${ }^{* *} p<0.01,{ }^{* *} p<0.05,{ }^{*} p<0.1$

Table 5.2b: OLS results private school attendance, PISA 2009

\begin{tabular}{|c|c|c|c|c|c|c|c|c|c|}
\hline $\begin{array}{l}\text { PISA } 2009 \\
\text { VARIABLES }\end{array}$ & $\begin{array}{c}\text { (1) } \\
\text { Mathematics }\end{array}$ & $\begin{array}{c}(2) \\
\text { Reading }\end{array}$ & $\begin{array}{c}(3) \\
\text { Science }\end{array}$ & $\begin{array}{c}(4) \\
\text { Mathematics }\end{array}$ & $\begin{array}{c}\text { (5) } \\
\text { Reading }\end{array}$ & $\begin{array}{c}-6 \\
\text { Science }\end{array}$ & $\begin{array}{c}(7) \\
\text { Mathematics }\end{array}$ & $\begin{array}{c}\text { (8) } \\
\text { Reading }\end{array}$ & $\begin{array}{c}(9) \\
\text { Science }\end{array}$ \\
\hline Constant & $\begin{array}{l}439.50^{* * *} \\
(64.940)\end{array}$ & $\begin{array}{c}309.32^{* * *} \\
(69.046)\end{array}$ & $\begin{array}{l}411.71^{* * *} \\
(70.944)\end{array}$ & $\begin{array}{l}327.70^{* * *} \\
(48.989)\end{array}$ & $\begin{array}{l}194.19^{* * *} \\
(55.577)\end{array}$ & $\begin{array}{l}295.15^{\star * *} \\
(56.726)\end{array}$ & $\begin{array}{l}332.32^{\star * \star} \\
(56.238)\end{array}$ & $\begin{array}{l}238.42^{\star * *} \\
(64.700)\end{array}$ & $\begin{array}{c}341.22^{* * *} \\
(75.076)\end{array}$ \\
\hline
\end{tabular}

Notes: Robust clustered standard errors (at school level) in parentheses ${ }^{* * *} p<0.01,{ }^{* *} p<0.05,{ }^{*} p<0.1$

\footnotetext{
${ }^{70}$ Students within a school are offered the same school resources, may have the same teachers and, are taught a common implemented curriculum, and so on. Furthermore, within sub-national entities and within a city, people tend to live in areas according to their financial resources. As children are more likely to attend schools close to their house, students attending the same school are more likely to come from similar social and economic backgrounds (OECD, 2006).
} 
Models 1-3 give the estimated effects on student achievement for the three different subjects (i.e. mathematics, science and reading), while controlling for a set of individual background characteristics. The results for this specification largely resemble the raw achievement differences referred to in Tables 5.1a and 5.1b. While none are statistically significant, moderate imprecise negative effects $(-0.15 \sigma)$ are found for private school attendance in the PISA 2009 data set (Table 5.2b). ${ }^{71}$

Models 4-6 present the results for when school-level background controls are added to the specification. Schools in the PISA data offer either vocational tracks or academic, which is strongly related to performance. ${ }^{72}$ In addition, they can differ by the average intake of students' ESCS-index, the proportion of students from an immigrant background they accommodate and whether or not they are located in a rural area. This specification yields more precise estimates for private school attendance across all subjects and both waves of data with a statistically significant, and positive, result found only for mathematics in PISA 2006. For the other subjects in PISA 2006, and for all in PISA 2009, private school students' achievement is statistically indistinguishable from that of public school students.

Models 7-9 provide an attempt in taking into account some school-level mechanisms that could relate to student achievement and might be distributed differently across school types, such as whether or not achievement data is used to evaluate teachers, whether parents are involved in the budgeting process, what the average student-teacher ratio is, what proportion of teachers is certified and the weekly hours spent on the subject of interest. This comes at the expense of dealing with much more missing data for those measures. The one additional insight from this is that the effect of private school attendance in PISA 2006 is now statistically significant for both mathematics and reading, with results for PISA 2009 remaining statistically indistinguishable between school types across all subjects. Another limitation of this OLS approach, as discussed, is the inability to control for unobserved selection effects; or omitted variable bias.

\footnotetext{
${ }^{71}$ The PISA data also has student-level information on the exact track and grade he or she is in at the time of the survey. Given that these indicators can be partially the result of the treatment (i.e. private school attendance), they are not included as background characteristics, to avoid controlling for post-treatment variables.

${ }^{72}$ A narrow definition for schools is used in the PISA data in that a school actually offering both types of tracks (i.e. vocational and academic) will instead appear in the data as two independent schools. The academic tracks (HAVO/VWO) together are referred to as one school, just as the vocational tracks (VMBO) in that school are identified as another school (De Knecht-van-Eekelen, Gille and Van Rijn, 2007).
} 
Ideally, an instrumental variable (IV) approach is successful in overcoming these limitations of the ordinary least square results. In order to have exogenous variation in treatment (i.e. private school attendance), the approach in Patrinos (2011) suggests that the school principal's answer, to whether parental endorsement of the school's religion or philosophy is taken into consideration in the student's admission process, is to be used as an instrument to predict private school attendance. Table 5.3 shows the instrument is a stronger predictor for private school attendance in the 2006, relative to 2009.

Table 5.3: First-stage results IV approach, PISA 2006 and 2009

\begin{tabular}{lcc}
\hline & PISA 2006 & PISA 2009 \\
\hline VARIABLES & private & private \\
\hline instrument & $0.35^{\star * *}$ & $0.17^{* *}$ \\
& $(0.064)$ & $(0.083)$ \\
individual covariates & & \\
school controls & yes & yes \\
school mechanisms & yes & yes \\
& yes & yes \\
Constant & & \\
& -0.05 & 0.79 \\
Observations & $(0.532)$ & $(0.560)$ \\
R-squared & & \\
Adj. R-squared & 3,838 & 3,086 \\
\hline Notes: Robust clustered standard errors (at school level) in parentheses, ${ }^{* * *} p<0.01,{ }^{* *} p<0.05,{ }^{*} p<0.1$
\end{tabular}

The results of applying the instrumental variable approach to PISA 2006 and 2009, based on the specification in equation (5.3), are presented in Tables 5.4a and 5.4b respectively. The point estimates for PISA 2006 are similar to those found in Patrinos (2011), suggesting that replication of the approach succeeded. Clustering the standard errors at the school level has the effect of making the estimates less precise and leaving only the results for reading and science statistically significant at the $5 \%$ and $10 \%$ level respectively. When the same methodology is applied to PISA 2009, the results for private school attendance on performance is reversed for all three subjects (Table 5.4b). For the more recent wave of data, this approach suggests moderate, though relatively imprecise, negative effects for 
private school attendance, instead. ${ }^{73}$ The relative impreciseness of the PISA 2009 results is arguably the result of the instrument being a stronger predictor for private school attendance in the 2006, relative to 2009. Both the impreciseness of the results and the instability across both waves of data make it difficult to draw general conclusions regarding the effect of private school attendance based on this approach.

Because the IV approach generates conflicting and unstable, an alternative approach (i.e. PSM) is proposed as the preferred method instead, using both PISA data sets. In the first stage of this estimation strategy, the propensity score of attending a private school is predicted for all students, using a set of individual background covariates and along the lines of the matching algorithm suggested by Deheja and Wahba (2002). ${ }^{74}$

Table 5.4a: 2SLS IV results private school attendance, PISA 2006

\begin{tabular}{lccc}
\hline PISA 2006 & $(\mathbf{1})$ & $(\mathbf{2})$ & $(\mathbf{3})$ \\
VARIABLES & Mathematics & Reading & Science \\
\hline private & 18.96 & $32.74^{* *}$ & $20.91^{*}$ \\
& $(11.528)$ & $(13.073)$ & $(10.726)$ \\
& & & \\
individual covariates & $y e s$ & yes & yes \\
school controls & $y e s$ & yes & yes \\
school mechanisms & yes & yes & yes \\
& & & \\
Constant & $645.17^{* * *}$ & $510.69^{* * *}$ & $429.81^{* * *}$ \\
& $(62.006)$ & $(65.967)$ & $(63.464)$ \\
Observations & & & \\
R-squared & 3,838 & 3,838 & 3,838 \\
Adj. R-squared & 0.67 & 0.58 & 0.63 \\
\hline Notes: Robust clustered standard errors (at school level) in parentheses, ${ }^{* * *} p<0.01,{ }^{* *} p<0.05,{ }^{*} p<0.1$
\end{tabular}

\footnotetext{
${ }^{73}$ Applying standard errors at the individual level, as in Patrinos (2011), would turn all results statistically significant at the $1 \%$ level. For reasons mentioned above, the results presented here are all clustered at the school level.

${ }^{74}$ The list of individual covariates used in this stage are age, gender, ESCS-index, books at home, home educational resources, mother's education, immigrant background, non-Western language used at home, academic track and rural.
} 
Table 5.4b: 2SLS IV results private school attendance, PISA 2009

\begin{tabular}{|c|c|c|c|}
\hline PISA 2009 & (1) & (2) & (3) \\
\hline VARIABLES & Mathematics & Reading & Science \\
\hline \multirow[t]{2}{*}{ private } & -28.02 & -23.23 & -43.90 \\
\hline & (28.655) & (32.996) & (36.987) \\
\hline individual covariates & yes & yes & yes \\
\hline school controls & yes & yes & yes \\
\hline school mechanisms & yes & yes & yes \\
\hline \multirow[t]{2}{*}{ Constant } & $875.45^{\star \star \star}$ & $588.18^{* * *}$ & $721.88^{* \star *}$ \\
\hline & $(73.842)$ & $(84.484)$ & $(88.055)$ \\
\hline Observations & 3,086 & 3,086 & 3,086 \\
\hline R-squared & 0.67 & 0.62 & 0.58 \\
\hline Adj. R-squared & 0.666 & 0.617 & 0.578 \\
\hline
\end{tabular}

Nearest-neighbor matching with replacement is used for matching private school students to their public counterparts. This matched sample is then used in a weighted regression framework; with comparison units weighted by the number of times they are matched to a treated unit, giving the model specification from equation (5.9). The results for private school attendance on achievement generated by this approach for PISA 2006 and 2009 are presented in Table 5.5a and 5.5b, respectively. In general, the results for 2006 in Table 5.5a imply that academic achievement for private school students is insignificantly different from their public school counterparts to which they have been matched, with the exception of Mathematics for which a positive effect is found (i.e. 0.120). For 2009, the results point to insignificant differences across all subjects (Table $5.5 \mathrm{~b}$ ). ${ }^{75}$

\footnotetext{
${ }^{75}$ Bootstrapping the standard errors, as the propensity scores they are based on are estimated, does not reveal large discrepancies that will alter these interpretations. Results of the bootstrapping procedure are available upon request.
} 
Table 5.5a: Weighted regression-adjusted PSM results, PISA 2006

\begin{tabular}{|c|c|c|c|}
\hline PISA 2006 & (1) & (2) & (3) \\
\hline VARIABLES & Mathematics & Reading & Science \\
\hline \multirow[t]{2}{*}{ private (treated=1) } & $10.26^{* *}$ & 5.94 & 4.08 \\
\hline & $(4.421)$ & $(5.387)$ & $(4.703)$ \\
\hline individual covariates & yes & yes & yes \\
\hline school covariates & yes & yes & yes \\
\hline \multirow[t]{2}{*}{ Constant } & $277.45^{\star * *}$ & $292.80^{* * *}$ & $253.44^{* * *}$ \\
\hline & $(56.024)$ & $(57.776)$ & $(62.960)$ \\
\hline Observations & 4,125 & 4,125 & 4,125 \\
\hline R-squared & 0.60 & 0.52 & 0.57 \\
\hline
\end{tabular}

Table 5.5b: Weighted regression-adjusted PSM results, PISA 2009

\begin{tabular}{|c|c|c|c|}
\hline PISA 2009 & (1) & (2) & (3) \\
\hline VARIABLES & Mathematics & Reading & Science \\
\hline \multirow[t]{2}{*}{ private (treated=1) } & 2.14 & 2.19 & 3.45 \\
\hline & $(4.229)$ & $(4.754)$ & $(5.175)$ \\
\hline individual covariates & yes & yes & yes \\
\hline school covariates & yes & yes & yes \\
\hline \multirow[t]{2}{*}{ Constant } & $277.45^{\star * *}$ & $292.80^{\star * *}$ & $253.44^{* * *}$ \\
\hline & $(56.024)$ & $(57.776)$ & $(62.960)$ \\
\hline Observations & 4,125 & 4,125 & 4,125 \\
\hline R-squared & 0.60 & 0.52 & 0.57 \\
\hline
\end{tabular}

Table 5.6 gives insight into whether the balance of the matched samples improved, relative to the unmatched samples. Importantly, matching students on propensity scores leads to a balanced set of students for important covariates such as, academic track, 
program type, ESCS-index, mother's education, immigrant background and non-Western language used at home. Improvements are also found for the school-level variables, which were not part of the matching procedure, although the average ESCS index at the schoollevel is still relatively low for private school students in the matched sample. ${ }^{76}$

Table 5.6: Balance before and after matching algorithm, PISA 2006 and 2009

\begin{tabular}{|c|c|c|c|c|c|c|c|c|c|c|c|}
\hline \multirow[b]{3}{*}{ Variable } & \multirow[b]{3}{*}{ Sample } & \multicolumn{5}{|c|}{ PISA 2006} & \multicolumn{5}{|c|}{ PISA 2009} \\
\hline & & \multicolumn{2}{|l|}{ Mean } & \multicolumn{3}{|c|}{ SD } & \multicolumn{2}{|l|}{ Mean } & \multicolumn{3}{|c|}{ SD } \\
\hline & & Treated & Control & $p>t$ & Treated & Control & Treated & Control & $p>t$ & Treated & Control \\
\hline \multirow[t]{2}{*}{ age } & Unmatched & 15.72 & 15.72 & 0.74 & 0.30 & 0.30 & 15.70 & 15.72 & 0.06 & 0.30 & 0.30 \\
\hline & Matched & 15.72 & 15.72 & 0.73 & 0.30 & 0.30 & 15.70 & 15.70 & 0.55 & 0.30 & 0.30 \\
\hline \multirow[t]{2}{*}{ female (yes=1) } & Unmatched & 0.49 & 0.48 & 0.39 & 0.50 & 0.50 & 0.51 & 0.51 & 0.91 & 0.50 & 0.50 \\
\hline & Matched & 0.49 & 0.50 & 0.66 & 0.50 & 0.50 & 0.51 & 0.49 & 0.24 & 0.50 & 0.50 \\
\hline \multirow[t]{2}{*}{ students' ESCS-index } & Unmatched & 0.28 & 0.38 & 0.00 & 0.90 & 0.90 & 0.31 & 0.39 & 0.00 & 0.80 & 0.80 \\
\hline & Matched & 0.28 & 0.29 & 0.96 & 0.90 & 0.80 & 0.31 & 0.32 & 0.49 & 0.80 & 0.80 \\
\hline \multirow[t]{2}{*}{ books at home } & Unmatched & 1.30 & 1.35 & 0.02 & 0.70 & 0.70 & 1.25 & 1.27 & 0.26 & 0.70 & 0.70 \\
\hline & Matched & 1.30 & 1.29 & 0.58 & 0.70 & 0.70 & 1.25 & 1.22 & 0.20 & 0.70 & 0.70 \\
\hline \multirow[t]{2}{*}{ one or more computer(s) at home (yes $=1$ ) } & Unmatched & 0.99 & 0.99 & 0.90 & 0.10 & 0.10 & 1.00 & 1.00 & 0.28 & 0.00 & 0.10 \\
\hline & Matched & 0.99 & 1.00 & 0.37 & 0.10 & 0.10 & 1.00 & 1.00 & 0.56 & 0.00 & 0.10 \\
\hline \multirow[t]{2}{*}{ home educational resources } & Unmatched & 0.18 & 0.15 & 0.33 & 0.80 & 0.80 & 0.13 & 0.04 & 0.00 & 0.80 & 0.80 \\
\hline & Matched & 0.18 & 0.16 & 0.40 & 0.80 & 0.80 & 0.13 & 0.14 & 0.64 & 0.80 & 0.80 \\
\hline \multirow[t]{2}{*}{ home possessions } & Unmatched & 0.28 & 0.32 & 0.11 & 0.80 & 0.90 & 0.36 & 0.37 & 0.50 & 0.70 & 0.80 \\
\hline & Matched & 0.28 & 0.26 & 0.56 & 0.80 & 0.80 & 0.36 & 0.38 & 0.32 & 0.70 & 0.80 \\
\hline \multirow[t]{2}{*}{ mother's education } & Unmatched & 4.19 & 4.29 & 0.08 & 1.60 & 1.70 & 4.12 & 4.22 & 0.01 & 1.30 & 1.30 \\
\hline & Matched & 4.19 & 4.21 & 0.75 & 1.60 & 1.70 & 4.12 & 4.15 & 0.43 & 1.30 & 1.30 \\
\hline \multirow[t]{2}{*}{ immigrant status (yes=1) } & Unmatched & 0.09 & 0.13 & 0.00 & 0.30 & 0.30 & 0.10 & 0.12 & 0.06 & 0.30 & 0.30 \\
\hline & Matched & 0.09 & 0.08 & 0.46 & 0.30 & 0.30 & 0.10 & 0.08 & 0.07 & 0.30 & 0.30 \\
\hline \multirow[t]{2}{*}{ non-western language at home (yes=1) } & Unmatched & 0.04 & 0.05 & 0.03 & 0.20 & 0.20 & 0.04 & 0.05 & 0.04 & 0.20 & 0.20 \\
\hline & Matched & 0.04 & 0.03 & 0.06 & 0.20 & 0.20 & 0.04 & 0.03 & 0.16 & 0.20 & 0.20 \\
\hline \multirow[t]{2}{*}{ academic track (yes=1) } & Unmatched & 0.44 & 0.51 & 0.00 & 0.50 & 0.50 & 0.48 & 0.51 & 0.06 & 0.50 & 0.50 \\
\hline & Matched & 0.44 & 0.45 & 0.59 & 0.50 & 0.50 & 0.48 & 0.49 & 0.80 & 0.50 & 0.50 \\
\hline \multirow[t]{2}{*}{ student's grade } & Unmatched & 9.50 & 9.50 & 0.83 & 0.60 & 0.60 & -0.52 & -0.46 & 0.00 & 0.60 & 0.60 \\
\hline & Matched & 9.50 & 9.48 & 0.12 & 0.60 & 0.60 & -0.52 & -0.48 & 0.02 & 0.60 & 0.60 \\
\hline \multirow[t]{2}{*}{ program type } & Unmatched & 7.22 & 7.47 & 0.01 & 2.70 & 2.80 & 4.86 & 4.89 & 0.63 & 1.90 & 2.10 \\
\hline & Matched & 7.22 & 7.13 & 0.19 & 2.70 & 2.80 & 4.86 & 4.81 & 0.39 & 1.90 & 2.10 \\
\hline \multirow[t]{2}{*}{ ESCS-index of school } & Unmatched & 0.28 & 0.37 & 0.00 & 0.40 & 0.50 & 0.30 & 0.38 & 0.00 & 0.40 & 0.40 \\
\hline & Matched & 0.28 & 0.32 & 0.00 & 0.40 & 0.50 & 0.30 & 0.37 & 0.00 & 0.40 & 0.40 \\
\hline \multirow[t]{2}{*}{ proportion immigrants at school } & Unmatched & 0.09 & 0.14 & 0.00 & 0.10 & 0.20 & 0.11 & 0.12 & 0.00 & 0.20 & 0.10 \\
\hline & Matched & 0.09 & 0.13 & 0.00 & 0.10 & 0.20 & 0.11 & 0.11 & 0.30 & 0.20 & 0.10 \\
\hline \multirow[t]{2}{*}{ rural } & Unmatched & 0.03 & 0.02 & 0.07 & 0.20 & 0.10 & 0.20 & 0.12 & 0.00 & 0.40 & 0.30 \\
\hline & Matched & 0.03 & 0.03 & 0.81 & 0.20 & 0.20 & 0.20 & 0.20 & 0.56 & 0.40 & 0.40 \\
\hline
\end{tabular}

\footnotetext{
${ }^{76}$ Such a discrepancy between groups in the matched sample is one of the reasons for including all the covariates in a weighted regression framework after matching.
} 
Figure 5.1 shows the propensity scores overlap considerably for both subgroups of students (i.e. treated and non-treated) in both PISA 2006 and 2009, suggesting the results found using this PSM approach could apply to a large proportion of students in the PISA data.

Figure 5.1: Overlap of propensity scores PISA 2006 and 2009

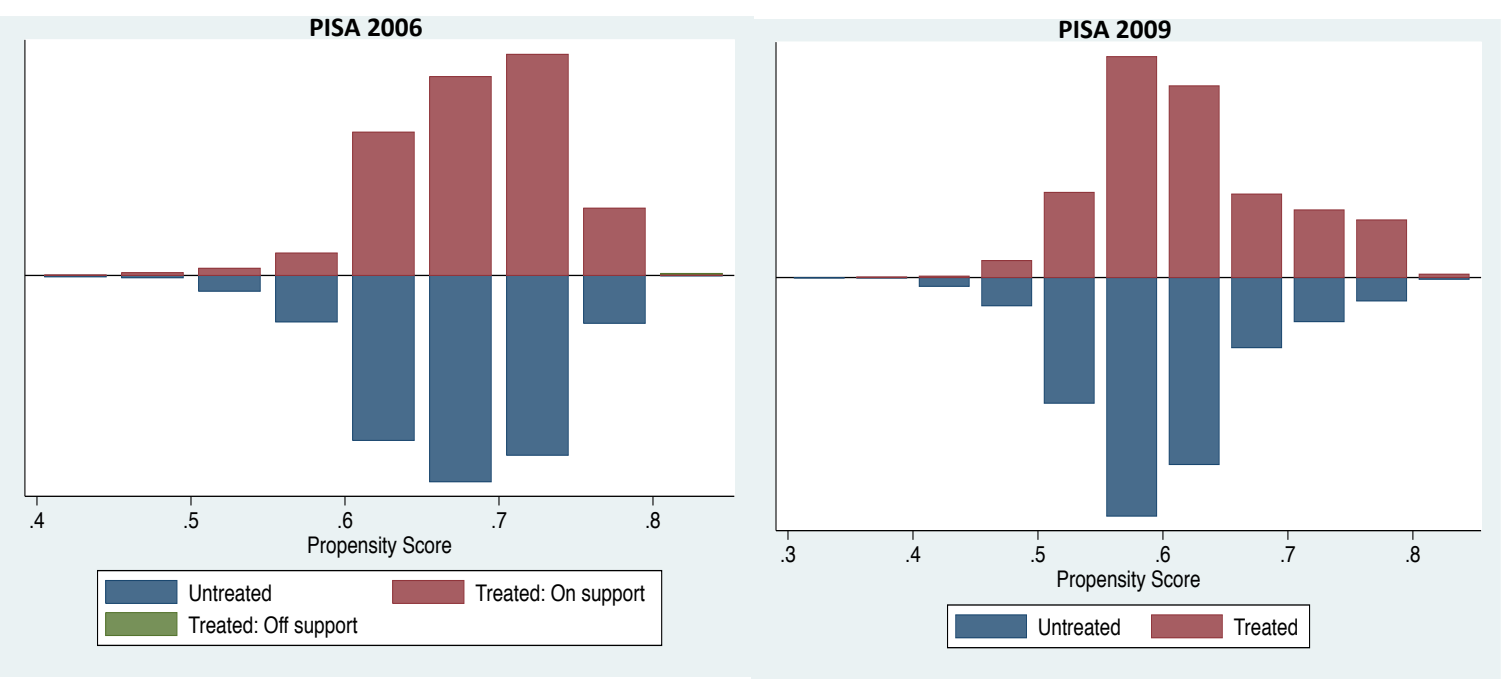

To allow for a comparison of the PISA results across all three methodologies, the results for the effect of private school attendance on mathematics is summarized in Table 5.7. In general the OLS and PSM results are similar and relatively precise, suggesting a positive effect for mathematics in PISA 2006, but no effect for PISA 2009. In contrast, the effect based on the IV approach is relatively imprecise, switches sign across both waves of data, and does not give a clear stable indication for a private school attendance effect on mathematics achievement. 
Table 5.7: Private school attendance effect mathematics, PISA 2006 and 2009

\begin{tabular}{|c|c|c|c|c|c|c|}
\hline & \multicolumn{3}{|c|}{ PISA 2006} & \multicolumn{3}{|c|}{ PISA 2009} \\
\hline & OLS & IV & PSM & OLS & IV & PSM \\
\hline \multirow[b]{2}{*}{ VARIABLES } & (1) & (2) & (3) & (4) & (5) & (6) \\
\hline & Mathematic & Mathematics & Mathematics & Mathematic & Mathematics & Mathematics \\
\hline \multirow[t]{2}{*}{ private } & $9.26^{*}$ & 18.96 & $10.26^{* *}$ & -0.08 & -28.02 & 2.14 \\
\hline & $(4.736)$ & (11.528) & $(4.421)$ & $(4.533)$ & (28.655) & $(4.229)$ \\
\hline individual covariates & yes & yes & yes & yes & yes & yes \\
\hline school covariates & yes & yes & yes & yes & yes & yes \\
\hline Observations & 4,487 & 3,838 & 4,125 & 4,173 & 3,086 & 3,723 \\
\hline R-squared & 0.61 & 0.67 & 0.60 & 0.61 & 0.67 & 0.62 \\
\hline Adj. R-squared & 0.605 & 0.669 & 0.595 & 0.613 & 0.666 & 0.616 \\
\hline
\end{tabular}

Notes: Robust clustered standard errors (at school level) in parentheses ${ }^{* * *} p<0.01,{ }^{* *} p<0.05,{ }^{*} p<0.1$

When taken at face value, one way to compare the IV results quantitatively to the OLS and PSM results is to calculate Rosenbaum bounds for the weighted differences in means (across treated and control students) obtained after the matching procedure for all three subjects. For PISA 2006, the hidden bias factors $\Gamma$, necessary to make these weighted differences in means compatible with the IV point estimates are 1.3, 1.7 and 1.4 for mathematics, reading and science, respectively (Table 5.8a). For PISA 2009, these hidden bias factors $\Gamma$, are 1.6, 1.5 and 2.0 for mathematics, reading and science, respectively (Table 5.8b). The confidence interval for the effect found by comparing the weighted differences in means after propensity score matching would only include the IV estimate if some unobserved variable caused the odds ratio of treatment assignment to differ between the treatment and comparison groups by those factors. A factor of 1.4 roughly means matching students with actual treatment probabilities of 0.65 and 0.57 . Similarly, a hidden bias factor $\Gamma$ of 1.7 roughly translates to matching two students with similar propensity scores whose actual treatment probabilities are 0.67 and 0.55 instead. Tables $5.8 \mathrm{a}$ and $5.8 \mathrm{~b}$ also show that no hidden bias is "required" for making the OLS results compatible with the weighted differences in means estimated after the PSM procedure (i.e. $\Gamma=1.0$ ), suggesting these two methods give similar results across all subjects and both waves of data. 
Table 5.8a: Unobserved bias for PSM to match with OLS and IV, PISA 2006

\begin{tabular}{ccccccc}
\hline & mathematics & \multicolumn{3}{c}{ reading } & science \\
\hline Unobserved Bias & lower bound & upper bound & lower bound & upper bound & lower bound & upper bound \\
1 & $\underline{5.375}$ & $\underline{12.424}$ & $\underline{0.661}$ & $\underline{8.315}$ & $\underline{-1.725}$ & $\frac{6.061}{12.777}$ \\
1.1 & 1.246 & 16.514 & -3.812 & -6.248 & 10.537 \\
1.2 & -2.532 & 20.252 & -7.880 & 16.870 & -10.444 & 14.686 \\
1.3 & -6.037 & 23.680 & -11.637 & 20.626 & -14.267 & 18.463 \\
1.4 & -9.269 & 26.873 & -15.120 & 24.096 & -17.810 & 21.960 \\
1.5 & -12.268 & 29.833 & -18.342 & 27.342 & -21.121 & 25.223 \\
1.6 & -15.111 & 32.599 & -21.376 & 30.377 & -24.198 & 28.254 \\
1.7 & -17.760 & 35.169 & -24.236 & 33.208 & -27.088 & 31.098 \\
1.8 & -20.252 & 37.623 & -26.923 & 35.885 & -29.839 & 33.802 \\
1.9 & -22.628 & 39.921 & -29.476 & 38.428 & -32.450 & 36.320 \\
2 & -24.887 & 42.102 & -31.883 & 40.820 & -34.921 & 38.744 \\
\hline
\end{tabular}

Notes: Alpha is 0.95 for lower- and upper bounds. Bounds for PSM, relative to OLS and IV, are underlined and bold, respectively.

Table 5.8b: Unobserved bias for PSM to match with OLS and IV, PISA 2009

\begin{tabular}{ccccccc}
\hline & mathematics & \multicolumn{5}{c}{ reading } \\
\hline Unobserved Bias & lower bound & upper bound & lower bound & upper bound & lower bound & upper bound \\
1 & $\underline{-6.192}$ & $\underline{2.570}$ & $\underline{-5.090}$ & $\underline{3.702}$ & $\underline{-7.509}$ & $\underline{1.955}$ \\
1.1 & -10.905 & 7.247 & -9.815 & 8.456 & -12.682 & 7.087 \\
1.2 & -15.189 & 11.607 & -14.110 & 12.746 & -17.344 & 11.797 \\
1.3 & -19.161 & 15.618 & -18.061 & 16.703 & -21.589 & 16.133 \\
1.4 & -22.785 & 19.280 & -21.744 & 20.326 & -25.596 & 20.188 \\
1.5 & -26.172 & 22.707 & -25.155 & 23.712 & -29.234 & 23.919 \\
1.6 & -29.328 & 25.901 & -28.344 & 26.881 & -32.637 & 27.414 \\
1.7 & -32.285 & 28.900 & -31.308 & 29.878 & -35.855 & 30.679 \\
1.8 & -35.052 & 31.704 & -34.096 & 32.700 & -38.884 & 33.754 \\
1.9 & -37.697 & 34.388 & -36.706 & 35.351 & -41.728 & 36.646 \\
2 & -40.154 & 36.883 & -39.189 & 37.854 & -44.431 & 39.352 \\
\hline
\end{tabular}

Notes: Alpha is 0.95 for lower- and upper bounds. Bounds for PSM, relative to OLS and IV, are underlined and bold, respectively.

Given that attending either a vocational or academic school in secondary education will largely be determined by the primary school advice (i.e. prior to treatment), this indicator, up till now, has been included as a background control. However, it could be that student mobility patterns for the first years of secondary education prior to the PISA survey (i.e. transferring from a vocational to an academic track and vice-versa) are structurally different across school types. Therefore, the same analyses, using all three methodologies, are performed on both the subset of students attending a vocational school (around 60\%) and on the subset of students attending an academic school (around 40\%). Again, for ease 
of comparison, the results are presented for the effect of private school attendance on mathematics only. ${ }^{77}$

Table 5.9a: Private vocational school attendance effect, PISA 2006 and 2009

\begin{tabular}{lccc|ccc|}
\hline \multicolumn{5}{c}{ PISA 2006, vocational subsample } & \multicolumn{3}{c|}{ PISA 2009, vocational subsample } \\
& OLS & IV & PSM & OLS & IV & PSM \\
\hline \multirow{2}{*}{ VARIABLES } & $(1)$ & $(2)$ & $(3)$ & $(4)$ & $(5)$ & $(6)$ \\
& Mathematics & Mathematics & Mathematics & Mathematics & Mathematics Mathematics \\
private & 6.17 & $33.25^{*}$ & 10.51 & 0.48 & -1.53 & 4.22 \\
& $(6.769)$ & $(17.826)$ & $(6.491)$ & $(7.434)$ & $(25.974)$ & $(6.591)$ \\
& & & & & & \\
individual covariates & yes & yes & yes & yes & yes & yes \\
school covariates & yes & yes & yes & yes & yes & yes \\
& & & & & & \\
Observations & 2,410 & 1,817 & 2,260 & 2,069 & 1,492 & 1,908 \\
R-squared & 0.29 & 0.37 & 0.26 & 0.20 & 0.36 & 0.21 \\
Adj. R-squared & 0.287 & 0.365 & 0.258 & 0.193 & 0.349 & 0.202 \\
\hline
\end{tabular}

Notes: Robust clustered standard errors (at school level) in parentheses ${ }^{* * *} p<0.01,{ }^{* *} p<0.05,{ }^{*} p<0.1$

Table 5.9b: Private academic school attendance effect, PISA 2006 and 2009

\begin{tabular}{|c|c|c|c|c|c|c|}
\hline & \multicolumn{3}{|c|}{ PISA 2006 academic subsample } & \multicolumn{3}{|c|}{ PISA 2009, academic subsample } \\
\hline & OLS & IV & PSM & OLS & IV & PSM \\
\hline & (1) & (2) & (3) & (4) & (5) & (6) \\
\hline VARIABLES & Mathematic & Mathematic & Mathematics & Mathematic & Mathematics & Mathematics \\
\hline private & $\begin{array}{l}7.26 \\
(6.306)\end{array}$ & $\begin{array}{c}-5.67 \\
(14.349)\end{array}$ & $\begin{array}{c}7.81^{*} \\
(4.662)\end{array}$ & $\begin{array}{c}1.52 \\
(4.711)\end{array}$ & $\begin{array}{c}-182.51 \\
(415.347)\end{array}$ & $\begin{array}{c}-0.43 \\
(4.832)\end{array}$ \\
\hline $\begin{array}{l}\text { individual covariates } \\
\text { school covariates }\end{array}$ & yes & yes & yes & $\begin{array}{l}\text { yes } \\
\text { yes }\end{array}$ & yes & $\begin{array}{l}\text { yes } \\
\text { yes }\end{array}$ \\
\hline Observations & 2,077 & 2,021 & 1,865 & 2,104 & 1,594 & 1,815 \\
\hline R-squared & 0.13 & 0.26 & 0.13 & 0.21 & & 0.21 \\
\hline Adj. R-squared & 0.124 & 0.255 & 0.118 & 0.201 & & 0.201 \\
\hline
\end{tabular}

Notes: Robust clustered standard errors (at school level) in parentheses ${ }^{* * *} p<0.01,{ }^{* *} p<0.05,{ }^{*} p<0.1$

${ }^{77}$ Results for the other two subjects lead to a qualitatively similar interpretation and are available on request. 
The OLS and PSM results for the vocational schools are largely similar to the results presented earlier, whereas the positive effect found for PISA 2006 based on the IV approach seems to be completely driven by this subset of schools (Table 5.9a). Similarly, the OLS and PSM results for the academic subsample do not differ from the overall results (Table 5.9b). However, the very imprecise, and negative, effect found for the overall PISA 2009 data set with the IV approach seems to be accounted for by the academic subset of schools (Table 5.9b) and points to an imprecisely estimated "zero effect" for the subset of vocational schools in PISA 2009 instead (Table 5.9a). ${ }^{78}$

\section{BRON PO '08-'09}

The raw achievement differences between public- and private school students at the end of primary education are displayed in Table 5.10. For the end-of-primary test scores (CITO), the raw differences tend to suggest that students at private government-dependent schools slightly outperform their public counterparts by around 1 point (or $0.1 \sigma)$. Also, they receive an advice making them eligible to attend the highest academic track (VWO) slightly more often ( $19 \%$ vs. $17 \%$ respectively). The additional students' weighted funds allocated to private school students tend to be slightly less on average ( 0.07 vs. 0.11 respectively) and they are less likely to have an immigrant background ( 0.13 vs. 0.20 respectively). The average index for socioeconomic status (ESCS) is somewhat favorable for private school students, both at the school and neighborhood level. Lastly, private school students are less likely to live in urban neighborhoods (i.e. lower index for urbanicity), which is corroborated by the smaller proportions of them residing in the largest 31 and 4 municipalities.

\footnotetext{
${ }^{78}$ It has to be noted that the relatively weak instrument in PISA 2009, together with the relatively small subset of academic schools make the negative point estimate vastly imprecise and unstable as indicated by the extremely large standard errors and the failure to report R-squared.
} 
Table 5.10: Summary statistics, BRON PO '08-'09

\begin{tabular}{|c|c|c|c|c|c|c|}
\hline VARIABLES & $\begin{array}{l}\text { Public } \\
\text { mean }\end{array}$ & (sd) & $\begin{array}{c}\text { Private } \\
\text { mean }\end{array}$ & (sd) & $\begin{array}{c}\text { All } \\
\text { mean }\end{array}$ & (sd) \\
\hline proportion attending a private primary school & 0.00 & $(0.00)$ & 1.00 & $(0.00)$ & 0.69 & $(0.46)$ \\
\hline proportion attending a private religious school & 0.00 & $(0.00)$ & 0.92 & $(0.27)$ & 0.64 & $(0.48)$ \\
\hline proportion attending a private non-religious school & 0.00 & $(0.00)$ & 0.08 & $(0.27)$ & 0.06 & $(0.23)$ \\
\hline CITO end-of-primary test score & 534.58 & $(9.86)$ & 535.49 & (9.53) & 535.25 & $(9.62)$ \\
\hline VMBO end-of-primary school advice & 0.55 & $(0.50)$ & 0.53 & $(0.50)$ & 0.53 & $(0.50)$ \\
\hline HAVO end-of-primary school advice & 0.14 & $(0.34)$ & 0.15 & $(0.36)$ & 0.15 & $(0.35)$ \\
\hline HAVO/VWO end-of-primary school advice & 0.16 & $(0.37)$ & 0.16 & $(0.37)$ & 0.16 & $(0.37)$ \\
\hline VWO end-of-primary school advice & 0.16 & $(0.37)$ & 0.16 & $(0.36)$ & 0.16 & $(0.37)$ \\
\hline upward mobility by year 3 of secondary education & 0.17 & $(0.38)$ & 0.19 & $(0.39)$ & 0.18 & $(0.39)$ \\
\hline age & -0.02 & $(0.66)$ & -0.04 & $(0.64)$ & -0.03 & $(0.64)$ \\
\hline female (yes=1) & 0.50 & $(0.50)$ & 0.50 & $(0.50)$ & 0.50 & $(0.50)$ \\
\hline student's weighted funding & 0.11 & $(0.27)$ & 0.07 & $(0.22)$ & 0.08 & $(0.24)$ \\
\hline single-parent household (yes=1) & 0.03 & $(0.17)$ & 0.02 & $(0.15)$ & 0.02 & $(0.15)$ \\
\hline non-western immigrant background (yes=1) & 0.20 & $(0.40)$ & 0.13 & $(0.33)$ & 0.15 & $(0.36)$ \\
\hline 2nd generation immigrant background (yes=1) & 0.22 & $(0.42)$ & 0.16 & $(0.36)$ & 0.18 & $(0.38)$ \\
\hline ESCS-index of primary school intake & -0.03 & $(0.88)$ & 0.03 & $(0.78)$ & 0.01 & $(0.81)$ \\
\hline proportion non-western immigrants at primary school & 0.20 & $(0.24)$ & 0.13 & $(0.20)$ & 0.15 & $(0.22)$ \\
\hline ESCS-index of secondary school intake & -0.06 & $(0.59)$ & 0.04 & $(0.52)$ & 0.01 & $(0.54)$ \\
\hline proportion non-western immigrants at secondary school & 0.18 & $(0.20)$ & 0.14 & $(0.17)$ & 0.15 & $(0.18)$ \\
\hline neighborhood ESCS index & -0.03 & $(1.04)$ & 0.03 & $(0.93)$ & 0.01 & $(0.96)$ \\
\hline neighborhood urbanicity index & 2.01 & $(1.28)$ & 1.85 & $(1.24)$ & 1.89 & $(1.25)$ \\
\hline proportion of students in G31 municipalities & 0.34 & $(0.47)$ & 0.26 & $(0.44)$ & 0.29 & $(0.45)$ \\
\hline proportion of students in G4 municipalities & 0.13 & $(0.33)$ & 0.09 & $(0.29)$ & 0.10 & $(0.30)$ \\
\hline Observations & 45986 & & 104544 & & 157749 & \\
\hline
\end{tabular}

Throughout the analyses, to avoid important estimating school type effects that are driven primarily by differences between urban and rural areas instead, results will be presented for the whole of the Netherlands (NL), as well as for subsets of the BRON-data set, covering all students within the 31 major municipalities (G31) and the 4 largest cities (G4) respectively. ${ }^{79}$

Table 5.11 gives the results for equation (5.10), in which models 1-3 give the empty model results for the three subsets of data. Given that the raw achievement difference is not present in the urban subsets of data (i.e. G31 and G4), suggests that this might be primarily due to important urban/rural differences. The results after controlling for individual background characteristics are given in models 4-6, whereas controls at the school- and neighborhood level are added in models 7-9. As such these latter models represent the full model specification of equation (5.10).

\footnotetext{
${ }^{79}$ The Dutch government's so-called urban policy is one in which the major cities in the Netherlands collaborate on a variety of topics, among which education is one of them. It was introduced in 1994 for the 31 large and medium-sized cities, the G31 municipalities. These are the four largest cities (G4) and 27 mediumsized cities (G27). Source: www.government.nl/issues/municipalities-and-cities/urban-policy
} 
Table 5.11: OLS, Private school attendance effect, BRON PO '08-'09

\begin{tabular}{|c|c|c|c|c|c|c|c|c|c|}
\hline & NL & G31 & G4 & $\mathrm{NL}$ & G31 & G4 & NL & G31 & G4 \\
\hline & (1) & $(2)$ & (3) & (4) & $(5)$ & (6) & (7) & $(8)$ & (9) \\
\hline VARIABLES & CITO & CITO & CITO & CITO & CITO & CITO & CITO & CITO & CITO \\
\hline \multirow[t]{2}{*}{ private } & $0.91^{* * *}$ & 0.29 & 0.18 & $0.54^{* *}$ & 0.04 & -0.09 & $0.37^{*}$ & -0.57 & -0.37 \\
\hline & -0.256 & -0.54 & -1.061 & -0.219 & -0.413 & -0.749 & -0.205 & -0.373 & -0.65 \\
\hline individual covariates & no & no & no & yes & yes & yes & yes & yes & yes \\
\hline school- and neighborhood controls & no & no & no & no & no & no & yes & yes & yes \\
\hline \multirow[t]{2}{*}{ Constant } & $534.58^{* * *}$ & $534.32^{* * *}$ & $533.15^{\star \star *}$ & $536.11^{* * *}$ & $537.05^{\star \star *}$ & $538.30^{* * *}$ & $535.31^{* * *}$ & $538.61^{* * *}$ & $536.48^{\star \star \star}$ \\
\hline & -0.221 & -0.446 & -0.876 & -0.193 & -0.353 & -0.677 & -0.221 & -0.922 & -2.053 \\
\hline Observations & 37954 & 12699 & 4727 & 37943 & 12689 & 4717 & 37911 & 12678 & 4712 \\
\hline R-squared & 0 & 0 & 0 & 0.11 & 0.15 & 0.2 & 0.12 & 0.19 & 0.23 \\
\hline Adj. R-squared & 0.0017 & $8.59 \mathrm{E}-05$ & -0.00015 & 0.109 & 0.148 & 0.198 & 0.123 & 0.192 & 0.232 \\
\hline
\end{tabular}

Controlling for the background characteristics of the student reduces the raw achievement differences between private and public school students by about half (models 4-6). The results for the full-model specification are further reduced and suggest a positive association of private school attendance with CITO performance of around $0.04 \sigma$ (model 7). No statistically significant relationship is found for the urban subsets (models 8-9).

It has been described that the private government-dependent sector comprises many different school types (e.g. religious and non-religious schools). The results for estimating the full-model specification, but this time with private school attendance disaggregated are given in table 5.12.

The results tend to point to a somewhat better performance for students attending private non-religious schools (i.e. "algemeen bijzonder"), although the effect is only present for the entire data set (i.e. $0.15 \sigma$ ) and the smaller subset of the 4 largest municipalities (i.e. $0.23 \sigma$ ). For the total of the 31 largest municipalities, no such relationship can be established. Similarly, private Catholic school attendance suggests a level of performance that is indistinguishable from public school students in the overall data set comprising all students, but points to a negative effect for students in the 31 largest municipalities (i.e. $-0.10 \sigma$ ) and 4 largest cities (i.e. $-0.16 \sigma$ ). Such instability across subsets of data could mean the treatment of private (Catholic or non-religious) schooling is different across regions and/or that important unobserved selection processes are potentially confounding the results based on covariate control. 
Table 5.12: OLS, Private school type attendance effects, BRON PO '08-'09

\begin{tabular}{lccc|}
\hline & NL & G31 & G4 \\
\hline VARIABLES & $(1)$ & $(2)$ & $(3)$ \\
\hline private Catholic & CITO & CITO & CITO \\
private Protestant & 0.32 & $-0.98^{* *}$ & $-1.66^{* *}$ \\
& $(0.233)$ & $(0.470)$ & $(0.844)$ \\
private other religion & 0.03 & -0.60 & -0.29 \\
& $(0.237)$ & $(0.476)$ & $(0.725)$ \\
private non-religious & -0.13 & 2.02 & $2.96^{*}$ \\
& $(1.755)$ & $(1.704)$ & $(1.587)$ \\
individual covariates & $1.42^{* * *}$ & -0.28 & $2.39^{* * *}$ \\
school- and neighborhood controls & $(0.448)$ & $(0.630)$ & $(0.813)$ \\
& & & \\
Constant & $y e s$ & $y e s$ & $y e s$ \\
& $y e s$ & $y e s$ & $y e s$ \\
Observations & & & \\
R-squared & $535.43^{* * *}$ & $538.60^{* * *}$ & $537.03^{* * *}$ \\
Adj. R-squared & $(0.224)$ & $(0.892)$ & $(1.955)$ \\
\hline & & & \\
Nes: Robust & 37,893 & 12,678 & 4,712 \\
& 0.12 & 0.20 & 0.24 \\
& 0.123 & 0.193 & 0.240 \\
\hline
\end{tabular}

Notes: Robust clusterd standard errors (at school level) in parentheses, ${ }^{* * *} p<0.01,{ }^{* *} p<0.05,{ }^{*} p<0.1$

Similar to the PISA data, an alternative approach (i.e. PSM) is proposed as to control more strictly for observed differences between students across different school types. The results suggest there is no significant difference between private and public students across all three subsets of data, once background characteristics at the individual, school and neighborhood level are taken into account (Table 5.13).

The results based on covariate control suggested there could be a statistically significant difference for at least two specific private school types (i.e. negative for private Catholic and positive for private non-religious schools). Applying the same weighted regression-adjusted propensity score method to these two cases yields statistically insignificant differences in achievement across all subsets of data (Table 5.14). 
Table 5.13: PSM, Private school attendance effects, BRON PO '08-'09

\begin{tabular}{|c|c|c|c|c|c|c|}
\hline & $\mathbf{N L}$ & NL & G31 & G31 & G4 & G4 \\
\hline & (1) & $(2)$ & (3) & $(4)$ & (5) & (6) \\
\hline VARIABLES & CITO & CITO & CITO & CITO & CITO & CITO \\
\hline \multirow[t]{2}{*}{ private } & $0.64^{* *}$ & 0.44 & -0.21 & -0.32 & 0.37 & 0.09 \\
\hline & $(0.314)$ & $(0.281)$ & $(0.575)$ & $(0.446)$ & $(1.268)$ & $(0.716)$ \\
\hline individual covariates & no & yes & no & yes & no & yes \\
\hline school- and neighborhood controls & no & yes & no & yes & no & yes \\
\hline \multirow[t]{2}{*}{ Constant } & $534.84^{* * *}$ & $535.03^{\star * *}$ & $534.82^{* * *}$ & $537.33^{\star * *}$ & $532.96^{\star * *}$ & $535.84^{* \star *}$ \\
\hline & $(0.285)$ & $(0.338)$ & $(0.488)$ & $(1.265)$ & $(1.118)$ & $(2.491)$ \\
\hline Observations & 31,991 & 31,989 & 10,524 & 10,522 & 3,799 & 3,799 \\
\hline R-squared & 0.00 & 0.12 & 0.00 & 0.19 & 0.00 & 0.28 \\
\hline Adj. R-squared & 0.00107 & 0.121 & $9.13 e-06$ & 0.184 & $1.33 e-05$ & 0.273 \\
\hline
\end{tabular}

Notes: Robust clusterd standard errors (at school level) in parentheses ${ }^{* * *} p<0.01,{ }^{* *} p<0.05,{ }^{*} p<0.1$

Table 5.14: Private Catholic/non-religious school effects, BRON PO '08-'09

\begin{tabular}{lcc|cc|cc|}
\hline & NL & NL & G31 & G31 & G4 & G4 \\
\hline & $(1)$ & $(2)$ & $(3)$ & $(4)$ & $(5)$ & $(6)$ \\
VARIABLES & ClTO & CITO & ClTO & CITO & ClTO & CITO \\
\hline private Catholic & & & & & & \\
& 0.20 & & -0.26 & & -1.01 & \\
private non-religious & $(0.262)$ & & $(0.468)$ & & $(0.892)$ & \\
& & 0.96 & & -0.17 & & 1.33 \\
& & $(0.805)$ & & $(0.807)$ & & $(0.952)$ \\
individual covariates & & & & & & \\
& $y e s$ & yes & yes & yes & yes & yes \\
school- and neighborhood controls & yes & yes & yes & yes & yes & yes \\
& & & & & & \\
Constant & $535.63^{* * *}$ & $536.19^{* * *}$ & $535.27^{* * *}$ & $532.97^{* * *}$ & $533.50^{* * *}$ & $531.52^{* * *}$ \\
& $(0.341)$ & $(1.144)$ & $(0.731)$ & $(1.530)$ & $(1.768)$ & $(4.167)$ \\
& & & & & & \\
Observations & 19,965 & 2,521 & 6,976 & 1,553 & 2,155 & 295 \\
R-squared & 0.13 & 0.13 & 0.20 & 0.20 & 0.24 & 0.36 \\
Adj. R-squared & 0.131 & 0.126 & 0.195 & 0.193 & 0.235 & 0.331 \\
\hline
\end{tabular}

Notes: Robust clusterd standard errors (at school level) in parentheses ${ }^{* * *} p<0.01,{ }^{* *} p<0.05,{ }^{*} p<0.1$ 
A likely caveat to all achievement comparisons presented so far is the large proportion of students for which no test scores are recorded. In this first attempt to generate a highly insightful panel data set, all primary schools in the data have been asked to submit both the 2008-2009 CITO-score and secondary school advice for all students under consideration in this 2008-2009 cohort. $^{80}$ This secondary sector offers three main options: pre-vocational secondary education (VMBO), general secondary education (HAVO) and pre-university education (VWO). In addition, pupils can also transfer into practical training (PRO), secondary special education (VSO) or get additional support to finish lower vocational education within mainstream education (LWOO). ${ }^{81}$ These latter groups of pupils can be exempt from performing the standardized CITO-test, just as students who lack behind in Dutch language skills and have entered the Netherlands less than 4 years ago. Eligibility for a specific track in secondary education is largely based on the CITO-scores. Response rates were low with both outcome variables known for only 34322 students (21.8\%), CITO-scores known for 38496 (24.4\%) and no outcome data whatsoever for as many as 60955 students (38.6\%). The result of comparing characteristics of students with data on CITO scores to those for which this information is unknown is presented in Table 5.15 .

As can be expected from the exemption criteria that apply to taking the CITO test, students with known CITO scores have somewhat better advice scores (i.e as indicated by the somewhat lower (higher) proportions of students receiving an advice towards a relatively low (high) track.). Also, related to this, they are from slightly advantageous neighborhoods and schools (a $0.02 \sigma$ difference).

\footnotetext{
${ }^{80}$ Advice scores are categorical values and determine the eligibility for (academic) tracks in secondary education and are largely based on the CITO-scores, but will also include elements such as student potential, motivation. They are unstandardized and (therefore) not used in the main analyses. However, response rates are much higher, relative to the standardized CITO-scores. See Appendix A for a description of all the variables. ${ }^{81}$ Students of primary or secondary education in need of special care and support are accommodated in either regular or specialized schools. In primary education, around $93 \%$ of all students are considered within mainstream education. The proportion of special needs pupils in secondary education (PRO, VSO and LWOO) almost doubled in recent years: from 9.3 per cent in 1990 to 17.5 per cent in 2010 (OCW, 2011a).
} 
Table 5.15: Missing CITO test score data comparisons, BRON PO '08-'09

\begin{tabular}{|c|c|c|c|c|c|c|c|c|c|c|}
\hline & \multicolumn{2}{|c|}{ no missing cito } & \multicolumn{2}{|c|}{ missing cito } & \multicolumn{2}{|c|}{ no missing advice } & \multicolumn{2}{|c|}{ missing advice } & \multicolumn{2}{|c|}{ all students } \\
\hline & mean & sd & mean & sd & mean & sd & mean & sd & mean & sd \\
\hline proportion attending a private primary school & 0.73 & $(0.44)$ & 0.68 & $(0.47)$ & 0.70 & 0.46 & 0.69 & 0.46 & 0.69 & $(0.46)$ \\
\hline proportion attending a private non-religious school & 0.04 & $(0.21)$ & 0.06 & $(0.24)$ & 0.06 & 0.23 & 0.06 & 0.23 & 0.06 & $(0.23)$ \\
\hline CITO end-of-primary test score & 535.23 & $(9.62)$ & . & . & 535.24 & 9.6 & 535.07 & 9.85 & 535.23 & (9.62) \\
\hline HAVO end-of-primary school advice & 0.15 & $(0.36)$ & 0.14 & $(0.34)$ & 0.14 & 0.35 & . & . & 0.14 & $(0.35)$ \\
\hline HAVO/NWO end-of-primary school advice & 0.15 & $(0.36)$ & 0.16 & $(0.37)$ & 0.16 & 0.37 & . & . & 0.16 & $(0.37)$ \\
\hline VWO end-of-primary school advice & 0.17 & $(0.37)$ & 0.15 & $(0.35)$ & 0.15 & 0.36 & . & . & 0.15 & $(0.36)$ \\
\hline upward mobility by year 3 of secondary education & 0.18 & $(0.38)$ & 0.18 & $(0.38)$ & 0.18 & 0.38 & . & . & 0.18 & $(0.38)$ \\
\hline non-western immigrant background (yes=1) & 0.16 & $(0.37)$ & 0.15 & $(0.36)$ & 0.15 & 0.36 & 0.16 & 0.36 & 0.15 & $(0.36)$ \\
\hline 2nd generation non-western background (yes=1) & 0.19 & $(0.39)$ & 0.18 & $(0.38)$ & 0.18 & 0.38 & 0.18 & 0.39 & 0.18 & $(0.38)$ \\
\hline ESCS-index of primary school intake & 0.02 & $(0.84)$ & 0.00 & $(0.80)$ & 0.00 & 0.8 & 0.01 & 0.82 & 0.00 & $(0.81)$ \\
\hline proportion non-western immigrants at primary school & 0.16 & $(0.23)$ & 0.15 & $(0.21)$ & 0.15 & 0.21 & 0.16 & 0.22 & 0.15 & $(0.22)$ \\
\hline ESCS-index of secondary school intake & 0.02 & $(0.55)$ & 0.00 & $(0.55)$ & 0.00 & 0.54 & 0.01 & 0.55 & 0.00 & $(0.55)$ \\
\hline proportion non-western immigrants at secondary school & 0.16 & $(0.19)$ & 0.15 & $(0.18)$ & 0.15 & 0.18 & 0.16 & 0.18 & 0.15 & $(0.18)$ \\
\hline neighborhood ESCS index & 0.02 & $(0.98)$ & 0.00 & $(0.96)$ & 0.00 & 0.96 & 0.01 & 0.98 & 0.00 & $(0.97)$ \\
\hline neighborhood urbanicity index & 1.91 & $(1.24)$ & 1.91 & $(1.25)$ & 1.86 & 1.24 & 1.97 & 1.26 & 1.91 & $(1.25)$ \\
\hline proportion of students in G31 municipalities & 0.33 & $(0.47)$ & 0.28 & $(0.45)$ & 0.28 & 0.45 & 0.3 & 0.46 & 0.29 & $(0.45)$ \\
\hline
\end{tabular}

Overall, the two groups seem rather balanced in terms of other background characteristics that are not (or only indirectly) related to the exemption criteria for taking the CITO test. One potentially worrisome indicator is the observation that students with missing CITO scores are relatively underrepresented among private (religious) school students and relatively overrepresented among private non-religious schools (Table 5.15). This will bias the results to the extent these missing outcome data patterns are non-random and related to (unobserved) performance.

The last series of analyses base performance on the primary school advice instead. These advices are known for the majority of students (i.e. 58.7\%). Moreover, students for whom such advice is unknown seem similar to those for which the advice is reported on all background characteristics (Table 5.15). The advice scores are used to estimate the effects of attending a private school on a successful trajectory during the first years of secondary education. The indicator used is whether or not the student has already progressed to a track higher than indicated by the primary school by the beginning of the third year in secondary education. The dummy variable as such created (i.e. level-up) suggests that 
almost $18 \%$ of students in year three of secondary education find themselves in a track higher than suggested by the advice given at the end of primary school. The results for estimating the effect of private schooling on such patterns of "upward mobility" are estimated by equation (5.11) and presented in Table 5.16.

Table 5.16: Logit, Private school attendance effect "upward mobility"

\begin{tabular}{lccc|ccc|ccc|}
\hline & NL & G31 & G4 & NL & G31 & G4 & NL & G31 & G4 \\
\hline & $(1)$ & $(2)$ & $(3)$ & $(4)$ & $(5)$ & $(6)$ & $(7)$ & $(8)$ & $(9)$ \\
VARIABLES & Level-Up & Level-Up & Level-Up & $\begin{array}{c}(9) \text { Level-Up } \\
\text { Level-Up }\end{array}$ & $\begin{array}{c}\text { Level-Up } \\
\text { Level-Up }\end{array}$ & $\begin{array}{c}\text { Level-Up } \\
\text { Level-Up }\end{array}$ \\
\hline & & & & & & & & & \\
switched to private secondary school & $-0.17^{*}$ & -0.21 & -0.13 & $-0.24^{* *}$ & $-0.28^{*}$ & -0.17 & 0.12 & 0.12 & 0.28 \\
& $(0.099)$ & $(0.161)$ & $(0.242)$ & $(0.096)$ & $(0.157)$ & $(0.211)$ & $(0.111)$ & $(0.178)$ & $(0.269)$ \\
primary school advice dummies & no & no & no & yes & yes & yes & no & no & no \\
end-of primary test score & no & no & no & no & no & no & yes & yes & yes \\
individual covariates & yes & yes & yes & yes & yes & yes & yes & yes & yes \\
school- and neighborhood controls & yes & yes & yes & yes & yes & yes & yes & yes & yes \\
& & & & & & & & & \\
Constant & $-1.71^{* * *}$ & -0.48 & $-1.57^{* * *}$ & $-0.42^{* * *}$ & 0.01 & -0.27 & $-38.74^{* * *}$ & $-38.73^{* * *}$ & $-43.68^{* * *}$ \\
& $(0.105)$ & $(0.895)$ & $(0.532)$ & $(0.105)$ & $(0.836)$ & $(0.449)$ & $(2.960)$ & $(4.282)$ & $(6.287)$ \\
& & & & & & & & & \\
Observations & 23,822 & 7,782 & 3,201 & 20,021 & 6,624 & 2,726 & 8,171 & 3,064 & 1,354 \\
Wald Chi2 & 265.55 & 170.62 & 82.41 & 858.82 & 511.25 & 232.31 & 233.02 & 225.78 & 92.03 \\
Pseudo R-Squared & 0.0199 & 0.0495 & 0.0576 & 0.1457 & 0.1665 & 0.1973 & 0.0632 & 0.086 & 0.0927 \\
\hline
\end{tabular}

Notes: Robust clusterd standard errors (at school level) in parentheses ${ }^{* * *} p<0.01,{ }^{* *} p<0.05,{ }^{*} p<0.1$

Models 1-3 show largely insignificant and negative associations of upward mobility with switching to a private secondary school (after having attended public primary school). Adding primary school advice dummies, as the advice is arguably related to the potential for experiencing upward mobility, makes the negative associations somewhat more pronounced but still insignificant for the four largest cities (i.e. models 4-6). In contrast, adding the CITO score as a more strict control for selection into secondary school types not only reduces the samples sizes drastically, but also changes the results to insignificant positive relationships between switching to a private secondary school and experiencing upward mobility within the first three years of secondary schooling (models 7-9).

Again, a model based on weighted regression adjusted propensity score matching is proposed as the preferred model to allow for strict comparability on observed characteristics between students who stay in the public sector (i.e. control) and those switching to a private secondary school instead (i.e. treatment). These results, presented in 
models 1,3 and 5, also point to slightly negative associations for private school attendance and upward mobility, though only statistically significant when the dataset considering all schools in the Netherlands is taken into account (Table 5.17).

Table 5.17: PSM, Private school attendance effect "upward mobility"

\begin{tabular}{lcc|cc|cc|}
\hline & NL & NL & G31 & G31 & G4 & G4 \\
\hline & $(1)$ & $(2)$ & $(3)$ & $(4)$ & $(5)$ & $(6)$ \\
VARIABLES & Level-Up & CITO & Level-Up & CITO & Level-Up & CITO \\
\hline & & & & & & \\
switched to private secondary school & $-0.03^{* *}$ & -0.87 & -0.04 & $-1.48^{*}$ & -0.03 & -0.33 \\
& $(0.013)$ & $(0.581)$ & $(0.024)$ & $(0.844)$ & $(0.023)$ & $(1.348)$ \\
primary school advice dummies & yes & $n o$ & yes & no & yes & no \\
individual covariates & yes & yes & yes & yes & yes & yes \\
school- and neighborhood controls & yes & yes & yes & yes & yes & yes \\
& & & & & & \\
Constant & 0.02 & $535.12^{* *}$ & -0.04 & $548.45^{* * *}$ & $-0.18^{* *}$ & $536.81^{* * *}$ \\
& $(0.014)$ & $(0.641)$ & $(0.048)$ & $(1.848)$ & $(0.086)$ & $(4.404)$ \\
Observations & & & & & & \\
R-squared & 18,851 & 6,426 & 6,343 & 2,510 & 2,779 & 1,162 \\
Adj. R-squared & 0.16 & 0.16 & 0.19 & 0.30 & 0.24 & 0.30 \\
\hline
\end{tabular}

Notes: Robust clusterd standard errors (at school level) in parentheses ${ }^{* * *} p<0.01,{ }^{* *} p<0.05,{ }^{*} p<0.1$

Models 2, 4 and 6 serve as a check of validity in the sense that the effect of treatment (i.e. switching to a private secondary school after having attended a public primary school) should not have an effect on a prior outcome of achievement that is correlated with the upward mobility outcome of interest, but unaffected by treatment (e.g. CITO test score). Whereas such a test cannot prove the unconfoundedness assumption required for equation (5.11) to have a causal interpretation, the validity cannot easily be rejected either based on the largely insignificant, albeit though imprecise, results presented in models 2, 4 and 6 .

An overview of the results for both effects (i.e. of attending a private school on endof-primary achievement, and of switching to a private secondary school on upward mobility) is provided in Table 5.18. The interpretation is that, based on BRON PO '08-'09 data, there 
seems to be no effect of private school attendance on either achievement or upward mobility.

Table 5.18: Overview (switched to) private school effects, PO BRON '08-'09

\begin{tabular}{|c|c|c|c|c|c|c|c|c|c|c|c|c|}
\hline & \multicolumn{4}{|c|}{ NL } & \multicolumn{4}{|c|}{ G31 } & \multicolumn{4}{|c|}{ G4 } \\
\hline & \multicolumn{2}{|c|}{ achievement } & \multicolumn{2}{|c|}{ upward mobility } & \multicolumn{2}{|c|}{ achievement } & \multicolumn{2}{|c|}{ upward mobility } & \multicolumn{2}{|c|}{ achievement } & \multicolumn{2}{|c|}{ upward mobility } \\
\hline & OLS & PSM & LOGIT & PSM & OLS & PSM & LOGIT & PSM & OLS & PSM & LOGIT & PSM \\
\hline & (1) & $(2)$ & (3) & (4) & (1) & $(2)$ & (3) & (4) & (1) & (2) & (3) & (4) \\
\hline VARIABLES & CITO & CITO & Level-Up & Level-Up & CITO & CITO & Level-Up & Level-Up & CITO & CITO & Level-Up & Level-Up \\
\hline (switched to) private school & $\begin{array}{c}0.37^{*} \\
(0.205)\end{array}$ & $\begin{array}{c}0.44 \\
(0.281)\end{array}$ & $\begin{array}{c}0.12 \\
(0.111)\end{array}$ & $\begin{array}{l}-0.03^{* *} \\
(0.013)\end{array}$ & $\begin{array}{c}-0.57 \\
(0.373)\end{array}$ & $\begin{array}{c}-0.32 \\
(0.446)\end{array}$ & $\begin{array}{c}0.12 \\
(0.178)\end{array}$ & $\begin{array}{c}-0.04 \\
(0.024)\end{array}$ & $\begin{array}{c}-0.37 \\
(0.650)\end{array}$ & $\begin{array}{c}0.09 \\
(0.716)\end{array}$ & $\begin{array}{c}0.28 \\
(0.269)\end{array}$ & $\begin{array}{c}-0.03 \\
(0.023)\end{array}$ \\
\hline individual covariates & yes & yes & yes & yes & yes & yes & yes & yes & yes & yes & yes & yes \\
\hline school- and neighborhood controls & yes & yes & yes & yes & yes & yes & yes & yes & yes & yes & yes & yes \\
\hline Observations & 37,911 & 31,989 & 8,171 & 18,851 & 12,678 & 10,522 & 3,064 & 6,343 & 4,712 & 3,799 & 1,354 & 2,779 \\
\hline R-squared / Wald Chi2 & 0.12 & 0.12 & 233.02 & 0.16 & 0.19 & 0.19 & 225.78 & 0.19 & 0.23 & 0.28 & 92.03 & 0.24 \\
\hline Adj. R-squared & 0.123 & 0.121 & 0.0632 & 0.163 & 0.192 & 0.184 & 0.086 & 0.188 & 0.232 & 0.273 & 0.0927 & 0.234 \\
\hline
\end{tabular}

\subsection{Concluding remarks}

This chapter first set out to apply three different non-experimental methodologies (i.e. OLS, IV and PSM) to Dutch PISA 2006 and 2009 data in an attempt to find a clear effect of private school attendance on student achievement in three subjects (i.e. mathematics, reading and science). Overall, these results do not point to a consistent effect across both waves of data. OLS and PSM results suggest private school attendance is positively associated with mathematics achievement, but only in PISA 2006. For the other subjects, the performance of private school students cannot be distinguished from their public counterparts, once observable characteristics are taken into account. Instead, the results generated by an instrumental variable approach (IV) are very unstable. Relatively large, but imprecise, positive estimates are found for all subjects in PISA 2006, whereas the exact opposite (i.e. a large imprecise, but negative result) is found for students in the PISA 2009 data set.

A sensitivity analysis based on Rosenbaum bounds points out that the OLS and PSM results are comparable to each other, but hard to reconcile with the results generated by the IV approach. Performing the same analyses on a subset of students in vocational schools and again on the other group of students attending an academic school gives OLS and PSM results similar to those obtained from the data set as a whole. Instead, the positive 
association found for PISA 2006 with the IV approach seems to be completely driven by the subset of students in vocational schools, whereas the opposite holds for the IV results for PISA 2009.

The propensity score matching (PSM) results indicate that matching students on observable achievement determinants does not yield a consistent, positive, private school attendance effects on student achievement. While relatively stable and precise estimates are obtained, this approach is not free of threats to validity either. The validity of the PSM approach hinges on the assumption that no (non-random) selection on unobserved characteristics is present across school types. Importantly, the school (type) effects estimates derived from PISA data are based on 2-3 years of attendance only. Students in the Netherlands have generally been exposed to 8 years of primary schooling. However, this remains unobserved, and its academic results are not taken account of, in the PISA data.

This is why the analyses were complemented with analyzing end-of-primary test scores, after 8 years of schooling, using BRON PO '08-'09 data. If the weighted regressionadjusted propensity score estimates are credible, in that private school students are being compared to public school students that can serve as proper counterfactuals, none of the results seem to suggest that, for those individuals for which the data set does provide test scores, private schools seem to perform significantly different. If anything, when the sample is restricted to cities only, private school types seem to be marginally more effective in educating students from non-Western backgrounds and perhaps slightly less so for students from Dutch- or Western immigrant background.

A final set of analyses looks at differences in upward mobility after the first two years of secondary education, exploiting the existence of "structural switches". These results point to slightly negative associations for private school attendance and upward mobility, though only statistically significant when the dataset considering all schools in the Netherlands is taken into account.

In addition to test scores and upward mobility, there are of course many other relevant school type effects to consider, which are not addressed here (e.g. graduation rates, non-cognitive skills, labor market outcomes, parental satisfaction, segregation and social cohesion). But, the analyses in this chapter do not provide conclusive evidence for a consistent school type effect for academic achievement in Dutch compulsory education. 


\section{A Appendix: Full estimation results}

Table 5.1a: Summary statistics PISA 2006

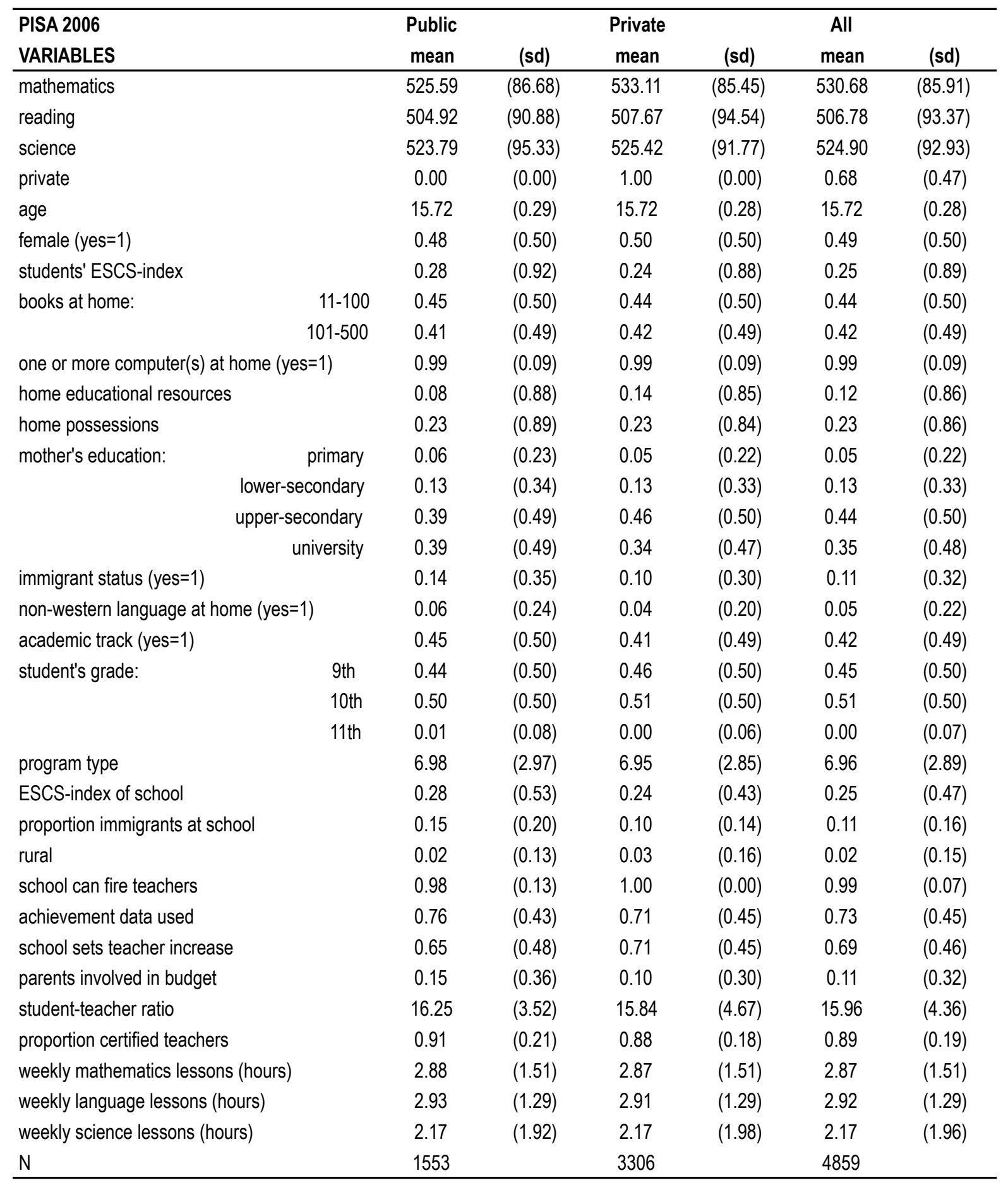


Table 5.A1b: Summary statistics PISA 2009

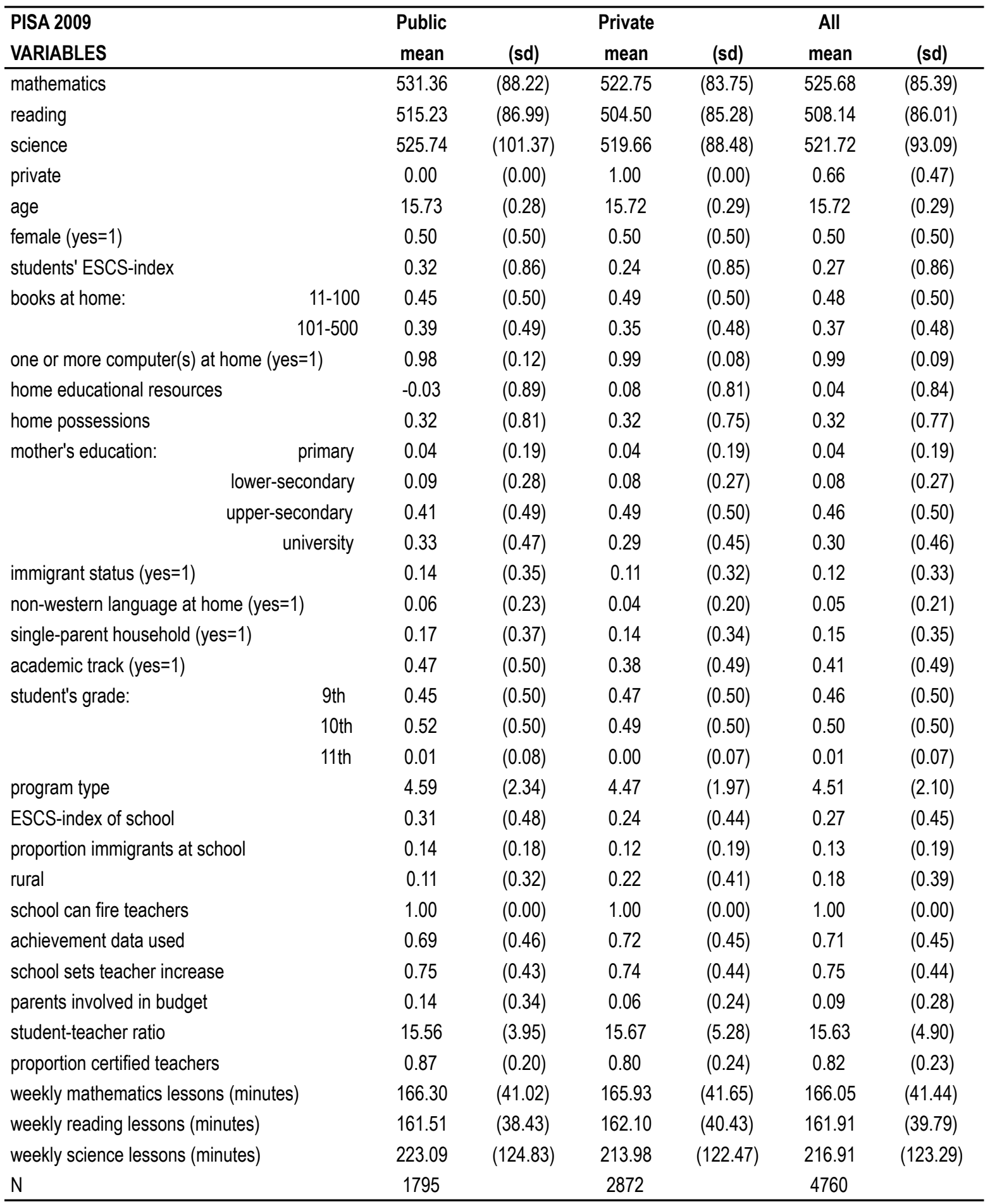


Table 5.2a: OLS results private school attendance, PISA 2006

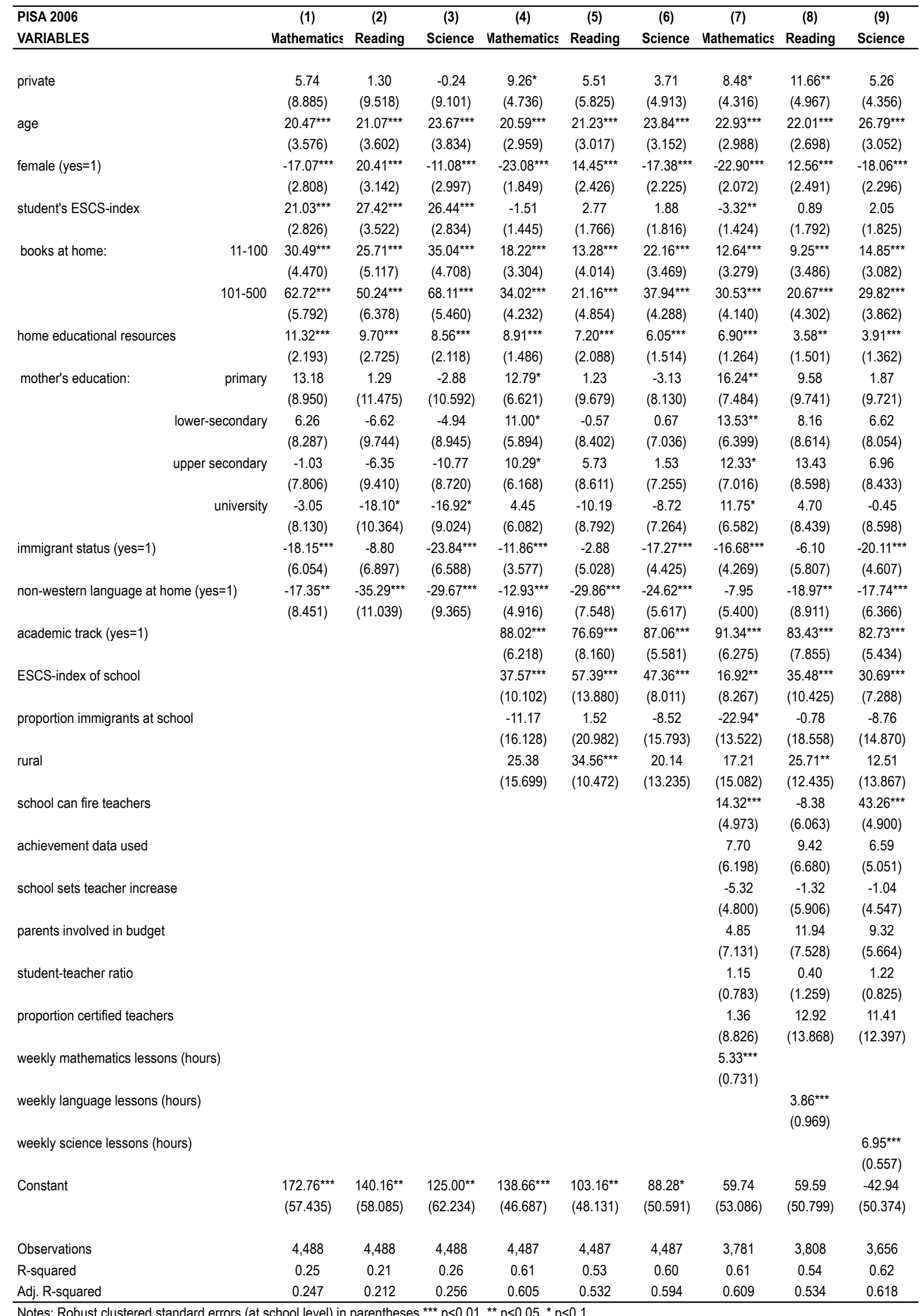


Table 5.2b: OLS results private school attendance, PISA 2009

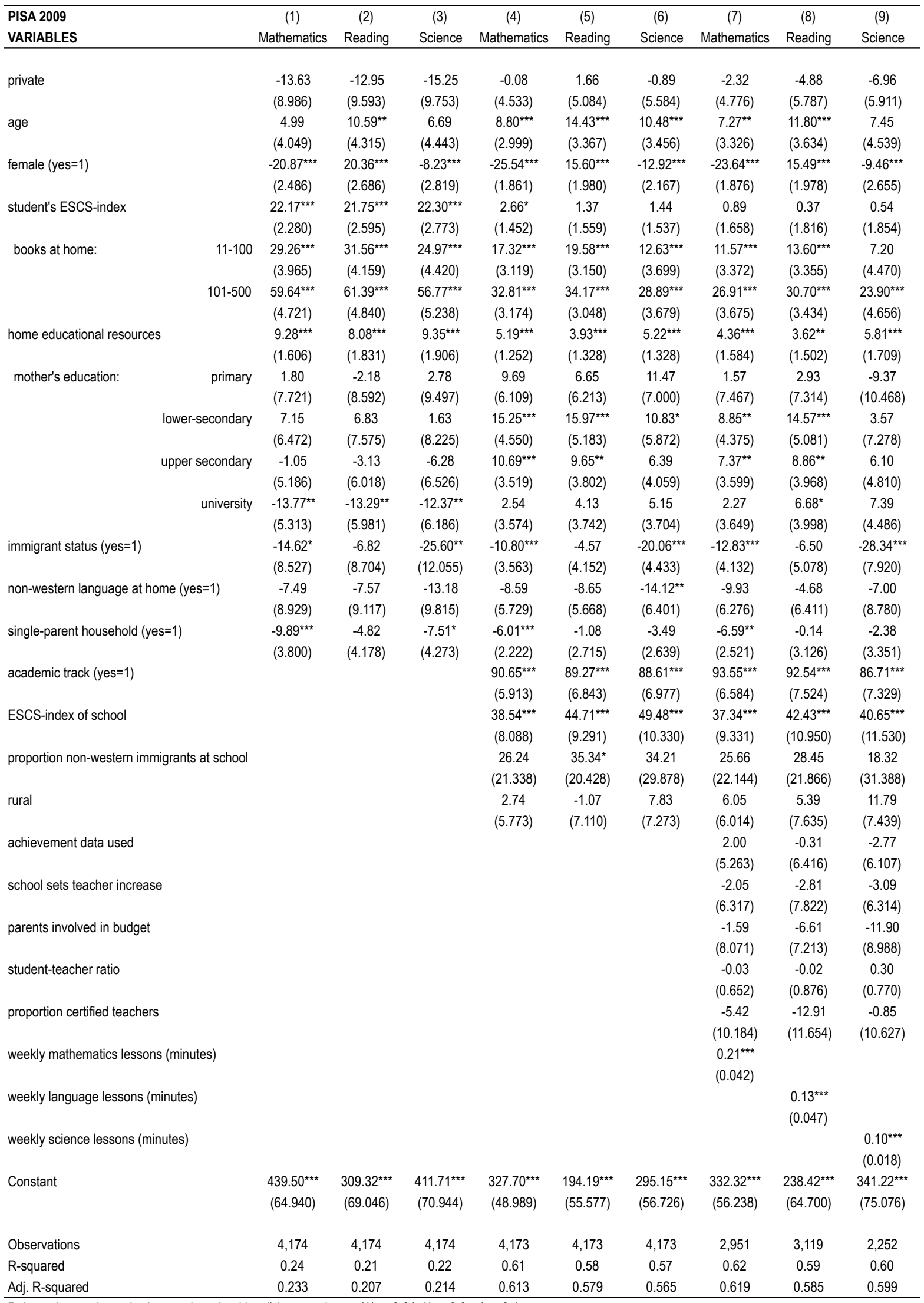

Robust clustered standard errors (at school level) in parentheses ${ }^{* \star *} p<0.01,{ }^{* *} p<0.05,{ }^{*} p<0.1$ 
Table 5.3: First-stage results IV approach, PISA 2006 and 2009

\begin{tabular}{|c|c|c|}
\hline & PISA 2006 & PISA 2009 \\
\hline VARIABLES & private & private \\
\hline \multirow[t]{2}{*}{ instrument } & $0.35^{\star \star \star}$ & $0.17^{* \star}$ \\
\hline & $(0.064)$ & $(0.083)$ \\
\hline \multirow[t]{2}{*}{ age } & -0.01 & -0.02 \\
\hline & $(0.030)$ & $(0.034)$ \\
\hline \multirow[t]{2}{*}{ female (yes=1) } & 0.01 & $-0.03^{* *}$ \\
\hline & $(0.016)$ & $(0.016)$ \\
\hline \multirow[t]{8}{*}{ mother's education: } & 0.08 & -0.03 \\
\hline & $(0.063)$ & $(0.048)$ \\
\hline & 0.09 & 0.01 \\
\hline & $(0.063)$ & $(0.042)$ \\
\hline & $0.12^{*}$ & 0.03 \\
\hline & $(0.064)$ & $(0.041)$ \\
\hline & 0.10 & 0.00 \\
\hline & $(0.059)$ & $(0.039)$ \\
\hline \multirow[b]{5}{*}{ one or more computer(c) at home (vec=1) } & -0.02 & $0.05^{*}$ \\
\hline & $(0.025)$ & $(0.028)$ \\
\hline & -0.04 & 0.03 \\
\hline & $(0.026)$ & $(0.031)$ \\
\hline & $0.16^{*}$ & $0.32^{\star *}$ \\
\hline one or more computer(s) at home (yes=1) & $(0.092)$ & $(0.153)$ \\
\hline \multirow[t]{2}{*}{ academic track (yes=1) } & -0.04 & 0.10 \\
\hline & $(0.095)$ & $(0.098)$ \\
\hline \multirow[t]{6}{*}{ student's grade: } & 0.06 & -0.10 \\
\hline & $(0.057)$ & $(0.065)$ \\
\hline & 0.08 & $-0.14^{* *}$ \\
\hline & $(0.059)$ & $(0.063)$ \\
\hline & -0.01 & -0.14 \\
\hline & $(0.104)$ & $(0.173)$ \\
\hline \multirow[t]{2}{*}{ ESCS-index of school } & -0.02 & $-0.28^{* * *}$ \\
\hline & $(0.121)$ & $(0.104)$ \\
\hline \multirow[t]{2}{*}{ rural } & -0.04 & $0.21^{* *}$ \\
\hline & $(0.202)$ & $(0.088)$ \\
\hline \multirow[t]{2}{*}{ school can fire teachers } & $0.63^{\star \star *}$ & - \\
\hline & $(0.071)$ & - \\
\hline \multirow[t]{2}{*}{ achievement data used } & -0.00 & 0.07 \\
\hline & $(0.075)$ & $(0.096)$ \\
\hline \multirow[t]{2}{*}{ school sets teacher increase } & 0.09 & -0.02 \\
\hline & $(0.072)$ & $(0.103)$ \\
\hline \multirow[t]{2}{*}{ parents involved in budget } & -0.08 & -0.16 \\
\hline & $(0.117)$ & $(0.140)$ \\
\hline \multirow[t]{2}{*}{ student-teacher ratio } & -0.01 & 0.00 \\
\hline & $(0.011)$ & $(0.007)$ \\
\hline \multirow[t]{2}{*}{ proportion certified teachers } & 0.01 & -0.24 \\
\hline & $(0.185)$ & $(0.182)$ \\
\hline \multirow[t]{2}{*}{ weekly mathematics lessons (hours) } & 0.00 & 0.00 \\
\hline & $(0.006)$ & $(0.000)$ \\
\hline \multirow[t]{2}{*}{ Constant } & -0.05 & 0.79 \\
\hline & $(0.532)$ & $(0.560)$ \\
\hline Observations & 3,838 & 3,086 \\
\hline R-squared & 0.18 & 0.14 \\
\hline Adj. R-squared & 0.179 & 0.134 \\
\hline
\end{tabular}

Notes: Robust clustered standard errors (at school level) in parentheses ${ }^{\star * *} p<0.01,{ }^{* *} p<0.05,{ }^{*} p<0.1$ 
Table 5.4a: 2SLS IV results private school attendance, PISA 2006

\begin{tabular}{|c|c|c|c|}
\hline $\begin{array}{l}\text { PISA } 2006 \\
\text { VARIABLES }\end{array}$ & $\begin{array}{c}\text { (1) } \\
\text { Mathematics }\end{array}$ & $\begin{array}{c}\text { (2) } \\
\text { Reading }\end{array}$ & $\begin{array}{c}(3) \\
\text { Science }\end{array}$ \\
\hline private & $\begin{array}{c}18.96 \\
(11.528)\end{array}$ & $\begin{array}{c}32.74^{\star *} \\
(13.073)\end{array}$ & $\begin{array}{c}20.91^{*} \\
(10.726)\end{array}$ \\
\hline age & $\begin{array}{c}-18.56^{* * *} \\
(3.359)\end{array}$ & $\begin{array}{l}-10.44^{* * *} \\
(3.593)\end{array}$ & $\begin{array}{l}-8.27^{* *} \\
(3.618)\end{array}$ \\
\hline female (yes=1) & $\begin{array}{c}-23.71^{* * *} \\
(1.980)\end{array}$ & $\begin{array}{l}12.55^{\star * *} \\
(2.649)\end{array}$ & $\begin{array}{c}-18.65^{* * *} \\
(2.389)\end{array}$ \\
\hline mother's education: & $\begin{array}{c}19.75^{\star * *} \\
(7.258)\end{array}$ & $\begin{array}{c}9.69 \\
(8.105)\end{array}$ & $\begin{array}{c}12.69 \\
(9.162)\end{array}$ \\
\hline lower-secondary & $\begin{array}{l}18.37^{* * *} \\
(6.070)\end{array}$ & $\begin{array}{c}8.47 \\
(6.894)\end{array}$ & $\begin{array}{l}18.32^{* *} \\
(7.628)\end{array}$ \\
\hline upper secondary & $\begin{array}{l}16.84^{* * *} \\
(6.304)\end{array}$ & $\begin{array}{l}13.08^{*} \\
(7.390)\end{array}$ & $\begin{array}{l}19.51^{* *} \\
(7.856)\end{array}$ \\
\hline university & $\begin{array}{l}14.81^{* *} \\
(5.942)\end{array}$ & $\begin{array}{c}6.74 \\
(7.182)\end{array}$ & $\begin{array}{l}14.33^{*} \\
(7.645)\end{array}$ \\
\hline books at home: & $\begin{array}{c}14.72^{* * *} \\
(2.881)\end{array}$ & $\begin{array}{l}10.56^{* * *} \\
(2.908)\end{array}$ & $\begin{array}{c}19.29^{* * *} \\
(2.874)\end{array}$ \\
\hline $101-500$ & $\begin{array}{c}32.52^{* * *} \\
(3.352)\end{array}$ & $\begin{array}{c}22.14^{* * *} \\
(3.278)\end{array}$ & $\begin{array}{c}38.60^{* * *} \\
(3.260)\end{array}$ \\
\hline one or more computer(s) at home (yes=1) & $\begin{array}{c}19.73 \\
(13.082)\end{array}$ & $\begin{array}{c}8.70 \\
(15.218)\end{array}$ & $\begin{array}{c}29.22^{* *} \\
(13.258)\end{array}$ \\
\hline academic track (yes $=1$ ) & $\begin{array}{c}84.45^{* * *} \\
(6.262)\end{array}$ & $\begin{array}{c}77.66^{* * *} \\
(7.212)\end{array}$ & $\begin{array}{c}79.84^{* * *} \\
(5.313)\end{array}$ \\
\hline student's grade: & $\begin{array}{c}29.40^{* * *} \\
(5.228)\end{array}$ & $\begin{array}{c}42.38^{* * *} \\
(7.290)\end{array}$ & $\begin{array}{c}27.07^{* * *} \\
(7.108)\end{array}$ \\
\hline 10th & $\begin{array}{c}74.40^{* * *} \\
(5.607)\end{array}$ & $\begin{array}{c}78.32^{* * *} \\
(7.542)\end{array}$ & $\begin{array}{c}64.93^{* * *} \\
(7.622)\end{array}$ \\
\hline 11th & $\begin{array}{c}129.78^{\star * *} \\
(10.707)\end{array}$ & $\begin{array}{c}123.52^{* * *} \\
(10.129)\end{array}$ & $\begin{array}{l}111.13^{* * *} \\
(12.873)\end{array}$ \\
\hline ESCS-index of school & $\begin{array}{l}19.06^{* * *} \\
(6.928)\end{array}$ & $\begin{array}{c}34.35^{* * *} \\
(8.481)\end{array}$ & $\begin{array}{c}35.65^{* * *} \\
(6.550)\end{array}$ \\
\hline rural & $\begin{array}{c}20.87^{\star} \\
(12.498)\end{array}$ & $\begin{array}{c}24.67^{* *} \\
(10.562)\end{array}$ & $\begin{array}{c}12.94 \\
(11.247)\end{array}$ \\
\hline school can fire teachers & $\begin{array}{c}0.36 \\
(9.477)\end{array}$ & $\begin{array}{c}-32.24^{* * *} \\
(9.953)\end{array}$ & $\begin{array}{c}14.45^{*} \\
(8.150)\end{array}$ \\
\hline achievement data used & $\begin{array}{c}5.57 \\
(5.895)\end{array}$ & $\begin{array}{c}7.73 \\
(6.414)\end{array}$ & $\begin{array}{c}5.17 \\
(4.944)\end{array}$ \\
\hline school sets teacher increase & $\begin{array}{c}-3.32 \\
(4.449)\end{array}$ & $\begin{array}{l}-1.04 \\
(5.495)\end{array}$ & $\begin{array}{c}-0.33 \\
(4.288)\end{array}$ \\
\hline parents involved in budget & $\begin{array}{c}8.32 \\
(7.459)\end{array}$ & $\begin{array}{l}17.01^{*} \\
(8.842)\end{array}$ & $\begin{array}{l}13.81^{* *} \\
(6.612)\end{array}$ \\
\hline student-teacher ratio & $\begin{array}{c}0.92 \\
(0.689)\end{array}$ & $\begin{array}{c}0.28 \\
(1.280)\end{array}$ & $\begin{array}{c}1.19 \\
(0.795)\end{array}$ \\
\hline proportion certified teachers & $\begin{array}{l}-1.68 \\
(9.605)\end{array}$ & $\begin{array}{c}14.68 \\
(12.178)\end{array}$ & $\begin{array}{c}14.16 \\
(12.734)\end{array}$ \\
\hline weekly mathematics hours (categorical) & $\begin{array}{l}5.20^{* * *} \\
(0.735)\end{array}$ & $\begin{array}{l}3.98^{* * *} \\
(0.757)\end{array}$ & $\begin{array}{l}4.72^{* * *} \\
(0.713)\end{array}$ \\
\hline Constant & $\begin{array}{c}645.17^{* * *} \\
(62.006)\end{array}$ & $\begin{array}{c}510.69^{* * *} \\
(65.967)\end{array}$ & $\begin{array}{c}429.81^{* * *} \\
(63.464)\end{array}$ \\
\hline Observations & 3,838 & 3,838 & 3,838 \\
\hline R-squared & 0.67 & 0.58 & 0.63 \\
\hline Adj. R-squared & 0.669 & 0.579 & 0.632 \\
\hline
\end{tabular}

Robust clusterd standard errors (at school level) in parentheses

${ }^{* * *} p<0.01,{ }^{* *} p<0.05,{ }^{*} p<0.1$ 
Table 5.4b: 2SLS IV results private school attendance, PISA 2009

\begin{tabular}{|c|c|c|c|}
\hline $\begin{array}{l}\text { PISA } 2009 \\
\text { VARIABLES }\end{array}$ & $\begin{array}{c}\text { (1) } \\
\text { Mathematics }\end{array}$ & $\begin{array}{c}\text { (2) } \\
\text { Reading }\end{array}$ & $\begin{array}{c}(3) \\
\text { Science }\end{array}$ \\
\hline private & $\begin{array}{c}-28.02 \\
(28.655)\end{array}$ & $\begin{array}{c}-23.23 \\
(32.996)\end{array}$ & $\begin{array}{c}-43.90 \\
(36.987)\end{array}$ \\
\hline age & $\begin{array}{c}-31.03^{* * *} \\
(3.933)\end{array}$ & $\begin{array}{c}-14.04^{* * *} \\
(4.538)\end{array}$ & $\begin{array}{c}-21.35^{* * *} \\
(4.587)\end{array}$ \\
\hline female $($ yes $=1)$ & $\begin{array}{l}-27.12^{* \star *} \\
(1.938)\end{array}$ & $\begin{array}{l}15.10^{\star \star \star} \\
(2.159)\end{array}$ & $\begin{array}{c}-14.09^{* * *} \\
(2.297)\end{array}$ \\
\hline mother's education: & $\begin{array}{c}1.36 \\
(6.085)\end{array}$ & $\begin{array}{c}3.16 \\
(5.717)\end{array}$ & $\begin{array}{c}2.04 \\
(7.177)\end{array}$ \\
\hline lower-secondary & $\begin{array}{l}13.07^{* * *} \\
(4.414)\end{array}$ & $\begin{array}{l}14.16^{\star * *} \\
(5.447)\end{array}$ & $\begin{array}{c}12.79^{*} \\
(7.763)\end{array}$ \\
\hline upper secondary & $\begin{array}{c}10.28^{* * *} \\
(3.526)\end{array}$ & $\begin{array}{l}10.29^{* *} \\
(4.119)\end{array}$ & $\begin{array}{c}11.34^{*} \\
(6.017)\end{array}$ \\
\hline university & $\begin{array}{c}5.61^{*} \\
(3.260)\end{array}$ & $\begin{array}{c}7.75^{\star *} \\
(3.735)\end{array}$ & $\begin{array}{l}12.30^{* *} \\
(5.087)\end{array}$ \\
\hline books at home: & $\begin{array}{c}15.84^{* * *} \\
(3.666)\end{array}$ & $\begin{array}{l}16.11^{* * *} \\
(4.756)\end{array}$ & $\begin{array}{c}12.18^{* * *} \\
(4.515)\end{array}$ \\
\hline $101-500$ & $\begin{array}{l}31.82^{* * *} \\
(3.540)\end{array}$ & $\begin{array}{c}32.75^{\star \star *} \\
(4.083)\end{array}$ & $\begin{array}{l}30.56^{\star \star *} \\
(4.399)\end{array}$ \\
\hline one or more computer(s) at home (yes $=1$ ) & $\begin{array}{c}30.16 \\
(19.631)\end{array}$ & $\begin{array}{c}29.75 \\
(21.267)\end{array}$ & $\begin{array}{c}39.25 \\
(27.530)\end{array}$ \\
\hline academic track $($ yes $=1)$ & $\begin{array}{c}90.59^{* * *} \\
(6.224)\end{array}$ & $\begin{array}{c}91.13^{* * *} \\
(7.317)\end{array}$ & $\begin{array}{c}88.90^{* * *} \\
(7.707)\end{array}$ \\
\hline student's grade: & $\begin{array}{c}34.13^{* * *} \\
(7.330)\end{array}$ & $\begin{array}{c}23.31^{* * *} \\
(8.577)\end{array}$ & $\begin{array}{l}22.41^{* *} \\
(10.671)\end{array}$ \\
\hline 10th & $\begin{array}{c}79.63^{* * *} \\
(7.341)\end{array}$ & $\begin{array}{c}54.43^{* * *} \\
(9.138)\end{array}$ & $\begin{array}{l}57.60^{* * *} \\
(10.748)\end{array}$ \\
\hline 11th & $\begin{array}{l}118.03^{* * *} \\
(13.028)\end{array}$ & $\begin{array}{l}83.90^{* * *} \\
(11.894)\end{array}$ & $\begin{array}{l}94.24^{* * *} \\
(15.856)\end{array}$ \\
\hline ESCS-index of school & $\begin{array}{c}22.88^{* *} \\
(10.388)\end{array}$ & $\begin{array}{l}25.29^{* *} \\
(11.617)\end{array}$ & $\begin{array}{c}31.21^{*} \\
(16.254)\end{array}$ \\
\hline rural & $\begin{array}{c}7.22 \\
(7.798)\end{array}$ & $\begin{array}{c}2.45 \\
(9.683)\end{array}$ & $\begin{array}{c}17.39 * \\
(10.292)\end{array}$ \\
\hline achievement data used & $\begin{array}{c}3.68 \\
(6.022)\end{array}$ & $\begin{array}{c}0.29 \\
(7.920)\end{array}$ & $\begin{array}{c}1.87 \\
(7.614)\end{array}$ \\
\hline school sets teacher increase & $\begin{array}{c}2.52 \\
(6.581)\end{array}$ & $\begin{array}{c}1.24 \\
(6.875)\end{array}$ & $\begin{array}{c}4.80 \\
(7.638)\end{array}$ \\
\hline parents involved in budget & $\begin{array}{c}-6.00 \\
(7.792)\end{array}$ & $\begin{array}{l}-11.40 \\
(8.396)\end{array}$ & $\begin{array}{c}-16.14 \\
(11.142)\end{array}$ \\
\hline student-teacher ratio & $\begin{array}{c}0.00 \\
(0.608)\end{array}$ & $\begin{array}{c}0.23 \\
(0.863)\end{array}$ & $\begin{array}{c}0.70 \\
(0.811)\end{array}$ \\
\hline proportion certified teachers & $\begin{array}{c}0.16^{* * *} \\
(0.036)\end{array}$ & $\begin{array}{l}0.14^{* * *} \\
(0.040)\end{array}$ & $\begin{array}{l}0.14^{* * *} \\
(0.042)\end{array}$ \\
\hline weekly mathematics hours (categorical) & $\begin{array}{c}-12.38 \\
(13.965)\end{array}$ & $\begin{array}{c}-16.90 \\
(16.514)\end{array}$ & $\begin{array}{c}-12.62 \\
(17.153)\end{array}$ \\
\hline Constant & $\begin{array}{l}875.45^{* * *} \\
(73.842)\end{array}$ & $\begin{array}{l}588.18^{* * *} \\
(84.484)\end{array}$ & $\begin{array}{l}721.88^{* * *} \\
(88.055)\end{array}$ \\
\hline Observations & 3,086 & 3,086 & 3,086 \\
\hline R-squared & 0.67 & 0.62 & 0.58 \\
\hline Adj. R-squared & 0.666 & 0.617 & 0.578 \\
\hline
\end{tabular}

Robust standard errors in parentheses

*** $p<0.01,{ }^{* *} p<0.05,{ }^{*} p<0.1$ 
Table 5.5a: Weighted regression-adjusted PSM results, PISA 2006

\begin{tabular}{|c|c|c|c|}
\hline \multirow{2}{*}{$\begin{array}{l}\text { PISA } 2006 \\
\text { VARIABLES }\end{array}$} & (1) & (2) & (3) \\
\hline & Mathematics & Reading & Science \\
\hline \multirow[t]{2}{*}{ private (treated $=1$ ) } & $10.26^{* *}$ & 5.94 & 4.08 \\
\hline & $(4.421)$ & $(5.387)$ & $(4.703)$ \\
\hline \multirow[t]{2}{*}{ age } & $11.81^{* \star *}$ & $9.48^{* *}$ & $13.47^{\star \star *}$ \\
\hline & $(3.509)$ & $(3.646)$ & $(3.950)$ \\
\hline \multirow[t]{2}{*}{ female (yes=1) } & $-21.44^{* * *}$ & $15.73^{\star \star *}$ & $-15.99^{* * *}$ \\
\hline & $(2.149)$ & $(2.500)$ & $(2.546)$ \\
\hline \multirow[t]{2}{*}{ student's ESCS-index } & -3.04 & 1.49 & 1.11 \\
\hline & $(1.912)$ & $(2.024)$ & $(2.225)$ \\
\hline \multirow[t]{4}{*}{ books at home: } & $15.23^{* \star *}$ & $10.47^{* *}$ & $19.26^{* \star *}$ \\
\hline & $(3.346)$ & $(4.148)$ & $(3.960)$ \\
\hline & $29.78^{* * *}$ & $16.06^{\star \star *}$ & $32.70^{* * *}$ \\
\hline & $(4.035)$ & $(4.693)$ & $(4.696)$ \\
\hline \multirow[t]{2}{*}{ home educational resources } & $7.23^{* * *}$ & $5.93^{* * *}$ & $4.36^{* *}$ \\
\hline & $(1.535)$ & $(2.029)$ & $(1.826)$ \\
\hline \multirow[t]{8}{*}{ mother's education: } & 7.15 & -10.19 & -7.33 \\
\hline & (9.051) & (11.182) & $(10.253)$ \\
\hline & $13.04^{* *}$ & 0.87 & 2.26 \\
\hline & (5.999) & $(7.731)$ & $(6.672)$ \\
\hline & $11.90^{*}$ & 5.96 & 1.77 \\
\hline & $(6.907)$ & $(8.219)$ & $(7.636)$ \\
\hline & 6.95 & -8.10 & -7.72 \\
\hline & $(7.208)$ & $(8.908)$ & $(8.340)$ \\
\hline \multirow[t]{2}{*}{ immigrant status (yes=1) } & $-16.80^{* * *}$ & $-10.47^{* *}$ & $-23.53^{* * *}$ \\
\hline & $(4.675)$ & $(5.259)$ & $(5.194)$ \\
\hline \multirow[t]{2}{*}{ non-western language at home (yes=1) } & -8.36 & $-23.09^{* * *}$ & $-19.39^{* * *}$ \\
\hline & $(6.527)$ & $(7.784)$ & $(6.581)$ \\
\hline \multirow[t]{2}{*}{ academic track (yes=1) } & $85.04^{* \star *}$ & $76.85^{\star \star \star}$ & $83.31^{\star \star *}$ \\
\hline & $(5.880)$ & $(7.230)$ & $(5.731)$ \\
\hline \multirow[t]{2}{*}{ ESCS-index of school } & $44.93^{* * *}$ & $56.84^{* * *}$ & $54.78^{* * *}$ \\
\hline & $(9.300)$ & $(11.514)$ & $(7.655)$ \\
\hline \multirow[t]{2}{*}{ proportion immigrants at school } & 4.67 & 8.71 & 8.50 \\
\hline & $(18.557)$ & $(17.052)$ & $(16.653)$ \\
\hline \multirow[t]{2}{*}{ rural } & $21.85^{* *}$ & $35.41^{* * *}$ & $17.37^{*}$ \\
\hline & $(11.046)$ & $(7.844)$ & $(9.882)$ \\
\hline \multirow[t]{2}{*}{ Constant } & $277.45^{\star \star \star}$ & $292.80^{* \star *}$ & $253.44^{\star \star \star}$ \\
\hline & $(56.024)$ & $(57.776)$ & $(62.960)$ \\
\hline Observations & 4,125 & 4,125 & 4,125 \\
\hline R-squared & 0.60 & 0.52 & 0.57 \\
\hline
\end{tabular}

Notes: Robust clustered standard errors (at school level) in parentheses

${ }^{* * *} p<0.01,{ }^{* *} p<0.05,{ }^{*} p<0.1$ 
Table 5.5b: Weighted regression-adjusted PSM results, PISA 2009

\begin{tabular}{|c|c|c|c|}
\hline PISA 2009 & (1) & $(2)$ & (3) \\
\hline VARIABLES & Mathematics & Reading & Science \\
\hline \multirow[t]{2}{*}{ private (treated $=1$ ) } & 2.14 & 2.19 & 3.45 \\
\hline & $(4.229)$ & $(4.754)$ & $(5.175)$ \\
\hline \multirow[t]{2}{*}{ age } & $8.05^{\star *}$ & $10.85^{\star \star \star}$ & $7.61^{*}$ \\
\hline & $(3.582)$ & $(3.817)$ & $(4.077)$ \\
\hline \multirow[t]{2}{*}{ female (yes=1) } & $-22.61^{* * *}$ & $17.03^{\star \star \star}$ & $-9.32^{* * *}$ \\
\hline & $(1.917)$ & $(2.050)$ & $(2.192)$ \\
\hline \multirow[t]{2}{*}{ student's ESCS-index } & 2.31 & 0.54 & 1.05 \\
\hline & $(1.555)$ & $(1.700)$ & $(1.826)$ \\
\hline \multirow[t]{4}{*}{ books at home: } & $11.06^{\star * *}$ & $18.38^{* * *}$ & 6.33 \\
\hline & (3.368) & $(3.819)$ & (3.981) \\
\hline & $27.16^{* \star *}$ & $32.40^{* * *}$ & $23.19^{* * *}$ \\
\hline & (3.591) & $(3.502)$ & $(3.628)$ \\
\hline \multirow[t]{2}{*}{ home educational resources } & $6.61^{* * *}$ & $4.35^{\star * *}$ & $5.86^{* * *}$ \\
\hline & $(1.494)$ & $(1.455)$ & $(1.652)$ \\
\hline \multirow[t]{8}{*}{ mother's education: } & 8.18 & 9.43 & 11.85 \\
\hline & $(5.841)$ & $(6.876)$ & (8.052) \\
\hline & $14.42^{\star \star \star}$ & $12.51^{* *}$ & 7.94 \\
\hline & $(4.775)$ & $(5.195)$ & $(6.289)$ \\
\hline & $10.33^{\star \star *}$ & $7.60^{* *}$ & 6.75 \\
\hline & $(3.494)$ & $(3.587)$ & $(4.099)$ \\
\hline & 4.70 & 5.65 & $9.58^{* *}$ \\
\hline & $(3.755)$ & (3.706) & $(4.200)$ \\
\hline \multirow[t]{2}{*}{ immigrant status (yes=1) } & $-14.21^{* * *}$ & $-9.62^{*}$ & $-26.90^{* * *}$ \\
\hline & $(4.347)$ & $(5.259)$ & $(5.712)$ \\
\hline \multirow[t]{2}{*}{ non-western language at home (yes $=1$ ) } & -10.37 & $-12.77^{*}$ & $-15.37^{* *}$ \\
\hline & $(6.407)$ & $(6.865)$ & $(7.269)$ \\
\hline \multirow[t]{2}{*}{ academic track (yes=1) } & $86.92^{* \star *}$ & $83.13^{* \star *}$ & $83.39^{\star * *}$ \\
\hline & $(5.604)$ & $(5.924)$ & $(6.336)$ \\
\hline \multirow[t]{2}{*}{ ESCS-index of school } & $39.23^{\star \star \star}$ & $39.46^{\star \star \star}$ & $57.02^{\star \star *}$ \\
\hline & (8.551) & $(9.040)$ & (11.308) \\
\hline \multirow[t]{2}{*}{ proportion immigrants at school } & 9.56 & 16.39 & 21.81 \\
\hline & $(19.964)$ & (19.898) & $(26.713)$ \\
\hline \multirow[t]{2}{*}{ rural } & -3.65 & $-11.94^{*}$ & -0.04 \\
\hline & $(6.217)$ & $(7.008)$ & $(6.976)$ \\
\hline \multirow[t]{2}{*}{ Constant } & $344.46^{* * *}$ & $260.94^{* \star *}$ & $341.75^{\star \star *}$ \\
\hline & $(57.898)$ & $(62.157)$ & $(66.227)$ \\
\hline Observations & 3,723 & 3,723 & 3,723 \\
\hline R-squared & 0.62 & 0.57 & 0.58 \\
\hline
\end{tabular}

Notes: Robust clustered standard errors (at school level) in parentheses.

${ }^{* * *} p<0.01,{ }^{* *} p<0.05,{ }^{*} p<0.1$ 
Table 5.11: OLS, Private school attendance effect, BRON PO '08-'09

\begin{tabular}{|c|c|c|c|c|c|c|c|c|c|}
\hline & $\mathrm{NL}$ & G31 & G4 & $\mathrm{NL}$ & G31 & G4 & $\mathrm{NL}$ & G31 & G4 \\
\hline & (1) & (2) & (3) & (4) & (5) & (6) & (7) & (8) & (9) \\
\hline VARIABLES & СITO & СІTO & СІTO & CITO & CITO & CITO & CITO & CITO & CITO \\
\hline \multirow[t]{2}{*}{ private } & $0.91^{* * *}$ & 0.29 & 0.18 & $0.54^{\star *}$ & 0.04 & -0.09 & $0.37^{*}$ & -0.57 & -0.37 \\
\hline & $(0.256)$ & $(0.540)$ & $(1.061)$ & $(0.219)$ & $(0.413)$ & $(0.749)$ & $(0.205)$ & $(0.373)$ & $(0.650)$ \\
\hline \multirow[t]{2}{*}{ age } & & & & $-3.30^{* \star *}$ & $-3.40^{\star \star *}$ & $-3.69^{* \star *}$ & $-3.26^{\star \star *}$ & $-3.28^{\star \star *}$ & $-3.51^{\star \star *}$ \\
\hline & & & & $(0.079)$ & $(0.137)$ & $(0.240)$ & $(0.078)$ & $(0.132)$ & $(0.237)$ \\
\hline \multirow[t]{2}{*}{ female (yes=1) } & & & & $-0.93^{* * *}$ & $-1.16^{\star \star *}$ & $-1.40^{\star \star \star}$ & $-0.93^{\star * *}$ & $-1.15^{\star \star *}$ & $-1.38^{\star * *}$ \\
\hline & & & & $(0.101)$ & $(0.184)$ & $(0.288)$ & $(0.100)$ & $(0.177)$ & $(0.280)$ \\
\hline \multirow[t]{2}{*}{ student's weighted funding } & & & & $-5.58^{\star \star *}$ & $-3.84^{* * *}$ & $-3.50^{\star \star \star}$ & $-4.38^{* * *}$ & $-2.17^{\star \star \star}$ & $-2.06^{\star * *}$ \\
\hline & & & & $(0.393)$ & $(0.528)$ & $(0.717)$ & $(0.389)$ & $(0.497)$ & $(0.672)$ \\
\hline \multirow[t]{2}{*}{ single-parent household } & & & & $-3.05^{\star \star *}$ & $-3.35^{\star \star \star}$ & $-3.45^{* \star *}$ & $-2.51^{* * *}$ & $-2.62^{\star \star *}$ & $-2.89^{\star \star \star}$ \\
\hline & & & & $(0.366)$ & $(0.468)$ & $(0.625)$ & $(0.353)$ & $(0.453)$ & $(0.607)$ \\
\hline \multirow[t]{2}{*}{ non-western immigrant background (yes=1) } & & & & $-2.29^{* * *}$ & $-3.74^{* \star *}$ & $-5.34^{* * *}$ & $-1.37^{* * *}$ & $-1.82^{\star \star \star}$ & $-2.90^{\star * \star}$ \\
\hline & & & & $(0.279)$ & $(0.401)$ & $(0.643)$ & $(0.254)$ & $(0.361)$ & $(0.559)$ \\
\hline \multirow[t]{2}{*}{ 2nd generation immigrant background (yes $=1$ ) } & & & & -0.01 & -0.28 & -0.21 & -0.00 & -0.24 & -0.14 \\
\hline & & & & $(0.207)$ & $(0.303)$ & $(0.464)$ & $(0.198)$ & $(0.289)$ & $(0.457)$ \\
\hline \multirow[t]{2}{*}{ ESCS-index of school intake } & & & & & & & 0.11 & -0.20 & -0.72 \\
\hline & & & & & & & $(0.175)$ & $(0.283)$ & $(0.544)$ \\
\hline \multirow[t]{2}{*}{ proportion non-western immigrants at school } & & & & & & & $-3.76^{* * *}$ & $-7.24^{* * *}$ & $-7.82^{\star * *}$ \\
\hline & & & & & & & $(0.683)$ & $(0.963)$ & $(1.493)$ \\
\hline \multirow[t]{2}{*}{ neighborhood ESCS index } & & & & & & & $0.77^{\star \star *}$ & $0.85^{* \star *}$ & $0.82^{* \star *}$ \\
\hline & & & & & & & $(0.098)$ & $(0.146)$ & $(0.228)$ \\
\hline \multirow[t]{2}{*}{ neighborhood urbanicity index } & & & & & & & $0.65^{* * *}$ & $0.71^{* \star *}$ & $1.13^{\star *}$ \\
\hline & & & & & & & $(0.095)$ & $(0.210)$ & $(0.497)$ \\
\hline municipality dummies included & no & no & no & no & no & no & no & yes & yes \\
\hline \multirow[t]{2}{*}{ Constant } & $534.58^{\star \star \star}$ & $534.32^{\star * *}$ & $533.15^{\star \star \star}$ & $536.11^{* * *}$ & $537.05^{\star \star \star}$ & $538.30^{\star \star *}$ & $535.31^{* \star *}$ & $538.61^{* \star *}$ & $536.48^{\star \star \star}$ \\
\hline & $(0.221)$ & $(0.446)$ & $(0.876)$ & $(0.193)$ & $(0.353)$ & $(0.677)$ & $(0.221)$ & $(0.922)$ & $(2.053)$ \\
\hline Observations & 37,954 & 12,699 & 4,727 & 37,943 & 12,689 & 4,717 & 37,911 & 12,678 & 4,712 \\
\hline R-squared & 0.00 & 0.00 & 0.00 & 0.11 & 0.15 & 0.20 & 0.12 & 0.19 & 0.23 \\
\hline Adj. R-squared & 0.00170 & $8.59 \mathrm{e}-05$ & -0.000154 & 0.109 & 0.148 & 0.198 & 0.123 & 0.192 & 0.232 \\
\hline
\end{tabular}


Table 5.12: OLS, Private school type attendance effects, BRON PO '08-'09

\begin{tabular}{|c|c|c|c|}
\hline & $\mathrm{NL}$ & G31 & G4 \\
\hline & (1) & $(2)$ & (3) \\
\hline VARIABLES & CITO & CITO & СІTO \\
\hline \multirow[t]{2}{*}{ private Catholic } & 0.32 & $-0.98^{\star *}$ & $-1.66^{* *}$ \\
\hline & $(0.233)$ & $(0.470)$ & $(0.844)$ \\
\hline \multirow[t]{2}{*}{ private Protestant } & 0.03 & -0.60 & -0.29 \\
\hline & $(0.237)$ & $(0.476)$ & $(0.725)$ \\
\hline \multirow[t]{2}{*}{ private other religion } & -0.13 & 2.02 & $2.96^{*}$ \\
\hline & $(1.755)$ & $(1.704)$ & $(1.587)$ \\
\hline \multirow[t]{2}{*}{ private non-religious } & $1.42^{* * *}$ & -0.28 & $2.39^{* * *}$ \\
\hline & $(0.448)$ & $(0.630)$ & $(0.813)$ \\
\hline \multirow[t]{2}{*}{ age } & $-3.26^{\star \star *}$ & $-3.28^{\star \star *}$ & $-3.48^{* * *}$ \\
\hline & $(0.079)$ & $(0.132)$ & $(0.236)$ \\
\hline \multirow[t]{2}{*}{ female (yes=1) } & $-0.93^{* * *}$ & $-1.16^{* * *}$ & $-1.37^{* * *}$ \\
\hline & $(0.100)$ & $(0.178)$ & $(0.287)$ \\
\hline \multirow[t]{2}{*}{ student's weighted funding } & $-4.31^{* \star *}$ & $-2.20^{\star \star \star}$ & $-2.00^{* * *}$ \\
\hline & $(0.389)$ & $(0.497)$ & $(0.663)$ \\
\hline \multirow[t]{2}{*}{ single-parent household } & $-2.51^{* * *}$ & $-2.61^{* * *}$ & $-2.85^{\star * *}$ \\
\hline & $(0.354)$ & $(0.454)$ & $(0.602)$ \\
\hline \multirow[t]{2}{*}{ non-western immigrant background (yes=1) } & $-1.34^{* * *}$ & $-1.80^{\star \star *}$ & $-2.83^{* * *}$ \\
\hline & $(0.253)$ & $(0.361)$ & $(0.555)$ \\
\hline \multirow[t]{2}{*}{ 2nd generation non-western background (yes=1) } & -0.04 & -0.26 & -0.25 \\
\hline & $(0.198)$ & $(0.290)$ & $(0.460)$ \\
\hline \multirow[t]{2}{*}{ ESCS-index of school intake } & 0.08 & -0.20 & -0.67 \\
\hline & $(0.176)$ & $(0.281)$ & $(0.528)$ \\
\hline \multirow[t]{2}{*}{ proportion non-western immigrants at school } & $-3.78^{* \star *}$ & $-7.38^{\star \star *}$ & $-7.98^{* * *}$ \\
\hline & $(0.679)$ & $(0.951)$ & $(1.449)$ \\
\hline \multirow[t]{2}{*}{ neighborhood ESCS index } & $0.77^{* * *}$ & $0.86^{* * *}$ & $0.83^{* * *}$ \\
\hline & $(0.098)$ & $(0.143)$ & $(0.219)$ \\
\hline \multirow[t]{2}{*}{ neighborhood urbanicity index } & $0.62^{* * *}$ & $0.73^{* * *}$ & $1.17^{\star * *}$ \\
\hline & $(0.096)$ & $(0.201)$ & $(0.449)$ \\
\hline municipality dummies included & no & yes & yes \\
\hline \multirow[t]{2}{*}{ Constant } & $535.43^{* * *}$ & $538.60^{* * *}$ & $537.03^{* * *}$ \\
\hline & $(0.224)$ & $(0.892)$ & $(1.955)$ \\
\hline Observations & 37,893 & 12,678 & 4,712 \\
\hline R-squared & 0.12 & 0.20 & 0.24 \\
\hline Adj. R-squared & 0.123 & 0.193 & 0.240 \\
\hline
\end{tabular}

Robust clusterd standard errors (at school level) in parentheses

${ }^{* * *} p<0.01,{ }^{* *} p<0.05,{ }^{*} p<0.1$ 
Table 5.13: PSM, Private school attendance effects, BRON PO '08-'09

\begin{tabular}{|c|c|c|c|c|c|c|}
\hline & NL & NL & G31 & G31 & G4 & G4 \\
\hline & (1) & (2) & (3) & (4) & (5) & (6) \\
\hline VARIABLES & CITO & CITO & CITO & CITO & CITO & CITO \\
\hline \multirow[t]{2}{*}{ private } & $0.64^{* *}$ & 0.44 & -0.21 & -0.32 & 0.37 & 0.09 \\
\hline & $(0.314)$ & $(0.281)$ & $(0.575)$ & $(0.446)$ & $(1.268)$ & $(0.716)$ \\
\hline \multirow[t]{2}{*}{ age } & & $-3.26^{\star \star *}$ & & $-3.19^{* * *}$ & & $-3.59^{* * *}$ \\
\hline & & $(0.158)$ & & $(0.209)$ & & $(0.339)$ \\
\hline \multirow[t]{2}{*}{ female (yes $=1$ ) } & & $-0.77^{\star \star *}$ & & $-1.62^{* * *}$ & & $-1.54^{* * *}$ \\
\hline & & $(0.212)$ & & $(0.333)$ & & $(0.467)$ \\
\hline \multirow[t]{2}{*}{ student's weighted funding } & & $-5.36^{\star \star \star}$ & & $-2.45^{\star * *}$ & & $-2.28^{* *}$ \\
\hline & & $(0.549)$ & & $(0.696)$ & & $(0.956)$ \\
\hline \multirow[t]{2}{*}{ single-parent household } & & $-2.94^{* * *}$ & & $-2.88^{* * *}$ & & $-1.90^{*}$ \\
\hline & & $(0.507)$ & & $(0.619)$ & & $(1.081)$ \\
\hline \multirow[t]{2}{*}{ non-western immigrant background (yes=1) } & & $-1.24^{\star \star *}$ & & $-1.79^{* * *}$ & & $-1.48^{*}$ \\
\hline & & $(0.408)$ & & $(0.664)$ & & $(0.799)$ \\
\hline \multirow[t]{2}{*}{ 2nd generation immigrant background (yes=1) } & & 0.29 & & $-1.00^{*}$ & & -1.03 \\
\hline & & $(0.298)$ & & $(0.579)$ & & $(0.776)$ \\
\hline \multirow[t]{2}{*}{ ESCS-index of school intake } & & -0.19 & & -0.17 & & $-1.37^{* *}$ \\
\hline & & $(0.302)$ & & $(0.335)$ & & $(0.584)$ \\
\hline \multirow[t]{2}{*}{ proportion non-western immigrants at school } & & $-4.07^{* \star *}$ & & $-6.29^{* * *}$ & & $-11.97^{* * *}$ \\
\hline & & $(0.963)$ & & $(1.162)$ & & $(1.829)$ \\
\hline \multirow[t]{2}{*}{ neighborhood ESCS index } & & $0.94^{* * *}$ & & $0.63^{* *}$ & & $0.90^{* * *}$ \\
\hline & & $(0.212)$ & & $(0.248)$ & & $(0.333)$ \\
\hline \multirow[t]{2}{*}{ neighborhood urbanicity index } & & $0.76^{* * *}$ & & $0.93^{* * *}$ & & $1.48^{* * *}$ \\
\hline & & $(0.134)$ & & $(0.300)$ & & $(0.547)$ \\
\hline municipality dummies included & no & no & no & yes & no & yes \\
\hline \multirow[t]{2}{*}{ Constant } & $534.84^{* * *}$ & $535.03^{* * *}$ & $534.82^{\star * *}$ & $537.33^{* * *}$ & $532.96^{* * *}$ & $535.84^{* * *}$ \\
\hline & $(0.285)$ & $(0.338)$ & $(0.488)$ & $(1.265)$ & $(1.118)$ & (2.491) \\
\hline Observations & 31,991 & 31,989 & 10,524 & 10,522 & 3,799 & 3,799 \\
\hline R-squared & 0.00 & 0.12 & 0.00 & 0.19 & 0.00 & 0.28 \\
\hline Adj. R-squared & 0.00107 & 0.121 & $9.13 e-06$ & 0.184 & $1.33 e-05$ & 0.273 \\
\hline
\end{tabular}

Notes: Robust clusterd standard errors (at school level) in parentheses ${ }^{* * *} p<0.01,{ }^{* *} p<0.05,{ }^{*} p<0.1$ 
Table 5.14: Private Catholic/non-religious school effects, BRON PO '08-'09

\begin{tabular}{|c|c|c|c|c|c|c|}
\hline & $\mathrm{NL}$ & $\mathrm{NL}$ & G31 & G31 & G4 & G4 \\
\hline & (1) & (2) & (3) & (4) & (5) & (6) \\
\hline VARIABLES & CITO & CITO & CITO & CITO & CITO & CITO \\
\hline \multirow[t]{2}{*}{ private Catholic } & 0.20 & & -0.26 & & -1.01 & \\
\hline & $(0.262)$ & & $(0.468)$ & & $(0.892)$ & \\
\hline \multirow[t]{2}{*}{ private non-religious } & & 0.96 & & -0.17 & & 1.33 \\
\hline & & $(0.805)$ & & $(0.807)$ & & $(0.952)$ \\
\hline \multirow[t]{2}{*}{ age } & $-3.29^{* * *}$ & $-3.00^{* * *}$ & $-3.50^{* * *}$ & $-2.85^{* \star *}$ & $-3.58^{* * *}$ & $-2.97^{* * *}$ \\
\hline & $(0.151)$ & $(0.408)$ & $(0.206)$ & $(0.372)$ & $(0.376)$ & $(0.834)$ \\
\hline \multirow[t]{2}{*}{ female (yes=1) } & $-1.20^{* * *}$ & 0.15 & $-1.52^{\star \star *}$ & -0.08 & $-1.41^{* *}$ & -1.33 \\
\hline & $(0.215)$ & $(0.619)$ & $(0.321)$ & $(0.523)$ & $(0.545)$ & (1.069) \\
\hline \multirow[t]{2}{*}{ student's weighted funding } & $-5.12^{\star * \star}$ & $-4.79^{\star \star *}$ & $-1.94^{\star * *}$ & -2.02 & $-2.99^{\star * *}$ & -3.41 \\
\hline & $(0.556)$ & $(1.518)$ & $(0.716)$ & (1.605) & $(1.016)$ & $(2.354)$ \\
\hline \multirow[t]{2}{*}{ single-parent household } & $-3.02^{* * *}$ & $-4.18^{* * *}$ & $-2.37^{* * *}$ & $-3.77^{\star *}$ & $-3.18^{* * *}$ & -4.29 \\
\hline & $(0.587)$ & $(1.528)$ & $(0.701)$ & $(1.640)$ & $(1.024)$ & $(4.880)$ \\
\hline \multirow[t]{2}{*}{ non-western immigrant background (yes=1) } & $-1.04^{* *}$ & $-2.28^{* * *}$ & $-2.44^{* * *}$ & $-3.25^{* * *}$ & $-1.89^{\star *}$ & 0.23 \\
\hline & $(0.422)$ & $(0.838)$ & $(0.608)$ & $(1.119)$ & $(0.902)$ & $(1.465)$ \\
\hline \multirow[t]{2}{*}{ 2nd generation immigrant background (yes $=1$ ) } & -0.03 & -0.17 & 0.61 & -0.55 & 0.34 & $-3.63^{* * *}$ \\
\hline & $(0.376)$ & $(0.623)$ & $(0.537)$ & $(0.907)$ & $(0.821)$ & $(1.122)$ \\
\hline \multirow[t]{2}{*}{ ESCS-index of school intake } & $0.58^{*}$ & 0.47 & -0.15 & -0.62 & $-1.25^{\star}$ & -0.25 \\
\hline & $(0.322)$ & $(0.569)$ & $(0.364)$ & $(0.743)$ & $(0.642)$ & $(1.045)$ \\
\hline \multirow[t]{2}{*}{ proportion non-western immigrants at school } & $-3.57^{\star * *}$ & $-6.13^{* *}$ & $-8.37^{\star * *}$ & $-10.78^{\star \star *}$ & $-9.81^{* * *}$ & $-6.46^{*}$ \\
\hline & $(0.923)$ & $(2.417)$ & $(1.148)$ & $(2.752)$ & $(1.771)$ & (3.637) \\
\hline \multirow[t]{2}{*}{ neighborhood ESCS index } & $0.53^{* *}$ & 0.19 & $0.89^{* * *}$ & $1.21^{* * *}$ & $1.31^{* * *}$ & $1.04^{* *}$ \\
\hline & $(0.241)$ & $(0.479)$ & $(0.240)$ & $(0.439)$ & $(0.416)$ & $(0.480)$ \\
\hline \multirow[t]{2}{*}{ neighborhood urbanicity index } & $0.65^{* * *}$ & 0.52 & $1.33^{* * *}$ & $2.25^{\star * *}$ & $2.11^{* \star *}$ & $3.03^{* * *}$ \\
\hline & $(0.131)$ & $(0.373)$ & $(0.236)$ & $(0.442)$ & $(0.518)$ & $(1.004)$ \\
\hline \multirow[t]{2}{*}{ Constant } & $535.63^{\star * *}$ & $536.19^{* \star *}$ & $535.27^{\star \star *}$ & $532.97^{* * *}$ & $533.50^{\star * *}$ & $531.52^{\star * *}$ \\
\hline & $(0.341)$ & $(1.144)$ & $(0.731)$ & $(1.530)$ & $(1.768)$ & $(4.167)$ \\
\hline Observations & 19,965 & 2,521 & 6,976 & 1,553 & 2,155 & 295 \\
\hline R-squared & 0.13 & 0.13 & 0.20 & 0.20 & 0.24 & 0.36 \\
\hline Adj. R-squared & 0.131 & 0.126 & 0.195 & 0.193 & 0.235 & 0.331 \\
\hline
\end{tabular}

Notes: Robust clusterd standard errors (at school level) in parentheses ${ }^{* * *} p<0.01,{ }^{* *} p<0.05,{ }^{*} p<0.1$ 
Table 5.16: Logit, Private school attendance effect "upward mobility"

\begin{tabular}{|c|c|c|c|c|c|c|c|c|c|}
\hline & $\mathrm{NL}$ & G31 & G4 & $\mathrm{NL}$ & G31 & G4 & $\mathrm{NL}$ & G31 & G4 \\
\hline & (1) & (2) & (3) & (4) & (5) & (6) & (7) & (8) & (9) \\
\hline VARIABLES & Level-Up & Level-Up & Level-Up & Level-Up & Level-Up & Level-Up & Level-Up & Level-Up & Level-Up \\
\hline \multirow[t]{2}{*}{ switched to private secondary school } & $-0.17^{*}$ & -0.21 & -0.13 & $-0.24^{\star *}$ & $-0.28^{*}$ & -0.17 & 0.12 & 0.12 & 0.28 \\
\hline & $(0.099)$ & $(0.161)$ & $(0.242)$ & $(0.096)$ & $(0.157)$ & $(0.211)$ & $(0.111)$ & $(0.178)$ & $(0.269)$ \\
\hline primary school advice dummies included & no & no & no & yes & yes & yes & no & no & no \\
\hline end-of primary test score included & no & no & no & no & no & no & yes & yes & yes \\
\hline \multirow[t]{2}{*}{ age } & $-0.26^{* \star *}$ & $-0.20^{* * *}$ & $-0.23^{* * *}$ & $-0.25^{* \star *}$ & $-0.22^{* * *}$ & $-0.23^{* * *}$ & -0.04 & 0.03 & -0.05 \\
\hline & $(0.027)$ & $(0.042)$ & $(0.064)$ & $(0.029)$ & $(0.047)$ & $(0.076)$ & $(0.045)$ & $(0.067)$ & $(0.108)$ \\
\hline \multirow[t]{2}{*}{ female (yes=1) } & $0.37^{\star \star *}$ & $0.39^{* * *}$ & $0.36^{* * *}$ & $0.43^{* * *}$ & $0.46^{\star \star *}$ & $0.44^{\star \star *}$ & $0.44^{* * *}$ & $0.48^{\star \star \star}$ & $0.39^{* \star *}$ \\
\hline & $(0.039)$ & $(0.069)$ & $(0.101)$ & $(0.044)$ & $(0.074)$ & $(0.115)$ & $(0.072)$ & $(0.111)$ & $(0.137)$ \\
\hline \multirow[t]{2}{*}{ student's weighted funding } & $-0.66^{\star \star *}$ & $-0.50^{* * *}$ & $-0.37^{\star}$ & $-0.58^{\star \star \star}$ & $-0.44^{* \star *}$ & -0.32 & $-0.33^{* *}$ & $-0.41^{\star *}$ & $-0.42^{*}$ \\
\hline & $(0.110)$ & $(0.146)$ & $(0.194)$ & $(0.114)$ & $(0.157)$ & $(0.209)$ & $(0.164)$ & $(0.205)$ & $(0.245)$ \\
\hline \multirow[t]{2}{*}{ single-parent household } & $-0.38^{\star \star \star}$ & $-0.42^{\star *}$ & $-0.41^{\star}$ & $-0.38^{* \star \star}$ & $-0.44^{\star *}$ & $-0.47^{*}$ & $-0.35^{\star}$ & $-0.46^{*}$ & -0.46 \\
\hline & $(0.135)$ & $(0.178)$ & $(0.225)$ & $(0.146)$ & $(0.196)$ & $(0.252)$ & $(0.203)$ & $(0.258)$ & $(0.311)$ \\
\hline \multirow[t]{2}{*}{ non-western immigrant background (yes=1) } & $0.17^{\star \star}$ & 0.11 & 0.06 & $0.18^{\star \star}$ & 0.11 & -0.02 & $0.58^{\star \star \star}$ & $0.38^{\star *}$ & 0.40 \\
\hline & $(0.082)$ & $(0.119)$ & $(0.175)$ & $(0.089)$ & $(0.131)$ & $(0.200)$ & $(0.138)$ & $(0.190)$ & $(0.269)$ \\
\hline \multirow[t]{2}{*}{ 2nd generation immigrant background (yes=1) } & 0.07 & 0.05 & -0.01 & $0.13^{*}$ & 0.08 & 0.09 & -0.18 & 0.08 & 0.03 \\
\hline & $(0.065)$ & $(0.098)$ & $(0.143)$ & $(0.072)$ & $(0.107)$ & $(0.165)$ & $(0.111)$ & $(0.163)$ & $(0.230)$ \\
\hline \multirow[t]{2}{*}{ ESCS-index of school intake } & $-0.10^{*}$ & 0.00 & -0.01 & $-0.10^{*}$ & -0.02 & -0.08 & -0.05 & 0.12 & 0.05 \\
\hline & $(0.058)$ & $(0.081)$ & $(0.111)$ & $(0.061)$ & $(0.081)$ & $(0.112)$ & $(0.086)$ & $(0.113)$ & $(0.156)$ \\
\hline \multirow[t]{2}{*}{ proportion non-western immigrants at school } & $-0.75^{\star \star \star}$ & $-0.89^{* * *}$ & $-1.25^{* * *}$ & $-0.65^{* * *}$ & $-0.79^{* * *}$ & $-1.15^{\star \star *}$ & $-0.52^{\star}$ & -0.18 & -0.38 \\
\hline & $(0.212)$ & $(0.281)$ & $(0.364)$ & $(0.204)$ & $(0.269)$ & $(0.351)$ & $(0.295)$ & $(0.389)$ & $(0.490)$ \\
\hline \multirow[t]{2}{*}{ neighborhood ESCS index } & $0.12^{\star \star *}$ & $0.13^{* * *}$ & 0.09 & $0.14^{* * *}$ & $0.16^{* * *}$ & $0.16^{\star *}$ & 0.03 & -0.02 & -0.02 \\
\hline & $(0.034)$ & $(0.046)$ & $(0.066)$ & $(0.039)$ & $(0.051)$ & $(0.072)$ & $(0.057)$ & $(0.072)$ & $(0.109)$ \\
\hline \multirow[t]{2}{*}{ neighborhood urbanicity index } & $0.10^{\star \star *}$ & 0.03 & 0.07 & $0.12^{\star \star *}$ & -0.01 & 0.08 & $0.07^{*}$ & 0.07 & 0.13 \\
\hline & $(0.034)$ & $(0.062)$ & $(0.127)$ & $(0.033)$ & $(0.064)$ & $(0.124)$ & $(0.044)$ & $(0.104)$ & $(0.222)$ \\
\hline municipality dummies included & no & yes & yes & no & yes & yes & no & yes & yes \\
\hline \multirow[t]{2}{*}{ Constant } & $-1.71^{\star \star \star}$ & -0.48 & $-1.57^{* \star *}$ & $-0.42^{* \star *}$ & 0.01 & -0.27 & $-38.74^{\star \star *}$ & $-38.73^{\star \star *}$ & $-43.68^{\star \star \star}$ \\
\hline & $(0.105)$ & $(0.895)$ & $(0.532)$ & $(0.105)$ & $(0.836)$ & $(0.449)$ & $(2.960)$ & $(4.282)$ & $(6.287)$ \\
\hline Observations & 23,822 & 7,782 & 3,201 & 20,021 & 6,624 & 2,726 & 8,171 & 3,064 & 1,354 \\
\hline Wald Chi2 & 265.55 & 170.62 & 82.41 & 858.82 & 511.25 & 232.31 & 233.02 & 225.78 & 92.03 \\
\hline Pseudo R-Squared & 0.0199 & 0.0495 & 0.0576 & 0.1457 & 0.1665 & 0.1973 & 0.0632 & 0.086 & 0.0927 \\
\hline
\end{tabular}


Table 5.17: PSM, Private school attendance effect "upward mobility"

\begin{tabular}{|c|c|c|c|c|c|c|}
\hline & $\mathrm{NL}$ & NL & G31 & G31 & G4 & G4 \\
\hline & (1) & (2) & (3) & (4) & $(5)$ & (6) \\
\hline VARIABLES & Level-Up & CITO & Level-Up & CITO & Level-Up & CITO \\
\hline \multirow[t]{2}{*}{ switched to private secondary school } & $-0.03^{* *}$ & -0.87 & -0.04 & $-1.48^{\star}$ & -0.03 & -0.33 \\
\hline & $(0.013)$ & $(0.581)$ & $(0.024)$ & $(0.844)$ & $(0.023)$ & $(1.348)$ \\
\hline \multirow[t]{2}{*}{ age } & $-0.03^{* * *}$ & $-2.88^{* * *}$ & $-0.04^{* * *}$ & $-2.49^{* * *}$ & $-0.03^{*}$ & $-2.35^{\star * *}$ \\
\hline & $(0.005)$ & $(0.219)$ & $(0.009)$ & $(0.287)$ & $(0.014)$ & $(0.394)$ \\
\hline \multirow[t]{2}{*}{ female (yes=1) } & $0.05^{* * *}$ & $-1.07^{* * *}$ & $0.05^{\star * *}$ & -0.26 & $0.06^{* * *}$ & 0.91 \\
\hline & $(0.008)$ & $(0.287)$ & $(0.012)$ & $(0.432)$ & $(0.019)$ & $(0.867)$ \\
\hline \multirow[t]{2}{*}{ student's weighted funding } & $-0.08^{* * *}$ & $-3.68^{* * *}$ & $-0.04^{*}$ & -0.94 & -0.04 & -0.05 \\
\hline & $(0.018)$ & $(0.768)$ & $(0.023)$ & (0.954) & $(0.034)$ & $(1.223)$ \\
\hline \multirow[t]{2}{*}{ single-parent household } & -0.02 & $-1.86^{* *}$ & $-0.06^{* *}$ & $-2.98^{* * *}$ & $-0.08^{* * *}$ & $-2.71^{* *}$ \\
\hline & $(0.024)$ & $(0.822)$ & $(0.026)$ & $(0.911)$ & $(0.031)$ & $(1.284)$ \\
\hline \multirow[t]{2}{*}{ non-western immigrant background (yes=1) } & $0.04^{* * *}$ & -1.00 & 0.02 & -1.23 & -0.03 & 0.36 \\
\hline & $(0.014)$ & $(0.705)$ & $(0.019)$ & $(1.004)$ & $(0.030)$ & $(2.339)$ \\
\hline \multirow[t]{2}{*}{ 2nd generation immigrant background (yes=1) } & 0.01 & -0.28 & 0.01 & -1.50 & -0.01 & $-5.91^{* *}$ \\
\hline & $(0.011)$ & $(0.573)$ & $(0.017)$ & $(0.914)$ & $(0.029)$ & $(2.542)$ \\
\hline \multirow[t]{2}{*}{ ESCS-index of school intake } & -0.01 & $3.28^{* * *}$ & 0.02 & $4.44^{\star \star \star}$ & -0.00 & 0.98 \\
\hline & $(0.016)$ & $(0.657)$ & $(0.033)$ & (1.293) & $(0.031)$ & $(2.056)$ \\
\hline \multirow[t]{2}{*}{ proportion non-western immigrants at school } & $-0.12^{\star *}$ & $-4.22^{* \star}$ & -0.15 & -4.98 & -0.10 & $-11.08^{*}$ \\
\hline & $(0.050)$ & $(2.094)$ & $(0.096)$ & (3.618) & $(0.093)$ & $(5.688)$ \\
\hline \multirow[t]{2}{*}{ neighborhood ESCS index } & $0.01^{*}$ & -0.20 & $0.02^{* * *}$ & -0.07 & $0.04^{* * *}$ & $-0.81^{* *}$ \\
\hline & $(0.005)$ & $(0.198)$ & $(0.007)$ & $(0.254)$ & $(0.010)$ & $(0.382)$ \\
\hline \multirow[t]{2}{*}{ neighborhood urbanicity index } & $0.02^{* * *}$ & $0.97^{* * *}$ & 0.01 & 0.76 & 0.03 & 0.82 \\
\hline & $(0.005)$ & $(0.245)$ & $(0.011)$ & $(0.472)$ & $(0.020)$ & $(1.166)$ \\
\hline municipality dummies & no & no & yes & yes & yes & yes \\
\hline primary school advice dummies & yes & no & yes & no & yes & no \\
\hline \multirow[t]{2}{*}{ Constant } & 0.02 & $535.12^{* \star *}$ & -0.04 & $548.45^{* * *}$ & $-0.18^{* *}$ & $536.81^{* * *}$ \\
\hline & $(0.014)$ & $(0.641)$ & $(0.048)$ & $(1.848)$ & $(0.086)$ & $(4.404)$ \\
\hline Observations & 18,851 & 6,426 & 6,343 & 2,510 & 2,779 & 1,162 \\
\hline R-squared & 0.16 & 0.16 & 0.19 & 0.30 & 0.24 & 0.30 \\
\hline Adj. R-squared & 0.163 & 0.162 & 0.188 & 0.289 & 0.234 & 0.294 \\
\hline
\end{tabular}

Notes: Robust clusterd standard errors (at school level) in parentheses ${ }^{* * *} p<0.01,{ }^{* *} p<0.05,{ }^{*} p<0.1$ 
School Choice, Competition and Achievement 


\section{Competition and Achievement in the}

\section{Netherlands ${ }^{*}$}

\subsection{Introduction}

Whereas school choice policies differ widely from country to country, as well as across time, they can commonly be described along two dimensions. At the demand side of schooling, choice programs are designed such that parents have more freedom to choose a school (type) for their children to attend. The effects this has on achievement were the focus of the analyses in Chapters 4 and 5. On the supply side of the education market, school choice policies foster competition among schools for students and revenues (Plank and Sykes, 2003). Although choice and competition are conceptually distinct, they can be difficult to separate at the school-level as greater choice for households is generally associated with more competition between schools (Gibbons, Machin and Silva, 2008).

This chapter sets out to analyze the relationship between competition intensity and student achievement in the Dutch primary education sector, a system characterized by a long history of universal school choice. Competition is calculated as a concentration index at the school-level, as schools compete for those students that reside within a reasonable distance. The observed variation in competition intensity across schools is used to assess its impact on students' achievement on end-of-primary standardized test scores (i.e. CITO).

\footnotetext{
* This chapter is based on the paper: Cornelisz I. (2013) "Competition and Student Achievement in Dutch Primary Education." Manuscript submitted for publication.
} 
The overall results indicate that, on average, competition is associated with modest improvements in cognitive achievement of around 0.06 of a standard deviation, with slightly larger effects found for the most urban areas and for private government-funded schools. The results cannot be explained by underlying differences in choice available to households and seem to be completely driven by the lower half of the skill distribution; with the largest effects found for the lower deciles of achievement (i.e. up to $0.2 \sigma$ ).

One interpretation of these results is that schools in the Dutch primary sector face incentives to meet minimum achievement targets, particularly when competitive pressure is high. However, beyond the median student level of academic achievement, competition intensity seems to be unrelated to academic performance instead and might induce schools to focus more on other (non-academic) features instead.

The next section (6.2) provides a brief description of both the background and scope of the analyses conducted in this chapter. Section 6.3 describes the data and methodology. The results of the analyses are discussed in 6.4, with some concluding remarks presented in the final section (6.5).

\subsection{Background and scope}

As described in Chapter 2, one of the main claims is that school choice will generate competition for students among schools and that the market pressure of competition will force schools to deliver high quality education. However, some of the (market) assumptions on which these productivity gains are premised have been challenged (e.g. Levin and Belfield, 2003). For example, if households' preferences towards student performance and other school attributes are heterogeneous, this limits the potential for school choice and competition for generating academic performance gains.

As such, competition between schools could lead to product differentiation, in which schools match their appeal to particular educational preferences of households, rather than offering a standardized educational product (Belfield and Levin, 2005; Levin, 2012). Differentiation in such a context allows schools to outperform competing schools in the provision of certain (e.g. non-academic) features, reducing the directness of (e.g. academic) competition and enabling cost/effort savings. 
Research thus faces methodological challenges in isolating the effect of competition on achievement. Belfield and Levin (2002) emphasize that much of the research on competition and achievement in education faces concerns of construct validity (i.e. how "markets" and "competition" are defined) and estimation (i.e. how causal effects of competition are "identified). Arguably because of the complexity of markets in education, and how schools respond to competition, the existing literature finds mixed results with respect to the effects of competition between schools on student performance (Gibbons et al., 2008).

As described in Chapter 3, the Dutch education market for compulsory schooling fits the definition of a quasi-market (cf. Onderwijsraad, 2001; Belfield and Levin, 2005), in that (1) suppliers of education are in competition with each other, (2) entry into, and exit from, the schooling market is regulated, (3) household demands are expressed through a vouchertype system of funding, and (4) the government maintains an important role in accountability and standards.

The main regulations refer to i) admission policies, ii) curriculum, attainment targets and national examinations, iii) teacher qualifications, training and salaries, and to iv) the quality of education provided. The Education Inspectorate focuses on ensuring all schools meet these targets. In particular, it identifies schools that are "at risk" on a yearly basis and aims to assess and monitor potential problems affecting the quality of education at these schools. Schools that perform adequately do not require such intense risk-based inspection, allowing the Inspectorate to focus most of its attention on the improvement of poorly performing schools. Beyond attaining to the centrally determined (academic) achievement targets, the educational process and experience can differ significantly across schools. It seems reasonable to assume that schools do compete for students as there are strict minimum school size requirements to remain eligible for government-funding, the level of such funding depends on the actual number of pupils enrolled, and the wages of primary school principals depend on the number of students enrolled.

Competing for students, with heterogeneous household preferences and facilitated by the earlier explained processes of deregulation, decentralization and lump sum financing (see Chapter 3), the Dutch primary education sector described above could arguably foster some level of product differentiation by schools. There is some indirect empirical support for this. 
First of all, Noailly, Vujic and Aouragh (2009) analyze the effect of competition on student-level performance on standardized exit-exams in primary education (i.e. CITO-test). They use two competition measures (i.e. number of alternative schools and an (inverted) Herfindahl index), based on a $1.5 \mathrm{~km}$ radius around the center of the 4-digit postcode in which a school is located. Controlling for some school- and neighborhood characteristics, the authors find small positive effects for competition on achievement. To account for the potential endogeneity of the competition measure, it is instrumented by the distance between the 4-digit zip code center and the town center, as schools close to the town center are likely to face more competition. This IV approach yields larger, though still modest, positive effects of competition on achievement (i.e. 0.05-0.10б). One interpretation for these modest effects is that schools compete on other activities, such as activities and their building. Excluding the most competitive markets (i.e. largest 4 cities) further reduces the effect of competition on achievement, which could imply that schools in less competitive rural areas compete relatively more on other characteristics, such as denomination (Noailly et al., 2009).

Secondly, a recent analysis uses administrative data on three school quality measures for secondary schools (i.e. average exit-exam scores, graduation rates, and the percentage of students graduating without delay) for the years 2002-2006 (Dijkgraaf et al., 2008). Their competition measure is also a Herfindahl-Hirschman-Index (HHI), based on the school locations located within a distance of $10 \mathrm{~km}$. Using OLS regression, and controlling for school- and neighborhood level characteristics, a negative effect for competition across all outcome measures is found. The authors also interpret these seemingly counterintuitive findings as that Dutch schools compete with other schools on the basis of "secondary" elements, such as sports- and music facilities, leaving less time and money for the primary process of teaching. Interestingly though, excluding the 21 largest cities, the results based on a subset of relatively more monopolistic schools in rural areas, yields even stronger negative results for competition, suggesting either a potential non-linear effect and/or important rural/urban differences.

Thirdly, another recent paper more explicitly deals with the notion of specific school characteristics, beyond those of academic quality (Weenink, 2009). Analyzing secondary schools introducing international streams, the paper shows that school managers associate quality and excellence in education more with abilities of students than with quality of 
educational programs, staff or facilities. Internationalized streams, then, serve to create a niche market and their introduction stems from schools' competitive engagement with local education markets (Weenink, 2009). This observation is in line with a situation in which schools try to keep, or improve, their position in their educational market by diversifying their programs, with schools at the top of their local hierarchy trying to guard their position by targeting their efforts to high-ability students through offering such special programs as international and bilingual tracks (Waslander et al., 2010).

\subsection{Methodology and data}

\subsubsection{Methodology}

For the analyses in this chapter, given the aforementioned complexity of Dutch education markets, several measures of school competition have been developed, as there are arguments for exploring multiple measures of competition (see: Agasisti, 2011; Figlio and Hart, 2010). As a first measure, the exact Euclidian distance was calculated between the physical address of each school location and the nearest (competing) school. Similar, to Figlio and Hart (2010), I refer to this as the "distance" measure of competition. Second, acknowledging that a school can actually face competition from multiple surrounding schools, the number of competing schools within a meaningful radius (i.e. $3 \mathrm{~km}$ ) around that school is calculated. Following Figlio and Hart (2010), this measure is referred to as the "density" measure of competition. Third, to account for the association between general urban- and school density, the number of surrounding schools per 100 cohort members within $3 \mathrm{~km}$ is derived. This takes into consideration the size of the pool of students schools are competing for in their local education market. Inspired by Agasisti (2011), I refer to this measure as the "school concentration" measure.

Similar to the choice intensity measure introduced in Chapter 4, this measure considers each surrounding school as equally contributing to competition. This does not acknowledge that some schools included in this radius might target different students and are not considered as a competitor. Similarly, there might be schools outside the $3 \mathrm{~km}$ radius that are a true competitor, but which are not included. The assumption underlying the school concentration measure is that, on average, having more surrounding schools per 100 students within $3 \mathrm{~km}$ corresponds to a higher level of competition intensity. 
This school concentration measure is chosen to be the default measure for measuring school competition. First of all, it allows for competition to come from different nearby school locations, regardless of which municipality they are located in. Furthermore, different radii can be used, as it is rather ambiguous to define the boundaries of educational markets in Dutch primary education. In particular, by calculating the number of surrounding schools on a "per 100 cohort members"-basis, this measure reduces the association with general urban density effects and focuses more precisely on school-concentration driven competition. $^{82}$

The identifying assumption is that, conditional on background characteristics, the observed variation in competition intensity measured is exogenous; thus making it possible to extract the effect of competition on achievement. Several considerations need to be examined. For example, it could be that the market structures observed is partially determined by households' residential decision. This would be problematic if households that are particularly motivated about their child's education and/or relatively affluent attend schools in which competition intensity is high (or low). Also, there can be important mobility differences between neighborhoods, making it relatively more/less costly or difficult to travel longer distances. In this case, using a radius of $3 \mathrm{~km}$ might not be a reasonable approximation of competition intensity for certain schools. Finally, in the presence of school openings and -closures, the current spatial distribution of schools observed could also be related to the socioeconomic characteristics of an area, with fewer schools in relatively disadvantageous areas when poorly performing schools have been closed down in recent history. The last section returns to some of these issues.

The main specification used in this paper used to explore the effects of competition between schools on student achievement is:

$$
Y_{i j k m}=\alpha_{0}+x_{i j k}^{\prime} \beta+\gamma \cdot C_{j k m}+\lambda_{m}+\varepsilon_{i j k m}
$$

where $Y_{i j k m}$ is the test score for student $i$, attending school $j$, from neighborhood $k$, in municipality $m$. A set of background characteristics is provided by $x_{i j k}$ with municipality

\footnotetext{
${ }^{82}$ Note that results are only reported for this school concentration measure based on local education markets with a radius of $3 \mathrm{~km}$. Using the natural logarithm, for reasons explained in Chapter 4, gives similar results at the expense of dropping observations for all students (around 900) at schools that have no other competitors nearby (for which the natural logarithm cannot be computed). Results for this logarithmic measure, just as for the measures of "distance", "density" and using different radii, are qualitatively similar to the results reported here and available upon request.
} 
dummies $\lambda_{m}$ to account for idiosyncratic differences in achievement between cities, and an idiosyncratic error term $\varepsilon_{i j k m}$. The level of competition is calculated as the number of other surrounding schools, within a meaningful radius (i.e. $3 \mathrm{~km}$ ) around the school of attendance, calculated per 100 cohort members residing in that local market $\left(C_{j k m}\right)$.

The description of competition in Dutch primary education presented in the previous section can be summarized as that i) parents are essentially free to choose a school and, in doing so, take into account academic quality, school identity and distance, ii) all schools are held accountable for meeting centrally determined threshold levels of academic achievement, and iii) over and above reaching these levels of academic achievement, schools could resort to product differentiation, when competing for students in their local heterogeneous education market.

These observations provide arguments for a more comprehensive understanding of the relationship between school-level competition and student-level performance at different levels of achievement. For example, it could be that, with heterogeneous demands, competition particularly affects a school's level of academic efficiency along some sections of the achievement distribution, whereas it primarily affects a school's efficiency in providing other non-academic features for other segments of the skill distribution. In an attempt to get more insight in such potentially important heterogeneities, a simultaneous quantile regression is performed with estimates for the effect of competition at the 10th, 25th, 50th, 75th and 90th percentile of the test score distribution.

Previous results for the Netherlands have indicated there could be important geographical differences (i.e. rural/urban) to consider when analyzing how schools respond to competition. In addition, school competition measures might reflect some general unobserved urban density differences, associated with achievement, instead of isolating variation in school-level competition only. Therefore, the main results are presented for the 31 major municipalities in the Netherlands (G31), in which it is more reasonable to assume schools will face some level of competition. ${ }^{83}$ These results will also be compared to those

\footnotetext{
${ }^{83}$ The Dutch government's so-called urban policy is one in which the major cities in the Netherlands collaborate on a variety of topics, among which education is one of them. It was introduced in 1994 for the 31 large and medium-sized cities, the G31 municipalities. These are the four largest cities (G4) and 27 mediumsized cities (G27). Source: www.government.nl/issues/municipalities-and-cities/urban-policy
} 
derived from performing the same analysis on a subset of data containing only the 4 largest cities (G4). ${ }^{84}$

\subsubsection{Data}

The primary data source for this paper is the Dutch administrative data set PO BRON '08-'09, and the student-level outcome variable used the CITO-test, a standardized test score derived at the end of primary education. ${ }^{85}$

From the BRON data set, it can be derived that $93 \%$ of all students travel $3 \mathrm{~km}$ or less to their chosen school. In deriving the preferred measure for competition intensity, defined in this chapter as the number of surroundings schools per 100 cohort members within a radius of $3 \mathrm{~km}$, geocoding software is used. For each school, both the number of (competitor) schools and the number of (potential) students that fall within these boundaries of their local education market are counted. The ratio of these two numbers is then multiplied by 100, which gives an index on a "per 100 students in the cohort" basis. The average competition intensity for schools using this index is around 3, with a standard deviation of 1.

Figure 6.1 illustrates the distribution of competition across schools for the largest municipality (i.e. Amsterdam), whereas Figure 6.2 gives the overall distribution for both subsets of data (i.e. G4 and G31). Important background neighborhood characteristics are added, made possible by using the information on students' zip code-level residence. ${ }^{86}$ Throughout the analyses, results are presented for a subset of the BRON-data set, covering all students within the 31 major municipalities (G31). In an attempt to grasp the importance of differences in urban density, with respect to competition and educational outcomes, all analyses are also performed on a subset containing only the 4 largest municipalities (G4).

\footnotetext{
${ }^{84}$ The four largest cities, referred to as G4, are Amsterdam, Rotterdam, The Hague and Utrecht. Collectively, these four cities account for approximately $10 \%$ of all students. Together with the other 27 major cities, the G31 account for close to $30 \%$ of all students.

${ }^{85}$ More information on the variables used for the analysis in this chapter is presented Appendix A.

${ }^{86}$ A rich index for socioeconomic status is the "statusscore", provided by the Netherlands Institute for Social Research (SCP). Further neighborhood information is obtained from "Kerncijfers Postcodegebieden 2008" and "Buurtkaarten 2008, versie 3", both constructed by Statistics Netherlands (CBS).
} 
Figure 6.1: Competition intensity across schools in Amsterdam

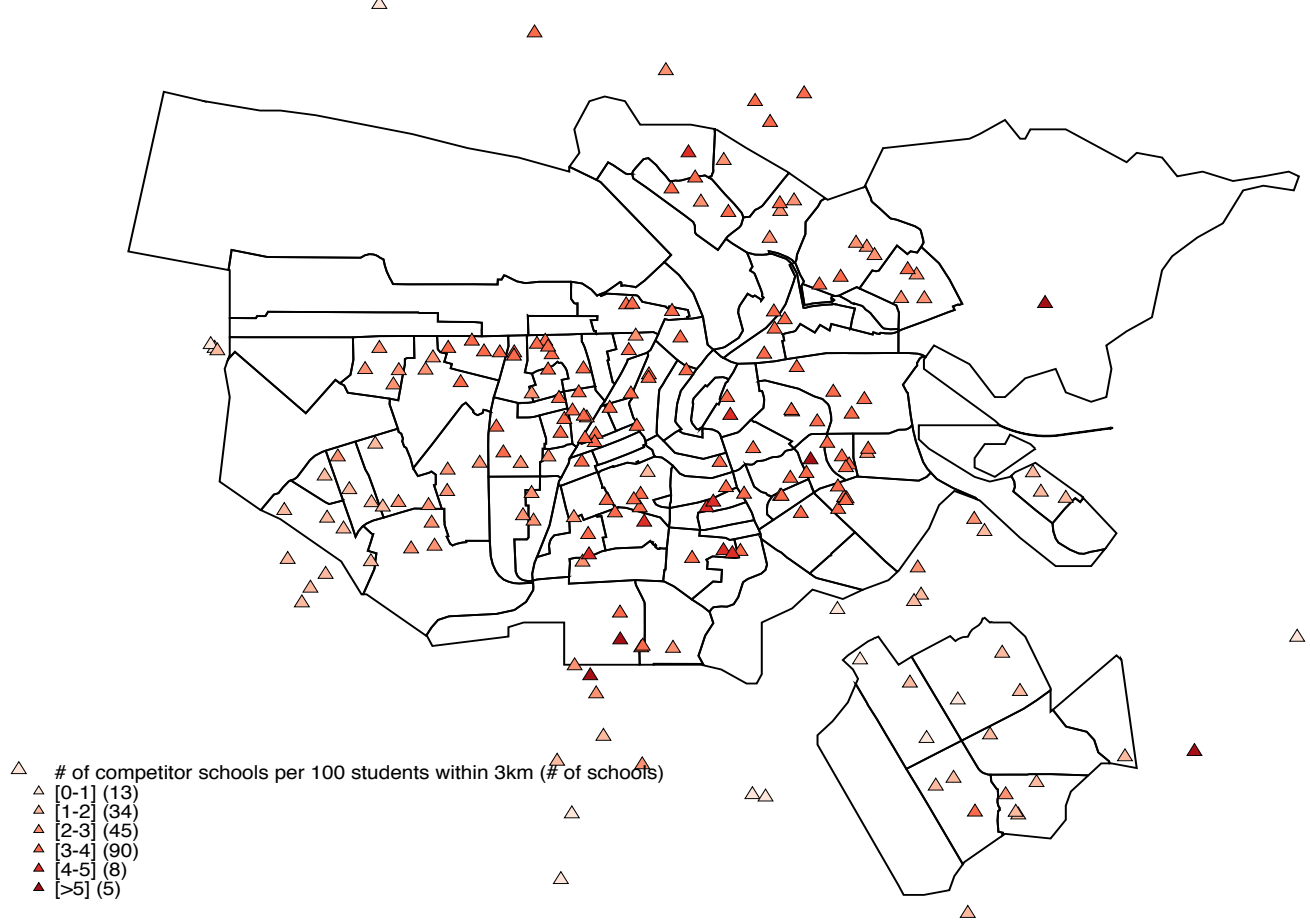

Notes: The neighborhoods depicted here do not refer to 4-digit zip codes. Instead, displayed are "buurten", which can contain multiple 4-digit zip codes. As to match the 4-digit zip code data to the map, the most prevalent zip code in each "buurt" is used. For Amsterdam, $81 \%$ or more of all addresses share the same zip code in 65 out of the 97 "buurten" (source: "CBS Buurtkaart met cijfers 2008", available at www.cbs.nl). The concept of "buurten" is only used for this graphical representation. Throughout the empirical analyses, 4-digit zip codes are used.

Figure 6.2: Distribution competition intensity, G31 and G4

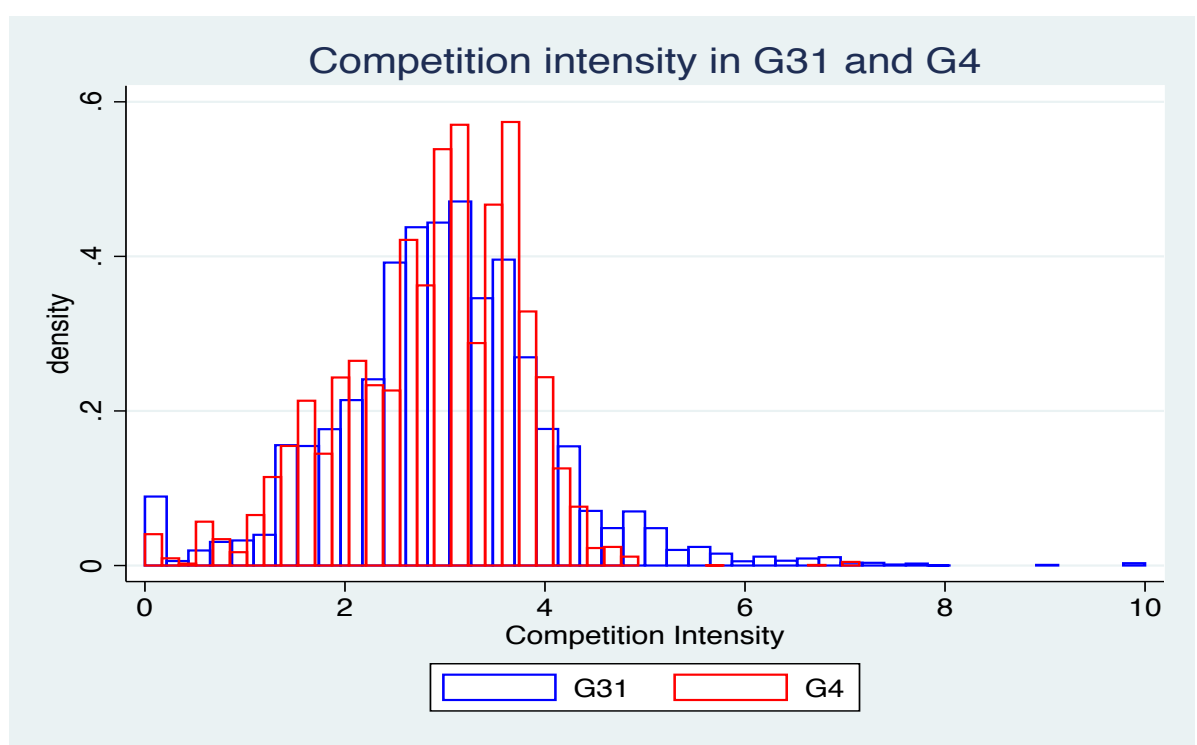


Descriptive characteristics of the data compiled in the above way are given in Table 6.1. It can be seen that the subsample of the 4 largest municipalities is indeed more urban and accommodates more students with a nonwestern background. Also, students in the G4 are on average from a relatively disadvantageous background, and are more likely to be eligible for (additional) weighted student funding. Students' test scores in these 4 large cities score are somewhat more diverse (i.e. $0.08 \sigma)$ and also, on average, slightly lower $(-0.1 \sigma)$. The "school concentration index" competition measure is relatively comparable across both subsets, with an average of 3 and a standard deviation of around 1 (Table 6.1). Given that, on average, this measure for competition intensity is actually slightly lower for the most urban areas gives some support to the idea this measure is not merely capturing general urban density.

Table 6.1: Summary statistics competition intensity, G31 and G4

\begin{tabular}{l|cc|cc}
\hline & G31 & & G4 & \\
VARIABLE & mean & $(\mathrm{sd})$ & mean & $(\mathrm{sd})$ \\
\hline test score & 534.43 & $(10.26)$ & 533.11 & $(11.06)$ \\
competition intensity & 2.98 & $(1.10)$ & 2.87 & $(0.89)$ \\
male & 0.5 & $(0.50)$ & 0.5 & $(0.50)$ \\
relative age (in years) & 0 & $(0.69)$ & 0.04 & $(0.70)$ \\
\% with nonwestern background & 0.31 & $(0.46)$ & 0.53 & $(0.50)$ \\
\% 2nd generation immigrant & 0.33 & $(0.47)$ & 0.52 & $(0.50)$ \\
student funding weight & 0.15 & $(0.32)$ & 0.27 & $(0.40)$ \\
$\%$ one-parent household & 0.05 & $(0.22)$ & 0.09 & $(0.29)$ \\
$\%$ non-western at primary school & 0.31 & $(0.30)$ & 0.53 & $(0.33)$ \\
mean school SES intake & 0 & $(1.10)$ & -0.43 & $(1.29)$ \\
school size (log) & 5.73 & $(0.48)$ & 5.75 & $(0.45)$ \\
neighborhood SES index & 0 & $(1.30)$ & -0.43 & $(1.49)$ \\
urbanicity index & 2.93 & $(1.07)$ & 3.63 & $(0.66)$ \\
G31 & 1 & $(0.00)$ & 1 & $(0.00)$ \\
G4 & 0.36 & $(0.48)$ & 1 & $(0.00)$ \\
$\mathrm{N}$ & 46084 & - & 16384 & - \\
$\%$ & $100.00 \%$ & - & $35.55 \%$ & - \\
\hline
\end{tabular}

Table 6.2 follows up on this idea by presenting pair-wise correlations with background characteristics for all of the three aforementioned competition measure alternatives: "distance", "density" and "concentration". The correlations and significance values show the latter (preferred) measure for competition intensity is indeed much less 
associated with urbanicity, as well as with several important background characteristics, such as a student's immigrant-, funding- and household status. ${ }^{87}$ This gives support for estimating, and presenting, the effect of competition intensity on achievement using this concentration index, arguing this measure is most successful in displaying variation that is unrelated with important differences in (un-)observed background characteristics.

Table 6.2: Associations competition measures and background characteristics

\begin{tabular}{|c|c|c|c|}
\hline $\begin{array}{l}\text { G31 } \\
\text { VARIABLES }\end{array}$ & $\begin{array}{c}\text { distance } \\
\text { pair-wise corr. } \\
\text { (p-value) }\end{array}$ & $\begin{array}{c}\text { density } \\
\text { pair-wise corr. } \\
\text { (p-value) }\end{array}$ & $\begin{array}{c}\text { concentration } \\
\text { pair-wise corr. } \\
(p \text {-value })\end{array}$ \\
\hline \multirow[t]{2}{*}{ distance to nearest other school } & 1.00 & & \\
\hline & - & & \\
\hline \multirow[t]{2}{*}{ \# of other schools within $3 \mathrm{~km}$} & -0.36 & 1.00 & \\
\hline & $(0.00)$ & - & \\
\hline \multirow[t]{2}{*}{ \# of schools per 100 cohort students within $3 \mathrm{~km}$} & -0.31 & 0.34 & 1.00 \\
\hline & $(0.00)$ & $(0.00)$ & - \\
\hline \multirow[t]{2}{*}{ male (yes=1) } & 0.00 & 0.00 & 0.01 \\
\hline & $(0.97)$ & $(0.72)$ & $(0.06)$ \\
\hline \multirow[t]{2}{*}{ relative age (in years) } & -0.03 & 0.06 & 0.01 \\
\hline & $(0.00)$ & $(0.00)$ & $(0.03)$ \\
\hline \multirow[t]{2}{*}{ non-western immigrant background (yes $=1$ ) } & -0.13 & 0.33 & 0.00 \\
\hline & $(0.00)$ & $(0.00)$ & $(0.69)$ \\
\hline \multirow[t]{2}{*}{ 2nd generation non-western background (yes $=1$ ) } & -0.12 & 0.28 & 0.01 \\
\hline & $(0.00)$ & $(0.00)$ & $(0.20)$ \\
\hline \multirow[t]{2}{*}{ student's weighted funding } & -0.12 & 0.28 & 0.03 \\
\hline & $(0.00)$ & $(0.00)$ & $(0.00)$ \\
\hline \multirow[t]{2}{*}{ single-parent household } & -0.03 & 0.09 & 0.00 \\
\hline & $(0.00)$ & $(0.00)$ & $(0.40)$ \\
\hline \multirow[t]{2}{*}{ proportion non-western immigrants at school } & -0.20 & 0.50 & 0.00 \\
\hline & $(0.00)$ & $(0.00)$ & $(0.48)$ \\
\hline \multirow[t]{2}{*}{ SES-index of school intake } & 0.19 & -0.39 & -0.17 \\
\hline & $(0.00)$ & $(0.00)$ & $(0.00)$ \\
\hline \multirow[t]{2}{*}{ school size (log) } & -0.02 & 0.00 & -0.18 \\
\hline & $(0.00)$ & $(0.48)$ & $(0.00)$ \\
\hline \multirow[t]{2}{*}{ neighborhood SES index } & 0.16 & -0.33 & -0.14 \\
\hline & $(0.00)$ & $(0.00)$ & $(0.00)$ \\
\hline \multirow[t]{2}{*}{ urbanicity index } & -0.31 & 0.59 & 0.09 \\
\hline & $(0.00)$ & $(0.00)$ & $(0.00)$ \\
\hline
\end{tabular}

${ }^{87}$ One important exception is school size, with which the concentration index is relatively strongly associated. This makes sense, as a local education market with relatively large schools will consist of fewer schools per 100 students in a cohort. School size, together with the other background characteristics, will be taken into account in the models estimating the effect of competition intensity on achievement. 


\subsection{Results}

Table 6.3 presents the results of the main specification in equation (1), for both the G31 and G4 cities. In all models, standard errors are clustered at the school level to account for unobserved interdependence of students and for the level of treatment. Model 1, the empty model, shows no statistically significant association between school-level competition and a student's performance. Model 2 adds the individual background characteristics, but leaves the relationship between competition and performance qualitatively unchanged. Model 3 adds school-level background characteristics that are (indirectly) related to quality and performance, such as the \% of nonwestern students, the average SES of the student-body composition and potentially important economies of scale effects (i.e. captured by school size). This increases the positive association of competition with performance to an effect size of 0.6 points (or $0.06 \sigma$ ), statistically significant at the $1 \%$ level. In the full specification (Model 4), neighborhood characteristics are added (SES and a general urbanicity index), as well as municipality dummies accounting for unobserved differences across different geographical areas. This only slightly alters the relation between competition and performance. Performing the same analysis on the 4 largest municipalities only gives a somewhat larger association (i.e. $0.1 \sigma$ ) albeit relatively imprecise and statistically significant at the $5 \%$ level.

Table 6.3: OLS, School competition intensity effect on CITO test score

\begin{tabular}{|c|c|c|c|c|c|}
\hline & G31 & G31 & G31 & G31 & G4 \\
\hline & (1) & $(2)$ & (3) & (4) & (5) \\
\hline VARIABLES & CITO & CITO & CITO & CITO & CITO \\
\hline \multirow[t]{2}{*}{ competition intensity } & 0.19 & 0.29 & $0.57^{\star * *}$ & $0.65^{* * *}$ & $1.08^{* *}$ \\
\hline & $(0.214)$ & $(0.179)$ & $(0.186)$ & $(0.195)$ & $(0.522)$ \\
\hline individual covariates & no & yes & yes & yes & yes \\
\hline school covariates & no & no & yes & yes & yes \\
\hline neighborhood controls & no & no & no & yes & yes \\
\hline \multirow[t]{2}{*}{ Constant } & $533.89^{* * *}$ & $534.93^{* * *}$ & $526.38^{* * *}$ & $529.14^{\star * *}$ & $528.79^{* * *}$ \\
\hline & $(0.655)$ & $(0.554)$ & $(2.451)$ & $(2.434)$ & $(4.409)$ \\
\hline Observations & 12,910 & 12,899 & 12,711 & 12,700 & 4,741 \\
\hline R-squared & 0.00 & 0.15 & 0.18 & 0.20 & 0.25 \\
\hline Adj. R-squared & 0.000291 & 0.154 & 0.179 & 0.201 & 0.245 \\
\hline
\end{tabular}


The results of the simultaneous quantile regression analyses are presented in Table 6.4. All results are based on full-model specifications and reported together with the initial OLS results for means of comparison. First, note that the quantile regression estimates for the 0.5 quantiles are indeed highly similar to the overall OLS results. In addition, the quantile regression coefficients differ markedly across quantiles, with larger (positive) effects for competition found in the lower sections of the achievement distribution. For the G31, competition intensity is associated with higher achievement in both the lower decile and .25 quantile of about 1 point on the CITO test (i.e. $0.1 \sigma$ ) whereas this relationship drops to 0.36 points for the .75 quantile and to a statistically insignificant 0.1 points for the upper decile of achievement.

This pattern is even more pronounced in the four largest cities (G4), where the association gradually moves from as much as 2 points $(0.2 \sigma)$ for the lower decile to an equally small, and statistically insignificant, -0.1 points for the upper decile of achievement. The difference between the initial OLS results for the $\mathrm{G} 31(0.06 \sigma)$ and $\mathrm{G} 4(0.1 \sigma)$ seems to be driven by the relatively more pronounced positive association of competition intensity and achievement in the G4 found for the lower half of the achievement distribution.

Table 6.4: SQR, School competition intensity effect on CITO test score

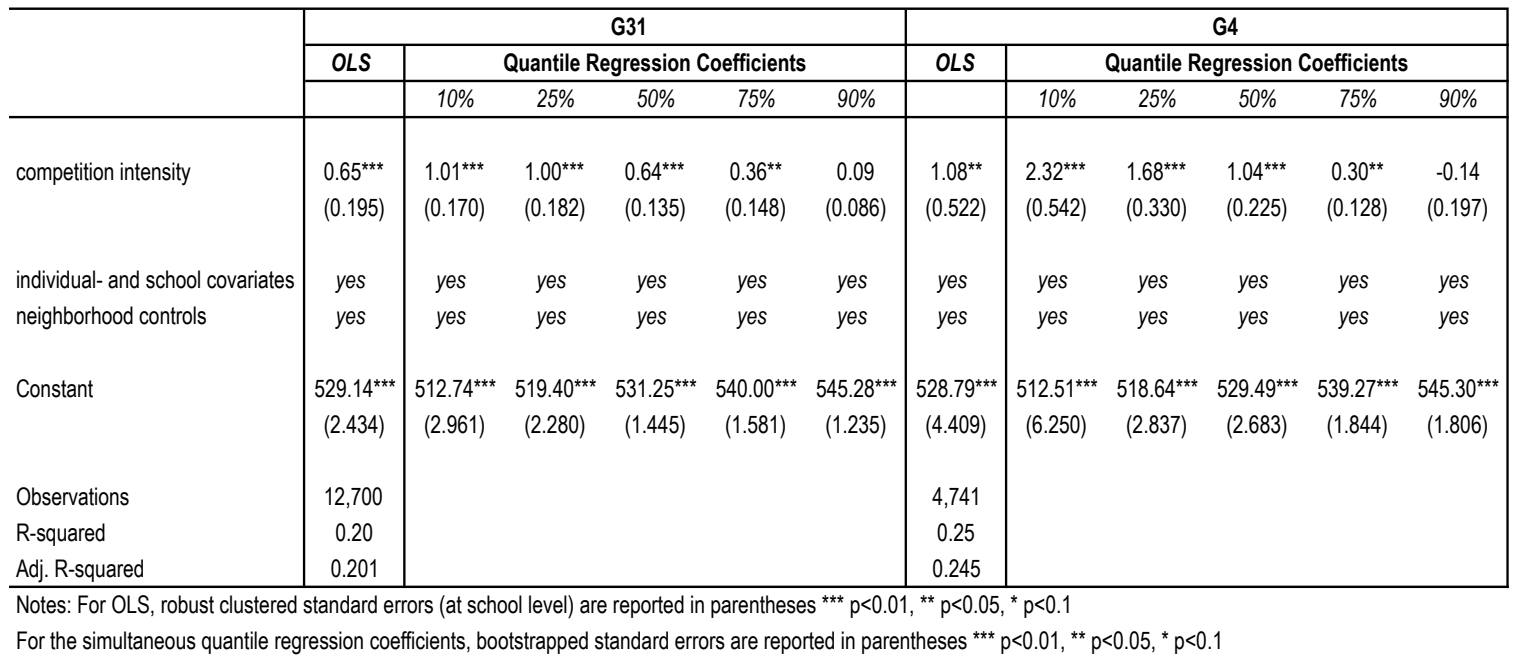

Whereas the analyses presented here focus on school-level competition in Dutch primary education, it is noteworthy to acknowledge that, although choice and competition are conceptually distinct, they can be difficult to separate at the school-level as greater choice for households is generally associated with more competition between schools 
(Gibbons et al., 2008). Importantly, both phenomena could independently affect academic achievement.

The BRON data set also contains information on households' residential location, by giving the coordinates of the neighborhood's centroid. The mean distance observed between this centroid and the actual school attended in the G31 is 1.16 kilometers. The level of choice available to a student in a certain neighborhood is calculated as the (natural logarithm of the) number of schools within a meaningful radius (i.e. $1 \mathrm{~km}$ ) around the centroid of a student's neighborhood of residence. A logarithm is used, because the effect of an absolute difference of 2 additional schools, for example, is arguably different in a context with 2 and 4 schools, than in one with 8 and 10 schools. The choice effect is therefore to be interpreted as the effect of a $100 \%$ change in the number of surrounding schools (within $1 \mathrm{~km}$ ) on students' test scores. ${ }^{88}$ This choice measure is, not surprisingly, related to the school-level measure of competition intensity (i.e. pairwise correlation is 0.19). However, both measures arguably display sufficient independent variation, which is used to compare the effects of both phenomena.

One approach then to distinguish between competition and choice effects, is to present estimates of the association between school-level competition and achievement, unconditional on the choice intensity available to students (i.e. results presented so far), and to compare these with the estimates when either a measure for choice, or when both are included in the analyses (cf. Gibbons et al., 2008). The results of this approach are presented in Table 6.5

From Table 6.5 it is apparent that performing the analyses using only choice intensity leads to OLS estimates that are smaller and less significant than those observed when using school-level competition intensity. Similarly, the patterns observed along the quantiles using choice intensity are "watered-down versions" of the initial competition-based results presented earlier. Importantly, when the competition and choice measures are both entered together, the OLS coefficients for competition intensity remain remarkably similar to those obtained using these "competition-only" specifications. Also, the OLS estimates for the association between choice intensity and achievement are statistically insignificant once the competition measure is included.

\footnotetext{
${ }^{88}$ Put differently, a percentage increase in the number of schools is associated with $1 / 100$ of the effect size change in test score $Y$.
} 
Table 6.5: SQR, School choice and competition effects on CITO test score

\begin{tabular}{|c|c|c|c|c|c|c|c|c|c|c|c|c|}
\hline & \multicolumn{6}{|c|}{ G31 } & \multicolumn{6}{|c|}{ G4 } \\
\hline & \multirow[t]{2}{*}{ OLS } & \multicolumn{5}{|c|}{ Quantile Regression Coefficients } & \multirow[t]{2}{*}{ OLS } & \multicolumn{5}{|c|}{ Quantile Regression Coefficients } \\
\hline & & $10 \%$ & $25 \%$ & $50 \%$ & $75 \%$ & $90 \%$ & & $10 \%$ & $25 \%$ & $50 \%$ & $75 \%$ & $90 \%$ \\
\hline \multicolumn{13}{|l|}{ COMPETITION ONLY } \\
\hline \multirow[t]{2}{*}{ competition intensity } & $0.65^{\star \star *}$ & $1.01^{* * *}$ & $1.00^{* \star *}$ & $0.64^{* * *}$ & $0.36^{\star *}$ & 0.09 & $1.08^{\star *}$ & $2.32^{* * *}$ & $1.68^{* * *}$ & $1.04^{* * *}$ & $0.30^{* *}$ & -0.14 \\
\hline & $(0.195)$ & $(0.170)$ & $(0.182)$ & $(0.135)$ & $(0.148)$ & $(0.086)$ & $(0.522)$ & $(0.542)$ & $(0.330)$ & $(0.225)$ & $(0.128)$ & $(0.197)$ \\
\hline \multicolumn{13}{|l|}{ CHOICE ONLY } \\
\hline \multirow[t]{2}{*}{ choice intensity } & $0.51^{*}$ & $0.96^{\star \star}$ & $0.88^{\star * *}$ & 0.20 & 0.12 & 0.13 & $0.95^{*}$ & $1.48^{*}$ & $1.84^{\star \star \star}$ & 0.67 & 0.30 & -0.24 \\
\hline & $(0.282)$ & $(0.436)$ & $(0.231)$ & $(0.182)$ & $(0.186)$ & $(0.187)$ & $(0.488)$ & $(0.790)$ & $(0.524)$ & $(0.423)$ & $(0.332)$ & $(0.470)$ \\
\hline \multicolumn{13}{|l|}{ COMPETITION AND CHOICE } \\
\hline \multirow[t]{2}{*}{ competition intensity } & $0.73^{\star \star *}$ & $1.30^{* * *}$ & $1.17^{\star \star \star}$ & $0.77^{* * *}$ & $0.44^{* \star *}$ & 0.06 & $0.96^{*}$ & $2.41^{* * *}$ & $1.50^{* \star *}$ & $1.01^{* * *}$ & $0.30^{*}$ & -0.15 \\
\hline & $(0.232)$ & $(0.290)$ & $(0.205)$ & $(0.142)$ & $(0.120)$ & $(0.114)$ & $(0.551)$ & $(0.433)$ & $(0.320)$ & $(0.148)$ & $(0.172)$ & $(0.278)$ \\
\hline \multirow[t]{2}{*}{ choice intensity } & 0.39 & $0.80^{\star \star}$ & $0.72^{\star \star \star}$ & 0.07 & 0.08 & 0.15 & 0.51 & 0.59 & $1.09^{\star \star}$ & 0.27 & 0.25 & -0.18 \\
\hline & $(0.267)$ & $(0.328)$ & $(0.215)$ & $(0.238)$ & $(0.182)$ & $(0.180)$ & $(0.438)$ & $(0.626)$ & $(0.457)$ & $(0.306)$ & $(0.294)$ & $(0.292)$ \\
\hline individual- and school covariates & yes & yes & yes & yes & yes & yes & yes & yes & yes & yes & yes & yes \\
\hline neighborhood controls & yes & yes & yes & yes & yes & yes & yes & yes & yes & yes & yes & yes \\
\hline Observations & 11,724 & & & & & & 4,606 & & & & & \\
\hline R-squared & 0.21 & & & & & & 0.25 & & & & & \\
\hline Adj. R-squared & 0.204 & & & & & & 0.245 & & & & & \\
\hline
\end{tabular}

A largely similar story holds for the quantile regression coefficients when both measures are included. However, statistically significant estimates for choice are found for the lower half of the achievement distribution in both G31 and G4. But, the estimates for competition intensity and achievement along the quantiles seem to dominate any associations with choice intensity across the entire achievement distribution and remain strongly unaffected by the decision whether or not to include choice intensity in the estimation specification.

All Dutch primary schools, whether privately- or publicly run, are equally funded by the central government and face similar requirements and attainment targets, as described in previous sections. Also, the freedom of decision-making for public schools seems to have increased over the last decades, making them almost indistinguishable from their private counterparts (cf. Zoontjens, 2003). However, it could still be the case that school types respond differently to competition intensity. One such argument would be, for example, that private government-funded schools have had a longer history of decentralized management and are more likely to respond to local education market competitiveness. The 
results of performing the full-specification OLS analyses, by subsets of publicly- and privately run government-funded schools, are presented in Table 6.6.

The results seem to support the notion that competition intensity is particularly affecting private government-funded schools' academic performance. The OLS results for the subsamples of public schools in both the G31 and G4 cities yield relatively low and statistically insignificant effects. However, despite the fact private government-funded schools account for roughly two-thirds of all schools, the estimates for this subsample are (relatively) imprecise. This could partially reflect that there is a wide variety of school types within this sector, as described earlier (i.e. different types of religious and non-religious private government-funded schools).

Table 6.6: OLS, School competition effects across private public schools

\begin{tabular}{|c|c|c|c|c|}
\hline & \multicolumn{2}{|l|}{ G31 } & \multicolumn{2}{|l|}{ G4 } \\
\hline & Public & Private & Public & Private \\
\hline & (1) & (2) & (3) & (4) \\
\hline VARIABLES & CITO & CITO & CITO & CITO \\
\hline \multirow[t]{2}{*}{ competition intensity } & 0.37 & $0.75^{\star \star \star}$ & 0.50 & $1.27^{*}$ \\
\hline & $(0.317)$ & $(0.249)$ & $(0.627)$ & $(0.723)$ \\
\hline individual- and school covariates & yes & yes & yes & yes \\
\hline neighborhood controls & yes & yes & yes & yes \\
\hline \multirow[t]{2}{*}{ Constant } & $527.73^{\star \star \star}$ & $530.59^{* \star *}$ & $530.12^{\star \star *}$ & $529.21^{\star \star \star}$ \\
\hline & $(4.159)$ & $(3.041)$ & $(7.870)$ & $(5.694)$ \\
\hline Observations & 3,790 & 8,910 & 1,640 & 3,101 \\
\hline R-squared & 0.22 & 0.21 & 0.30 & 0.23 \\
\hline Adj. R-squared & 0.209 & 0.203 & 0.289 & 0.230 \\
\hline
\end{tabular}

Notes: Robust clustered standard errors (at school level) in parentheses ${ }^{* \star *} p<0.01,{ }^{* *} p<0.05,{ }^{*} p<0.1$

Again, similar to the analyses in previous chapters, the issue of missing achievement data on a large proportion of students could have important consequences for the validity of the results presented in this chapter. Table 6.6 gives no clear signs of strong non-random response patterns in terms of competition intensity being related to missing outcome and, furthermore, the two groups seem rather balanced in terms of other background characteristics that are not (or only indirectly) related to the exemption criteria for taking 
the CITO test. To summarize, Table 6.7 gives no direct signs of endogenous non-random selection of the treatment and outcome variables that would easily explain the results.

Table 6.7: Missing CITO test score data comparisons, BRON PO '08-'09

\begin{tabular}{l|cc|cc|cc|}
\hline & \multicolumn{3}{|c|}{ no missing cito } & missing cito & & all students \\
\cline { 2 - 7 } & mean & (sd) & mean & (sd) & mean & (sd) \\
\hline CITO-score & 534.43 & $(10.26)$ &. &. & 534.43 & $(10.26)$ \\
VMBO & 0.54 & $(0.50)$ & 0.60 & $(0.49)$ & 0.58 & $(0.49)$ \\
HAVO & 0.14 & $(0.35)$ & 0.12 & $(0.33)$ & 0.13 & $(0.34)$ \\
HAVO/NWO & 0.15 & $(0.35)$ & 0.14 & $(0.34)$ & 0.14 & $(0.35)$ \\
VWO & 0.17 & $(0.38)$ & 0.14 & $(0.35)$ & 0.21 & $(0.18)$ \\
competion intensity & 0.18 & $(0.14)$ & 0.21 & $(0.17)$ & 0.20 & $(0.16)$ \\
male & 0.49 & $(0.50)$ & 0.51 & $(0.50)$ & 0.50 & $(0.50)$ \\
relative age (in years) & -0.05 & $(0.68)$ & 0.02 & $(0.70)$ & 0.00 & $(0.69)$ \\
nonwestern background & 0.31 & $(0.46)$ & 0.30 & $(0.46)$ & 0.31 & $(0.46)$ \\
2nd generation immigrant & 0.33 & $(0.47)$ & 0.32 & $(0.47)$ & 0.33 & $(0.47)$ \\
weighted student funding & 0.16 & $(0.33)$ & 0.15 & $(0.32)$ & 0.15 & $(0.32)$ \\
one-parent household & 0.05 & $(0.21)$ & 0.05 & $(0.23)$ & 0.05 & $(0.22)$ \\
\% non-western at primary school & 0.31 & $(0.31)$ & 0.30 & $(0.30)$ & 0.31 & $(0.30)$ \\
mean school SES & 0.07 & $(1.13)$ & -0.03 & $(1.08)$ & 0.00 & $(1.10)$ \\
school size & 5.72 & $(0.49)$ & 5.73 & $(0.48)$ & 5.73 & $(0.48)$ \\
neighborhood SES 2006 & 0.07 & $(1.32)$ & -0.03 & $(1.29)$ & 0.00 & $(1.30)$ \\
urbanicity & 2.89 & $(1.10)$ & 2.94 & $(1.06)$ & 2.93 & $(1.07)$ \\
G4 & 0.35 & $(0.48)$ & 0.38 & $(0.48)$ & 0.36 & $(0.48)$ \\
school quality score & 1.12 & $(0.43)$ & 1.10 & $(0.38)$ & 1.11 & $(0.40)$ \\
N & 12910 & - & 33174 & - & 46084 & - \\
\hline
\end{tabular}

\subsection{Concluding remarks}

This chapter set out to analyze the relationships between school-level competition and students' academic achievement in the Dutch primary sector, thereby distinguishing competition from choice effects. For this purpose, school concentration measures have been constructed for all schools in the largest 31 municipalities, describing "the number of surrounding schools per 100 cohort student member within in a radius of 3 kilometers $(\mathrm{km})$ around the school".

The results suggest there is a positive association between school-level competition and academic achievement. This relationship is particularly strong for the lower half of the achievement distribution, but beyond the median level of performance increased 
competition intensity is not related to academic performance. A measure for household choice, related to school-level competition intensity, is not able to explain the patterns described above. The effect seems to be particularly strong for private government-funded schools, but this sector holds a variety of quite distinct school types. There are many schools that did not respond to the request to submit performance data to BRON. But, the previous section argues that no strong signs of important non-random patterns of non-response are observed that would completely overhaul the above story.

Of course, there are other issues to be considered as well. School-level competition indices generally suffer from very strong associations with general urban density and school size. Also, important mobility differences can exist between rural and urban areas. This is also why the analyses are performed on the subset of 31 largest municipalities, and why competition intensity is proxied by a "school concentration" measure. The pair-wise correlations of competition intensity in this dataset with urban density and school size are 0.09 and -0.18 respectively, with both factors included in the full-specification models as covariates. Also, as mentioned, this school concentration measure weighs each school within $3 \mathrm{~km}$ equally as a competitor. A more refined version of this measure could include school- and household characteristics to determine, a-priori, which schools should count more heavily towards the competition index. The approach taken here is that having more surrounding schools per 100 cohort members within a radius of $3 \mathrm{~km}$, on average, corresponds to a higher level of competition intensity.

In addition, residential sorting of households can lead to market configurations in which this measure of competition is endogenous (e.g. when particularly motivated parents move to high-competition schooling markets or vice-versa). Nechyba $(1999,2000)$ describes how, in a neighborhood schooling system, the household choice of attending a public school is essentially bundled with the choice of residence. Thus, even in a public schooling system with no tuition fees, public schools are then in practice not free to households who pay for access to schools through housing prices. Given that choice in the Netherlands is both universal and mandatory, this could ease some of those concerns regarding residential sorting. A relevant observation in this respect is that the pair-wise correlations of competition intensity with the student's funding weight and the neighborhood's SES index are 0.02 and -0.14 , respectively. These statistically significant associations of competition intensity with relative educational disadvantage could imply the estimates presented are 
(slightly) biased downward to the extent such relative disadvantages are not captured by the full specification of the model.

The closure of poorly performing schools, and the opening of new schools, are other ways in which observed competition intensity could be related to unobserved quality differences of schools. For example, if all students are drawn to a single high quality school in the neighborhood, leading to the closure of nearby competing schools, this will lead to a low level of competition intensity being associated with higher performance levels due to (unobserved) school quality of the remaining school. In Dutch primary education, changes to minimum school-size requirements led to an average reduction in the number of schools per municipality of about $15 \%$ in the 1990s (see: De Haan et al., 2011). However, between 2000-2010, the number of primary schools dropped only slightly (i.e. from 7059 to 6993); most of which is due to demographic patterns in rural areas. 


\section{A Appendix: Full-estimation results}

Table 6.3: OLS, School competition intensity effect on CITO test score

\begin{tabular}{|c|c|c|c|c|c|}
\hline & G31 & G31 & G31 & G31 & G4 \\
\hline & $(1)$ & $(2)$ & $(3)$ & $(4)$ & (5) \\
\hline VARIABLES & CITO & CITO & CITO & CITO & CITO \\
\hline \multirow[t]{2}{*}{ competition intensity } & 0.19 & 0.29 & $0.57^{* * *}$ & $0.65^{\star * *}$ & $1.08^{\star *}$ \\
\hline & $(0.214)$ & $(0.179)$ & $(0.186)$ & $(0.195)$ & $(0.522)$ \\
\hline \multirow[t]{2}{*}{ male (yes=1) } & & $1.11^{* * *}$ & $1.13^{* * *}$ & $1.13^{* * *}$ & $1.37^{* * *}$ \\
\hline & & $(0.182)$ & $(0.178)$ & $(0.177)$ & $(0.283)$ \\
\hline \multirow[t]{2}{*}{ relative age (in years) } & & $-3.42^{* * *}$ & $-3.36^{* * *}$ & $-3.27^{\star * *}$ & $-3.47^{\star \star *}$ \\
\hline & & $(0.136)$ & $(0.137)$ & $(0.131)$ & $(0.242)$ \\
\hline \multirow[t]{2}{*}{ non-western immigrant background (yes=1) } & & $-3.82^{* * *}$ & $-1.91^{* * *}$ & $-1.71^{* \star *}$ & $-2.71^{\star \star *}$ \\
\hline & & $(0.393)$ & $(0.369)$ & $(0.357)$ & $(0.555)$ \\
\hline \multirow[t]{2}{*}{ 2nd generation non-western background (yes $=1$ ) } & & -0.22 & -0.09 & -0.25 & -0.15 \\
\hline & & $(0.296)$ & $(0.290)$ & $(0.284)$ & $(0.448)$ \\
\hline \multirow[t]{2}{*}{ student's weighted funding } & & $-3.88^{* * *}$ & $-2.33^{* \star *}$ & $-2.30^{\star \star *}$ & $-2.51^{* * *}$ \\
\hline & & $(0.524)$ & $(0.523)$ & $(0.495)$ & $(0.705)$ \\
\hline \multirow[t]{2}{*}{ single-parent household } & & $-3.24^{* * *}$ & $-2.39^{* * *}$ & $-2.48^{\star \star *}$ & $-2.71^{* * *}$ \\
\hline & & $(0.458)$ & $(0.439)$ & $(0.439)$ & $(0.587)$ \\
\hline \multirow[t]{2}{*}{ proportion non-western immigrants at school } & & & $-3.92^{* \star *}$ & $-6.66^{\star \star \star}$ & $-6.83^{\star \star *}$ \\
\hline & & & $(0.856)$ & $(0.947)$ & $(1.453)$ \\
\hline \multirow[t]{2}{*}{ SES-index of school intake } & & & $0.65^{\star * *}$ & 0.01 & -0.44 \\
\hline & & & $(0.233)$ & $(0.274)$ & $(0.497)$ \\
\hline \multirow[t]{2}{*}{ school size $(\log )$} & & & $1.40^{* * *}$ & 0.65 & 0.67 \\
\hline & & & $(0.399)$ & $(0.400)$ & $(0.712)$ \\
\hline \multirow[t]{2}{*}{ neighborhood SES index } & & & & $0.76^{* * *}$ & $0.67^{* * *}$ \\
\hline & & & & $(0.138)$ & $(0.209)$ \\
\hline \multirow[t]{2}{*}{ urbanicity index } & & & & $0.48^{* *}$ & 0.53 \\
\hline & & & & $(0.202)$ & $(0.562)$ \\
\hline municipality dummies included & no & no & no & yes & yes \\
\hline \multirow[t]{2}{*}{ Constant } & $533.89^{* * *}$ & $534.93^{* * *}$ & $526.38^{* * *}$ & $529.14^{\star * *}$ & $528.79^{* * *}$ \\
\hline & $(0.655)$ & $(0.554)$ & $(2.451)$ & $(2.434)$ & $(4.409)$ \\
\hline Observations & 12,910 & 12,899 & 12,711 & 12,700 & 4,741 \\
\hline R-squared & 0.00 & 0.15 & 0.18 & 0.20 & 0.25 \\
\hline Adj. R-squared & 0.000291 & 0.154 & 0.179 & 0.201 & 0.245 \\
\hline
\end{tabular}

Notes: Robust clustered standard errors (at school level) in parentheses ${ }^{* * *} p<0.01,{ }^{* *} p<0.05,{ }^{*} p<0.1$ 


\section{Competition, Sorting by Ability and Productive Efficiency ${ }^{*}$}

\subsection{Introduction}

The previous chapters have focused on the effects of choice, school type attendance and competition on academic achievement. For such analyses, it is necessary to take into account patterns of student sorting across schools. But, the effects of school choice and competition on the sorting of students are not only important for interpreting productive efficiency results, but are themselves relevant. Hoxby (2003) focuses on this by stating that the two main forces operating when analyzing choice or competition are: (1) the competitive force working to increase effectiveness and productivity in schools, and (2) the impact of any consequential differences in the allocation of students to schools.

The objective of this chapter is to estimate the effects of competition between Dutch schools i) on the sorting of students by performance levels at the start of secondary education, and ii) on performance gains in the secondary school career. To achieve these objectives, this chapter uses longitudinal data from about 13,000 students going to 102 different school locations in the Netherlands (i.e. VOCL99). Kernel matching techniques are used to account for differences in the underlying student population between local education markets. The results indicate that the sorting of students across schools is in equilibrium across local market in education, giving rise to an overall zero-effect of

\footnotetext{
"This chapter is based on the paper: Cabus, S.J. and Cornelisz I. (2013) "Competition, Student Sorting and Performance in Local Education Markets: The Dutch Secondary Sector." Manuscript submitted for publication.
} 
competition on sorting by performance levels. However, this outcome is stratified by (innate) ability across school types and, with increasing competition, relatively more schools target the group of high-achieving students. As a result, schools in competitive local education markets have to settle for enrolling more students performing at the margins achievement, as to ensure sufficient enrollment rates. In addition, accounting for sorting patterns, competition is related to improvements in academic achievement within the first three years of secondary education, corroborating the findings in Chapter 6.

\subsection{Background and scope}

When estimating the effects of competition on performance gains, omitted variable bias with non-random patterns of student sorting is a serious reason for concern (Belfield and Levin, 2002). The effects of competition on the sorting of students are not only important for interpreting productive efficiency results, but are themselves relevant. Hoxby (2003) focuses on this by stating that the two main forces operating when analyzing choice or competition are i) the competitive force working to increase effectiveness and productivity in schools, and ii) the impact of any consequential differences in the allocation of students to schools. The objective of this chapter is on understanding the latter issue of sorting, while dealing with potential productive efficiency effects afterwards.

There are several mechanisms through which competition may affect the sorting of students by performance levels. Among them three are considered here to be relevant in Dutch compulsory education: (1) peer effects; (2) curriculum or other (non-academic) features; and (3) school reputation.

\section{Peer effects}

The international literature on the effects of (increased) competition between schools on the actual sorting of students by performance levels, both across and within educational markets, highlights the role of peer effects. Peer effects are generally defined as the extent to which a student's learning outcomes depend on the characteristics of his or her classmates. Rothstein's (2006) model argues that households, in the presence of peer effects and school choice, may actually prefer less effective schools with desirable peer groups to better, more effective, schools. In equilibrium, high-competition educational 
markets will then be more stratified by ability than low-competition markets (Rothstein, 2006). Individual schools, in this case, will face incentives enrolling high-quality peers, rather than offering effective instruction (see Burgess et al., 2007). In addition to average peer quality, the variation of peer ability within schools can be an important determinant of school quality. In their attempt to improve quality, schools facing intense competition, could resort to curriculum targeting in an effort to improve productive efficiency, leading to more homogeneous student populations within schools (cf. Nechyba, 2003).

\section{Curriculum or other (non-academic) features}

Disregarding potential peer effects, there are several ways in which school competition can still affect student sorting. As described in Chapter 6, competition between schools could lead to product differentiation, in which schools match their appeal to particular educational preferences of households, rather than offering a standardized educational product (Belfield and Levin, 2005; Levin, 2012). When facing competition, schools seem to use their position in the local hierarchy of their education market to obtain control over their enrollment. If explicit ability selection is not allowed, schools can adopt enrolment schemes that could well be less ability-neutral than they might appear at first (Waslander et al., 2010). Alternatively, schools can use the curriculum or other (non-academic) features to target certain preferred households. Highlighting the importance of enrolling sufficient numbers of students, McMillan (2004) suggests that some schools will actually show rentseeking behavior and go "down-market" in targeting certain households as a way to ensure sufficient enrollment patterns. Given this variety of mechanisms at play, school choice advocates and -opponents disagree on the actual effects competition will have on schools' curricula and academic standards (Hoxby, 1999).

\section{School reputation}

In the absence of both peer effects and differential preferences towards school attributes, MacLeod and Urquiola (2009) point to school reputation as another factor affecting the sorting of students across schools. In their model, socioeconomic- and ability stratification across schools will occur through student admission selection processes, regardless of any potential peer effects. Excluding unfavorable students can occur both explicitly as well as implicitly. One strategy could be to diversify course offerings with respect to, for example, 
sports, arts or international components, exploiting the knowledge that some courses attract some students more than others. Waslander et al. (2010, p.50), conclude that under the influence of competition: "Implicitly or explicitly schools seek the most "desirable" students: First, students who are academically able followed by students who possess other favorable characteristics such as specific socio-economic and ethnic backgrounds." Based on these observations, competition between schools has the potential to foster, or to maintain, a clear hierarchy in local markets in education.

\subsection{Methodology and data}

\subsubsection{Methodology}

At the start of secondary education, students take another CITO exam especially for reasons of follow-up of student sorting across schools. ${ }^{89}$ In the data set that is used in this chapter, these test scores have been collected for about 13,000 students enrolled in 102 Dutch secondary schools in grade 7 in the school year 1999-00. The data also includes a rich set of background variables on the students, their parents, and the schools. The standardized exam is interpreted as the composite effect of a student's innate ability, their exposure to primary schooling (i.e., the value added by the primary school attended), motivation and other important background characteristics (e.g. parental education, motivation, support and socioeconomic background). ${ }^{90}$ Kernel matching estimation techniques are used to match students in high-competitive markets in education (HCM, or the treatment group) to low- or non-competitive market in education ( $\mathrm{NCM}$, or the control group), along the distribution of our competition measure. The objective of this approach is to account for differences in the underlying student population between markets in education with different levels of competition intensity. The mean performance level of the school is also included in one of the specifications, as to control for differences in the value added of primary education.

\footnotetext{
${ }^{89}$ Note that the CITO follow-up exam takes place after students have been sorted into the secondary sector, but before educational production in the secondary schools takes place. Differences in student performance between low- and high competitive areas are then interpreted to be the direct result of student sorting, and not due to productive efficiency differences of secondary schools.

${ }^{90}$ The data is discussed in more detail in the next section. An overview of the variables used in this chapter is presented in Appendix B.
} 
Thus, sorting is measured by student performance on standardized exams at the start of secondary education, as this is relatively easy to measure, accurate, and comparable across different schools. Once differences in the underlying student population between $\mathrm{NCM}$ and $\mathrm{HCM}$ are accounted for, the effect of increasing competition intensity on sorting by performance levels is estimated using an appropriate school concentration index. Several model specifications are proposed, which gradually disentangle supply- from demand-driven competition mechanisms influencing the sorting of students.

Interestingly, the data set and this approach also allow for estimating the effect of competition on performance gains within the first three years of secondary education. For this, the additional follow-up exam (i.e. grade 9) is used, also constructed by CITO. If, conditional on the enrollment decision at the start of secondary education, competition intensity is indeed associated with positive differences in productive efficiency across schools, this would corroborate the findings for competition in the Dutch primary sector presented in Chapter 6.

Using the municipality border is arguably inadequate to correctly define the relevant educational market; particularly for a secondary school in the Netherlands. For example, Herweijer (2008) describes that in some cities already $25 \%$ of all households send their child beyond the municipality border. As to estimate competition intensity in secondary education Dijkgraaf et al. (2008) used an approach based on the number of surrounding schools within $10 \mathrm{~km}$, which is around the nation-wide average of travelling distance, and base their performance effect of competition on a Herfindahl Index-measure. In this chapter, as to account for the association between general urban- and school density, the number of surrounding schools within $10 \mathrm{~km}$ per 100 cohort members is derived. As with the measure for choice intensity in Chapter 4, the natural logarithm of this number is used, as this would arguably better grasp the nature of competition intensity. The measure for competition intensity can thus be expressed as:

$$
\text { Competition }_{j}=\ln \left(\frac{\# \text { of surrounding schools within } 10 \mathrm{~km}}{\# \text { of cohort members within } 10 \mathrm{~km}} * 100\right),
$$

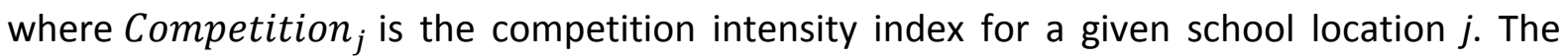
objective is to explicitly focus on the effect of secondary school-level competition on the sorting of students by analyzing student performance on standardized exams at the start of secondary education (cf. the CITO exam on math and language). All students have to switch 
schools when making the transition from the primary- to the secondary sector. Therefore, this individual achievement indicator, determining what track(s) in secondary education a student is eligible to attend, is considered to be an important source of information to Dutch secondary schools. The functional form of student performance on standardized exams at the start of secondary education can be represented by:

$$
\mathrm{y}_{i} \sim f\left(\alpha_{i}, X_{i j}, v_{i}\right) \text {, }
$$

where $y_{i}$ denotes the outcome measure 'performance' of an individual $i$ on this standardized exam. This outcome measure captures students' innate ability $\alpha_{i}$, a vector of $k$ exogenous student characteristics that influence the performance level $X_{i k}$, and the value added of the primary school $v_{i}$. As such, $\mathrm{y}_{i}$ measures student performance i) after finishing primary education, ii) after the student sorting process in secondary education, and ii) before schooling has been produced in secondary education. The latter is particularly important, as it excludes potential value added by the secondary school; thereby enabling an analysis of student sorting by ability. This, at least partially, meets the critique of distinguishing between effects of competition on productive efficiency and student sorting (Gibbons et al., 2008).

The first objective is to find a causal effect of competition intensity between schools on sorting by performance levels. As such, students going to a school in a relatively competitive area (treatment group, further abbreviated by HCM) are matched to students attending a school in a non- or low-competitive area (control group, further abbreviated by NCM). HCM and NCM are defined, respectively, right and left of the median student along the distribution of the competition measure. A $5 \%$ error bound around the median student is taken into account, as to account for potential computational errors in the measure of competition intensity. ${ }^{91}$ For causal statistical inference, at the mean-level, $\alpha_{i}, X_{i k}$, and $v_{i}$ in formula 7.2 should not statistically differ between HCM and NCM.

One can reasonably argue that students in HCM are different from students in NCM, violating overall comparability with respect to $\alpha_{i}$ and $X_{k i}$, (see also Gibbons et al., 2008). Therefore, a Kernel matching estimation technique is proposed which accounts for

\footnotetext{
${ }^{91}$ Given that the exact address of the schools' locations is used, large computational errors seem unlikely. But, especially close to the median, computational errors with respect to the competition measure would bias the results (i.e., students are wrongly assigned to high-competitive or low-competitive education markets).
} 
differences in the underlying student population between HCM and NCM (cf. Rubin, 2006). ${ }^{92}$ Kernel matching assigns non-zero weights to each individual within a given subgroup of individuals. The weights are assigned according to the distance, as determined by the propensity scores of students, within each subgroup of individuals. When two students have a similar propensity score, calculated using a discrete choice Probit model, this implies they are similar, based on a set of observed exogenous student-level characteristics.

Kernel matching relies on overlap in characteristics between individuals within a given subgroup (i.e. common support). Each subgroup of individuals is specified by a chosen bandwidth. A bandwidth by normal approximation does not trim away individuals at the tail of the distribution, as is the case with the default bandwidth by Epanechnikov approximation used in the analysis here:

$$
\mathrm{w}\left(\mathrm{p}_{\mathrm{n}}\left(\mathrm{x}_{\mathrm{i}}\right), \mathrm{p}_{\mathrm{n}}\left(\mathrm{x}_{\mathrm{c}}\right)\right)=\frac{\mathrm{K}\left[\frac{\mathrm{p}_{\mathrm{n}}\left(\mathrm{x}_{\mathrm{i}}\right)-\mathrm{p}_{\mathrm{n}}\left(\mathrm{x}_{\mathrm{c}}\right)}{\mathrm{h}_{\mathrm{n}}}\right]}{\sum_{\mathrm{k}=1}^{\mathrm{C}}\left[\frac{\mathrm{p}_{\mathrm{n}}\left(\mathrm{x}_{\mathrm{i}}\right)-\mathrm{p}_{\mathrm{n}}\left(\mathrm{x}_{\mathrm{k}}\right)}{\mathrm{h}_{\mathrm{n}}}\right]},
$$

where $n$ denotes the total sample size, $c=1, \ldots C$ an index for untreated students and $i=1, \ldots I$ an index for treated students. Formula 7.3 estimates the counterfactual outcome for a treated student as the weighted average outcome of untreated students. As such, w(.) denotes the weights assigned to each individual within a specified bandwidth $h_{n}$. In the results section, ttest statistics are used to check for differences between treated and matched untreated students on student-level characteristics, and to analyze the notion of common support. The above matching procedure enables the first model specification for estimating the effects of competition on student sorting by performance levels:

$$
\mathrm{y}_{i}=\alpha_{0}+\theta\left(\text { Competition }_{j}\right)+\sum_{k=1}^{k} \gamma_{k} X_{k i}+u_{i}
$$

Here, the estimate of interest is that of $\vartheta$, which is the effect of competition on student sorting by performance levels. Note that $\alpha_{0}$ denotes a constant, and $u_{i}$ the residual. Kernel matching does not account for underlying differences with respect to the value added of primary education between NCM and HCM.

\footnotetext{
${ }^{92}$ Note, however, that Kernel matching does not account for omitted variable bias.
} 
Therefore, the second model specification controls for differences between NCM and $\mathrm{HCM}$ with respect to the mean level of school performance $\overline{y_{J}}$. For the productive efficiency analyses, this performance level of the school also acts a covariate, capturing potential peer effects (see also Hastings and Weinstein, 2008):

$$
y_{i}=\alpha_{0}+\beta \overline{y_{J}}+\theta\left(\text { Competition }_{j}\right)+\sum_{k=1}^{k} \gamma_{k} X_{k i}+u_{i}
$$

In the third model specification, covariates are added to acknowledge observed (demandside) differences in the underlying student population with respect to school choice determinants:

$$
\mathrm{y}_{i}=\alpha_{0}+\beta \overline{y_{j}}+\theta\left(\text { Competition }_{j}\right)+\sum_{k=1}^{k} \gamma_{k} X_{k i}+\sum_{c=1}^{c} \delta_{c} D_{c i}+u_{i}
$$

where $D_{c i}$ denotes a vector of $c$ school choice determinants.

Lastly, Model 4 represents the most restricted conceptualization of competition in which, in addition to the above factors, controls for differences in supply-driven factors (i.e. school type and denomination) are added. Also, the effect of competition on student sorting is explored by comparing similar school types only (e.g. "vwo"). This is realized by interacting competition intensity with dummies representing a particular school type; thus generating a $\theta$ for each school type:

$\mathrm{y}_{i}=\alpha_{0}+\beta \bar{y}_{j}+\sum_{k=1}^{k} \gamma_{k} X_{k i}+\sum_{c=1}^{c} \delta_{c} D_{c i}+\sum_{p=1}^{p} \rho_{p} S_{p j}+\sum_{\text {type }=1}^{\text {TYPE }} \theta_{\text {type }}\left(S_{\text {type }} *\right.$ Competition $\left._{j}\right)+u_{i}$

where $S_{p j}$ denotes a vector of $p$ school supply covariates (including school type, abbreviated by $\left.\mathrm{S}_{\text {type }}\right)$, and the interaction effect of school type $\left(\mathrm{S}_{\text {typej }}\right)$ and competition intensity.

Then, the first model specification in equation 7.4 is used to analyze the total average of achievement gains from grade 7 to grade 9 as a result of school-level competition. This basic model specification is the preferred model for achievement gains, as this model takes a more comprehensive approach towards the concept of competition intensity, allowing for different demand and supply mechanisms, whereas the other models estimate the effect of a more restricted concept of competition on achievement. However, productive efficiency effects generated by this model with individual prior achievement 
added are also reported. These results are interpreted as the effect of competition on achievement in secondary education, net of differences in both innate capacity and exposure to school quality in primary education across local education markets.

\subsubsection{Data}

The above analyses are performed using the longitudinal data set VOCL99 (cf. Voortgezet Onderwijs Cohort Leerlingen 1999) on students enrolling into secondary education in grade 7 in the school year 1999-00 (for an extensive data description, see Kuyper et al., 2003). The data consist of a rich set of variables, such as information on standardized test scores (i.e. CITO) for math and language separately in grade 7 and grade 9; gender; religion/ideology; household information on socioeconomic status and composition; and students' and parents' responses on follow-up questionnaires.

The VOCL99 data are considered nationally representative. From a total of 1,144 secondary school locations in the Netherlands, Statistics Netherlands (CBS) composed a random sample of 246 schools. In total 126 schools representing 19,391 students have participated in VOCL99. Merging this data with information on the competition intensity measure causes 22 schools to be dropped from the sample, representing about 5,000 students. ${ }^{93}$ Further data cleaning on missing values with respect to the set of exogenous covariates, and controlling for a 5\% error bound around the median drops another 1,000 students.

The total sample size for evaluating the impact of competition between schools on the sorting of students by performance is then 13,226 students. Of this group, achievement scores in grade 9 are available for 8,000 students in order to evaluate the effects of competition intensity on student achievement (i.e. productive efficiency).

\footnotetext{
${ }^{93}$ The geographical information can be traced thanks to the 6 digit BRIN-code. However, the BRIN-code has been changed since 2000 owing to mergers and acquisitions. This arguably has an effect on the follow-up test scores, so these schools are not included in the analyses.
} 


\subsection{Results}

After defining the cut-point of competition intensity at the median level, and after trimming $5 \%$ of the students around the median, a total of 6,524 students attend schools in NCM (i.e. the control group) and 6,702 students in $\mathrm{HCM}$ (i.e. the treatment group). Figure 7.1 displays the distribution of the competition intensity measure, based on a radius of $10 \mathrm{~km}$. Table 7.1 summarizes the descriptive statistics of the dependent variables, test scores on math and language with respect to grade $7(\mathrm{~N}=13,226)$ and grade $9(\mathrm{~N}=8,375)$, by control- and treatment group. The standardized test scores for math and language at the start of secondary education (i.e. CITO) have both a minimum test score of 0 and a maximum score of $20 .{ }^{94}$ Control students perform on average 13.33 on both subjects. Students in high competitive markets perform on average 13.15 on math and 13.27 on language. With respect to the math score, this amounts to a small, negative, and statistically difference. Larger differences between control and treatment students are found with respect to the test results in grade 9. ${ }^{95}$ There is a significant, and high, correlation between the tests of grade 7 and grade 9 . The correlation coefficients with respect to math are about $p=0.60$ (Pvalue $=0.0000)$, and with respect to language about $p=0.50$ ( $\mathrm{P}$-value $=0.0000)$.

Figure 7.1: Distribution of competition intensity measure

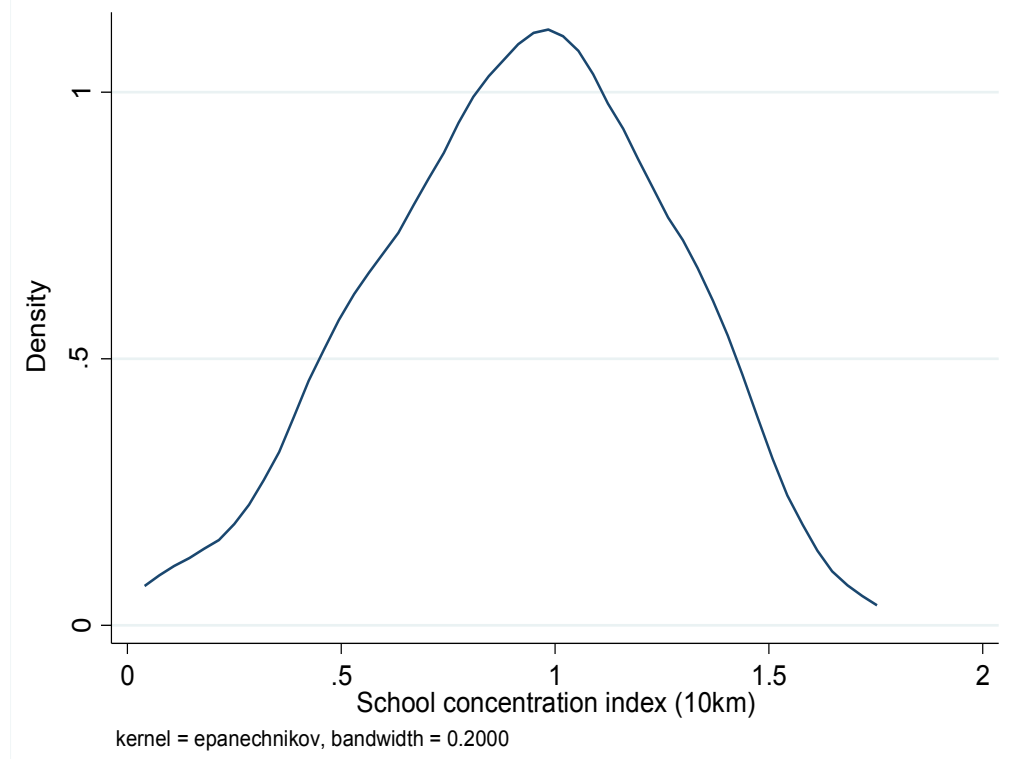

\footnotetext{
${ }^{94}$ Cronbach's alpha is equal to 0.83 , indicating an overall high reliability of the CITO test.

${ }^{95}$ The test in grade 9 has also been developed by CITO to measure performance on math and on language and has a Cronbach's alpha of 0.78 .
} 
Table 7.1: T-test mean differences outcomes between control and treatment group

\begin{tabular}{|c|c|c|c|c|c|c|c|}
\hline Variable & Obs. & Untreated(1) & Treated(2) & $\operatorname{Diff}(2)-(1)$ & T-value & Min & Max \\
\hline Math grade 7 & 13,226 & 13.33 & 13.15 & -0.18 & -2.5649 & & 20 \\
\hline Language grade 7 & 13,226 & 13.33 & 13.27 & -0.06 & -1.0601 & & 20 \\
\hline Math grade 9 & 8,375 & 54 & 54.9 & 0.88 & 3.83 & & 100 \\
\hline Language grade 9 & 8,534 & 53.3 & 54.3 & 1.01 & 4.71 & & 100 \\
\hline
\end{tabular}

Table 7.2 presents the descriptive statistics of the exogenous covariates, before the matching of students, and a list of school and school choice variables by control group $(T=0)$ and treatment group $(T=1)$ for the total sample of 13,226 students. Both groups are similar with respect to most of the student characteristics. There is a male-female ratio close to 1 , more than $80 \%$ of students are native Dutch, almost $90 \%$ of students have parents who are married and students have on average 2 siblings. Also, 30\% of students report to be nonreligious and another $30 \%$ of students to be Catholic. With respect to socioeconomic status, status1 denotes the lowest category and status6 the highest. ${ }^{96}$ About $40 \%$ of treated/untreated students are assigned to the third category, with much smaller proportions found in the lowest and highest categories.

Table 7.3 adds further descriptive statistics on school type and denomination of the school. Here, there are important differences to note. Among treatment students, relatively few are enrolled in schools offering categorical pre-vocational (vmbo) classrooms (22\% vs. $28 \%$ ) or categorical pre-university (vwo) classroom ( $8 \%$ vs. $10 \%$ ), but relatively more in categorical general secondary (havo) education (6\% vs. 1\%). Some schools in the Netherlands, however, offer a combination of educational tracks to students for their first year(s) of secondary education, referred to as comprehensive classroom settings. This can be either school-types joined together (vwo-havo-vmbo), pre-university and general secondary education together (vwo-havo), or general secondary and pre-vocational education together (havo-vmbo).

\footnotetext{
${ }^{96}$ The variable socioeconomic status has been constructed by Statistics Netherlands. It is partially based on the educational level, track and diploma of both parents and on their verbal responses with respect to their schooling. The statuses are sorted in ascending order going from low to high socioeconomic status (Kuyper et al., 2003).
} 
Table 7.2: T-test mean differences in student background characteristics

\begin{tabular}{|c|c|c|c|c|c|c|}
\hline Variable & Untreated(1) & Treated(2) & $\operatorname{Diff}(2)-(1)$ & T-value & Min & Max \\
\hline Gender (male $=1$ ) & 0.4697 & 0.49 & 0.0204 & 2.34 & 0 & 1 \\
\hline Age & 12.47 & 12.46 & -0.01 & -1.52 & 10 & 14 \\
\hline \multicolumn{7}{|l|}{ Country of origin } \\
\hline Netherlands & 0.885 & 0.8657 & -0.0193 & -3.36 & 0 & 1 \\
\hline Morocco & 0.0078 & 0.0093 & 0.0014 & 0.9 & 0 & 1 \\
\hline Sur/Ant/Aruba & 0.0156 & 0.0275 & 0.0118 & 4.68 & 0 & 1 \\
\hline Turkey & 0.0103 & 0.0134 & 0.0032 & 1.68 & 0 & 1 \\
\hline Other & 0.0812 & 0.0842 & 0.0029 & 0.61 & 0 & 1 \\
\hline \multicolumn{7}{|l|}{ Marital Status } \\
\hline Married & 0.8981 & 0.8868 & -0.0113 & -2.1 & 0 & 1 \\
\hline Living together & 0.0282 & 0.0331 & 0.0049 & 1.64 & 0 & 1 \\
\hline Never married & 0.0061 & 0.0127 & 0.0066 & 3.9 & 0 & 1 \\
\hline Widow & 0.0106 & 0.0109 & 0.0003 & 0.18 & 0 & 1 \\
\hline Divorced & 0.057 & 0.0566 & -0.0005 & -0.12 & 0 & 1 \\
\hline Children in household & 2.5162 & 2.6826 & 0.1664 & 8.45 & 0 & 1 \\
\hline Language parent1-child & 0.0185 & 0.0176 & -0.0009 & -0.41 & 0 & 1 \\
\hline Language parent2-child & 0.0184 & 0.0182 & -0.0002 & -0.08 & 0 & 1 \\
\hline \multicolumn{7}{|l|}{ Religion/Ideology } \\
\hline None & 0.3397 & 0.2753 & -0.0644 & -8.04 & 0 & 1 \\
\hline Catholic & 0.3225 & 0.2062 & -0.1163 & -15.31 & 0 & 1 \\
\hline Protestant & 0.1426 & 0.1119 & -0.0306 & -5.3 & 0 & 1 \\
\hline Reformation & 0.0679 & 0.248 & 0.1801 & 29.2 & 0 & 1 \\
\hline Islam & 0.0288 & 0.0322 & 0.0034 & 1.14 & 0 & 1 \\
\hline Other & 0.0986 & 0.1264 & 0.0278 & 5.06 & 0 & 1 \\
\hline Culture parent1-child & 0.0222 & 0.017 & -0.0052 & -2.16 & 0 & 1 \\
\hline Culture parent2-child & 0.0202 & 0.0181 & -0.0022 & -0.91 & 0 & 1 \\
\hline \multicolumn{7}{|l|}{ Socioeconomic status } \\
\hline Status 1 & 0.0599 & 0.0637 & 0.0038 & 0.9 & 0 & 1 \\
\hline Status 2 & 0.1275 & 0.1247 & -0.0028 & -0.48 & 0 & 1 \\
\hline Status 3 & 0.4413 & 0.4166 & -0.0247 & -2.87 & 0 & 1 \\
\hline Status 4 & 0.2561 & 0.2532 & -0.0029 & -0.39 & 0 & 1 \\
\hline Status 5 & 0.0967 & 0.1227 & 0.0259 & 4.77 & 0 & 1 \\
\hline Status 6 & 0.0184 & 0.0191 & 0.0007 & 0.3 & 0 & 1 \\
\hline
\end{tabular}

Table 7.3: T-test mean differences in school supply characteristics

\begin{tabular}{|c|c|c|c|c|c|c|}
\hline Variable & Untreated(1) & Treated(2) & $\operatorname{Diff}(2)-(1)$ & T-value & Min & Max \\
\hline \multicolumn{7}{|l|}{ School type } \\
\hline vwo & 0.0987 & 0.0759 & -0.0228 & -4.64 & 0 & 1 \\
\hline vwohavovmbo & 0.0578 & 0.0592 & 0.0014 & 0.36 & 0 & 1 \\
\hline vwohavo & 0.3466 & 0.4009 & 0.0544 & 6.47 & 0 & 1 \\
\hline havo & 0.0103 & 0.06 & 0.0497 & 15.6 & 0 & 1 \\
\hline havovmbo & 0.2082 & 0.1887 & -0.0194 & -2.8 & 0 & 1 \\
\hline vmbo & 0.2785 & 0.2152 & -0.0634 & -8.48 & 0 & 1 \\
\hline \multicolumn{7}{|l|}{ Denomination } \\
\hline Public & 0.3671 & 0.1047 & -0.2624 & -37.5 & 0 & 1 \\
\hline Catholic & 0.2761 & 0.3261 & 0.05 & 6.27 & 0 & 1 \\
\hline Protestant & 0.2062 & 0.1498 & -0.0565 & -8.51 & 0 & 1 \\
\hline Reformation & 0.0819 & 0.2977 & 0.2159 & 32.8 & 0 & 1 \\
\hline Other & 0.0687 & 0.1217 & 0.053 & 10.4 & 0 & 1 \\
\hline
\end{tabular}


In general, the comprehensive classroom settings "vwo-havo" (40 and 35\% of treated and untreated students, respectively) and "havo-vmbo" (19 and 21\% of treated and untreated students, respectively) accommodate relatively many students. Table 7.3 also highlights that a relatively high share of the student population in highly competitive markets attend Catholic (33\%) and Reformation schools (30\%). Fewer attend Public (10\%) and Protestant schools (15\%). In contrast, in areas with relatively little competition between schools, Public (37\%), Catholic (28\%) and Protestant (21\%) schools accommodate the majority of the student population.

Table 7.4 displays the descriptive statistics on household preferences with respect to school choice. In the follow-up questionnaires, parents had to fill in one particular question that dealt with the main reason why they had chosen the secondary school of their child. In the control group as well as the treatment group, more than $30 \%$ of parents had chosen the secondary school according to the wishes of their child. Major differences between students' parents of low- versus high-competitive markets in education exist when it comes to the denomination of the school.

In addition to "wishes of the child", which accounts for the majority of parents, particularly so in relatively low-competitive areas, the main school choice determinants are spread out more equally across the different answer possibilities in this control group. The "results of the school" and "total number of educational choices" together apply to $23 \%$ of untreated students' parents. In contrast, for the treatment group, as much as $27 \%$ of parents have answered that "denomination of the school" was the main reason of school choice. This figure is only $8 \%$ for parents in the control group. 
Table 7.4: T-test mean differences in school choice determinants

\begin{tabular}{|c|c|c|c|c|c|c|c|}
\hline Variable & Untreated(1) & Treated(2) & $\operatorname{Diff}(2)-(1)$ & T-value & Min & & Max \\
\hline Results of school & 0.1004 & 0.0816 & -0.0188 & -3.7585 & & 0 & \\
\hline Distance to school & 0.0612 & 0.0376 & -0.0236 & -6.27 & & 0 & \\
\hline Denomination of school & 0.1093 & 0.2731 & 0.1638 & 24.42 & & 0 & \\
\hline Educational choices & 0.1058 & 0.073 & -0.0328 & -6.63 & & 0 & \\
\hline Atmosphere at school & 0.0687 & 0.0563 & -0.0124 & -2.95 & & 0 & \\
\hline Guidance of students & 0.0848 & 0.0907 & 0.006 & 1.21 & & 0 & \\
\hline Type of first class & 0.049 & 0.0254 & -0.0237 & -7.22 & & 0 & \\
\hline Other sibling in school & 0.0185 & 0.0221 & 0.0035 & 1.44 & & 0 & \\
\hline Wishes of child & 0.3768 & 0.3244 & -0.0524 & -6.32 & & 0 & \\
\hline Other & 0.0256 & 0.016 & -0.0096 & -3.89 & & 0 & \\
\hline
\end{tabular}

Note 1: Educational provision denotes pre-university (vwo), general secondary (havo) or pre-vocational education (vmbo). Note 2: Denomination denotes the denomination of the school. Note that public schools and state schools are synonyms throughout this paper.

With respect to the matching on the basis of propensity scores, these scores denote the likelihood of assignment to $\mathrm{HCM}(\mathrm{T}=1)$, conditional on student-level and household-level characteristics. This excludes the school choice determinants as these could (partially) be influenced by competition intensity.

After matching, students are more likely to be assigned to the treatment group when they: (1) have the male gender; (2) have the country of origin Suriname/Aruba/Netherlands Antilles; (3) expressed to be part of the "Reformation" or "Other" religion and (4) have parents who either live together or are not married. On the contrary, students are less likely to attend school in HCM when they: (1) have parents who are from a different cultural background; and (2) expressed to be "Catholic".

Table 7.5 summarizes the balance improvements after the Kernel matching procedure has been applied. ${ }^{97}$ Figure 7.2 plots a fair overlap in the propensity score values between the control group and the treatment group for $(\mathrm{N}=13,130)$, losing 100 students that are off common support.

\footnotetext{
${ }^{97}$ Some significant t-values for the variables "children in the household", "Catholic" and the fifth category in "socioeconomic status" remain. The mean differences in this respect between treated and weighted untreated individuals are very small, but for reasons of robustness, the list of covariates will be included in all of the model specifications.
} 
Table 7.5: T-test mean differences in student characteristics after Kernel matching

\begin{tabular}{|c|c|c|c|c|}
\hline & Diff. & T-value & Min & Max \\
\hline Gender $($ male $=1)$ & 0.007 & 0.8 & 0 & 1 \\
\hline Age & -0.01 & -1.33 & 10 & 14 \\
\hline \multicolumn{5}{|l|}{ Country of origin } \\
\hline Netherlands & -0.0097 & -1.67 & 0 & 1 \\
\hline Morocco & -0.0001 & -0.05 & 0 & 1 \\
\hline Sur/Ant/Aruba & 0.0036 & 1.29 & 0 & 1 \\
\hline Turkey & 0.0004 & 0.18 & 0 & 1 \\
\hline Other & 0.0059 & 1.25 & 0 & 1 \\
\hline \multicolumn{5}{|l|}{ Marital Status } \\
\hline Married & -0.009 & -1.67 & 0 & 1 \\
\hline Living together & 0.004 & 1.34 & 0 & 1 \\
\hline Never married & 0.0016 & 0.87 & 0 & 1 \\
\hline Widow & 0.0015 & 0.89 & 0 & 1 \\
\hline Divorced & 0.0019 & 0.47 & 0 & 1 \\
\hline Children in household & 0.0503 & 2.46 & 1 & 5 \\
\hline Language parent1-child & 0.0025 & 1.11 & 0 & 1 \\
\hline Language parent2-child & 0.0019 & 0.85 & 0 & 1 \\
\hline \multicolumn{5}{|l|}{ Religion/Ideology } \\
\hline None & -0.0055 & -0.71 & 0 & 1 \\
\hline Catholic & 0.0024 & 0.34 & 0 & 1 \\
\hline Protestant & -0.0004 & -0.08 & 0 & 1 \\
\hline Reformation & -0.0008 & -0.1 & 0 & 1 \\
\hline Islam & 0.0018 & 0.58 & 0 & 1 \\
\hline Other & 0.0025 & 0.43 & 0 & 1 \\
\hline Culture parent1-child & 0.0007 & 0.3 & 0 & 1 \\
\hline Culture parent2-child & -0.0006 & -0.25 & 0 & 1 \\
\hline \multicolumn{5}{|l|}{ Socioeconomic status } \\
\hline Status 1 & 0 & -0.01 & 0 & 1 \\
\hline Status 2 & -0.0067 & -1.14 & 0 & 1 \\
\hline Status 3 & -0.0144 & -1.67 & 0 & 1 \\
\hline Status 4 & -0.0025 & -0.34 & 0 & 1 \\
\hline Status 5 & 0.0211 & 3.88 & 0 & 1 \\
\hline Status 6 & 0.0025 & 1.13 & 0 & 1 \\
\hline
\end{tabular}


Figure 7.2: Distribution propensity scores HCM and NCM in matched sample

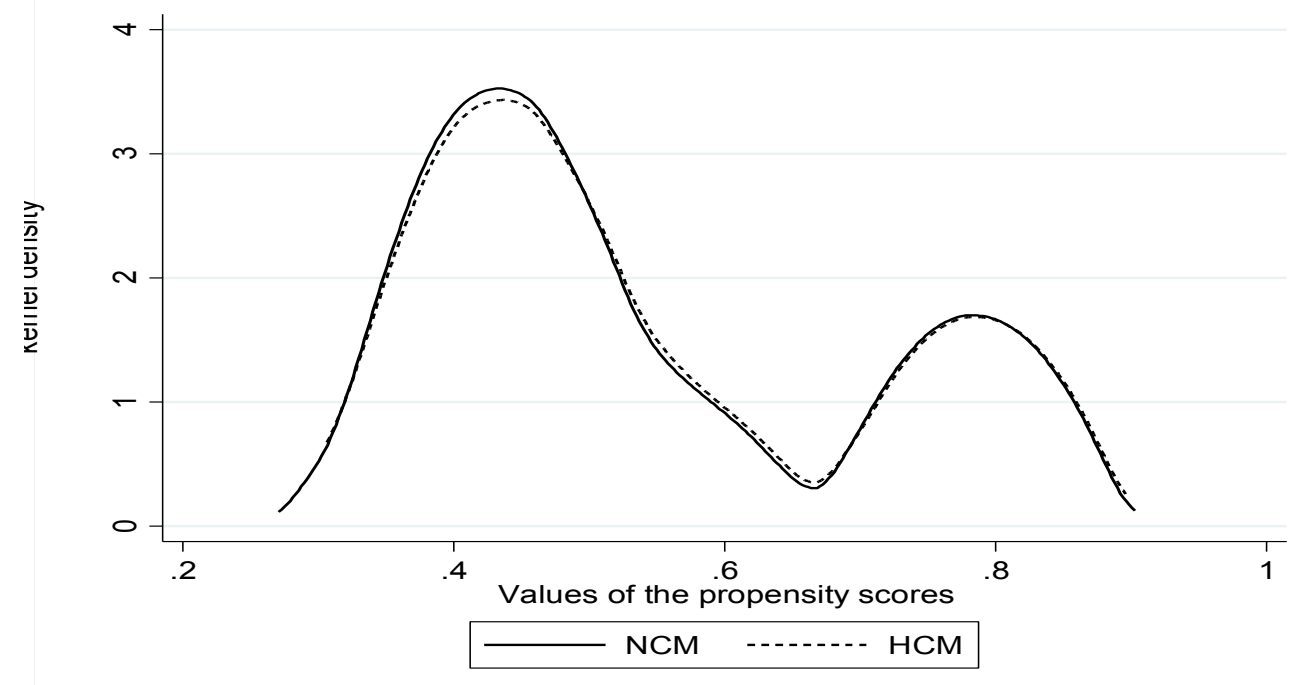

All four model specifications proposed in the previous section are estimated in order to evaluate the effects of competition between schools i) on the sorting of students by performance levels, and ii) on achievement in the first three years of secondary education.

\subsubsection{Competition and sorting by ability}

Table 7.6 displays the standardized effect sizes for sorting by math performance and shows no significant overall differences in math performance between HCM and NCM. This is true for Models 1-3. However, taking into account supply-driven differences in schooling, negative, and significant effects of competition on the sorting of students by math performance is observed for highly competitive markets (HCM). To analyze this effect across different school types, referring to the level and composition of classrooms (i.e. categorical or comprehensive), the "vwo-havo-vmbo" classroom setting is chosen as the reference category.

Overall, Table 7.6 shows that the strongest effects of competition on the sorting of students are found among the highest levels of performance. For the school type "havo", relative to the reference category, the standardized effect size is -0.27 . Such findings are in line with the hypothesis that, as competition increases, schools are competing for relatively "favorable students".

Given a similar pool of students, in terms of performance, to draw from, but with more schools offering relatively high-ability classroom settings, schools in high competitive markets seem to be forced, on average, to settle for accommodating relatively lower 
performing students (as to still ensure sufficient enrollments). Similar results are found for language performance (Table 7.7).

Table 7.6: Competition and sorting across schools by math grade 7 performance

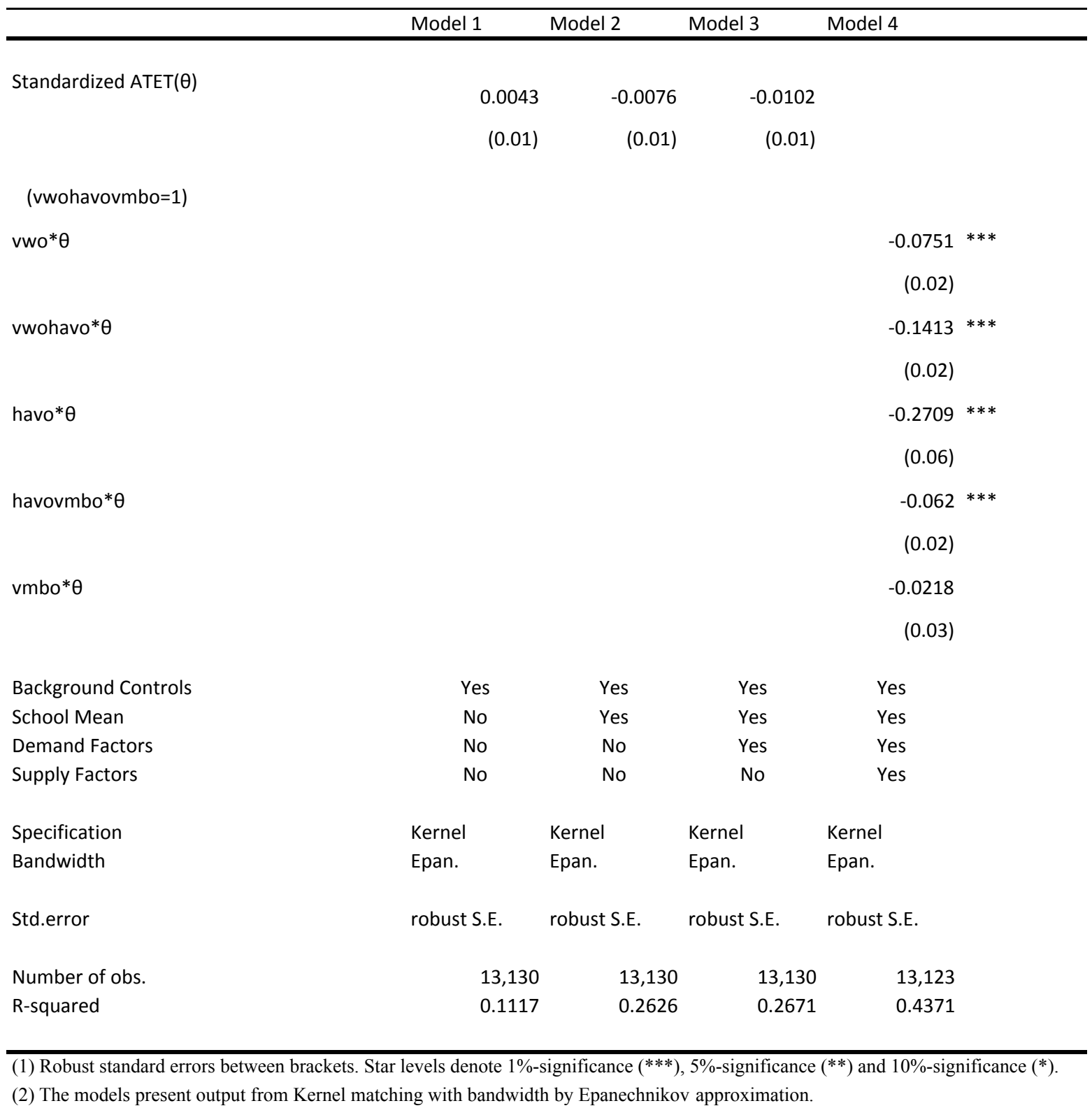

Of course, choosing the median level of competition as a cut-point for deciding whether a market competitive or not is highly arbitrary. To check whether the estimate are sensitive to this cut-point, the distribution of the estimated effect for Model 1 is explored by choosing values ranging from the initial 50th percentile down to the 25 th percentile. The mean value of the sorting effect across this range of threshold levels is very robust, and equal to 0.0106 with a standard deviation of 0.0070 . 
Table 7.7: Competition and sorting across schools by language grade 7 performance

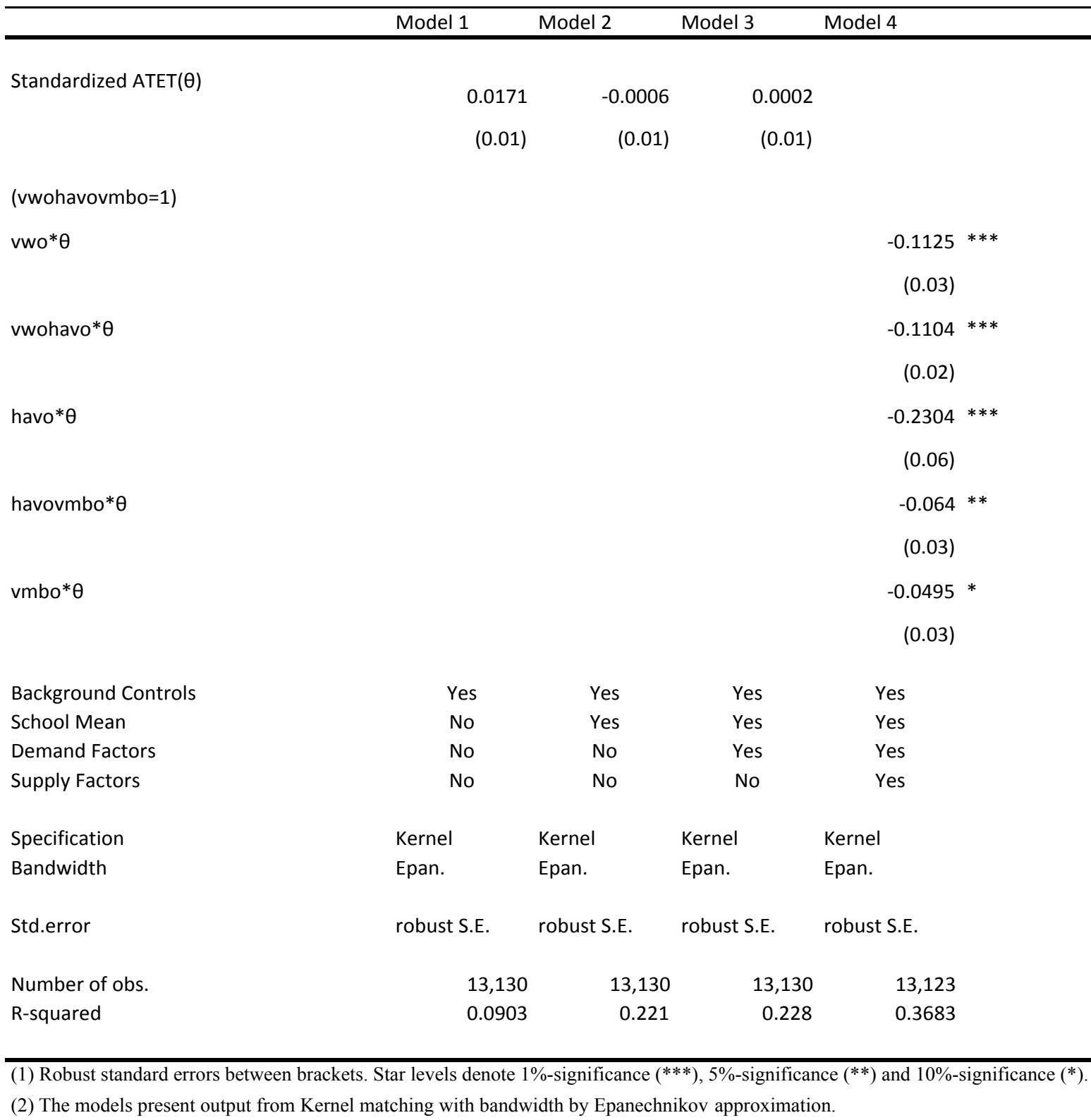

To summarize, from Model 1 it appears that the sorting of students by performance across markets is similar on average. However, in line with Epple and Romano (2003), the outcome is stratified by (innate) ability across school types. Also, conditional on demandand supply factors (i.e. Model 4), it appears that increasing competition causes schools to compete for their target student population in terms of performance levels on math and language, through offering relatively more classroom settings of higher academic tracks. As such, the results indicate that higher ability school types are forced to settle for relatively lower performing students (i.e. compared to a similar classroom setting in a low competitive market), as to attract sufficient numbers of students. Thus, when facing increased 
competition, the average performance of theses schools converges to that of the other (lower ability) schools in the local education market.

In other words, conditional on individual background characteristics, school choice determinants, and school-supply characteristics, schools seem to use supply-driven product differentiation (i.e. academic tracks) in order to compete for their desired target population of students.

\subsubsection{Competition and student performance}

The estimation results of Model 1 (i.e. only controlling for background characteristics), and Model 1 including the CITO test scores at the start of secondary education, is summarized on Figure 7.3 (math performance) and Figure 7.4 (language performance). Both consider a linear trend from grade 7 to grade 9. First, competition positively influences student performance on math over the academic years. By grade 9, the standardized estimate of competition is close to $0.05 \sigma$ (Figure 7.3). After controlling for the CITO test scores on math at the start of secondary education, this effect declines to around $0.02 \sigma$.

Results are similar for language performance (Figure 7.4). The reduction in effect sizes after inclusion of the CITO test scores is in line with an interpretation in which competition intensity also contributes to achievement in primary education; thereby assuming the level competition intensity is correlated across both education sectors. In addition, adding prior achievement would also capture differences in innate capacity for students across schools in HCM and NCM. Overall, the positive effects of competition intensity on performance in secondary education corroborate the findings presented for primary education in the previous chapter.

Figure 7.3: Competition and performance gains in math performance

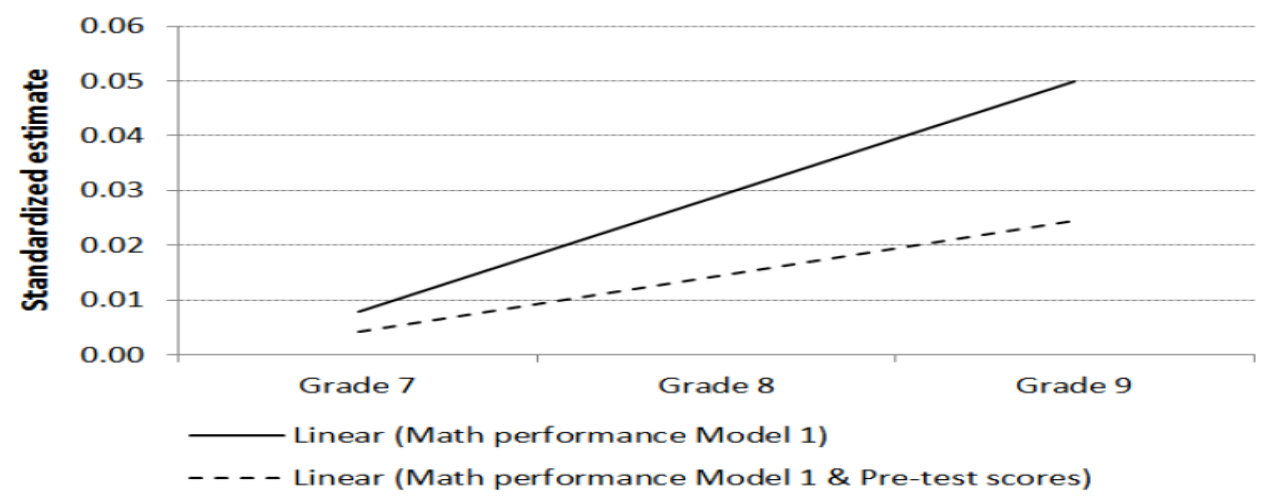


Figure 7.4: Competition and performance gains in language performance

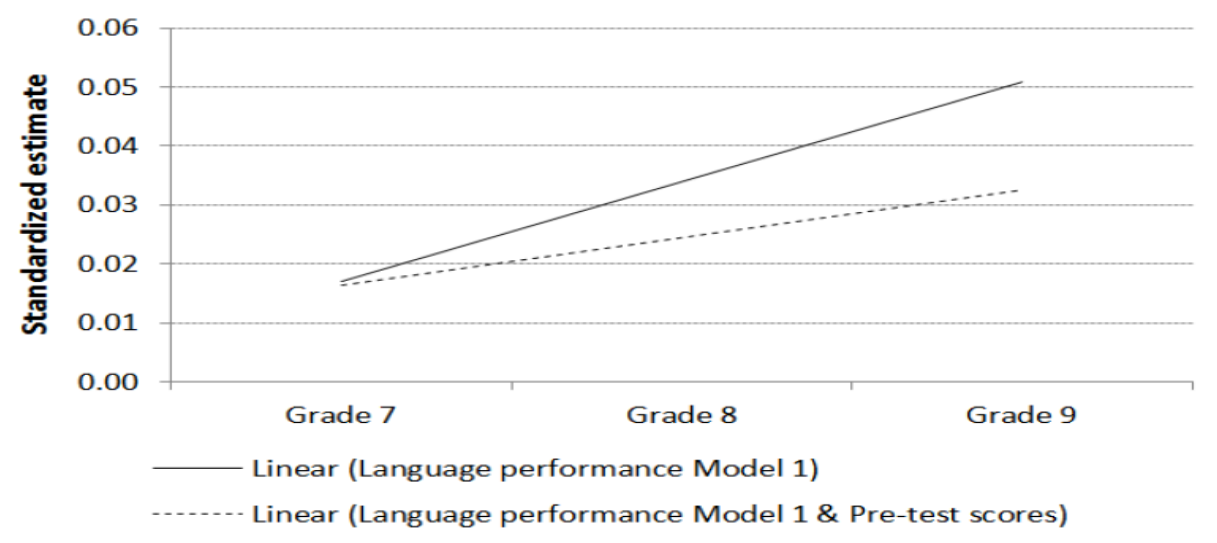

These findings are in contrast with Dijkgraaf et al. (2008), who find a negative effect for competition across several school quality measures. The authors interpret these seemingly counterintuitive findings as that Dutch schools seem compete through product differentiation on the basis of "secondary" elements, such as sports and music facilities, leaving less time and money for the primary process of teaching. Excluding the 21 largest cities, their results based on a subset of relatively more monopolistic schools in rural areas yield even stronger negative results for competition, suggesting either a potential non-linear effect and/or important rural/urban differences.

However, the findings here are in line Noailly et al. (2009), who analyze Dutch primary schools. Controlling for school- and neighborhood characteristics, the authors find small positive effects for competition on achievement. ${ }^{98}$ Noailly et al. (2009) interpret these modest effects in line with the concept of product differentiation, and argue that schools also compete on other (non-academic) activities and/or facilities. The results are also in line with the modest gains found for competition intensity in primary education, as described in Chapter 6.

\footnotetext{
${ }^{98}$ To account for the potential endogeneity of their competition measures, these are instrumented by the distance between the 4-digit zip code center and the town center, as schools close to the town center are likely to face more competition. This IV approach yields somewhat larger, though still modest, positive effects of competition on achievement (i.e. 0.05-0.10 s.d.).
} 


\subsection{Concluding remarks}

This chapter focused on the effects of competition between schools on student sorting, but also allowed to check the claim made in the previous chapter with respect to performance gains in competitive markets in Dutch education. The analyses are performed acknowledging that student performance level upon entry into secondary education is the composite result of innate ability, exogenous (socioeconomic) student characteristics and the value-added in primary education. Based on the analyses, schools operating in a competitive market do compete for "favorable students" through supply-driven product differentiation. The concept of a favorable student is determined by their level of academic performance at the end of primary education.

The clustering of favorable students in school is a relevant outcome in education to consider. These results indicate an important role for supply-driven sorting in that different school types are attracting students based on predefined ranges of performance levels. A school competing for the most favorable students operates largely within a specific range of performance levels. Thus, with higher competition intensity, selectivity increasingly plays a role to match the right student to the right school (i.e., schools compete for "their favorable students" by taking a unique position in their local education market). Consequently, schools in competitive areas more explicitly accommodate a student based on his/her performance level, having their decision supported by alternative schools in the neighborhood, relative to schools in low- or non-competitive areas. These findings are especially observed among the higher ability schools, as the results indicate that academically oriented schools (i.e. vwo, havo) are more prominent in competitive markets and need to select students at the margin as to ensure sufficient enrollment rates. Consequently, higher ability schools converge to lower ability schools when facing increased competition. To conclude, the results reiterate that competition in Dutch education is related to small improvements in academic achievement, based on performance differences in the first three years of secondary education. 
School Choice, Competition and Achievement 


\section{Social Justice in Dutch Compulsory}

\section{Education $^{*}$}

\subsection{Introduction}

The previous chapters have analyzed several aspects of the Dutch compulsory education system, thereby focusing on choice, privatization and competition. The emphasis throughout these analyses has been on one objective in particular: productive efficiency. However, multiple outcomes of education, both private and public, have been identified (see Chapters 2 and 3.) This chapter sets out to summarize the main implications of the design of Dutch compulsory education (i.e. privatization, choice and competition), using the framework of educational outcomes developed by Levin (i.e. freedom of choice, productive efficiency, equity and social cohesion). The existing body of literature on the Netherlands is summarized in Chapter 3. The emphasis in this chapter will be on interpreting the main results discussed throughout this dissertation in terms of an important goal of education: social justice.

The conclusion from this is that the Dutch compulsory education system, thanks to a series of policies and regulations in place, performs relatively well on social justice, when looking at freedom of choice and overall productive efficiency. However, for equity and social cohesion, despite clear policy efforts, the privatized system seems to undermine social justice for certain groups in the population. The dilemma observed here is that some private benefits of education must be compromised as to achieve greater equity and social

\footnotetext{
${ }^{*}$ This chapter is based on: Levin, H. M., I. Cornelisz and B. Hanisch-Cerda (2013). "Does educational privatisation promote social justice?" Oxford Review of Education 39(4): 514-532.
} 
cohesion, thereby improving social justice. It is an open question whether society and policy makers are willing to make such trade-offs.

The next section (8.2) introduces the concept of social justice in terms of the four educational outcomes of interest. This framework is then applied for analyzing social justice in Dutch compulsory education (8.3). The chapter ends with some concluding remarks (8.4).

\subsection{Social justice and educational outcomes}

The term "social justice" is used frequently in education because of the expectation that the educational system provide fairness in its access to opportunities and results. In most countries, the schools serving populations with high levels of poverty, working class families, immigrants, and minorities show considerably poorer educational results relative to schools enrolling students from more advantaged families. Advocates of educational privatization believe that a shift in policy from government schools towards a competitive marketplace of private providers will be a strike for social justice. This claim proceeds from the fact that school attendance zones are often defined by neighborhoods circumscribed by social class and race. A private market of schools supported by government funding would enable families to escape these constraints.

At the same time, it is maintained that the pressures of market competition for students by private schools would increase efficiency and allow families to choose schools that would better serve different educational needs. Under a system of educational privatization, students from disadvantaged families would allegedly have better options than the assigned schools in their neighborhoods and would be expected to take advantage of those options. Further, all schools would be expected to improve because they would need to compete for student enrollments. These are the most fundamental assertions put forth by Milton Friedman (1962) in his classic article calling for educational vouchers.

The evaluation of social justice in education, as in other spheres, depends heavily on how it is defined and on subjective judgments (Rawls, 2001). Education has both private and public consequences and conceptions of social justice have features of both. Education as a private good refers to its ability to confer benefits to individuals and their families according to their preferences and efforts. Education as a public good refers to its contribution to the functioning and maintenance of a fair, productive, and democratic society. Social justice in 
the private consequences of education is reflected in the responsiveness of the educational system to family educational goals. Social justice in public consequences for society is reflected in the overall effectiveness on promoting democratic values and civic function as well as overall fairness in the distribution of opportunities and outcomes.

\subsection{Social justice in Dutch compulsory education}

The above tensions between the public and private become particularly obvious when one addresses four prominent goals for evaluating educational outcomes in Western democracies: freedom of choice, productive efficiency, equity, and social cohesion (Levin, 2002). Below is a description of how each of these goals has implications for social justice.

\subsubsection{Freedom of choice}

A variety of school types on offer in the Netherlands enable households to choose schools based on their preferences towards schooling. In primary education, parents can freely choose among any government-funded school. Households have access to several schools close-by. About $89 \%$ of the students live less than one kilometer, from the nearest primary school (Bunschoten, 2008). The results in Chapter 4 corroborate this by showing that in primary education, on average, households are surrounded by 4 schools within $1 \mathrm{~km}$ to choose from; a figure that goes up to as many as 20 schools for some households. Even for students travelling less than $1 \mathrm{~km}, 60 \%$ of those attend a school that is not the closest school. Thus, in general, households appear to make a deliberate choice, even when they choose a school that is in close proximity. National regulations do not allow schools to select by ability, although private schools can reject students by criteria strictly related to religious denomination or ideological character of the school (Eurydice, 2009). ${ }^{99}$

In secondary education, ability tracking is used and $83 \%$ of all schools do not offer all program tracks (Herweijer, 2008). Eligibility to enroll into a track is determined by the primary school's advice, but beyond this criterion, secondary schools are not supposed to cream-skim the highest ability students. But, secondary schools are increasingly offering special programs (e.g. dual-language) within the existing system (Weenink, 2009). For these add-ons, additional fees are charged and selective admission processes, such as interviews

\footnotetext{
${ }^{99}$ As highlighted in previous chapters, applicants do not seem to be rejected on a regular basis (Karsten et al., 2003).
} 
or school-level tests, can be used. Popular schools facing capacity constraints are required to apply ability-neutral preference rules and employ lotteries for admissions.

A system of vouchers, where private and public schools are financed on an equal basis, promotes the fulfillment of privately held demands towards education. In the Netherlands, school options are regulated in behalf of promoting universal household choice. Whereas applicants do not seem to be rejected on a regular basis, more implicit barriers to entry and product differentiation could still constrain choice. Empirical support for this is found in a study conducted by Karsten et al. (2003) on ethnic segregation in primary schools, in which school principals reported that while the variation in ethnic composition across schools could perhaps be largely attributed to residential sorting and choice, schools do also i) market certain profiles, ii) practice a variety of gatekeeping methods, and iii) compete for students.

Over time, the government has bequeathed more freedom in terms of school control of the educational process and school management. Universal freedom to choose schools reflects concerns for social justice in the Netherlands' educational system, although some restrictions arise from ability tracking in secondary education, disparate knowledge on schools, and ongoing school consolidation. Taken at face value, financial and transportation constraints do not seem to challenge the social objectives of enabling educational choice for everyone.

\subsubsection{Productive efficiency}

Productive efficiency in education serves social justice criteria when there are shared benefits of effective education, efficient use of public resources, and appropriate resources targeting individuals that require extra support. In general, the use of resources to maximize educational outcomes in the Netherlands' educational system is commendable. Dutch students perform well above the OECD country average, while expenditures in education are around average (see e.g.: Sutherland, Price and Gonand, 2009).

The seemingly adequate level of performance achieved by most students can be partially understood as a response of schools to meet national regulations and through special opportunities and resources for students from disadvantaged backgrounds. National academic standards, examinations and regulations urge public and private schools to meet academic thresholds. For students from disadvantaged backgrounds, and students with 
special needs, higher vouchers are in place, destined for extra or targeted educational opportunities. The results in Chapter 4 suggest that providing households universal choice contributes to academic performance at the end of primary education. Social justice seems to be served in the provision of good overall academic results across almost all schools, fostered by the aforementioned characteristics of the system.

But, Dutch education, with public funding and strong adequacy targets, has not been successful in promoting academic excellence beyond achievement requirements. School efforts beyond the academic threshold seem to be oriented towards product differentiation instead (see Noailly et al., 2009 and Dijkgraaf et al., 2008). Results in line with such an interpretation have also been demonstrated in previous chapters, where competition intensity improved achievement particularly in the lower half of the achievement distribution (Chapter 6), and where schools seem to target favorable students (Chapter 7).

In summary, the productive efficiency of the system seems to serve social justice. In comparison with other countries the average outcomes for Dutch students are excellent relative to the adequate level of spending. The system has room to increase efficiency when considering the potential for producing more high performing students and reducing its high repetition rates (see Chapter 3 ).

\subsubsection{Equity}

With the educational goal of equity, social justice is promoted through greater fairness in the distribution of inputs of schooling and the distribution of educational outcomes across students and schools.

When comparing performance across school types, Dronkers (2004) mentions that that the relative outperformance by Catholic and Protestant schools in terms of academic outcomes seems to be more pronounced in primary education and appear to be confined to a period between the late 1960's and early 1990's. The results presented in Chapter 5, based on PISA 2006, 2009 and Dutch administrative data for 2008-2009, also fail to construct a consistent story in which one school type outperforms the others. Similarly, it cannot be argued that certain school types seem to consistently underperform. Instead, across school types, similar performance levels are observed when student-body intake is taken into account. 
Regarding the distribution of inputs, the three adjustments to student funding and the absence of tuition fees contribute to the public objectives of horizontal and vertical equity. Dijkstra et al. (2004) point out that equal funding of private and public schools, with strict regulations regarding financial and ability selection of students for private schools, has promoted the diminution of prestigious elite schools outside the state-subsidized sector. Equal funding and the absence of tuition thus prevented any extreme form of cream skimming the most able students by either public or private schools. Moreover, the importance of extra funding to meet educational challenges is reflected by the fact that, in 2010 , the portion of students in mainstream education covered by the weighted funding system was around $13 \%$ (OCW, 2011a).

This notion of vertical equity in inputs seems to be matched by student outcomes, in terms of the high number of students meeting a meaningfully adequate level of performance. But, the high levels of grade repetition could endanger socioeconomic inequity, as socioeconomic differences in performance tend to widen with retention rates (OECD, 2011). Results show that the socioeconomic achievement gap in the Netherlands is comparable to those of other industrialized countries. A notable difference is that the deleterious effect of socioeconomic status on achievement is initially low for lower levels of SES, but as socioeconomic background improves, there is an increase in the extent to which background inequalities translate into performance differences (OECD, 2010).

There are other dimensions that are a matter of concern for whether the Dutch education context promotes social justice because of the early onset of tracking as the students enter secondary school at age 12 . This system is likely to contribute to the relatively poor performance of students from non-Western migrant backgrounds in secondary education (see Chapter 3). In addition, since 2006 (primary education) and 2007 (secondary education), the additional educational funding is based only on the socioeconomic characteristics of the students, and not any longer on their ethnic background, so direct scrutiny by ethnic group for recent years is not forthcoming.

In summary, using equity as a criterion of social justice, there is still considerable progress to be made. There seems to be a high degree of equity in distribution of inputs and outcomes in the sense that most students reach and share an adequate level of academic achievement. However, there are inequities among students of different migration origins, which in secondary education seem to be exacerbated by the tracking system. The 
Netherlands sponsors a school system that is among the more ethnically and socioeconomically stratified systems in Europe, particularly at the tracked secondary level (Jenkins et al., 2006; Herweijer, 2009). Such segregation has generally been attributed to a combination of residential sorting and universal school choice by parents (Bakker, 2012). Certainly, a portion of these inequities is due directly to a system in which parents choose schools that mirror their own religion, ethnicity and socio-economic identities. Several additional policies and programs have been implemented to address this issue, but the evidence available provides mixed conclusions on whether such interventions have been successful (see Chapter 3).

\subsubsection{Social cohesion}

The educational goal of social cohesion reflects social justice when the provision of a common educational experience prepares students equally to be active citizens in a democratic society. In this scenario, there are three key aspects to consider: the curriculum (what is taught), educational processes (how it is taught), and student sorting (who are fellow students).

For Dutch compulsory education, there is a strong monitoring policy that oversees whether schools actually comply with the regulations. A rich set of curriculum goals for each subject is set by the Ministry and tested in standardized national end-of-secondary exams. As noted, the empirical results presented throughout this dissertation suggest that measurable academic outcomes are largely similar when student-body intake is taken into account, as the same targets apply across all schools and school types (see Chapter 5).

However, the educational process and experience could differ significantly across schools. Partially facilitated by the processes of deregulation, decentralization and lump sum financing, schools tailor the educational process to meet demands. This is a direct result of the emphasis on choice, competition and the resulting product differentiation by schools as to appeal to particular niches of household preferences. To the extent there is a discrepancy between public and private objectives, the Dutch system, itself, promotes the latter over the former, private goals over public ones.

Not only are there incentives to promote the schooling experience as different across schools, but also much of this differentiation in the Netherlands seems to be based upon ethnic and socioeconomic status. A segregated school system by ethnic and 
socioeconomic niches means that the educational process does not allow for many interactions between students from different socioeconomic, ethnic, and/or religious backgrounds. In addition, it can be hypothesized that schools face incentives to avoid serving relatively difficult disadvantaged neighborhoods and/or students. One objective of weighted student funding is to counter such behavior by schools. Despite this system, the empirical results in Chapter 7 do suggest that schools, when facing competition, have a tendency to target relatively favorable students (i.e. as determined by their level of performance at the end of primary education).

From the demand-side of education, behavior in line with the outgroup avoidance theory is observed among majority households (Karsten et al., 2003). Herweijer (2008) points out that, particularly in the four largest cities, Dutch students in secondary education choose to attend schools outside the municipality border which accommodate far fewer students from non-Western backgrounds. Herweijer (2008) furthermore asserts that the system of universal parental choice and early tracking promotes school stratification by socioeconomic status. This is particularly true for urban areas, where schools more often offer only a subset of tracks (i.e. vocational or academic). Administrative data indicate that private (religious) schools are relatively underrepresented in both the highest and lowest urban density areas, which are generally areas where relatively low-income households live (Steenbekkers, Simon and Veldheer, 2006).

As to survive in a secularized society, most private religious schools from traditional denominations now only offer selective religious courses, which are often courses in world religions or religious orientation (OCW, 2011a). In contrast, the establishment of new private religious schools, like the Islamic schools, is regarded as a threat to the social integration of these students into Dutch society (Dijkstra et al., 2004). These households, together with orthodox Protestant families, also show the strongest tendency to selfsegregate (Denessen et al., 2005).

With heterogeneous demands and characteristics of households, the Dutch education context has always been segregated, particularly along religious lines. In recent decades, this segregation has focused on socioeconomic and ethnic differences. The arrival of non-Western immigrants has made these social inequities noticeable (Merry and Karsten, 2011). The magnitudes of these segregation patterns are high, even in relation to those observed in the US. This raises the question to what extent social justice in the Dutch 
education context is challenged. Aiming to reduce segregation in primary schools, particularly ethnic segregation, the Ministry allocated financial resources for pilots, to be conducted by 12 segregated municipalities, in the years 2008-2011. Across these municipalities, virtually all school boards share the public objective of having integrated schools. However, student-body compositions have not followed, as private schools find it difficult to compromise parental freedom to choose, often find the increased role of the municipality to be intrusive, and are afraid to lose their (beneficial) position in the education market (Brink and van Bergen, 2012).

\subsection{Concluding remarks}

There is a fundamental tension between offering households universal choice among schools and the societal goals of equity and social cohesion. One purpose of privatization, choice and competition is to match schools with the preferences of families based upon their values, beliefs, personal goals, and perceived educational needs. With heterogeneous demands towards education, the resulting product differentiation by schools can overlap substantially with the socioeconomic status, religious commitments, political philosophies, and ethnicity of the student populations they serve. But social justice in the forms of equity and a cohesive society with common economic, social, and political institutions may be compromised by the divisiveness of choices and the advantages of some groups in identifying and obtaining enrollments at those schools that are perceived as most effective. Of course, the solution is to try to obtain balance between the private goals of families in choosing schools and the safeguarding of equity and social cohesion through the policy tools of finance, regulation, and support services.

At present, the highly privatized Dutch system is reasonably successful in safeguarding freedom of choice and largely successful in the provision of productive efficiency. In particular, this system, in which additional funds are made available for students from disadvantageous socioeconomic backgrounds and for those with special educational needs, fosters adequate performance by these students and contributes to vertical equity. However, there are still challenges to social justice in the domains of equity and social cohesion, resulting primarily from high patterns of socioeconomic and ethnic stratification across schools and school types. These patterns are not exclusively found in the Dutch educational system; voucher systems in Chile (see e.g.: Elacqua, 2012) and 
Sweden (see e.g.: Skolvervet, 2012) seem to be facing similar challenges. The educational dilemma in these contexts is how much of the private benefits of education must be compromised to achieve greater equity and social cohesion, and whether the countries are willing to make such trade-offs.

Whereas this dissertation has focused on the effects of privatization, choice and competition on academic outcomes in particular, it should also be of interest to policymakers to better understand the causal linkages between these mechanisms and patterns of socioeconomic and ethnic segregation. 


\section{Conclusions and Discussion}

\subsection{Introduction}

This dissertation set out to explore several features of educational choice in Dutch compulsory education sector, using Levin's (2002) framework for evaluating educational outcomes (i.e. freedom of choice, productive efficiency, equity and social cohesion). The theoretical literature on school choice (expansion) ranges from either very positive to fairly negative, depending also on what outcomes are considered. Instead, the existing body of empirical results is generally less pronounced with, overall, relatively small (but positive) results for freedom of choice and productive efficiency, but with a more worrisome picture emerging for the domains of equity and social cohesion. Levin's framework emphasizes the importance of design features in this respect and highlights that such tradeoffs among outcomes are apparent when examining the effects of school choice. This is important to acknowledge when informing educational policy.

The empirical analyses throughout this dissertation focused, in particular, on student achievement and explored the relative effectiveness of different school types, choice and competition in this respect. The variety of results presented in this dissertation are based on multiple data sources and using different methods. In this chapter the objective is to reduce the findings to a concise list of key conclusions, thereby constructing potential implications for policy making (9.2). The chapter concludes by pointing out the main limitations of the data and methodologies used, and by making suggestions for further research (9.3). 


\subsection{Key Conclusions and Policy Implications}

The results presented throughout the different chapters are reduced to a list of four key conclusions. For each one, an interpretation is provided and potential policy implications are explored.

1. Dutch compulsory education displays comparable levels of academic achievement across public- and private government-dependent school types.

Overall, the results in Chapter 5 do not point to a consistent relative school type effect across two waves of recent PISA data. Analyses based on a recently developed administrative data set (i.e. BRON) yield similar, and largely indistinguishable, results between public and private school types. This is in line with Dronkers (2004) who notes that the relatively better performance for private (Catholic) schools appears to be confined to a period between the late 1960's and early 1990's. This contrasts with much of the earlier body of empirical literature, pointing predominantly to the relatively better academic performance of private (Catholic) schools in the Netherlands. Recently, results on three years of test scores (i.e. 2010-2012) for nearly all schools in primary education have been made public. Distinguishing between different denominations, these results point to some differences in "value-added". Within private school types, certain denominations and educational approaches (e.g. general non-religious "algemeen bijzonder", Montessori, and Islamic schools) perform relatively well, whereas other types (e.g Dutch-Reformed "gereformeerd vrijgemaakt", "Dalton" and Anthroposophy "antroposofisch" schools) seem to relatively underperform in this respect. ${ }^{100}$

There are several potential explanations for which, nowadays, we would expect an overall absence of differences in relative effectiveness across public and private school types in the Netherlands. Many of the potential mechanisms for increased student achievement (i.e. funding, teacher input, instruction hours and curriculum) are not allowed to significantly differ across these two school types. Also, there has been a converging trend in the Dutch education sector over the last few decades with the ongoing increasing autonomy of public schools, a decrease in the religious orientation of private schools, and an increase

${ }^{100}$ For these results, and the media attention based on them, see: http://www.rtlnieuws.nl/nieuws/special/cito 
in cross-school type mergers. As such, it has become more and more difficult to actually distinguish between private- and public schools in the Netherlands (cf. Karsten et al., 1996; Zoontjens, 2003). Strict private school effects could well have disappeared with the decentralization of public schools and with school consolidation processes disproportionately affecting private religious schools (cf. Dronkers, 2004).

Not finding a consistent pattern in relative effectiveness of public and private school types in Dutch compulsory education also has implications for the current debate on publicprivate partnerships (PPPs) in education. One of the arguments made is that private management of public schools tends to be efficient and yields higher test scores than public institutions at the end of basic education (cf. Patrinos et al., 2009). The Dutch education sector is used as an example to make this claim. But, this conclusion does not seem not be supported by Dutch PISA 2006 and 2009 data, nor by a Dutch administrative data set with students in the final grade of primary education in 2008-2009.

2. In the Dutch context, choice and competition promote academic adequacy, with no clear results for students or schools being induced to strive for academic excellence.

Adequacy has always been prevalent in the Dutch attitude towards education and results confirm reasonable success in terms of reaching this goal. Chapter 3 describes several design features of the Dutch education system that promote adequacy, such as curriculum requirements, clear attainment targets, national examinations, and strong monitoring by the Education Inspectorate with consequences for schools if goals are not accomplished. International assessments of student performance confirm that Dutch education performs well on average. The seemingly adequate level of performance achieved by most students can thus be understood as the joint result of households valuing adequate academic performance when exercising choice, schools' responses in addressing such demands, a rich set of national regulations, and additional opportunities and resources made available for students from disadvantaged backgrounds or with special needs.

Chapter 4 set out to estimate the influence of choice on average performance at the end of primary education in the Netherlands. The analyses reveal a positive association between choice and achievement in which a $100 \%$ increase in the number of surrounding schools is associated with around a 0.05-0.09o increase in achievement. This is in line with 
existing (survey) results, pointing out that academic quality is generally a consistent choice determinant (cf. Dronkers, 1995; Karsten et al. 2002; Herweijer and Vogels, 2004; Denessen et al., 2005; Borghans et al., 2013). The empirical effect of choice on achievement is interpreted as the joint result of a variety of mechanisms associated with school choice (e.g. competition, matching, sorting and parental involvement).

Chapter 6 set out to analyze the relationships between school-level competition and students' academic achievement in the Dutch primary sector, thereby distinguishing competition- from choice effects. The results suggest there is a positive association between school-level competition and academic achievement in primary education, with an average effect size of around $0.06 \sigma$. This relationship cannot seem to be explained by choice and is stronger for the lower half of the achievement distribution, as well as more urban settings $(0.1 \sigma)$. Results in Chapter 7 further indicate that competition in Dutch secondary education is related to small improvements in academic achievement, thereby corroborating the findings in Chapter 6. Importantly, beyond the median level of performance, competition intensity is no longer statistically significantly related to academic performance. This could be partially due to a system with strict regulations and monitoring designed to meet academic thresholds, but with a lack of strong incentives for students, and schools, to perform well beyond them.

In recent years, there has been a notable shift in Dutch policy, in which the importance of "excellence in education" is increasingly being emphasized, implying that schools should provide high value-added to students at all levels of performance. ${ }^{101}$ For example, whereas the highest possible qualification of primary schools used to be "satisfactory", The Education Inspectorate is currently adapting the assessment framework for enabling schools to be rewarded the qualification "excellent". ${ }^{102}$ This change in scope seems partially attributable to trends in international student assessments. ${ }^{103}$ These

\footnotetext{
${ }^{101} \mathrm{~A}$ recent example of this emphasis is the fact that "excellence in education" is recognized as a key theme in the coalition agreement signed on October 29, 2012, which includes 24 policy measures designed to make a transition in Dutch education from performing "good" to "excellent" (source: http://www.rijksoverheid.nl/regering/regeerakkoord/van-goed-naar-excellent-onderwijs).

${ }^{102}$ From the group of primary schools that volunteered to participate in a pilot, designed to try out this new assessment framework, 31 schools were rewarded with the qualification "excellent" in February 2013 (source: http://www.onderwijsinspectie.nl/actueel/nieuwsberichten/jury-kiest-eerste-excellente-scholen-vannederland.html)

${ }^{103}$ Pointing out this increasing prominence of international indicators in Dutch educational policy, Borghans (2007) adds that they particularly receive attention when they augment existing national debates on the state of education.
} 
comparisons point out that the performance of Dutch students in primary education is dropping and that relatively few belong to the international top students. The results presented here suggest that competition in primary education, as it is currently designed, does not promote this desired "excellence" for high-achieving students (i.e. at least not as measured by their standardized "CITO" test scores). One interpretation could be that, beyond the median level of student performance, primary schools still compete, but on other features instead.

3. Heterogeneous demand in the Dutch choice context limits the potential for strictly realizing achievement gains and seems to induce product differentiation instead.

The results reported here are in line with existing school choice and competition literature in that the effect of choice on student achievement appears to be modest and heterogeneous $(0.05-0.1 \sigma)$. This could well be because the education market in the Netherlands is arguably an heterogeneous one (cf. Merry and Karsten, 2011), with households valuing not only cognitive student achievement, but other school aspects as well. Rather than offering a standardized educational product, schools can differentially focus on other (non-academic) features of schooling in improving consumer satisfaction (cf. Belfield and Levin, 2005; Levin, 2012).

The results in Chapter 6 suggest that competition only contributes to academic performance in the lower half of the skill distribution in primary education. One interpretation for this would be that, at higher levels of performance, schools will compete primarily on the basis of these heterogeneous demands of the households, thereby differentiating their non-academic features and/or the non-regulated processes of schooling. Chapter 7 focuses on the effects of competition between schools on such student sorting and on performance gains in competitive markets in secondary education. The analyses suggest that schools operating in a competitive market do compete for attracting "favorable" (i.e. high-performing) students. With increasing competition, relatively more schools in a local education market target this group of high-achieving students. The effects of competition on student sorting by performance levels are therefore primarily observed among higher ability schools, as the results indicate that these academic-oriented schools 
need to accept students at the margin as to ensure sufficient enrollment rates in competitive local education markets.

Several policy implications result from potential product differentiation and competition-induced sorting. For example, early-ability tracking in the first year(s) of secondary education is an important feature of the Dutch education system. By its very design, this leads to strong patterns of sorting by ability and performance across schools and a system of early tracking could arguably increase the socioeconomic achievement gap (cf. Woessmann, 2009). For the Netherlands, migrant students are underrepresented in the highest tracks of secondary education. This could imply that the system of early ability tracking is disproportionately challenging to non-Western immigrant students, thereby undermining equity (cf. Herweijer, 2009). Also, early tracking, and strict thresholds that are too strict, can have important consequences for schooling, higher educational attainment, and labor market outcomes (cf. van Elk et al. 2011; Borghans et al., 2012).

One potential policy response to the above observations could be to eliminate, or defer, ability tracking. However, a proper understanding of whether schools, facing competition, would still resort to product differentiation is necessary when making predictions about whether or not such policy measures will actually proof to be successful in reducing disproportionate levels of sorting by performance. Instead, even without ability tracking, sorting by performance could remain persistent due to product differentiation in a market where schools compete for a heterogeneous group of students.

4. School choice in the Netherlands induces tradeoffs among private and public goals of education, thereby highlighting the importance of the design of the educational system.

Levin's framework of educational outcomes, introduced in Chapter 2, shows there are both private (i.e. individual and household) and public (i.e. other members in society) benefits of education and, sometimes, these can be at odds with each other. By shifting power over schools to households, school choice plans are more likely to promote private outcomes, as measured through the dimensions of freedom of choice and productive efficiency. Therefore, if societal benefits of education are valued, as expressed not only by productive efficiency but also by equity and social cohesion, they will need to be safeguarded through the design of a school choice plan (i.e. finance, regulation and support services). 
At present, the highly privatized (i.e. universal choice and relatively autonomous schools), but strongly regulated, Dutch system is reasonably successful in safeguarding freedom of choice and largely successful in the provision of adequate productive efficiency. Equity and social cohesion are recognized through important features such as weighted student funding, a rich set of regulations and attainment targets, and a strong monitoring body. Yet, as discussed in Chapter 8, there are still challenges to social justice in these two domains, resulting primarily from high patterns of socioeconomic and ethnic stratification across schools and school types.

There is an inevitable tension between offering households universal choice and the societal goals of equity and social cohesion. The purpose of choice, and allowing privately operated schools to enter the market, is to match schools with the preferences of families based upon their values, beliefs, personal goals, and perceived educational needs. With heterogeneous demands towards education, the resulting product differentiation by schools will likely improve the matching of students to schools, but can overlap substantially with the socioeconomic status, religious commitments, political philosophies, and ethnicity of the student populations they serve. In terms of policy making, the solution is to try to strike a balance between these private goals of families in choosing schools and the safeguarding of equity and social cohesion through the policy tools of finance, regulation, and support services. If policy makers would like to explore whether changes to the current choice system are to be preferred, such important tradeoffs will need to be acknowledged.

\subsection{Limitations and suggestions for further research}

Recurring themes in the methodological challenges that empirical research on school choice effects faces are sorting processes and unobserved differences between (actively) choosingand non-choosing households. In addition, the nature of the results also tends to depend on the scale of a choice plan. Much of the existing research is on relatively recent and smallscale choice programs. Thus, particularly for understanding the effects on societal benefits of education (i.e. equity and social cohesion), more empirical research on long-term, largescale choice contexts seems desirable. It is in these dimensions the results presented here on Dutch compulsory education aspire to contribute. 
This dissertation used different data sources and methodologies to empirically explore relative school type effectiveness and the effects of school choice and competition on student performance in the Netherlands. Each of the data sets and empirical approaches used come with their own limitations and challenges. The threats to validity for each of the empirical strategies are outlined in each of the corresponding chapters. With respect to data it is important to acknowledge that the PISA data set is cross-sectional and provides no information about the length of the stay of the pupils at the current school or about the characteristics of former schools of the students. Therefore, the PISA school (type) effects estimates for the Netherlands are based on 2-3 years of attendance only, with the exposure of 8 years of primary schooling remaining unobserved in PISA data. This makes research on school type effectiveness based on this data difficult, particularly when acknowledging the data set is constructed to be representative at the national level only. Another limitation is that the PISA data set does not allow distinguishing between different types of private schools (e.g. Catholic, Protestant or non-religious). In addition, it is impossible to distinguish between immigrants from different countries of origin. Lastly, the data set has no (or only very weak) information to distinguish between school segregation and residential sorting.

To an extent, the BRON data set used overcomes these challenges. However, a likely caveat to the achievement analyses using these data is the large proportion of students for test scores are missing. Overall, though, the group of students with missing outcome data seems balanced in terms of background characteristics, choice intensity and school-level competition. The students in the BRON data set entered secondary education in the academic year 2009-2010 and each year their educational progress can be added to the data set. The fact that students can be tracked from the end of primary education onwards holds great potential for future use of this data set to conduct analyses on other important academic outcomes (e.g. graduation rates, non-cognitive skills, labor market outcomes).

The VOCL99 data set offers representative longitudinal data for secondary education and does not suffer from the problem of missing data on student outcomes. In addition, the data contains student-level school choice determinants. The absence of a robust pattern in relative effectiveness between public and private school types is consistent across different data sets. The small positive effects of school choice intensity are inferred from the BRON data set. The moderate positive gains of school-level competition on achievement are also largely based on this data set and could be corroborated using the VOCL99 data set. The 
empirical analyses on sorting by ability using these data are in line with the notion that schools, being exposed to school choice and competition, are likely to resort to product differentiation.

Product differentiation has been put forward as posing a risk towards reaching equity and social cohesion in education. Recent studies on the effects of school choice and the competition in the Netherlands suggest product differentiation is an important feature of Dutch education (cf. Noailly et al., 2009; Dijkgraaf et al., 2008; Weenink, 2009). However, more research and better data will be necessary to better understand whether, and more specifically how, schools actually employ such differentiation and whether it can be causally linked to the existence of school choice and competition. To answer such questions, it is necessary to have detailed information on how households choose a particular school and on how schools go about in attracting, targeting and educating their clientele. In particular, it seems important to improve our understanding of the causal effects on a wider range of educational, labor market, and life-long outcomes and to better understand the tradeoffs that policy-making faces in deciding whether to restrict or adjust school choice. 
School Choice, Competition and Achievement 


\section{References}

Agasisti, T. (2011). "Does Competition Affect Schools' Performance? Evidence from Italy through OECD PISA Data." European Journal of Education 46(4): 549-565.

Altonji, J. G., T. E. Elder, et al. (2005). "An evaluation of instrumental variable strategies for estimating the effects of Catholic schooling." Journal of Human Resources 40(4): 791.

Andersen, S. C. and S. Serritzlew (2007). "The unintended effects of private school competition." Journal of Public Administration Research and Theory 17(2): 335.

Archbald, D. A. (2004). "School choice, magnet schools, and the liberation model: An empirical study." Sociology of Education 77(4): 283.

Baarsma, B. and M. v. Leeuwen (2002). "Kennis over Kosten: De beheersing van schoolkosten in het voortgezet onderwijs en de BOL."

Bakker, J. (2012). "Cultureel-etnische segregatie in het onderwijs: achtergronden, oorzaken en waarom te bestrijden." Pedagogiek 32(2): 104-128.

Bayer, P., F. Ferreira, et al. (2007). A unified framework for measuring preferences for schools and neighborhoods, National Bureau of Economic Research Cambridge, Mass., USA.

Belfield, C. (2004). "Modeling school choice: A comparison of public, private-independent, private-religious and home-schooled students." education policy analysis archives 12: 30.

Belfield, C. and H. M. Levin (2005). "Vouchers and Public Policy: When Ideology Trumps Evidence." American Journal of Education 111(4): 20. 
Belfield, C. R. and H. M. Levin (2002). "The effects of competition on educational outcomes: A review of US evidence." Review of Educational Research 72(2): 279-341.

Belfield, C. R. and H. M. Levin (2005). Privatizing Educational Choice: Consequences for Parents, Schools, and Public Policy, ERIC.

Bifulco, R. and H. F. Ladd (2007). "School choice, racial segregation, and test-score gaps: Evidence from North Carolina's charter school program*." Journal of Policy Analysis and management 26(1): 31-56.

Bifulco, R., H. F. Ladd, et al. (2009). "Public school choice and integration evidence from Durham, North Carolina." Social Science Research 38(1): 71-85.

Black, S. E. (1999). "Do Better Schools Matter? Parental Valuation of Elementary Education*." Quarterly journal of economics 114(2): 577-599.

Boehlmark, A. and M. Lindahl (2007). "The impact of school choice on pupil achievement, segregation and costs: Swedish evidence." Bonn: Institute for the Study of Labor. Verf,gbar unter: http://ftp. iza. org/dp2786. pdf.

Boehlmark, A. and M. Lindahl (2008). Does School Privatization Improve Educational Achievement?: Evidence from Sweden's Voucher Reform, IZA.

Boehlmark, A. and M. Lindahl (2012). "Independent schools and long-run educational outcomes: Evidence from Sweden's large scale voucher reform."

Booker, K., R. Zimmer, et al. (2005). "The effects of charter schools on school peer composition."

Borghans, L. (2007). De betekenis van internationale indicatoren voor de verbetering van het onderwijs [The meaning of international indicators for improving the education system]. Maastricht, the Netherlands, University of Maastricht.

Borghans, L., R. Diris, et al. (2012). "The Labor Market Effects of Secondary School Track Assignment: A Regression Discontinuity Approach."

Borghans, L., B. Golsteyn, et al. (2013). "Parental Preferences for Primary School Characteristics."

Bound, J., D. A. Jaeger, et al. (1995). "Problems with instrumental variables estimation when the correlation between the instruments and the endogenous explanatory variable is weak." Journal of the American Statistical Association 90(430): 443-450.

Brink, M. and C. T. A. van Bergen (2012). "Tegengaan Segregatie in het Basisonderwijs: Monitoring van de OCW-pilots." Regioplan Beleidsonderzoek(1838). 
Broersen, S. and T. Klein (2004). "Schoolkostenonderzoek: Schoolkosten in het voortgezet onderwijs en MBO/BOL 2003-2004."

Bronneman-Helmers, H. (2007). "Vijftien jaar onderwijsvernieuwingen in Nederland."

Deelstudie bij het rapport van de commissie-Dijsselbloem. TK 2008: 31007.

Brunner, E. J., J. Imazeki, et al. (2010). "Universal Vouchers and Racial and Ethnic Segregation." The Review of Economics and Statistics 92(4): 912-927.

Bunschoten, B. (2008). "Hoe ver woon ik van." Bevolkingstrends, 2e kwartaal 2008: 19-22.

Burgess, S., B. McConnell, et al. (2007). "11 The Impact of School Choice on Sorting by Ability and Socioeconomic Factors in English Secondary Education." Schools and the equal opportunity problem: 273.

Canton, E., R. Venniker, et al. (2001). Higher education reform: getting the incentives right, Sdu Uitgevers.

Carnoy, M. and P. McEwan (2003). "Does privatization improve education? The case of Chileís national voucher plan." Choosing choice: School choice in international perspective: $24 \tilde{n} 44$.

CBS (2012). "StatLine: Centraal Bureau voor de Statistiek http://statline.cbs.nl."

Christensen, G. and M. Segeritz (2008). "Immigrant Student Achievement in 2006: An International Perspective." Sonderauswertung der PISA-Daten im Auftrag der Bertelsmann-Stiftung. G, tersloh: Bertelsmann.

Chubb, J. E. and T. M. Moe (1990). Politics, markets, and America's schools, Brookings Institution Press.

CITO (2010). "'Samenvatting Resultaten PISA-2009: Praktische kennis en vaardigheden van 15-jarigen"."

Cobb, C. D. and G. V. Glass (1999). "Ethnic Segregation in Arizona Charter Schools." education policy analysis archives $7: \mathrm{n} 1$.

Cohn, E. and T. Geske (1990). The economics of education, 3rd Edition, Pergamon Press.

Coleman, J. S. (1988). "Social capital in the creation of human capital." The American journal of sociology 94(1): 95-120.

Coleman, J. S., T. Hoffer, et al. (1982). High school achievement: Public, Catholic, and private schools compared, Basic Books New York.

Corten, R. and J. Dronkers (2006). "School achievement of pupils from the lower strata in public, private government-dependent and private government-independent schools: 
A cross-national test of the Coleman-Hoffer thesis 1." Educational Research and Evaluation 12(02): 179-208.

Cullen, J. B., B. A. Jacob, et al. (2005). "The impact of school choice on student outcomes: an analysis of the Chicago Public Schools." Journal of Public Economics 89(5-6): 729-760.

Cullen, J. B. and S. G. Rivkin (2003). The role of special education in school choice, University of Chicago Press.

Cuyck-Remijssen, A. v. and J. Dronkers (1990). "Catholic and Protestant schools, a better choice in the Netherlands?" School Effectiveness and School Improvement 1(3): 211220.

De Boer, E. (2005). "The dynamics of school location and school transportation: Illustrated with the Dutch town of Zwijndrecht." TR News(237).

De Haan, M., E. Leuven, et al. (2011). "Scale economies can offset the benefits of competition: Evidence from a school consolidation reform in a universal voucher system."

De Knecht-van Eekelen, A., E. Gille, et al. (2007). Resultaten PISA-2006. Praktische kennis en vaardigheden van 15-jarigen, Arnhem: Cito Instituut voor Toetsontwikkeling.

de Regt, A. and D. Weenink (2005). "When negotiation fails: private education as a disciplinary strategy." Journal of Education Policy 20(1): 59-80.

Dehejia, R. H. and S. Wahba (2002). "Propensity score-matching methods for nonexperimental causal studies." Review of Economics and Statistics 84(1): 151-161.

Denessen, E., G. Driessena, et al. (2005). "Segregation by choice? A study of group-specific reasons for school choice." Journal of Education Policy 20(3): 347-368.

Dijkgraaf, E., S. Van der Geest, et al. (2008). "School Choice and Competition: Evidence from The Netherlands."

Dijkstra, A. B., J. Dronkers, et al. (2001). "Private Schools as Public Provision for Education: School Choice and Marketization in the Netherlands and Elsewhere in Europe. Occasional Paper."

Dijkstra, A. B., J. Dronkers, et al. (2004). Private schools as public provision for education: School choice and market forces in the Netherlands. Educating Citizens. International Perspectives on Civic Values and School Choice. Washington DC, Brookings Institute: 67-90. 
Driessen, G. and H. Dekkers (2008). "Dutch policies on socio-economic and ethnic inequality in education." International Social Science Journal 59(193-194): 449-464.

Dronkers, J. (1993). "Educational reform in the Netherlands: did it change the impact of parental occupation and education?" Sociology of Education: 262-277.

Dronkers, J. (1995). "The existence of parental choice in the Netherlands." Educational Policy 9(3): 227.

Dronkers, J. (1999). "Veranderden leerlingaantallen in het voortgezet onderwijs in het schooljaar 1998-1999 door de publicatie van inspectiegegevens en de berekening van het schoolcijfer door Trouw in oktober 1997? Een nadere analyse." Tijdschrift voor onderwijsresearch 24(1): 63-66.

Dronkers, J. (2004). "Do public and religious schools really differ? Assessing the European evidence."

Dronkers, J. and S. Avram (2010). "A cross-national analysis of the relations of school choice and effectiveness differences between private-dependent and public schools." Educational Research and Evaluation 16(2): 151-175.

Dronkers, J. and P. Robert (2008). "Differences in scholastic achievement of public, private government-dependent, and private independent schools." Educational Policy 22(4): 541.

Education Inspectorate (2009). "Risk-based Inspection as of 2009. Primary and Secondary Education." Education Inspectorate, Ministry of Education, Culture and Science.

Education Inspectorate (2010). "De Vrijwillige Ouderbijdrage in het Primair Onderwijs: Hoe worden ouders geinformeerd over de vrijwillige ouderbijdrage in de schoolgids 20082009." Inspectie van het Onderwijs, Ministerie van Onderwijs, Cultuur en Wetenschap.

Education Inspectorate (2011). VVE-Bestandsopname. Tussenrapportage stand van zaken per medio 2011, Utrecht: Inspectie van het Onderwijs.

Education Inspectorate (2012). "The Dutch Inspectorate of Education, http://www.onderwijsinspectie.nl/english."

Elacqua, G. (2012). "The impact of school choice and public policy on segregation: Evidence from Chile." International Journal of Educational Development 32(3): 444-453. 
Epple, D., D. Figlio, et al. (2004). "Competition between private and public schools: testing stratification and pricing predictions." Journal of Public Economics 88(7-8): 12151245.

Epple, D. and R. E. Romano (1998). "Competition between private and public schools, vouchers, and peer-group effects." The American Economic Review 88(1): 33-62.

Epple, D. N. and R. Romano (2003). Neighborhood schools, choice, and the distribution of educational benefits, University of Chicago Press.

Eurydice (2009). "Organization of the education system: the Netherlands. Retrieved January 20, 2011, from European Commission: http://eacea.ec.europa.eu/education/eurydice/documents/eurybase/eurybase_full_ reports/NL_EN.pdf."

Fack, G. and J. Grenet (2010). "When do better schools raise housing prices? Evidence from Paris public and private schools." Journal of Public Economics 94(1): 59-77.

Figlio, D. N. and C. Hart (2010). Competitive effects of means-tested school vouchers, National Bureau of Economic Research.

Fiske, E. B. and H. F. Ladd (2000). When schools compete: A cautionary tale, Brookings Inst $\operatorname{Pr}$.

Fiske, E. B. and H. F. Ladd (2003). "School choice in New Zealand: A cautionary tale." Choosing choice: School choice in international perspective: 45-67.

Friedman, M. (1955). The role of government in education, Rutgers University Press.

Friedman, M. (1962). Capitalism and freedom: A leading economistís view of the proper role of competitive capitalism, Chicago: University of Chicago Press.

Gibbons, S., S. Machin, et al. (2008). "Choice, competition, and pupil achievement." Journal of the European Economic Association 6(4): 912-947.

Gijsberts, M. and L. Herweijer (2007). "Allochtone leerlingen in het onderwijs." Dagevos, J. \& M. Gijsberts (2007), Jaarrapportage Integratie.

Godwin, R. K. and F. R. Kemerer (2002). School Choice Tradeoffs: Liberty, Equity and Diversity, The University of Texas Press.

Goldberger, A. S. and G. G. Cain (1982). "The causal analysis of cognitive outcomes in the Coleman, Hoffer and Kilgore report." Sociology of Education 55(2): 103-122. 
Goldhaber, D. D. (1999). "School choice: An examination of the empirical evidence on achievement, parental decision making, and equity." Educational researcher 28(9): 16.

Gorard, S., J. Fitz, et al. (2001). "School choice impacts: what do we know?" Educational researcher 30(7): 18.

Greene, J., P. Peterson, et al. (1998). "School Choice in Milwaukee." Learning from school choice: $335-356$.

Grogger, J., D. Neal, et al. (2000). "Further Evidence on the Effects of Catholic Secondary Schooling [with Comments]." Brookings-Wharton papers on urban affairs: 151-201.

Groot, W. and H. Maassen van den Brink (2003). "Investeren en terugverdienen." Den Haag: SBO 80.

Hansson, B. and E. Charbonnier (2010). Education at a Glance 2010: OECD Indicators, Organisation for Economic Co-operation and Development.

Hanushek, E. (1997). "Assessing the effects of school resources on student performance: An update." Educational Evaluation and Policy Analysis 19(2): 141.

Hanushek, E. A. (2003). "The Failure of Input based Schooling Policies*." The economic journal 113(485): F64-F98.

Hanushek, E. A., J. F. Kain, et al. (2002). "The impact of charter schools on academic achievement." Unpublished Manuscript: Hoover Institute.

Hanushek, E. A., J. F. Kain, et al. (2007). "Charter school quality and parental decision making with school choice." Journal of Public Economics 91(5-6): 823-848.

Hastings, J. S., T. Kane, et al. (2008). "Heterogeneous preferences and the efficacy of public school choice." NBER Working Paper 2145.

Hastings, J. S., T. J. Kane, et al. (2005). Parental preferences and school competition: Evidence from a public school choice program, National Bureau of Economic Research Cambridge, Mass., USA.

Hastings, J. S. and J. M. Weinstein (2008). "Information, School Choice, and Academic Achievement: Evidence from Two Experiments*." Quarterly journal of economics 123(4): 1373-1414.

Henderson, A. (1981). Parent participation--student achievement: the evidence grows, National Committee for Citizens in Education. 
Herweijer, L. (2008). "Segregatie in het basis-en voortgezet onderwijs." SCP (red.), Betrekkelijke betrokkenheid. Sociaal en Cultureel Rapport: 209-236.

Herweijer, L. (2009). Making up the gap: migrant education in the Netherlands, The Netherlands Institute for Social Research (SCP).

Herweijer, L. and H. M. G. Vogels (2004). Ouders over opvoeding en onderwijs, Sociaal en Cultureel Planbureau.

Hirsch, D. (2002). School: A Choice of Directions, OECD CERI Working Paper: What Works in Innovation in Education.

Hirschman, A. O. (1970). Exit, voice, and loyalty, Harvard university press Cambridge, MA. Holland, P. W. (1986). "Statistics and causal inference." Journal of the American Statistical Association 81(396): 945-960.

Hoxby, C. (1999). The effects of school choice on curriculum and atmosphere, Washington, DC: Brookings Institution Press.

Hoxby, C. M. (2000). "Does Competition Between Public Schools Benefit Students and Taxpayers?" American Economic Review 90(5): 1209-1238.

Hoxby, C. M. (2003). School Choice and School Productivity. Could school choice be a tide that lifts all boats?, University of Chicago Press.

Hsieh, C. T. and M. Urquiola (2003). When schools compete, how do they compete? An assessment of Chile's nationwide school voucher program, National Bureau of Economic Research Cambridge, Mass., USA.

Hsieh, C. T. and M. Urquiola (2006). "The effects of generalized school choice on achievement and stratification: Evidence from Chile's voucher program." Journal of Public Economics 90(8-9): 1477-1503.

Jacob, B. A. and L. Lefgren (2007). "What Do Parents Value in Education? An Empirical Investigation of Parents' Revealed Preferences for Teachers." The Quarterly Journal of Economics 122(4): 1603-1637.

James, E. (1984). "Benefits and costs of privatized public services: Lessons from the Dutch educational system." Comparative Education Review: 605-624.

Jenkins, S. P., J. Micklewright, et al. (2006). Social segregation in schools: An international comparison.

Kane, T. J., S. K. Riegg, et al. (2006). "School quality, neighborhoods, and housing prices." American Law and Economics Review 8(2): 183-212. 
Karsten, S., G. Ledoux, et al. (2003). "School choice and ethnic segregation." Educational Policy 17(4): 452.

Karsten, S. and J. Meijer (1999). "School-based management in the Netherlands: the educational consequences of lump-sum funding." Educational Policy 13(3): 421.

Karsten, S., J. Meijer, et al. (1996). "Vrijheid van inrichting onderzocht." NTOR: Nederlands tijdschrift voor onderwijsrecht(2): 101-110.

Karsten, S., J. Roeleveld, et al. (2002). Schoolkeuze in een multi-etnische samenleving, SCOKohnstamm Instituut.

Koning, P. and K. van der Wiel (2013). "Ranking the Schools: How quality information affects school choice in the Netherlands." Journal of the European Economic Association 11(2): 466-493.

Kuyper, H., M. Lubbers, et al. (2003). VOCL'99-1: Technisch rapport, Groningen: GION.

Labaree, D. F. (1997). "Public goods, private goods: The American struggle over educational goals." American Educational Research Journal 34(1): 39.

Ladd, H. (2002). "School vouchers: a critical view." The Journal of Economic Perspectives 16(4): 3-24.

Ladd, H. F. (2003). "Introduction in "Choosing Choice: School Choice in International Perspective" " edited by David N. Plank and Gary Sykes Teachers College Pr.

Ladd, H. F. and E. B. Fiske (2009). "The Dutch experience with weighted student funding: Some lessons for the US." Sanford School of Public Policy Working Paper (Duke University), SAN09-03.

Ladd, H. F., E. B. Fiske, et al. (2010). "Parental Choice in the Netherlands: Growing Concerns about Segregation."

Lankford, H. and J. Wyckoff (1999). "The effect of school choice and residential location on the racial segregation of students." Albany: Departments of Economics and Public Administration and Policy, State University of New York at Albany.

Lara, B., A. Mizala, et al. (2011). "The Effectiveness of Private Voucher Education." Educational Evaluation and Policy Analysis 33(2): 119.

Leuven, E., M. Lindahl, et al. (2007). "The effect of extra funding for disadvantaged pupils on achievement." The Review of Economics and Statistics 89(4): 721-736.

Levin, H. (1991). "The Economics of Educational Choice." Economics of Education Review 10(2): 137-158. 
Levin, H. (1999). "The public-private nexus in education." American Behavioral Scientist 43(1): 124.

Levin, H. (2002). "A comprehensive framework for evaluating educational vouchers." Educational Evaluation and Policy Analysis 24(3): 159.

Levin, H. M. (1998). "Educational vouchers: Effectiveness, choice, and costs." Journal of Policy Analysis and management 17(3): 373-392.

Levin, H. M. (2009). "An Economic Perspective on School Choice." Handbook of research on school choice: 19.

Levin, H. M. (2012). "Some economic guidelines for design of a charter school district." Economics of Education Review 31(2): 331-343.

Levin, H. M. and C. R. Belfield (2003). "The marketplace in education." Review of Research in Education 27: 183-219.

Levin, H. M. and C. E. Driver (1997). "Cost of an educational voucher system." Education Economics 5(3): 265-283.

Levin, J. (2004). "Differences in Educational Production Between Dutch Public and Religious Schools." National Center for the Study of Privatization in Education Occasional Paper 93.

Loeb, S. and P. J. McEwan (2010). "Education Reforms." Targeting Investments in Children: Fighting Poverty When Resources Are Limited: 145.

Lubienski, C. and S. T. Lubienski (2006). "Charter, private, public schools and academic achievement: New evidence from NAEP mathematics data." National Center for the Study of Privatization in Education, Teachers College, Columbia University (January).

MacLeod, W. B. and M. Urquiola (2009). Anti-lemons: School reputation and educational quality, National Bureau of Economic Research Cambridge, Mass., USA.

Mayer, D. P., P. E. Peterson, et al. (2002). "School choice in New York City after three years: An evaluation of the school choice scholarships program." Washington, DC: Mathematica Policy Research, Inc.

McEwan, P. (2000). "Comparing the effectiveness of public and private schools: a review of evidence and interpretations." Occasional paper 3: 1.

McEwan, P. J. and M. Carnoy (2000). "The effectiveness and efficiency of private schools in Chile's voucher system." Educational Evaluation and Policy Analysis 22(3): 213. 
McMillan, R. (2000). Competition, parental involvement and public school performance. National Tax Association Proceedings, 2000: 150-155.

McMillan, R. (2004). "Competition, incentives, and public school productivity." Journal of Public Economics 88(9-10): 1871-1892.

Merry, M. and S. Karsten (2011). "Pluralism and Segregation: The Dutch Experience." Canadian Issues. Diversity and Education for Liberation: Realities, Possibilities, and Problems Spring 2011.

Minne, B., M. Rensman, et al. (2007). Excellence for productivity?, Centraal PlanBureau (CPB).

Miron, G., J. Urschel, et al. (2011). "What Makes KIPP Work? A Study of Student Characteristics, Attrition, and School Finance." Western Michigan University.

Morgan, S. L. (2001). "Counterfactuals, causal effect heterogeneity, and the Catholic school effect on learning." Sociology of Education 74(4): 341-374.

Murnane, R. J., S. Newstead, et al. (1985). "Comparing public and private schools: The puzzling role of selectivity bias." Journal of Business \& Economic Statistics 3(1): 23-35.

Murnane, R. J. and J. B. Willett (2010). Methods matter: Improving causal inference in educational and social science research, Oxford University Press, USA.

Neal, D. (1998). "What have we learned about the benefits of private schooling?" Economic Policy Review 4(1): 79-86.

Nechyba, T. J. (1999). "School finance induced migration and stratification patterns: The impact of private school vouchers." Journal of Public Economic Theory 1(1): 5-50.

Nechyba, T. J. (2000). "Mobility, targeting, and private-school vouchers." The American Economic Review 90(1): 130-146.

Nechyba, T. J. (2003). Introducing school choice into multidistrict public school systems. The economics of school choice, University of Chicago Press: 145-194.

Noailly, J., S. Vujic, et al. (2009). "The effects of competition on the quality of primary schools in the Netherlands."

OCW, M. (2010). "Key Figures 2005-2009." Ministry of Education Culture and Science (OCW), the Hague, the Netherlands.

OCW, M. (2011). "Key Figures 2006-1010." Ministry of Education Culture and Science (OCW), the Hague, the Netherlands. 
OCW, M. (2011). "Nota Werken in het Onderwijs 2011." Ministry of Education Culture and Science (OCW), the Hague, the Netherlands.

OECD (2006). "Science Competencies For Tomorrows World: Volume 1 Analysis."

OECD (2010). "PISA 2009 Results: Overcoming Social Background: Equity in Learning

Opportunities and Outcomes (Volume II)." Paris: Organisation for Economic Cooperation and Development.

OECD (2011). " When Students Repeat Grades or Are Transferred Out of School

What Does it Mean for Education Systems?".

Onderwijsraad (1982). "Voorontwerp voor de overgangswet bij de Wet op het basisonderwijs." Den Haag, Onderwijsraad.

Onderwijsraad (2001). "Verkenning De Markt Meester? Een verkenning naar marktwerking in het onderwijs." Den Haag, Onderwijsraad.

Patrinos, H. A. (2002). "Private education provision and public finance: The Netherlands as a possible model." NCSPE Occasional Paper.

Patrinos, H. A. (2011). "Private education provision and public finance: the Netherlands." Education Economics.

Patrinos, H. A., F. B. Osorio, et al. (2009). The role and impact of public-private partnerships in education, World Bank Publications.

Peterson, P., W. Howell, et al. (2003). School vouchers. Results from randomized experiments, University of Chicago Press.

Plank, D. N. and G. Sykes (2003). Choosing choice: School choice in international perspective, Teachers College Pr.

Rangvid, B. S. (2007). "Living and learning separately? Ethnic segregation of school children in Copenhagen." Urban studies 44(7): 1329.

Rawls, J. (2001). Justice as fairness: A restatement, Harvard University Press.

Reardon, S. F., J. E. Cheadle, et al. (2009). "The effect of Catholic schooling on math and reading development in kindergarten through fifth grade." Journal of Research on Educational Effectiveness 2(1): 45-87.

Reay, D. (2004). "Exclusivity, exclusion, and social class in urban education markets in the United Kingdom." Urban education 39(5): 537.

Reback, R. (2005). "House prices and the provision of local public services: Capitalization under school choice programs." Journal of Urban Economics 57(2): 275-301. 
Ritzen, J. M., J. Van Dommelen, et al. (1997). "School finance and school choice in the Netherlands." Economics of Education Review 16(3): 329-335.

Rothstein, J. (2005). Does competition among public schools benefit students and taxpayers? A comment on Hoxby (2000), National Bureau of Economic Research Cambridge, Mass., USA.

Rothstein, J. M. (2006). "Good principals or good peers? Parental valuation of school characteristics, Tiebout equilibrium, and the incentive effects of competition among jurisdictions." The American Economic Review 96(4): 1333-1350.

Rouse, C. E. (1998). "Private School Vouchers and Student Achievement: An Evaluation of the Milwaukee Parental Choice Program*." Quarterly journal of economics 113(2): 553-602.

Rouse, C. E. and L. Barrow (2009). "School Vouchers and Student Achievement: Recent Evidence and Remaining Questions." Annual Review of Economics 1(1): 17-42.

Rubin, D. B. (2006). Matched sampling for causal effects, Cambridge University Press. Ruijs, N. and H. Oosterbeek (2012). School choice in Amsterdam: Which schools do parents prefer when school choice is free? Working paper version presented at the 2012 EALE. Source: http://www.ieb.ub.edu/aplicacio/fitxers/WSEE12Ruijs.pdf.

Rutkowski, L. and D. Rutkowski (2009). "Private and Public Education: A Cross-National Exploration with TIMSS 2003." http://www.ncspe.org Occasional Paper \#192.

Saporito, S. (2003). "Private choices, public consequences: Magnet school choice and segregation by race and poverty." Social Problems 50(2): 181-203.

Schmidt, H. and J. Sperling (2010). "Moet jij niet naar school?".

Schneider, M. and J. Buckley (2002). "What do parents want from schools? Evidence from the Internet." Educational Evaluation and Policy Analysis 24(2): 133.

Schneider, M., P. Teske, et al. (2002). Choosing schools, Princeton University Press.

Schneider, M., P. Teske, et al. (1997). "Institutional arrangements and the creation of social capital: The effects of public school choice." The American Political Science Review 91(1): 82-93.

Shewbridge, C., M. Kim, et al. (2010). "OECD Reviews of Migrant Education."

Shleifer, A. (1998). State versus private ownership, National Bureau of Economic Research Cambridge, Mass., USA. 
Skolvervet (2012). "Educational equity in the Swedish School System? A quantitative analysis of equity over time.".

Smeets, E. (2007). Speciaal of apart: onderzoek naar de omvang van het speciaal onderwijs in Nederland en andere Europese landen, ITS-Radboud Universiteit Nijmegen.

Smeets, E. F. L., G. Driessen, et al. (2009). Allochtone leerlingen en speciale onderwijsvoorzieningen, ITS, Radboud Universiteit Nijmegen.

Smeets, E. F. L., C. Ramakers, et al. (2008). Het persoonsgebonden budget in het onderwijs, ITS.

Soederstroem, M. and R. Uusitalo (2010). "School Choice and Segregation: Evidence from an Admission Reform*." Scandinavian Journal of Economics 112(1): 55-76.

Steenbekkers, A., C. Simon, et al. (2006). Thuis op het platteland: de leefsituatie van platteland en de stad vergeleken, Sociaal en Cultureel Planbu.

Sturm, J., L. Groenendijk, et al. (1998). "Educational Pluralism-a historical study of socalled'pillarization'in the Netherlands, including a comparison with some developments in South African education." Comparative education 34(3): 281-297.

Sutherland, D., R. Price, et al. (2009). "Improving public spending efficiency in primary and secondary education." OECD Journal: Economic Studies 2009(1).

Teske, P. and M. Schneider (2001). "What research can tell policymakers about school choice." Journal of Policy Analysis and management 20(4): 609-631.

Tiebout, C. M. (1956). "A pure theory of local expenditures." The Journal of Political Economy 64(5): 416-424.

Tsang, M. C. (2003). "School choice in the Peopleís Republic of China." Choosing Choice. School Choice in International Perspective: 164-195.

Urquiola, M. (2005). "Does school choice lead to sorting? Evidence from Tiebout variation." American Economic Review: 1310-1326.

Van der Houwen, K., J. Goossen, et al. (2004). Reisgedrag kinderen basisschool, Travel Behaviour of Primary School Children](Veenendaal: Traffic Test).

Van Elk, R., M. Van Der Steeg, et al. (2011). "Does the timing of tracking affect higher education completion?" Economics of Education Review 30(5): 1009-1021.

Van Laarhoven, P., B. Baker, et al. (1990). "Achievement in public and private secondary education in The Netherlands.'." The Third Sector: Comparative studies of nonprofit organizations. 
Vandenberghe, V. and S. Robin (2004). "Evaluating the effectiveness of private education across countries: a comparison of methods." Labour economics 11(4): 487-506.

Veen, A., J. Roeleveld, et al. (2010). Onderwijs en opvang voor jonge kinderen: deelname aan opvang door driejarigen en kwaliteit van onderwijs en opvang voor drie-en vierjarigen, Onderwijsraad.

Vermeer, N. and M. van der Steeg (2011). "Nederlandse onderwijsprestaties in perspectief." CPB Policy Brief 2011/05.

Waslander, S., C. Pater, et al. (2010). "Markets in Education: An Analytical Review of Empirical Research on Market Mechanisms in Education." OECD Education Working Papers.

Waterreus, I. (2009). "Is er een economische reden voor een fusietoets in het onderwijs?" Voortijdige schoolverlaters: Aanleiding en kansen op de arbeidsmarkt 6: 80.

Weenink, D. (2009). "Creating a niche in the education market: the rise of internationalised secondary education in the Netherlands." Journal of Education Policy 24(4): 495-511.

Weiher, G. R. and K. L. Tedin (2002). "Does choice lead to racially distinctive schools? Charter schools and household preferences." Journal of Policy Analysis and management 21(1): 79-92.

West, M. R. and L. Woessmann (2010). "'Every Catholic Child in a Catholic School": Historical Resistance to State Schooling, Contemporary Private Competition and Student Achievement across Countries." The economic journal 120(546): F229-F255.

White, J. P. and P. S. Maxim (2003). "Social Capital, Social Cohesion, and Population Outcomes in Canadaís First Nations Communities." Aboriginal Conditions: Research as a Foundation for Public Policy: 7-34.

Willms, J. D. (1996). "School choice and community segregation: Findings from Scotland." Generating School Stratification: Toward a New Research Agenda.

Witte, J. F. (1998). "The Milwaukee voucher experiment." Educational Evaluation and Policy Analysis 20(4): 229.

Woessmann, L. (2006). "Public-Private Partnership and Schooling Outcomes across Countries." CESifo Working Paper Series.

Woessmann, L. (2009). "International Evidence on School Tracking: A Review."

Yinger, J. (2004). "State aid and the pursuit of educational equity: An overview." Helping children left behind: State aid and the pursuit of educational equity: 3-57. 
School Choice, Competition and Achievement

Zoontjens, P. (2003). "Bijzonder en openbaar onderwijs." Recht en religie-bijzonder nummer Ars Aequi 7: 59-68. 
Appendix A: Overview of variables used

Appendix A.1 PISA 2006 data set

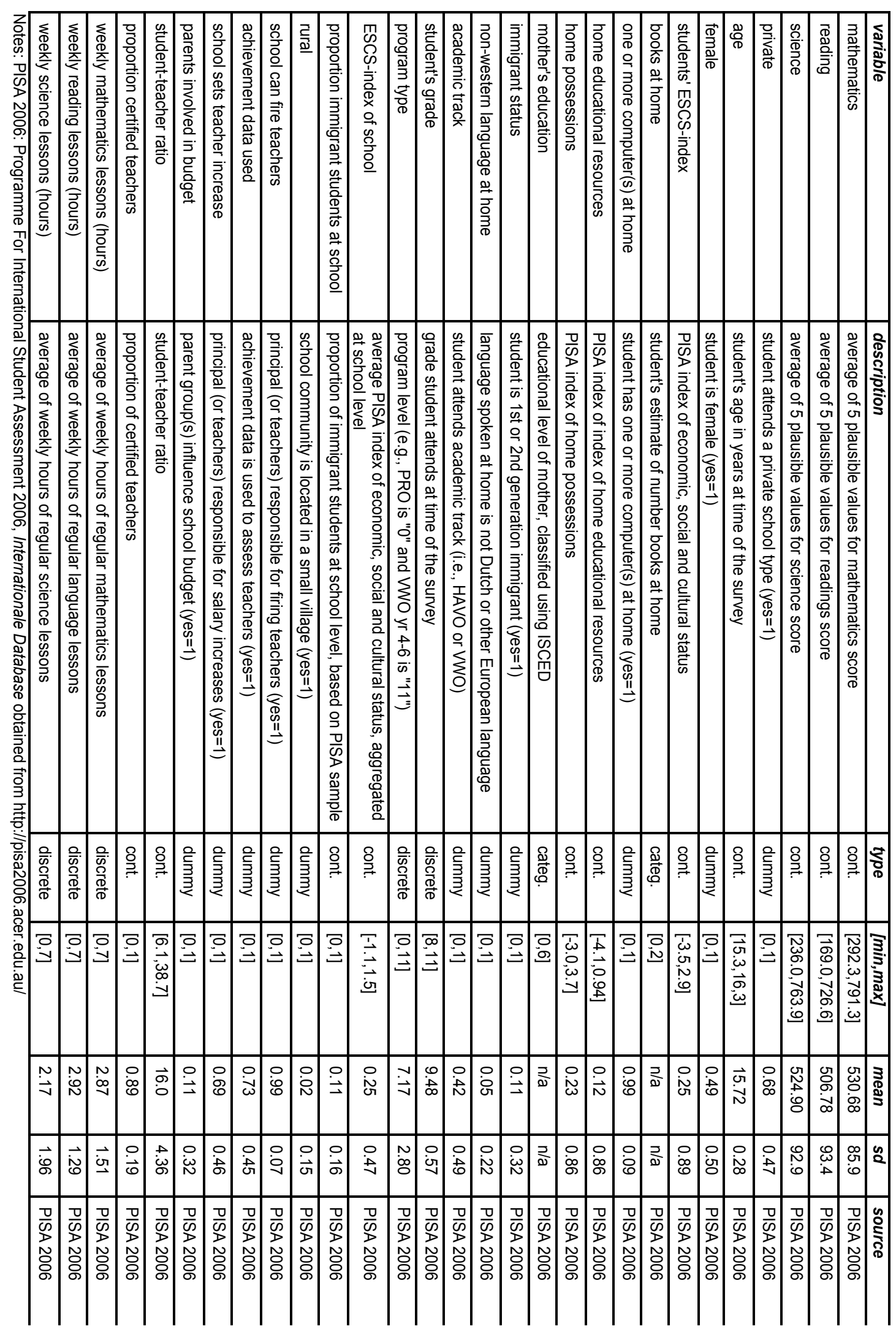


Appendix A.2

PISA 2009 data set

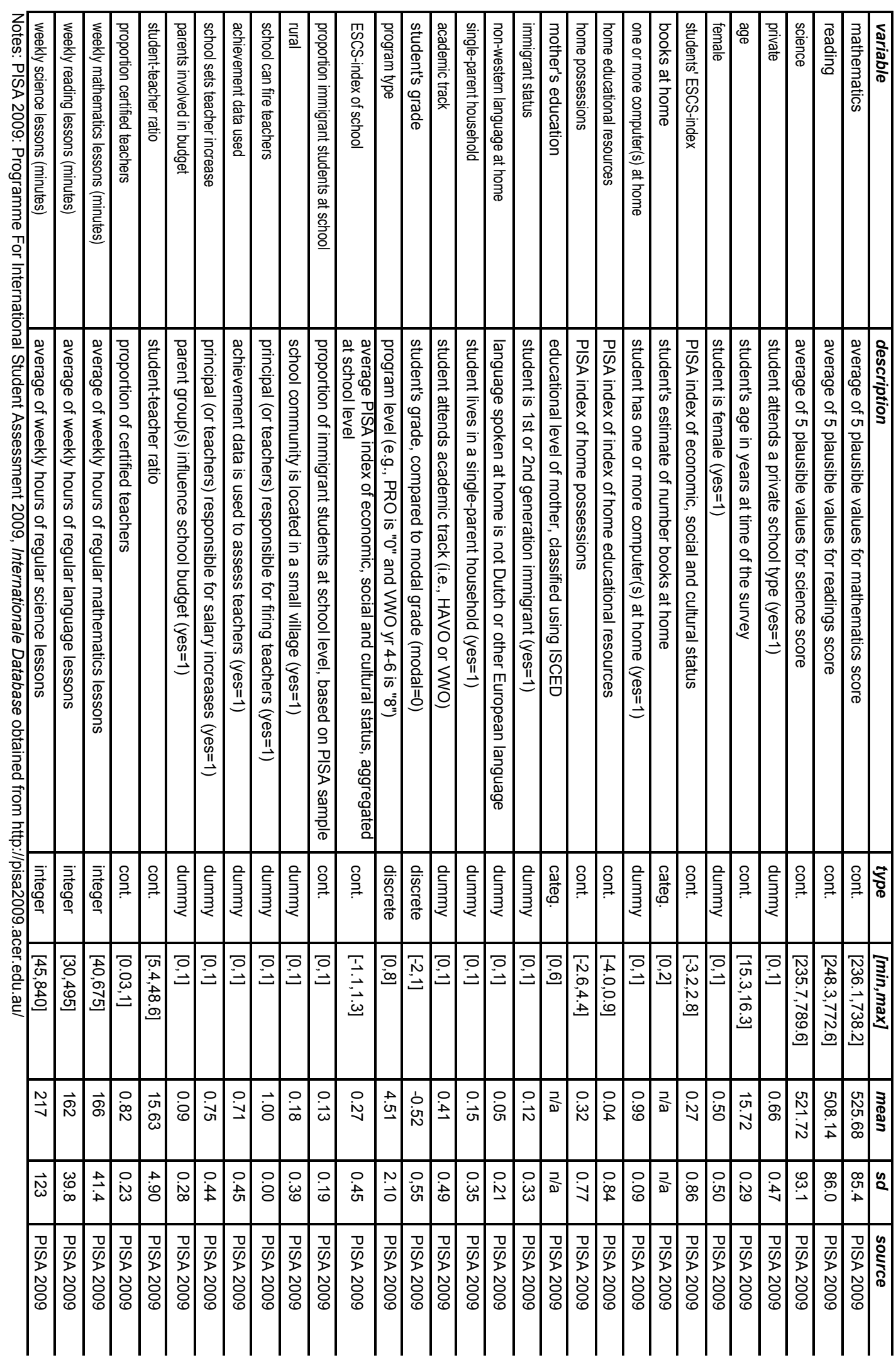


Appendix A.3

BRON PO '08-'09 data set

\begin{tabular}{|c|c|c|c|c|c|c|c|c|c|c|c|c|c|c|c|c|c|c|c|c|c|c|}
\hline 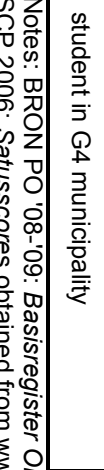 & 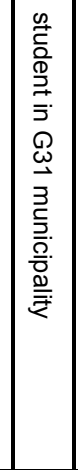 & 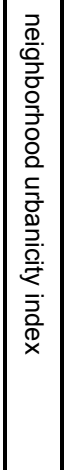 & 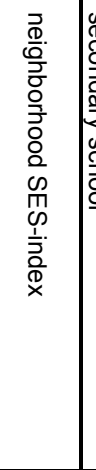 & 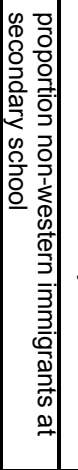 & 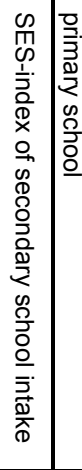 & 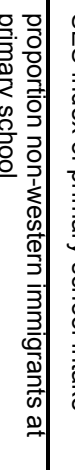 & 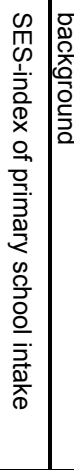 & 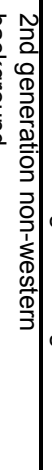 & 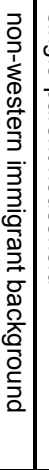 & & 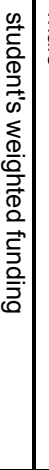 & & & 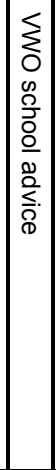 & 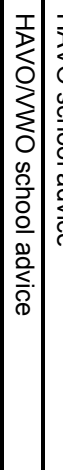 & & 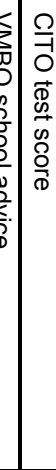 & 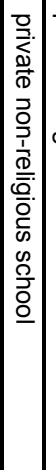 & 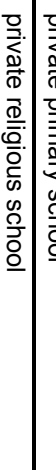 & 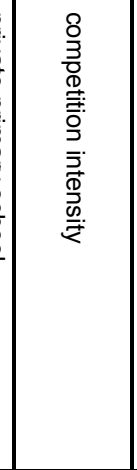 & 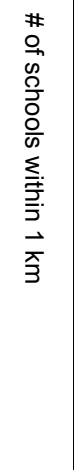 & \\
\hline 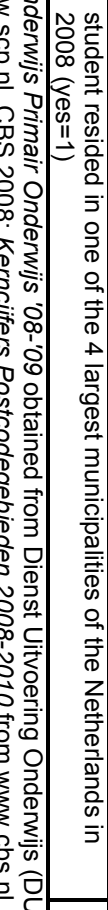 & 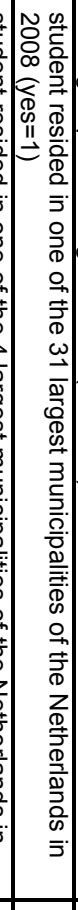 & 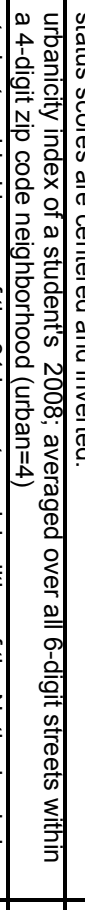 & 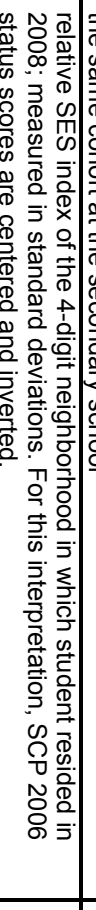 & 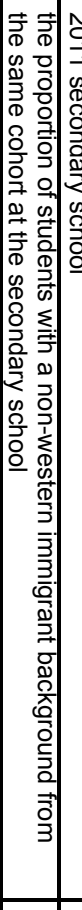 & 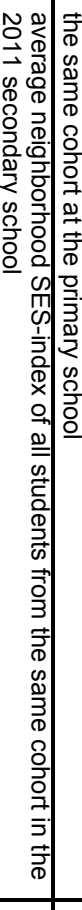 & 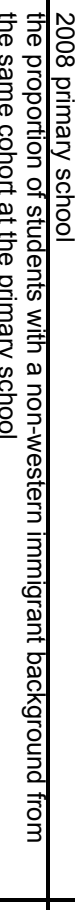 & 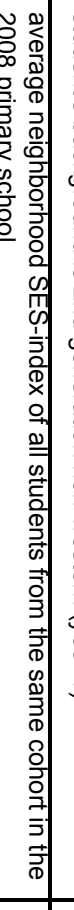 & 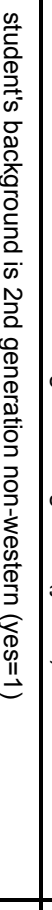 & 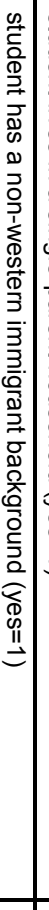 & & 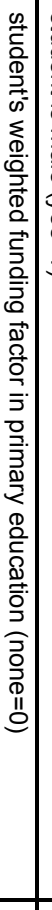 & 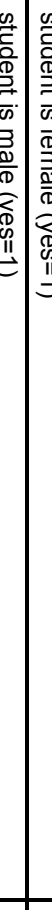 & 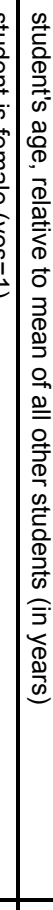 & 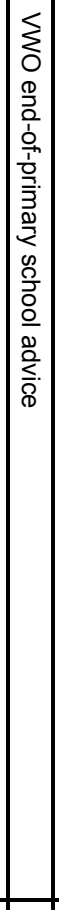 & 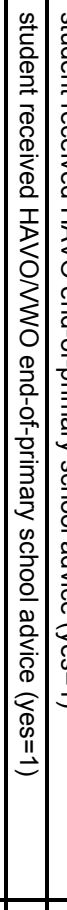 & 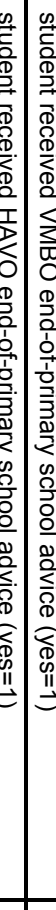 & 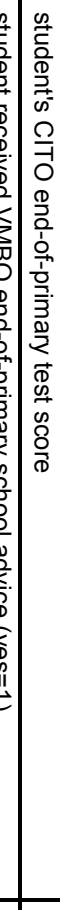 & 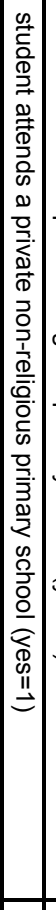 & 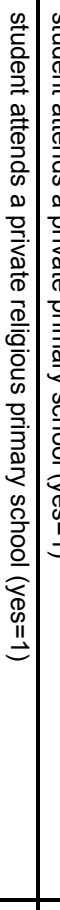 & 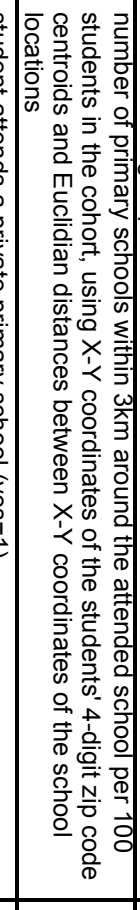 & 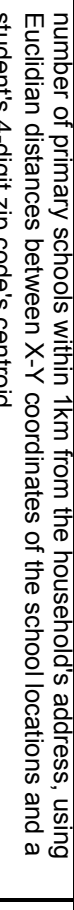 & \\
\hline 氞 & 彦 & $\stackrel{\rho}{ٍ ٍ p}$ & 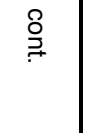 & $\stackrel{8}{ٍ}$ & $\stackrel{\varrho}{ٍ ٍ ~}$ & $\stackrel{\bigcirc}{\stackrel{\rho}{F}}$ & $\stackrel{\circ}{\stackrel{\rho}{\rightleftharpoons}}$ & 总 & 胥 & & $\begin{array}{l}\frac{2}{0 .} \\
\frac{0}{0} \\
\frac{0}{0} \\
\end{array}$ & 2 & $\frac{2}{P}$ & $\mid \begin{array}{l}0 \\
\text { 旁 } \\
\text { 产 }\end{array}$ & 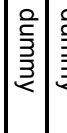 & & 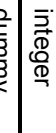 & $\mid \begin{array}{l}0 \\
\text { 总 } \\
\text { 产 }\end{array}$ & & 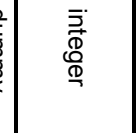 & 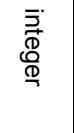 & క్ర \\
\hline$\stackrel{\overline{0}}{=}$ & $\stackrel{\circ}{\stackrel{D}{\Xi}}$ & $\begin{array}{l}D \\
D \\
\pm\end{array}$ & $\begin{array}{l}\frac{F}{b} \\
\infty \\
\omega \\
\stackrel{\omega}{\mid} \\
\end{array}$ & $\stackrel{\square}{=}$ & 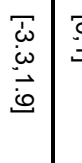 & $\begin{array}{l}\bar{O} \\
\stackrel{\Xi}{*}\end{array}$ & $\begin{array}{l}\bar{i} \\
\dot{0} \\
\stackrel{0}{N} \\
\dot{Q} \\
\end{array}$ & $\stackrel{\bar{O}}{\vec{\Xi}}$ & $\begin{array}{l}\partial \\
\vec{\Xi}\end{array}$ & & $\begin{array}{l}\dot{\hat{\omega}} \\
\stackrel{\vec{v}}{2}\end{array}$ & 3 & $\begin{array}{l}\bar{N} \\
\dot{N} \\
\dot{0}\end{array}$ & $\stackrel{0}{\stackrel{0}{=}}$ & $\stackrel{D}{=}$ & $=$ & 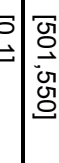 & & $\begin{array}{l}\bar{D} \\
\end{array}$ & $\begin{array}{l}\bar{\partial} \\
\stackrel{\vec{\theta}}{0}\end{array}$ & $\begin{array}{l}\overline{\tilde{U}} \\
\stackrel{\tilde{U}}{0}\end{array}$ & \\
\hline $\begin{array}{l}\stackrel{\circ}{\overrightarrow{0}} \\
\end{array}$ & : & $\overrightarrow{0}$ & $\dot{8}$ & $\stackrel{\circ}{\dot{\vec{v}}}$ & $\dot{8}$ & $\begin{array}{l}\stackrel{0}{\vec{v}} \\
\dot{\vec{v}}\end{array}$ & $\ddot{8}$ & $\vec{\infty}$ & $\stackrel{0}{\vec{v}}$ & | & 市 & $\underline{b}$ & مُ & $\begin{array}{l}0 \\
\vec{v}\end{array}$ & $\stackrel{\circ}{\vec{\sigma}}$ & 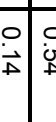 & 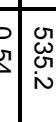 & ○े & \begin{tabular}{l|l} 
& \\
$\dot{\$}$ & \\
&
\end{tabular} & $\stackrel{\omega}{\omega}$ & $\stackrel{P}{\rightarrow}$ & \\
\hline$\stackrel{\circ}{\dot{\omega}}$ & $\begin{array}{l}\text { Pे } \\
\text { जि }\end{array}$ & $\vec{\omega}$ & 过 & $\stackrel{\stackrel{\circ}{\vec{\infty}}}{\dot{\infty}^{\prime}}$ & 이 & $\begin{array}{l}\stackrel{\sim}{N} \\
\text { N }\end{array}$ & $\stackrel{\circ}{\stackrel{\infty}{\rightarrow}}$ & $\begin{array}{l}\stackrel{0}{\infty} \\
\infty\end{array}$ & : & $\vec{\sigma}$ & iे & $\dot{q}$ & 诏 & $\mid \begin{array}{l}\stackrel{\circ}{\dot{\omega}} \\
\stackrel{\omega}{\omega}\end{array}$ & 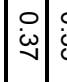 & 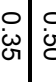 & 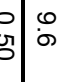 & $\mid \begin{array}{l}0 \\
\stackrel{\omega}{\omega}\end{array}$ & $\mid \begin{array}{l}0 \\
\dot{0} \\
\infty\end{array}$ & $\vec{\prime}$ & $\underset{\sim}{\omega}$ & $\underline{\xi}$ \\
\hline 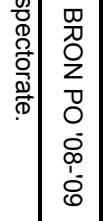 & 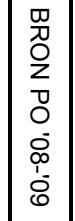 & $\begin{array}{l}\text { 怘 } \\
\text { N } \\
\widetilde{O} \\
\infty\end{array}$ & 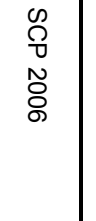 & $\begin{array}{l}\text { Do } \\
0 \\
O_{2} \\
0 \\
0 \\
0 \\
0 \\
\vdots \\
0 \\
0\end{array}$ & $\begin{array}{l}0 \\
0 \\
0 \\
\tilde{0} \\
0 \\
\sigma\end{array}$ & $\begin{array}{l}\text { 署 } \\
\text { Oे } \\
\text { D } \\
0 \\
0 \\
0 \\
0 \\
0 \\
0\end{array}$ & $\begin{array}{l}\infty \\
0 \\
0 \\
\tilde{y} \\
0 \\
\sigma\end{array}$ & $\begin{array}{l}\text { 罚 } \\
\text { Oे } \\
0 \\
0\end{array}$ & 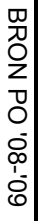 & & $\begin{array}{l}\text { 罚 } \\
2 \\
0 \\
0\end{array}$ & $\begin{array}{l}0 \\
\lambda \\
\end{array}$ & 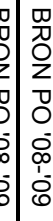 & $\begin{array}{l}0 \\
0 \\
0 \\
2 \\
0 \\
0 \\
0 \\
0 \\
0 \\
1 \\
0 \\
0 \\
0\end{array}$ & $\mid$\begin{tabular}{l|l}
0 \\
0 \\
0 \\
2 \\
0 \\
0 \\
0 \\
0 \\
0 \\
0 \\
0 \\
0
\end{tabular} & 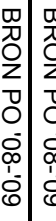 & 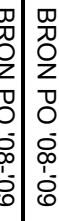 & \begin{tabular}{|l|}
$\bar{\nabla}$ \\
0 \\
$\tilde{O}$ \\
$\bar{N}$ \\
\end{tabular} & $\begin{array}{l}0 \\
\hat{O} \\
\vec{N}\end{array}$ & $\begin{array}{l}\text { 罚 } \\
\text { Oे } \\
0 \\
0 \\
0 \\
0 \\
\vdots \\
\vdots \\
0 \\
0\end{array}$ & 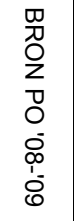 & \\
\hline
\end{tabular}


School Choice, Competition and Achievement

Appendix A.4

VOCL99 data set

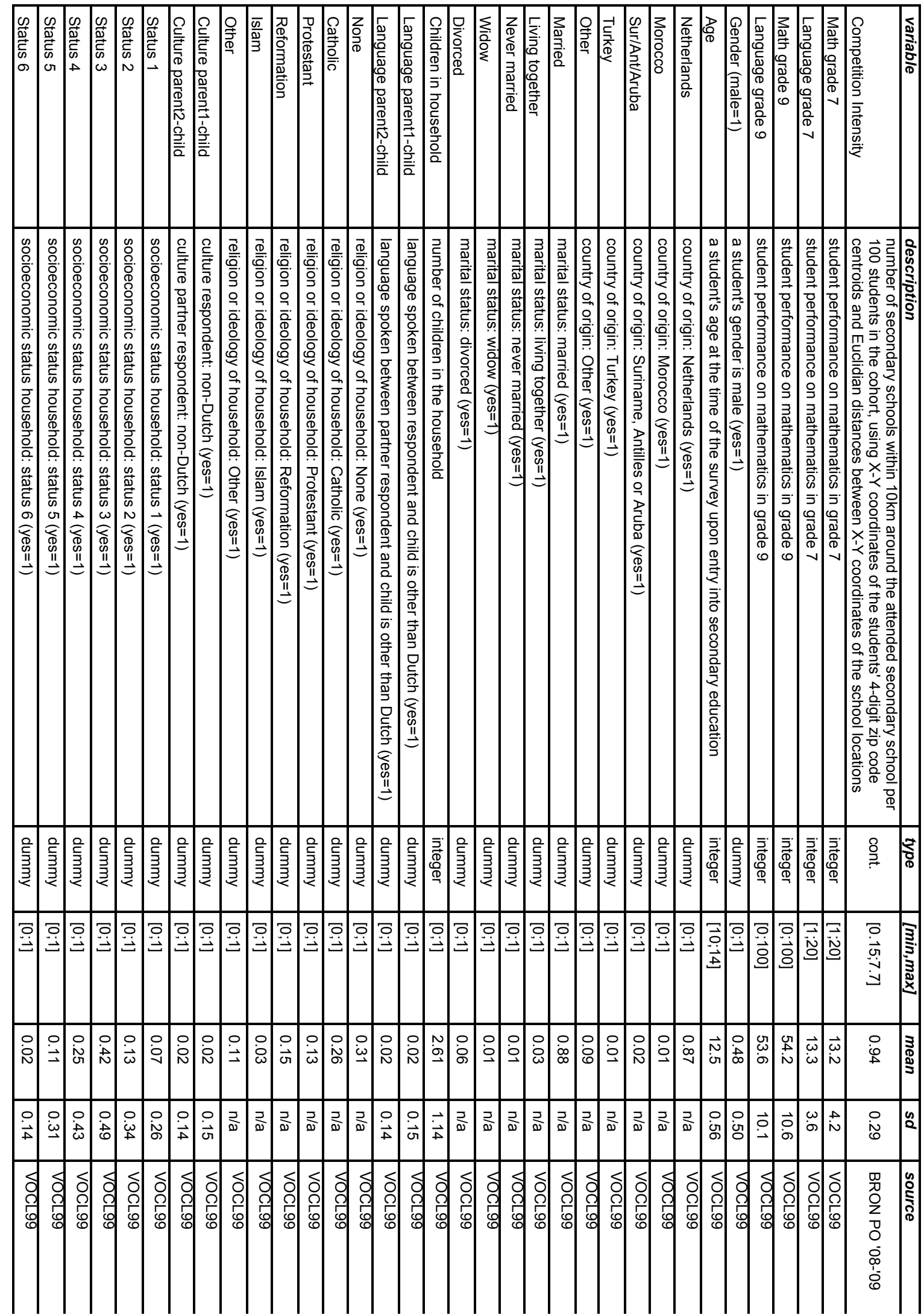




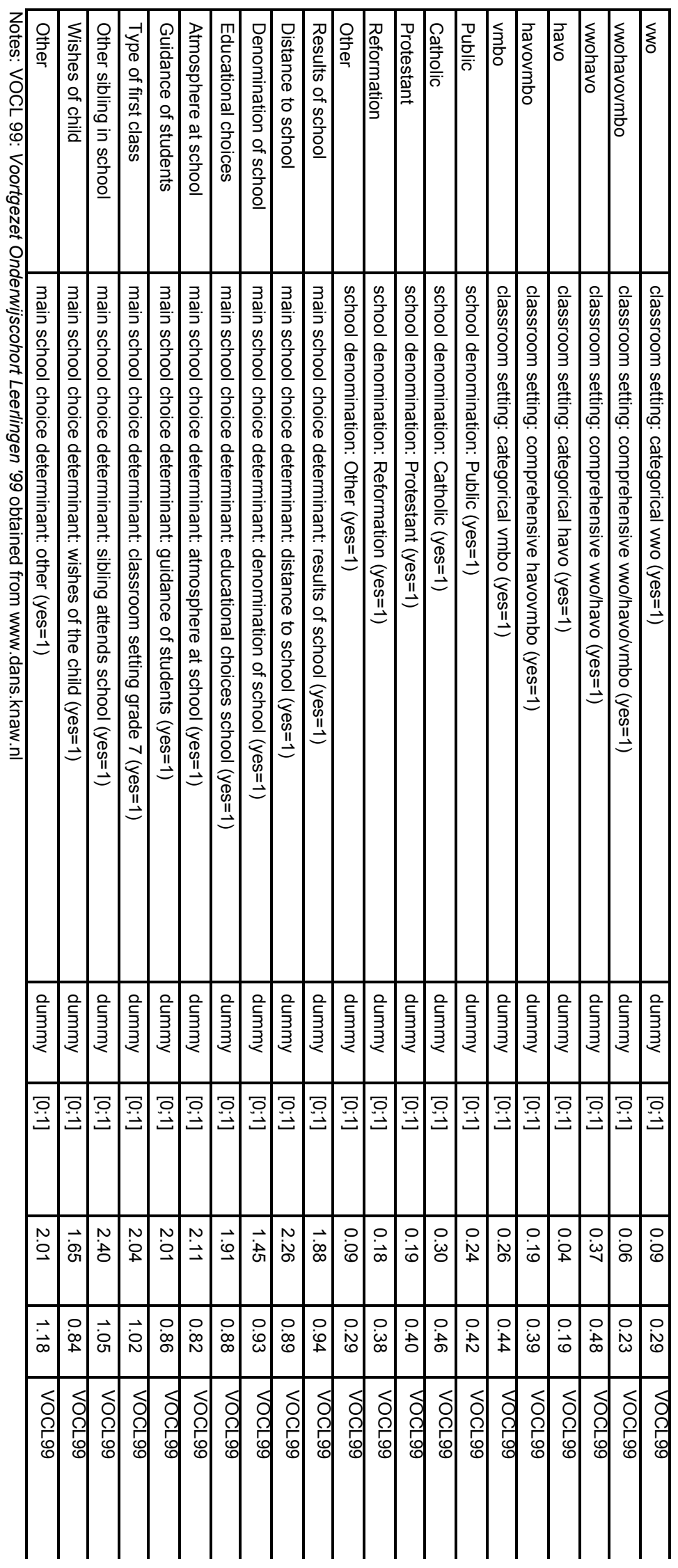


School Choice, Competition and Achievement 


\section{Summary}

Educational choice has become an integral part of the educational landscape in many countries. It has been at the heart of the educational debate in the United States and other countries, including the Netherlands. The current state of research expresses: i) a demand for empirical results on large-scale choice contexts, ii) a lack of consensus on which type of educational provisions yields efficient results, and iii) the need to interpret results on educational choice along a range of educational objectives (i.e. both private and public).

This dissertation sets out to address the above issues by exploring several features of the Dutch compulsory education sector. In particular, the empirical analyses focus on analyzing relative private school type effectiveness, school choice and student performance, and how school-level competition relates to achievement and sorting by ability. Levin's (2002) framework of multiple educational outcomes (i.e. freedom of choice, productive efficiency, equity and social cohesion) is adopted for interpretation. The results presented throughout this dissertation are based on multiple data sources and using different econometric methods. The key findings can be summarized as: i) largely comparable academic achievement levels are observed across public and private school types, ii) the Dutch context of choice and competition emphasizes adequacy, iii) heterogeneous demand in the Dutch choice context limits the potential for achievement gains and seems to particularly induce product differentiation instead, and iv) school choice in the Netherlands induces tradeoffs among private and public goals of education, highlighting the importance of how the educational system is designed and regulated. 
Chapter 2 provides an overview of the international school choice literature regarding freedom of choice, productive efficiency, equity and social cohesion. In terms of freedom of choice, school choice expansion improves this outcome with households displaying a wide variety in preferences towards school attributes. However, all else equal, households tend to prefer schools of high academic quality and with a student-body composition of a relatively advantageous socioeconomic background. Regarding productive efficiency, the results are modestly positive for the potential of choice and competition to increase overall average achievement. The relative advantage of private schools finds only mixed, and marginal, support for achievement, whereas attainment gains appear to be more consistent. The effects of school choice expansion on equity depend largely on its design (i.e. finance, regulation, support services). A well-designed choice plan, targeted at disadvantageous households, can improve their educational opportunities, whereas large-scale choice systems hold the potential to reinforce existing inequity. Empirical research on social cohesion, a public goal that is difficult to define and measure, is limited. However, by shifting the power over the school from policy makers to households, there are reasons to believe that school choice expansion, particularly through stratifying student-body compositions of schools, is more likely to support private goals of education and undermine social cohesion.

Chapter 3 reviews the Dutch choice context in compulsory education, which seems to fit the definition of a quasi-market. Within the dimension of freedom of choice, the freedom for schools to choose is highly regulated in terms of their inputs and outcomes, although there is increasingly more freedom in terms of the educational process and school management. Regarding productive efficiency, achievement within the compulsory education system, when contrasted with other countries, is favorable on average, but seems to be dropping. Relative private school effectiveness seems to be more pronounced in primary education for academic outcomes, and based upon results restricted to the period between the late 1960's and early 1990's. In terms of equity, horizontal equity and adequacy seem to be guaranteed through equal funding and academic standards for all schools. Vertical equity is acknowledged through additional funding for students from lower socioeconomic backgrounds and for those with special educational needs. Social 
cohesion is safeguarded through the imposition of strict curriculum- and outcome regulations; although schools are relatively autonomous in organizing the actual educational process that students are exposed to. Importantly, there is a considerable degree of stratification in the system, and particularly so in the abilitytracked secondary sector.

Chapter 4 exploits the variance in the number of schools in their proximity to households in order to estimate the influence of choice intensity (a measure of competition) on student achievement at the end of primary education in the Netherlands. Using a rich set of controls at the student-, school,- and neighborhood levels reveals a moderate positive association between choice and achievement in which a $100 \%$ increase in the number of surrounding schools is associated with around a $0.05-0.09 \sigma$ increase in achievement. This is similar to an increase of 0.03$0.06 \sigma$ for each standard deviation increase in choice intensity. Limiting the sample to the 4 largest cities reduces variation in urban density and gives estimates in the upper end of the range of estimates. With school choice intensity instrumented by the distance to the main road entry/exit, results are imprecise but qualitatively similar.

The next set of empirical analyses (Chapter 5) sets out to apply three different non-experimental methodologies (i.e. OLS, IV and PSM) to Dutch PISA 2006 and 2009 data in an attempt to find a clear effect of private school attendance on student achievement in three subjects (i.e. mathematics, reading and science). Overall, the results do not point to a consistent effect across both waves of data. OLS and PSM results suggest private school attendance is positively associated with mathematics achievement, but only in PISA 2006. Instead, the results generated by an instrumental variable approach (IV) are very unstable. Relatively large, but imprecise, positive estimates are found for all subjects in PISA 2006, whereas the exact opposite (i.e. a large imprecise, but negative result) is found for students in the PISA 2009 data set. Similar analyses performed on the end-of-primary test scores available in the BRON data set also yield largely indistinguishable results between school types, as do results on "upward mobility" for the first two years of secondary education.

Chapter 6 analyzes the relationships between school-level competition and 
School Choice, Competition and Achievement

students' academic achievement in the Dutch primary sector, thereby distinguishing competition- from choice effects. For this purpose, school concentration measures are constructed for all schools in the largest 31 municipalities, describing "the number of surrounding schools per 100 cohort student member within a radius of 3 kilometers $(\mathrm{km})$ around the school". The results suggest a positive association between school-level competition and academic achievement, with an average effect size on CITO test scores of around $0.06 \sigma$. This relationship is stronger for the lower half of the achievement distribution and for more urban settings $(0.1 \sigma)$, but beyond the median level of performance increased competition intensity is no longer related to academic performance.

Chapter 7 focuses on the effects of competition between schools on student sorting and on performance gains in competitive markets in secondary education using the VOCL99 data set. The analyses suggest that schools operating in a competitive market do compete for "favorable" (i.e. high-performing) students, through supply-driven product differentiation. With increasing competition, relatively more schools in a local education market target the group of highachieving students. The effects of competition on sorting by ability are therefore primarily observed among higher ability schools. The results indicate that these academic-oriented schools (i.e. havo, vwo) need to accept students at the margin as to ensure sufficient enrollment rates in competitive local education markets. The results indicate that the Dutch competition mechanism is related to small improvements in academic achievement in the first three years of secondary education, thus corroborating the findings in Chapter 6.

Chapter 8 summarizes the above results in Levin's framework for evaluation, with an emphasis on social justice in education. The term "social justice" is used frequently in education because of the expectation that the educational system provides fairness in its access, opportunities and results. At present, the highly privatized (i.e. universal choice and autonomous schools) Dutch system is reasonably successful in safeguarding freedom of choice and largely successful in the provision of productive efficiency. However, there are also challenges to social justice in the domains of equity and social cohesion, resulting primarily from high patterns of socioeconomic and ethnic stratification. 


\section{Samenvatting}

Keuzevrijheid is in veel landen een belangrijk kenmerk van het onderwijsbestel. Keuzevrijheid is lange tijd een centraal thema geweest in het onderwijsdebat in de Verenigde Staten, maar ook in andere landen waaronder Nederland. Gezien de huidige stand van het onderzoek bestaat er: i) een behoefte aan meer empirische resultaten over onderwijsstelsels met universele vrije schoolkeuze, ii) een gebrek aan consensus ten aanzien van wat de meest efficiënte wijze van onderwijsvoorziening is en iii) de noodzaak om onderzoeksresultaten over de effecten van schoolkeuze te interpreteren in een breder kader van onderwijsuitkomsten (i.e. zowel private als maatschappelijke).

Dit proefschrift heeft daarom als doel om verschillende eigenschappen van het Nederlandse primair- en secundair onderwijssysteem te onderzoeken. Meer specifiek concentreren de empirische analyses zich op de relatieve effectiviteit van "bijzondere" scholen, op de effecten van vrije schoolkeuze op leerlingprestaties en op hoe competitie op schoolniveau samenhangt met prestatie en de verdeling van leerlingen tussen scholen op basis van capaciteiten. Het raamwerk van Levin (2002) met verschillende onderwijsuitkomsten (i.e. keuzevrijheid, doelmatigheid, gelijke kansen en sociale cohesie) wordt daarbij gebruikt voor de interpretatie van de resultaten. De resultaten in dit proefschrift zijn gebaseerd op meerdere databronnen en verschillende econometrische methoden. De hoofdbevindingen kunnen worden samengevat als dat: i) er weinig verschillen in prestatieniveaus zijn tussen verschillende schooltypen (i.e. "bijzonder" en openbaar), ii) het Nederlandse stelsel 
School Choice, Competition and Achievement

van keuzevrijheid en competitie met name is gericht op het terugdringen van onderwijsachterstanden, iii) diversiteit in de onderwijsvraag de mogelijkheden voor prestatiewinst beperkt en vrije schoolkeuze en competitie met name productdifferentiatie bevordert, en iv) vrije schoolkeuze in Nederland leidt tot uitruil van private en maatschappelijke onderwijsdoelstellingen, waarmee het belang van ontwerp en regelgeving in het onderwijssysteem wordt benadrukt.

Hoofdstuk 2 geeft een overzicht van de internationale literatuur aangaande de effecten van schoolkeuze op onderwijsuitkomsten als keuzevrijheid, doelmatigheid, gelijke kansen en sociale cohesie. Vrije schoolkeuze bevordert keuzevrijheid indien huishoudens uiteenlopende voorkeuren hebben ten aanzien van schoolkenmerken. Echter, ceteris paribus, geven huishoudens de voorkeur aan scholen van hoge academische kwaliteit en met leerlingen van ouders met een relatief hoge sociaal-economische status. Ten aanzien van verbeteringen in doelmatigheid, of efficiency, als gevolg van vrije schoolkeuze zijn de resultaten gematigd positief: keuzevrijheid en competitie leiden tot beperkte verbetering van leerprestaties. Voor de veronderstelde relatief betere kwaliteit van private scholen wordt in de empirische literatuur slechts wisselvallige ondersteuning gevonden, terwijl de effecten op onderwijsvoortgang en -vervolg een meer consistent (en positief) beeld geven. De gevolgen van de expansie van vrije schoolkeuze voor gelijke kansen hangen grotendeels af van hoe het onderwijsstelsel ontworpen is (i.e. financiering, regelgeving en ondersteunende voorzieningen). Keuzevrijheid, mits op een juiste wijze vormgegeven en gericht op achterstandsleerlingen, lijkt in staat te zijn om de kansen voor deze groepen te verbeteren, terwijl voor universele keuzesystemen het risico bestaat dat dit bestaande ongelijkheden in stand houdt of zelfs verder vergroot. Empirisch onderzoek aangaande sociale cohesie, een maatschappelijke doelstelling van onderwijs dat zich lastig laat kwantificeren, is vooralsnog beperkt. Echter vrije schoolkeuze, in de vorm van het overhevelen van controle over de school van beleidsmakers naar huishoudens, lijkt, met name door toenemende stratificatie van groepen leerlingen tussen scholen, eerder bij te dragen aan de private opbrengsten van onderwijs.

Hoofdstuk 3 beschrijft de Nederlandse keuzecontext in het algemeen onderwijs, welke binnen de omschrijving van een quasi-markt lijkt te passen. De 
vrijheid van scholen om te kiezen en selecteren is streng gereguleerd in termen van input- en output-indicatoren, maar het systeem staat meer vrijheden toe in termen van het onderwijsproces en management. Ten aanzien van doelmatigheid zijn de prestaties van het primair- en secundair onderwijs in Nederland, wanneer men deze vergelijkt met andere landen, gemiddeld redelijk goed, maar lijkt er een dalende tendens te zijn. Met name in het basisonderwijs, voor academische uitkomsten en voor de periode tussen eind jaren zestig en begin jaren negentig van de vorige eeuw, presteerden bijzondere scholen relatief beter dan openbare scholen. De gelijke financiering en academische richtlijnen die van toepassing zijn op alle scholen garanderen het bieden van gelijke kansen en waarborgen "horizontal equity" en "adequacy". Het feit dat substantieel meer middelen beschikbaar zijn voor scholen met veel leerlingen van lagere sociaaleconomische afkomst en voor de ondersteuning van zorgleerlingen draagt verder bij aan gelijke kansen door het versterken van "vertical equity". Sociale cohesie wordt bewaakt middels uitgebreide kerndoelen en prestatie-eisen, al zijn scholen relatief autonoom in het organiseren van het daadwerkelijke onderwijsproces. Belangrijk om te vermelden is ook het feit dat er een behoorlijke mate van stratificatie bestaat, met name in het voortgezet onderwijs waarin leerlingen al vroeg gegroepeerd worden in verschillende schooltypen.

Hoofdstuk 4 benut de variatie in het aantal scholen in de nabijheid van een huishouden om het effect van relatief meer keuzemogelijkheden op de prestatie van de leerlingen aan het eind van het primair onderwijs in Nederland te onderzoeken. Analyses op een rijke dataset, met controlevariabelen op individueel-, school- en buurtniveau, geven aan dat er een gematigd positieve associatie is tussen meer keuzemogelijkheden en leerprestaties, waarbij een toename van $100 \%$ in het aantal nabijgelegen scholen samenhangt met een 0.05-0.09 $\sigma$ toename in leerprestatie. Dit komt overeen met een 0.03-0.06 $\sigma$ toename voor elke standaarddeviatie toename in keuzemogelijkheden. Wanneer de data beperkt worden tot de 4 grootste steden - en de variatie in stedelijkheid wordt beperkt - wordt dit effect groter. Als de hoeveelheid nabijgelegen scholen geïnstrumenteerd wordt middels de afstand tot de oprit/afrit van de hoofdweg zijn de resultaten veel minder precies, maar kwalitatief vergelijkbaar. 
School Choice, Competition and Achievement

In de volgende set van analyses (Hoofdstuk 5) worden drie verschillende nietexperimentele methodes (i.e. OLS, IV en PSM) toegepast op de Nederlandse PISA 2006 en 2009 data om zodoende een beeld te schetsen van het effect van bijzondere scholen op leerlingprestaties in drie domeinen (i.e. wiskunde, lezen en natuur/scheikunde). Over het algemeen geven de resultaten geen eenduidig beeld. Resultaten op basis van OLS en PSM suggereren dat bijzondere scholen positief bijdragen aan wiskundeprestaties, maar enkel in PISA 2006. Daarentegen zijn de resultaten op basis van en instrumentele variabele (IV) zeer onstabiel. Relatief grote, maar onzuivere, positieve effecten worden gevonden voor PISA 2006, terwijl het omgekeerde (i.e. relatief grote, onzuivere, maar negatieve effecten) blijkt voor leerlingen in de PISA 2009 dataset. Vergelijkbare analyses, alsook analyses van zogeheten "structurele switchers", uitgevoerd op CITO-scores en schooladviezen aanwezig in de BRON dataset, leveren ook grotendeels vergelijkbare resultaten voor verschillende schooltypen.

Hoofdstuk 6 analyseert de relaties tussen competitie en leerlingprestaties in het Nederlands primaire onderwijs. Hierbij wordt onderscheid gemaakt tussen competitie en vrije schoolkeuze. Voor dit doel worden schoolconcentratie-indices geconstrueerd voor alle scholen in de 31 grootste gemeenten. Deze zijn bepaald als "het aantal omliggende scholen per 100 cohortleerlingen binnen een radius van 3 kilometer $(\mathrm{km})$ rond de school". De resultaten suggereren een positief verband tussen deze maat voor competitie en academische prestatie, met een gemiddelde effectgrootte op CITO scores van $0.06 \sigma$. Dit effect is groter voor de onderste helft van de vaardigheidsverdeling en in meer stedelijke omgevingen $(0.1 \sigma)$, maar voorbij de modale prestatie draagt competitie niet langer bij tot hogere prestaties.

Hoofdstuk 7 richt zich op de effecten van competitie tussen scholen op het sorteren van leerlingen en op leerlingprestaties in competitieve markten in het secundair onderwijs. Hierbij wordt gebruik gemaakt van de VOCL99 dataset. De analyses suggereren dat scholen in een competitieve markt concurreren voor de "voorkeursleerlingen" (i.e. hoog-presterend), door aanbod-gedreven productdifferentiatie. Met toenemende competitie zijn er relatief meer scholen binnen de lokale onderwijsmarkt die zich richten op deze groep van hoogpresterende leerlingen. De effecten van competitie op sortering zijn daarom met 
name terug te zien op scholen met academische schooltypen (zoals havo en vwo), aangezien de resultaten erop wijzen dat deze scholen vaker genoegen moeten nemen met de "marginale" leerling om voldoende studenten aan te blijven trekken in competitieve lokale onderwijsmarkten. De resultaten wijzen er eveneens op dat competitie in Nederland leidt tot gematigd hogere academische prestaties binnen de eerste 3 jaar van het voortgezet onderwijs. Dit bevestigt de eerdere resultaten van Hoofdstuk 6.

Hoofdstuk 8 vat de bovenstaande resultaten samen binnen Levin's evaluatieraamwerk, met daarbij de nadruk op sociale rechtvaardigheid in het onderwijs. De term "sociale rechtvaardigheid" wordt binnen het onderwijs vaak gebruikt omwille van de verwachting dat het onderwijssysteem gelijke kansen in toegang, mogelijkheden en resultaten biedt. Het huidige, grotendeels geprivatiseerde (i.e. vrije schoolkeuze en relatief autonome scholen) Nederlandse onderwijssysteem is redelijk succesvol in het waarborgen van keuzevrijheid en grotendeels succesvol in termen van doelmatigheid en efficiency. Echter, er zijn ook uitdagingen aangaande sociale rechtvaardigheid in de domeinen van gelijke kansen en sociale cohesie, welke met name het resultaat zijn van sterke sociaaleconomische- en etnische stratificatie. 
School Choice, Competition and Achievement 


\section{Biography}

Ilja Cornelisz (1981) graduated in Business Economics from the Faculty of Economic Sciences and Econometrics (FEE) in 2005, and in Teaching Business Economics from the Instituut voor de Lerarenopleiding (ILO) in 2006, both at the University of Amsterdam (UvA).

He started his professional career as a teacher in Mathematics and (Business) Economics at a secondary school in the Netherlands, where he worked for seven years. During this period, he was also the coordinator of the newly enacted bilingual education program and a coach for new teachers and trainees.

In 2009, he became a PhD-researcher for the Top Institute for Evidence Based Education Research (TIER) at Maastricht University and enrolled in the Economics of Education PhD program at Teachers College (TC), Columbia University. While in the program at Teachers College, he was a Teaching Assistant in Microeconomics at Columbia University School of Social Work (CUSSW) and in the Economics of Education Program at Teachers College (TC).

Ilja Cornelisz is currently affiliated with Maastricht University as a PhDresearcher and teaches several courses in the Economics of Education graduate program at the Education Policy and Social Analysis (EPSA) department at Teachers College (TC). His research interests include school choice, privatization and cost analysis in education. 


\section{Top Institute for Evidence Based Education Research (TIER)}

The Top Institute for Evidence Based Education Research (TIER) is an inter-university institute that conducts research to develop evidence based education. The institute has three partners: the University of Amsterdam, Maastricht University and the University of Groningen and is located in Amsterdam, Maastricht and Groningen.

TIER contributes to the improvement of the quality of education in the Netherlands by promoting an evidence based approach as a guiding principle in education policy and practice. It accomplishes this by developing (cost) effective education interventions that are grounded in sound scientific research. TIER research is funded by the Ministry of Education, Culture and Science and the participating universities through the NWO and complies with the quality standards and evaluation procedures used by NWO.

The following books recently appeared in the TIER Research Series:

I. C. Haelermans (2012), On the productivity and efficiency of education. The role of innovations in Dutch secondary education

II. L. van Welie (2013), They Will Get There! Studies on Educational Performance of Immigrant Youth in the Netherlands

III. S. Cabus (2013), An Economic Perspective on School Dropout Prevention using Microeconometric Techniques

IV. I. Cornelisz (2013) School choice, competition and achievement: Dutch compulsory education 